Food and Agriculture
Organization of the
United Nations

\title{
Integration of environment and nutrition in life cycle assessment of food items: opportunities and challenges
}

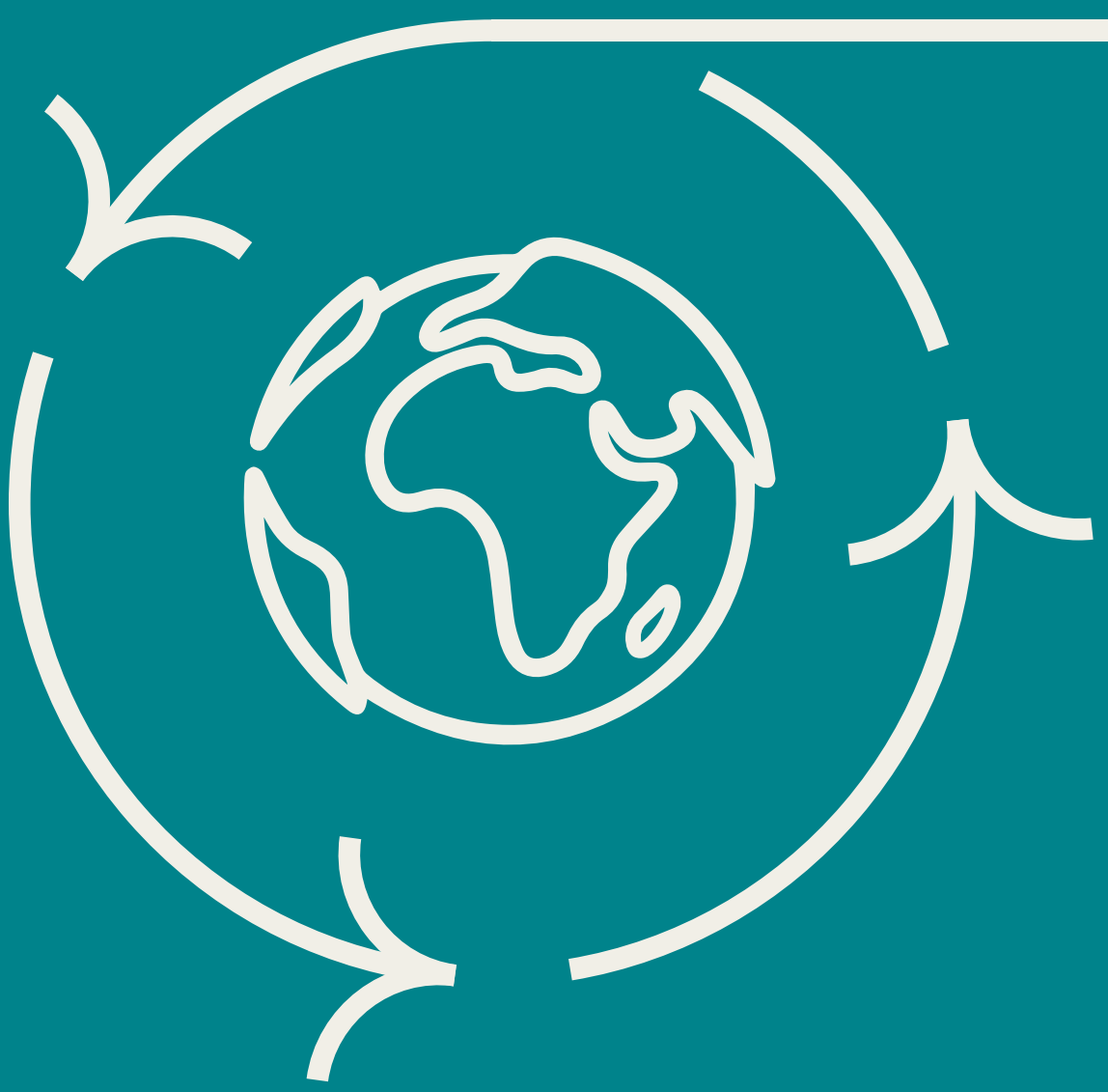





\title{
Integration of environment and nutrition in life cycle assessment of food items: opportunities and challenges
}

\begin{abstract}
Authors:
Sarah McLaren, Andrew Berardy, Andrew Henderson, Nicholas Holden, Thom Huppertz, Olivier Jolliet, Camillo De Camillis, Marguerite Renouf, Benedetto Rugani, Merja Saarinen, Jolieke van der Pols, Ian Vázquez-Rowe, Assumpció Antón Vallejo, Marta Bianchi, Abhishek Chaudhary, Canxi Chen, Margot Cooreman-Algoed, Hongmin Dong, Tim Grant, Ashley Green, Elinor Hallström, Hong Minh Hoang, Adrian Leip, John Lynch, Graham McAuliffe, Brad Ridoutt, Sophie Saget, Laura Scherer, Hanna Tuomisto, Peter Tyedmers, Hannah van Zanten
\end{abstract}


Required citation:

McLaren, S., Berardy, A., Henderson, A., Holden, N., Huppertz, T., Jolliet, O., De Camillis, C., Renouf, M., Rugani, B., Saarinen, M., van der Pols, J., Vázquez-Rowe, I., Antón Vallejo, A., Bianchi, M., Chaudhary, A., Chen, C., CooremanAlgoed, M., Dong, H., Grant, T., Green, A., Hallström, E., Hoang, H., Leip, A., Lynch, J., McAuliffe, G., Ridoutt, B., Saget, S., Scherer, L., Tuomisto, H., Tyedmers, P. \& van Zanten, H. 2021. Integration of environment and nutrition in life cycle assessment of food items: opportunities and challenges. Rome, FAO.

The designations employed and the presentation of material in this information product do not imply the expression of any opinion whatsoever on the part of the Food and Agriculture Organization of the United Nations (FAO) concerning the legal or development status of any country, territory, city or area or of its authorities, or concerning the delimitation of its frontiers or boundaries. The mention of specific companies or products of manufacturers, whether or not these have been patented, does not imply that these have been endorsed or recommended by FAO in preference to others of a similar nature that are not mentioned.

The views expressed in this information product are those of the author(s) and do not necessarily reflect the views or policies of FAO.

ISBN 978-92-5-135532-9

(C) FAO, 2021 last updated 10/01/2022

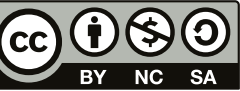

Some rights reserved. This work is made available under the Creative Commons Attribution-NonCommercialShareAlike 3.0 IGO licence (CC BY-NC-SA 3.0 IGO; https://creativecommons.org/licenses/by-nc-sa/3.0/igo/ legalcode).

Under the terms of this licence, this work may be copied, redistributed and adapted for non-commercial purposes, provided that the work is appropriately cited. In any use of this work, there should be no suggestion that FAO endorses any specific organization, products or services. The use of the FAO logo is not permitted. If the work is adapted, then it must be licensed under the same or equivalent Creative Commons licence. If a translation of this work is created, it must include the following disclaimer along with the required citation: "This translation was not created by the Food and Agriculture Organization of the United Nations (FAO). FAO is not responsible for the content or accuracy of this translation. The original [Language] edition shall be the authoritative edition."

Disputes arising under the licence that cannot be settled amicably will be resolved by mediation and arbitration as described in Article 8 of the licence except as otherwise provided herein. The applicable mediation rules will be the mediation rules of the World Intellectual Property Organization http://www.wipo. int/amc/en/mediation/rules and any arbitration will be conducted in accordance with the Arbitration Rules of the United Nations Commission on International Trade Law (UNCITRAL).

Third-party materials. Users wishing to reuse material from this work that is attributed to a third party, such as tables, figures or images, are responsible for determining whether permission is needed for that reuse and for obtaining permission from the copyright holder. The risk of claims resulting from infringement of any third-party-owned component in the work rests solely with the user.

Sales, rights and licensing. FAO information products are available on the FAO website (www.fao.org/ publications) and can be purchased through publications-salesafao.org. Requests for commercial use should be submitted via: www.fao.org/contact-us/licence-request. Queries regarding rights and licensing should be submitted to: copyrightlafao.org.

Cover photograph:

CFAO/Michela Paganini 


\section{Foreword}

\section{Integration of environment and nutrition in life cycle assessment of food items: opportunities and challenges}

Today's agrifood systems are not delivering on their urgently needed contribution to the Sustainable Development Goals (SDGs). After decades of progress, the number of hungry people has been increasing for the past five years, reaching 811 million people in 2020. More than 3 billion people still cannot afford a healthy diet, obesity and non-communicable diseases are on the rise, and agrifood systems are contributing significantly to natural resource degradation and to exacerbating the effects of climate change. A major contributor to greenhouse gas emissions, agrifood systems are also the primary driver of biodiversity loss. Agriculture is also responsible for a continued overuse of freshwater, degraded soils and for eroding the productive capacity of land.

The complexity of the challenges facing policy makers has resulted in the development of multiple frameworks, definitions and methods to capture the interaction between the components of agrifood systems and the linkages with other systems, such as health and energy. Navigating through this complexity requires neutral, balanced and science-based approaches and tools, which will enable an evaluation of these complex agrifood system problems, leading to the design of context-specific interventions and innovations. Robust data and evidence are essential to enable an objective analysis of the interdependencies and trade-offs in order to ensure that the desired transformations are happening at the necessary scale and with speed towards sustainability.

To this end, policies related to food systems must focus on their direct and indirect economic, social, environmental, cultural, nutritional and health impacts, paying special attention to the poorest and most vulnerable populations and to addressing the barriers that they face in accessing healthy diets through sustainable food systems.

Tools such as life cycle assessment (LCA), which is often used by food system actors and policymakers, could provide a reliable basis for assessing and comparing sustainability in different contexts. However, LCA methodologies also have some limitations and often fail to provide sufficient guidance on environmental and nutrition impacts that users should be capturing when comparing the overall sustainability and health impacts of different food products.

In 2021, the United Nations Food Systems Summit provided an opportunity for food systems stakeholders to begin to identify how best to approach an agrifood systems transformation in line with their national contexts and capacities, recognizing that there is no one policy solution that fits all. In the context of the follow-up to the Food Systems Summit, we hope that this report provides a first step in addressing the complex food systems decisions that countries will have to take and that it will support policy makers and food systems actors in improving the sustainability of their food systems. We also expect the results of this research to inform the design of a second phase of the project, to include the social and economic dimensions of diets, including aspects related to accessibility and affordability.

We take this opportunity to thank the research group, composed of 30 international researchers, who have been at the core of this project and have led the delivery of the main technical outputs bringing to bear their diverse knowledge and expertise. Their work and the resulting report will provide a significant contribution to the efforts of the Food and Agriculture Organization of the United Nations (FAO) to promote a science-based approach to assessing the impact of decisions and interventions on communities, the environment, economies and health and it will help to move the agenda of transforming agrifood systems forward.

Jamie Morrison

Director, Food Systems and Food Safety Division

The Food and Agriculture Organization of the United Nations 



\section{CONTENTS}

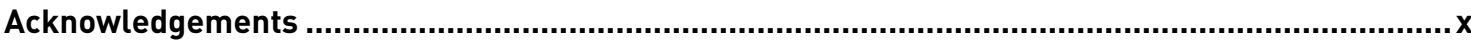

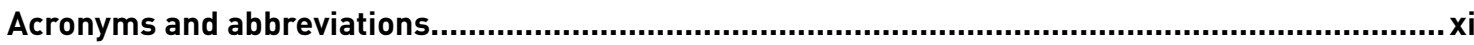

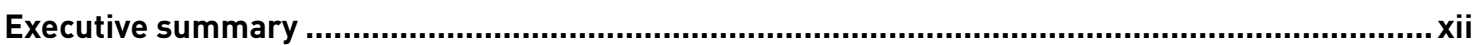

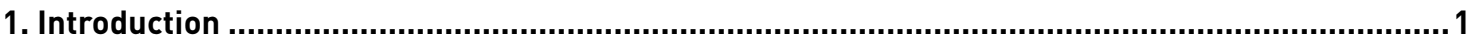

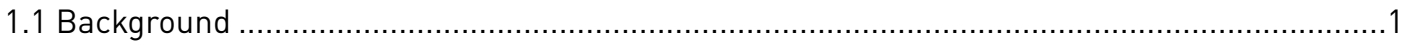

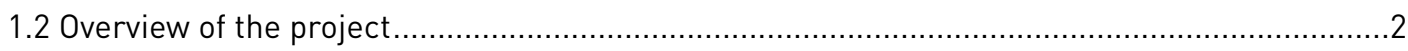

$2 \mathrm{~A}$ brief overview of food life cycle assessment and the context for this project .........................

$2.1 \mathrm{~A}$ brief history of food life cycle assessment .................................................................

2.2 FAO project on environmental and nutritional life cycle assessment ....................................5

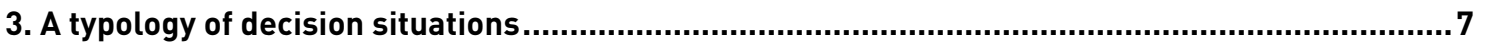

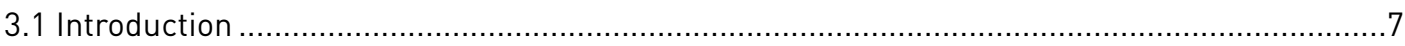

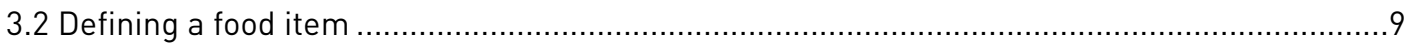

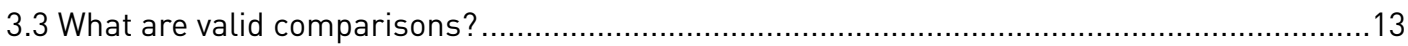

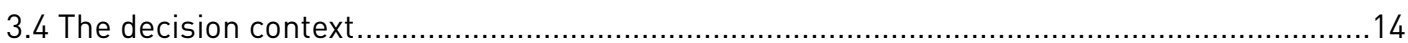

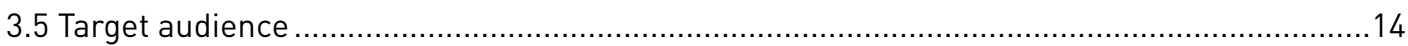

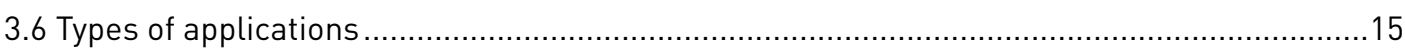

3.7 Towards best practice recommendations.................................................................

4. Modelling issues for a nutritional life cycle assessment .......................................................... 19

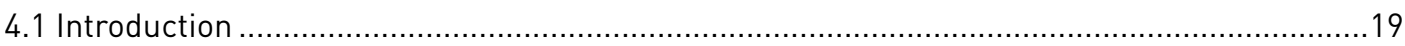

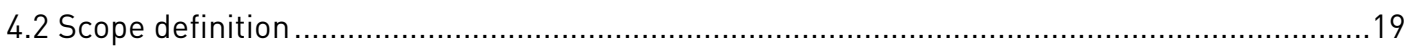

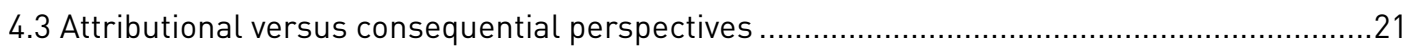

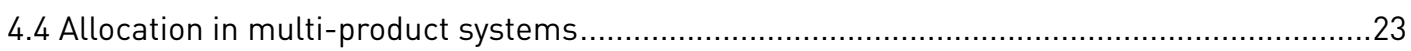

4.5 General data requirements for a food life cycle assessment................................................26

4.6 Nutrient data requirements for a nutritional life cycle assessment ....................................27

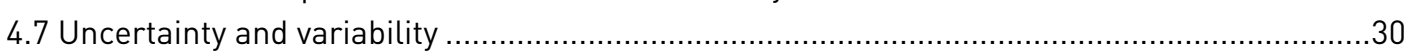

4.8 Quantifying food loss and waste in the life cycle inventory ............................................

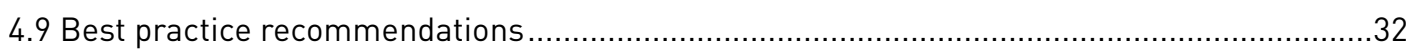

5. Assessing nutritional value in the life cycle assessment of food items...................................35

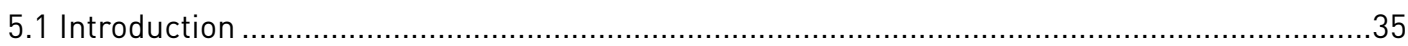

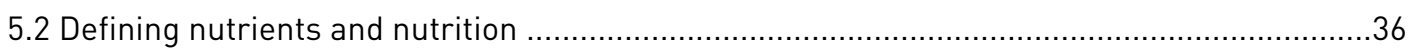

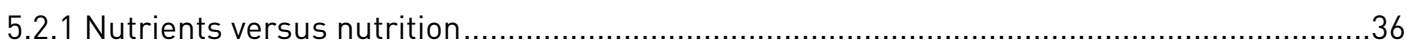

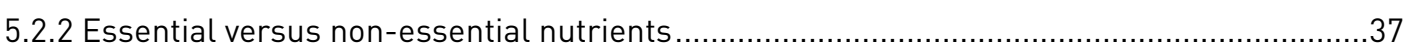

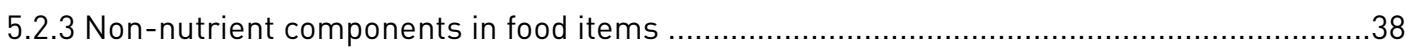

5.3 Influence of food processing methods on nutrients and nutritional value ............................39

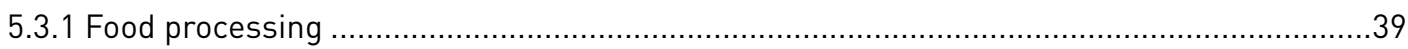

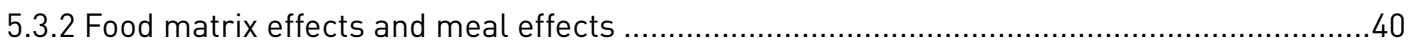

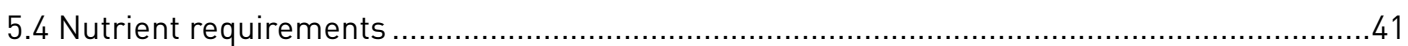

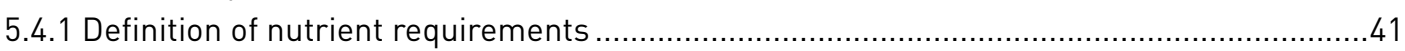

5.4.2 The purpose and the process of establishing reference nutrient intake values...................41

5.4.3 Using reference nutrient intake values in a nutritional life cycle assessment ....................43 
5.4.4 Link between nutrient reference values and dietary recommendations ..........................43

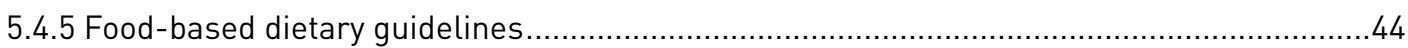

5.5 Methods for assessing nutritional value in food life cycle assessment studies .....................45

5.5.1 Parallel approaches - assessment of nutrition at impact assessment................................45

5.5.2 Integrated approaches - nutrition-based functional units..............................................45

5.6 Towards best practice recommendations ........................................................................

6. Defining the functional unit...............................................................................................47

6.1 A brief history of the functional unit in life cycle assessment studies of food items.............47

6.2 Key considerations in defining the functional unit ....................................................... 48

6.2.1 Principles in defining the functional unit ...................................................................

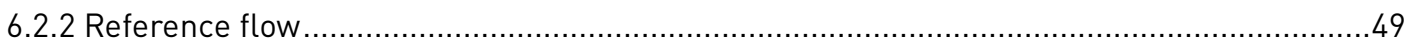

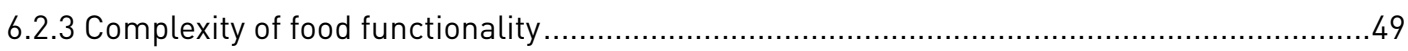

6.3 Key methodological issues in defining a nutritional functional unit .....................................50

6.3.1 Should nutritional quality be included in the functional unit and to what extent? ..............50

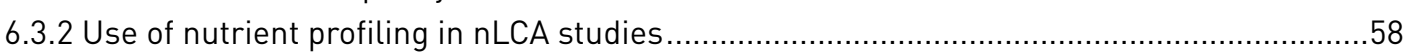

6.4 Functional unit options in relation to the goal(s) of a nutritional life cycle assessment .........63

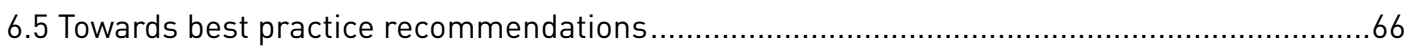

6.5.1 Selecting a functional unit for a nutritional life cycle assessment ..................................66

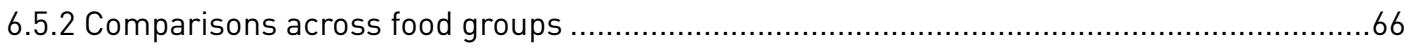

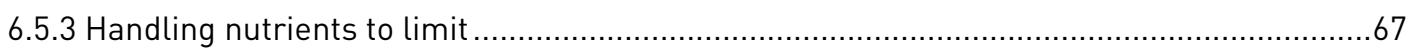

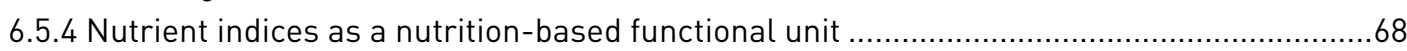

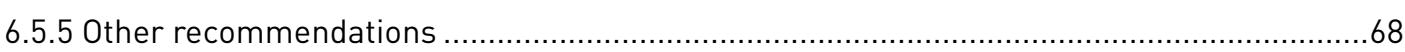

7. Assessing environmental and human health impacts relevant to life cycle assessment of foods... 69

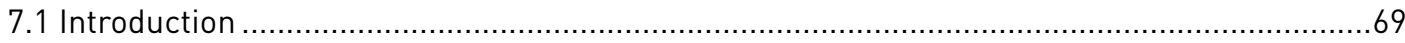

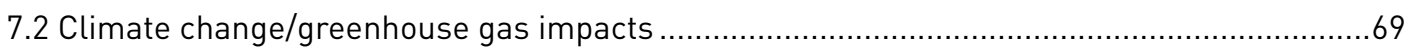

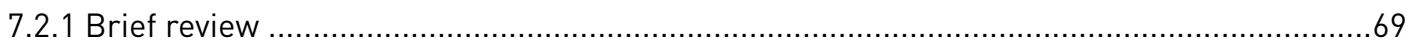

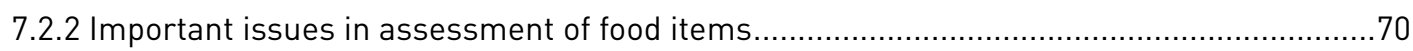

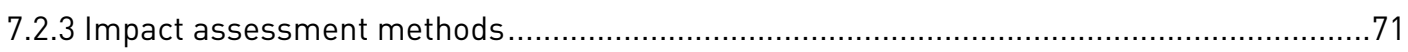

7.2.4 Recommendations and further research needs ........................................................ 74

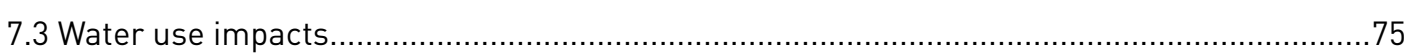

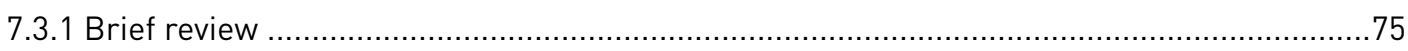

7.3.2 Important issues in the assessment of food items ......................................................

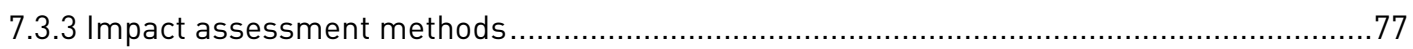

7.3.4 Recommendations and further research needs..................................................... 78

7.4 Biodiversity impacts associated with land use, fertilizers (eutrophication) and pesticides



7.4.1 Biodiversity impacts associated with land use ............................................................ 79

7.4.2 Biodiversity impacts associated with eutrophication or fertilizers ...................................81

7.4.3 Biodiversity impacts associated with ecotoxicity or pesticides ......................................84

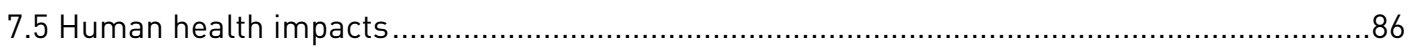

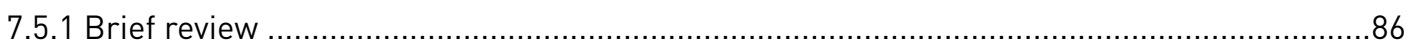

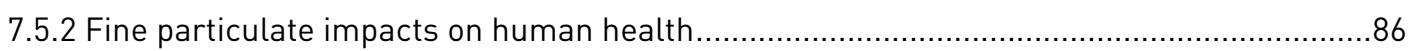

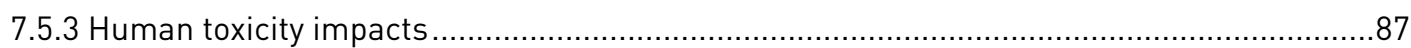

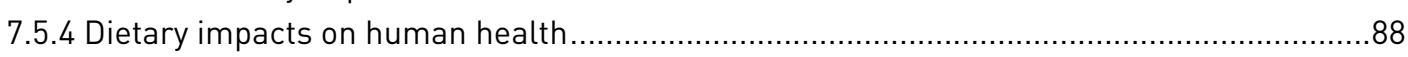

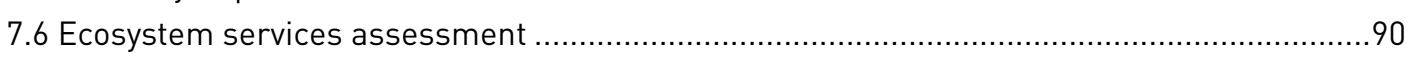




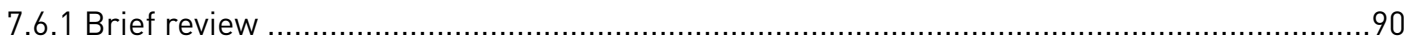

7.6.2 Important issues in the assessment of food items .................................................... 91

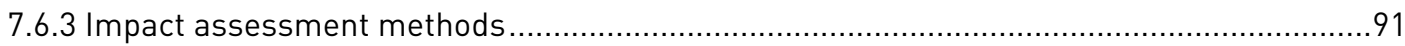

7.6.4 Recommendations and further research needs .......................................................91

7.7 Other impacts and the emerging issue of microbial resistance .........................................92

7.7.1 Background and problems for antibiotic resistance.....................................................93

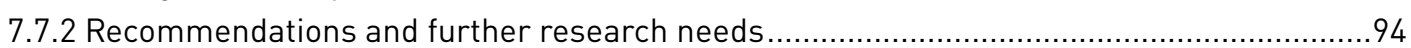

7.8 Integration of recommendations in existing global LCIA methods ...................................... 94

8. Towards an agreed upon methodology for nutritional life cycle assessment............................95

8.1 Outstanding issues in assessing nutritional value in nutritional life cycle assessment studies

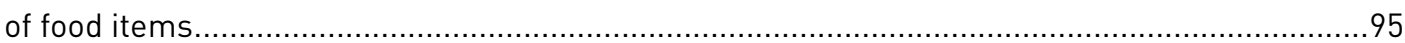

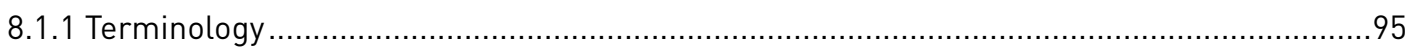

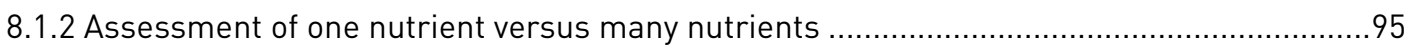

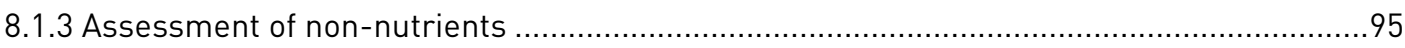

8.1.4 Distinguishing between nutrients and nutritional value .................................................96

8.1.5 Use of nutrient indices in a nutritional life cycle assessment ........................................96

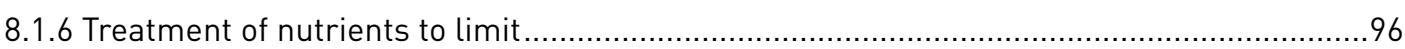

8.1.7 Nutritional value addressed in functional unit versus in the impact assessment...............96

8.1.8 Role of system boundaries in affecting nutritional value ............................................97

8.1.9 Comparisons between alternative foods ................................................................ 97

8.2 Additional methodological issues of particular relevance to food life cycle assessment

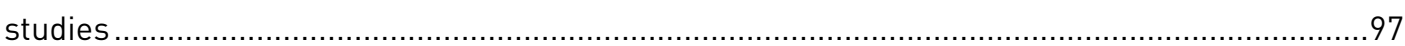

8.3 Operationalizing methodology for nutritional life cycle assessment.................................. 98

8.3.1 Nutritional effects considered in the impact assessment..........................................98

8.3.2 Nutritional value as (part of) the functional unit ..................................................... 98

8.3.3 Guidance on undertaking a nutritional life cycle assessment .......................................98

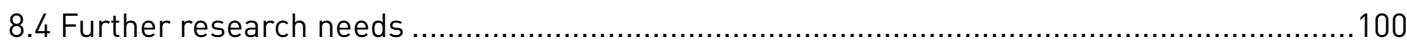

8.5 Limitations in using nutritional life cycle assessment studies to support decision-making

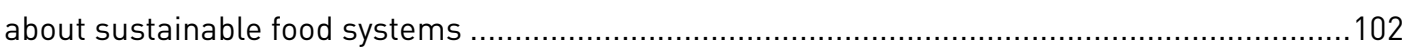

9. Final recommendations for nutritional life cycle assessment of food items.......................... 103

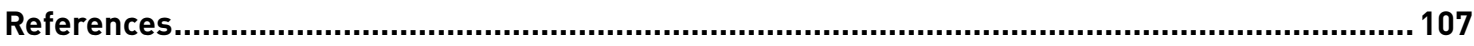

Glossary.......................................................................................................................... 134

Appendix 1 Project Group Members .................................................................................. 137 


\section{Figures}

Figure 1. Six application areas and their relationship with data specificity, timescale and

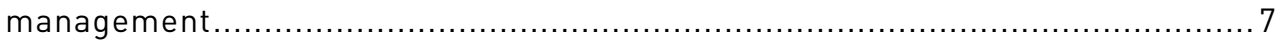

Figure 2. Decision tree to guide in scoping nutritional LCA (nLCA) for selection of the most suitable approach in relation to a food item

Figure 3. Change in monthly nominal price of soybean meal and oil (in USD) over a ten-year

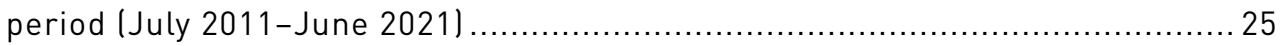

Figure 4. Number of studies per year since 2000 combining LCA with nutrition or health ..........35

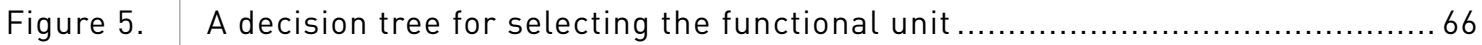

Figure 6. $\quad$ Decision tree to support development of a nutrition life cycle assessment study ...99

\section{Tables}

Table 1. Common applications of LCA with examples for food systems (not necessarily



Table 2 .

Table 3.

Definition of terms relating to objects studied in food LCA research .............. 10

Relevant key actors/stakeholders in the food chain ............................. 14

Most common nLCA applications organized by different actors/stakeholders in the food system

Table 5 .

Summary of strengths and limitations of three frequently employed bases of

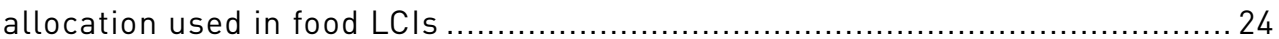

Table 6 Summary of uncertainty and variability characteristics in LCA ...................... 30

Table 7.

Overview of differences in context suitability between nutrition-based methods and disease-risk-factor-based methods

Table 8

Codex Alimentarius nutrient reference values for the general population older than 36 months

Table 9.

Table 10 Overview of the methodological advantages and challenges of parallel and integrated approaches for the combined assessment of the environmental and nutrition effects of food 45 Overview of functional units used in food LCA studies and their benefits and drawbacks when interpreted in the context of nLCA 51

Table 11. Examples of greenhouse gas emissions ( $\mathrm{kg} \mathrm{CO}$ e) of food items across a selection of functional units....

Table 12. Examples of greenhouse gas emissions ( $\mathrm{kg} \mathrm{CO}$ el of various food items across a selection of functional units based on NRF indices

Table 13. Interest areas and related goals of food LCA study applications, and potentially compatible FU options 65

Table 14. Global warming potential for a time horizon of $20\left(G_{20}\right)$ and $100\left(G_{2} P_{100}\right)$ years and Global temperature potential 100 years (GTP100) for the most relevant agricultural GHGs, as provided by the (6th) IPCC Assessment Report (AR6) ..... 73

Table 15. GBD maximum theoretical limits, dietary risks characterization factors, and determination of dietary human health impacts: illustrative application to a chicken wing consumed in the United States of America 


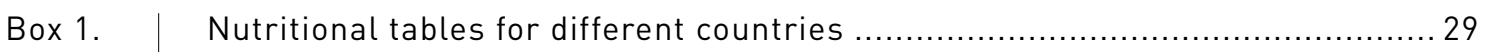

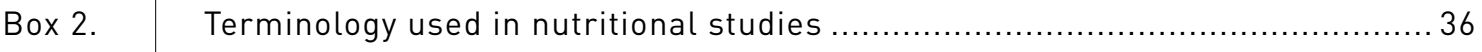

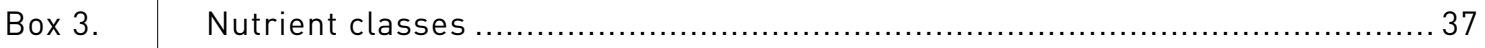

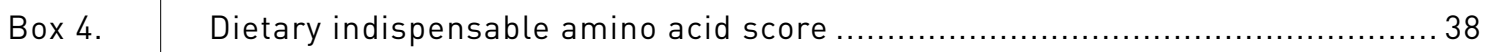

Box 5. Non-nutrient components and anti-nutritional factors ................................ 38

Box 6. Effect of processing and food preparation on nutrients and nutritional value - some examples .................................................................. 39

Box 7. Examples of reported food matrix effects on physiological and metabolic

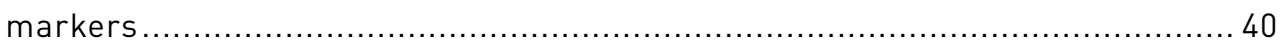

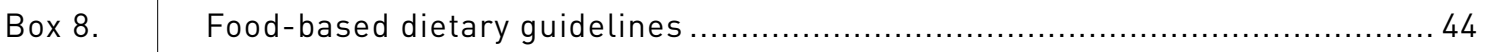

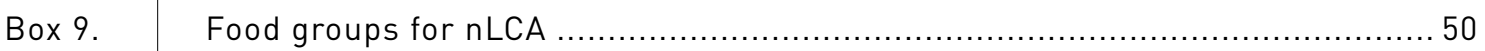

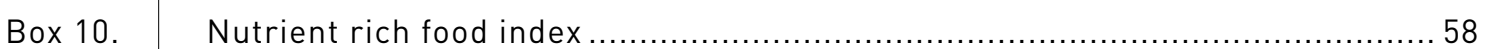

Box 11. Food group-specific or across-the-board approach in defining the methodology

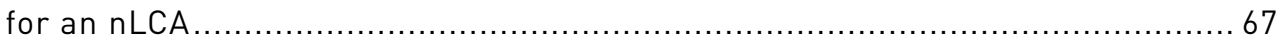

Box 12. Solving the negative score problem of commonly used nutrient indices. ........667 


\section{Acknowledgements}

This report is the outcome of a Food and Agriculture Organization of the United Nations (FAO) Food Systems and Food Safety Division project, coordinated by Maryam Rezaei (Agro-food industry officer) under the leadership of Jamie Morrison (Director).

The lead authors of the chapters in the report are:

- Chapters 1 and 2: Sarah McLaren, Massey University

- Chapter 3: Nicholas Holden, University College Dublin; Benedetto Rugani, Luxembourg Institute of Science and Technology

- Chapter 4: Marguerite Renouf, Queensland University of Technology; lan Vázquez-Rowe, Pontificia Universidad Católica del Peru

- Chapter 5: Thom Huppertz, Wageningen University and Research; Jolieke van der Pols, Queensland University of Technology

- Chapter 6: Andrew Berardy, Loma Linda University; Merja Saarinen, Natural Resources Institute Finland

- Chapter 7: Andrew Henderson, Eastern Research Group and University of Texas School of Public Health; Jolieke van der Pols, Queensland University of Technology

- Chapters 8 and 9: Sarah McLaren, Massey University.

Review of the draft report undertaken by the following experts is gratefully acknowledged:

- Assumpció Antón Vallejo, Institute of Agrifood Research and Technology (IRTA), Barcelona, Spain

- Shabbir H. Gheewala, Joint Graduate School of Energy and Environment, King Mongkut's University of Technology Thonburi, Thailand

- Marjukka Kolehmainen, University of Eastern Finland, Institute of Public Health and Clinical Nutrition, Finland

- Ilkka Leinonen, Natural Resources Institute Finland

- Annie Levasseur, École de Technologie Supérieure, Montréal, Canada

- Ralph Rosenbaum, IRTA, Barcelona, Spain

- Serenella Sala, European Commission Joint Research Centre, Ispra, Italy

- Cássia Maria Lie Ugaya, Center of Life Cycle Sustainability Assessment (Gyro) of the Federal University of Technology, Paraná, Brazil

- FAO colleagues from Animal Production and Health Division, Food Systems and Food Safety Division, and the Nutrition and Food Division.

This project has been made possible thanks to the financial contribution of the Government of New Zealand and the Government of Ireland.

Any omission of contributors to this guide is unintentional. 


\section{Acronyms and abbreviations}

\begin{tabular}{|c|c|}
\hline ADI & Acceptable daily intake \\
\hline Al & Adequate intake \\
\hline ALCA & Attributional life cycle assessment \\
\hline AMR & Anti-microbial resistance \\
\hline AWARE & Available WAter REmaining \\
\hline CF & Characterization factors \\
\hline CGTP & Combined global temperature change potential \\
\hline CICES & Common International Classification of Ecosystem Services \\
\hline CLCA & Consequential life cycle assessment \\
\hline DALY & Disability adjusted life years \\
\hline DIAAS & Digestible indispensable amino acid score \\
\hline EAR & Estimated average requirement \\
\hline ES & Ecosystem services \\
\hline FAO & Food and Agriculture Organization of the United Nations \\
\hline FAO LEAP & FAO Livestock Environmental Assessment and Performance \\
\hline FLW & Food loss and waste \\
\hline FU & Functional unit \\
\hline GBD & Global Burden of Disease \\
\hline GHG & Greenhouse gas \\
\hline GRADE & Grading of Recommendations, Assessment, Development and Evaluations \\
\hline GTP & Global temperature change potential \\
\hline GWP & Global warming potential \\
\hline HC & Hazardous concentrations \\
\hline ILCD & International Reference Life Cycle Data System \\
\hline ISO & International Organization for Standardization \\
\hline IUCN & International Union for Conservation of Nature \\
\hline LCA & Life cycle assessment \\
\hline $\mathbf{L C}$ & Life cycle inventory \\
\hline LCIA & Life cycle impact assessment \\
\hline LCSA & Life cycle sustainability assessment \\
\hline LUCIA & Land use change impact assessment \\
\hline NEVO & Dutch Food Composition Database \\
\hline NGO & Non-governmental organization \\
\hline nFU & Nutrition-based functional unit \\
\hline nLCA & Nutritional life cycle assessment \\
\hline NRF & Nutrient rich food \\
\hline RDA & Recommended daily allowance \\
\hline RDI & Recommended daily intake \\
\hline RF & Reference flow \\
\hline SID & Standardized ileal digestibility \\
\hline UNEP & United Nations Environment Programme \\
\hline UNFCCC & United Nations Framework Convention on Climate Change \\
\hline USDA & United States Department of Agriculture \\
\hline WHO & World Health Organization \\
\hline
\end{tabular}




\section{Executive summary}

Food systems have become increasingly efficient and technologically advanced in providing food products to meet the needs of the world's growing population. However, providing healthy diets within environmental limits remains a key sustainability issue as food systems continue to over use increasingly scarce natural resources while making a major contribution to environmental impacts such as climate change, water scarcity and biodiversity loss. At the same time, hundreds of millions of people suffer from chronic hunger or adult obesity, and healthy diets continue to be more expensive than energy- and nutrient-sufficient diets.

Many stakeholders are interested in the question of how to assess the environmental impacts of healthy diets, and in exploring solutions for minimizing trade-offs between nourishing populations and safeguarding the environment. Life cycle assessment (LCA) studies have an important role in contributing to solutions because they evaluate the environmental impacts of different practices, products and systems, and they facilitate the exploration of benefits and trade-offs across multiple types of impacts. LCA studies of food items increasingly address nutritional as well as environmental aspects, and this requires consideration of additional methodological aspects.

The Food and Agriculture Organization of the United Nations (FAO) initiated a project to identify opportunities for further developing environmental and nutritional LCA methodology and building consensus about best practice, and to propose future research needs. The project involved 30 environmental and nutritional LCA researchers from 18 countries and ran between May and November 2021. The project focused on assessing food items as opposed to raw materials, meals and/or diets, and it is a step towards more comprehensive meal and dietary LCA studies.

A key issue concerns the intended purpose of an LCA study. This requires some consideration of the reason for the study, the intended application and the audience. Foods may be consumed for a variety of reasons including for their nutritional value, for enjoyment, and/or as a means of taking part in or contributing to - socio-cultural functions. This report defines a nutritional LCA (nLCA) study as an LCA study where the provision of nutrient(s) is considered as either the main function or one of the main functions of a food item. nLCA studies should be undertaken by multidisciplinary teams involving nutritional and health scientists as well as environmental scientists.

At the outset, the goal and scope of an nLCA study should be carefully defined following the recommendations in this report, including:

- Undertake an nLCA when nutrients are and/or nutrition is relevant to the decision-maker and decision context (Chapter 3).

- Clearly identify the target audience and the target population for a study because different populations have different nutritional requirements, and this may influence the assessment of nutritional value (Chapter 5 ).

- Report the quantities of as many essential nutrients as possible (Chapters 5 and 6).

- Aim to provide information on the nutritional quality and/or health impacts in addition to nutrient quantities (Chapter 5, Chapter 6, Section 7.5.4).

- The system boundaries should include all stages of the product life cycle that affect nutritional value. The final processing, storage and/or preparation of food items may have a notable effect on their nutritional value, and this should be taken into consideration lincluding the potential fortification of foods) (Chapter 5).

- Choose a modelling perspective (typically attributional or consequential) based on the relevance to the decision situation (Chapter 4). 
The functional unit in an nLCA study can be defined in many ways (Chapter 6). These include: a quantity of one or more nutrients, a nutrient density value (calculated using a nutrient index), a quality-corrected quantity of nutrient(s), or another nutritional property (such as energy content). Alternatively, the functional unit could be a serving size. In all cases it should be relevant to the target population and its nutritional requirements. If possible, nutrients not included in the functional unit should be listed and discussed in the LCA report. Figure 5 and Figure 6 provide decision trees for guiding the choice of a functional unit in an nLCA study.

When assessing nutrition, consideration should be given to: accounting for nutritional value as well as nutrient quantities (for example, using nutrient indices), separate treatment of nutrients to encourage (e.g. calcium) and of nutrients to limit (e.g. sodium), and assessment of non-nutrients that contribute to nutrition (e.g. dietary fibre) (Chapter 5, Chapter 6).

In the impact assessment, research on the potential human health impacts of food items is at an early stage (Section 7.5.4). This report recommends using a nutrition impact category to account for the benefits or impacts of nutrition on human health (Section 8.1.1). Other particularly relevant impact categories to consider in an nLCA of food items include (Chapter 7): climate change, water use, land use, eutrophication (related to fertilizer use), ecotoxicity (related to pesticide use), and other human health impacts (in particular, fine particulates from agricultural activities and indoor use of some stoves, pesticide exposure and residues in food, chemical migration into food from contact materials, persistent organic pollutants and metals that bioconcentrate in foods). Antibiotic resistance is an emerging issue that requires consideration in the context of an LCA of food items (Section 7.7). Additional insights may be gained from integrating elements of the ecosystem services approach into an LCA (Section 7.6).

The project led to numerous recommendations about reporting nLCA results. To increase the usefulness of nLCA studies of food items for future meal and dietary studies, the results should be reported using a mass- or volume-based reference flow as well as a nutritional functional unit. The results should identify whether the approach is nutrient-based or whether it also includes nutritional aspects. And the reported result should discuss the limitations of the adopted approach, for example, not accounting for interactions with other food items in a meal or diet (i.e. food matrix and meal effects) (Chapter 5).

Some additional outstanding issues were identified in the project that require further attention (Chapter 8):

- definition of a minimum number of nutrients to be considered in an nLCA study, and whether this should be based on food groups (Chapter 6);

- treatment of nutrients to limit alongside, or separately from, encouraged nutrients (Chapter 6);

- use of nutrient indices to assess nutrition (Chapter 6);

- nutrition impact category methodology (Section 7.5.4), and further development of impact assessment methods for other impact categories (Chapter 7);

- how to represent nutritional changes that could occur during food storage, distribution and preparation if the system boundary for an nLCA study is set at a life cycle stage prior to consumption (Chapter 4);

- guidelines for use of an nLCA in different applications, including use of attributional and consequential modelling perspectives (Chapter 4);

- representation of data uncertainty and variability in nLCA studies (Chapter 4); and

-representative data for different regions (particularly developing countries) for the processing, distribution, retail, and consumption life cycle stages, and for food loss and waste (Chapter 4). 
Finally, there is a need to extend nLCA methodology for the assessment of meals and diets, to consider further how to account for the multi-functionality of food in a sustainability framework, and to set nLCA studies within the context of environmental limits.

In summary, the constructive consensus-building process described in this report led to the identification of key outstanding issues and recommendations for the environmental and nutritional LCA of food items. The results provide a robust basis for future research to improve nLCA methodology and apply it to identify solutions that minimize the trade-offs between nourishing populations and safeguarding the environment. 



\section{Introduction}

\subsection{Background}

Food systems have become increasingly efficient and technologically advanced in providing food products to meet the needs of the world's growing population. However, providing healthy diets while living within environmental limits remains a key sustainability issue as food systems continue to over use increasingly scarce natural resources including water, land and energy. The agricultural sector is the largest user of the world's freshwater resources $(70$ percent of total freshwater withdrawal [OECD, 2010]), it occupies 38 percent of global land surface (FAO, 2020a), and one-third of the energy used globally is expended on food production and supply (Sims et al., 2015). Food systems contribute about one-third of the total anthropogenic greenhouse gas (GHG) emissions (Tubiello et al., 2021). At the same time, the global impact of climate change on food systems is widespread and complex, and it is exacerbated by poor socio-economic conditions that disproportionately affect low-income small producers and consumers (FAO et al., 2018).

In 2020, nearly 811 million people suffered from chronic hunger. The number of hungry people increased by almost 118 million compared with 2019, which was mainly due to the impact of the COVID-19 pandemic on economies, but also on extreme weather conditions, the unaffordability of a healthy diet and regular conflict, among other reasons. At the same time, adult obesity has continued to rise - the global prevalence increased from 11.7 percent in 2012 to 13.1 percent in 2016 (FAO et al., 2021) - and 39 percent of adults are now overweight (WHO, 2021). The Food and Agriculture Organization of the United Nations (FAO) estimates that more than 3 billion people cannot afford a healthy diet. Across the different regions of the world, a healthy diet is two to five times more expensive than an energy (caloric) sufficient diet, and up to two times more expensive than a nutrient sufficient diet (Herforth et al., 2020). Micronutrient deficiencies remain common globally and are prevalent regardless of weight status (underweight, normal weight or overweight) (Osendarp et al., 2020).

Meanwhile, the world's population continues to increase and by 2050 there are projected to be 2 billion more people than there are today, mainly in Africa, bringing the total world population to an estimated 9.7 billion (UN DESA, 2019). In this context, Sustainable Development Goal (SDG) 2 is particularly relevant with its aim to "end hunger, achieve food security and improve nutrition and promote sustainable agriculture." SDG12 is also pertinent with its remit to "ensure sustainable consumption and production patterns," as well as SDG13 which requires "urgent action to combat climate change and its impacts" (United Nations, 2015).

Therefore, as evidence of the negative impacts of food systems on ecosystems, natural resources and human health continues to emerge, researchers are re-examining the environmental impacts of food systems relative to their basic role of providing nutrition, and their social, aesthetic, hedonic and economic functions (e.g. Springmann et al., 2018; Willett et al., 2019). Essentially, the debate is over how food systems can best be organized and operate in a way that provides for the needs - and wants - of the global human population while also operating within environmental limits.

Many stakeholders are interested in the question of how to assess the environmental impacts of healthy diets, and in exploring solutions for minimizing trade-offs between nourishing populations and safeguarding the environment. These vary from international organizations and non-governmental organizations (NGOs) to national and regional governments, to private sector food companies, to farmers, to individual citizens. They also span across multiple economic sectors and activities, including agriculture, financial systems and 
health services. Each of these stakeholder groups has different views, interests and priorities for defining future sustainable food systems. However, there is general agreement that "something needs to be done" to enable food systems to operate within environmental limits.

Life cycle assessment (LCA) has increasingly been used to evaluate the environmental impacts associated with alternative agricultural and food technologies, food supply chains, ingredients, foods, meals and diets. LCA studies make important contributions to the debate over sustainable food systems because they evaluate the environmental impacts of alternative practices, products and systems, and allow for the exploration of benefits and trade-offs across multiple types of impacts. Thus, they can provide information to support international and national policymaking, operational, tactical and strategic management in organizations, and about the behaviour and choices of individuals related to alternative ingredients, food items, meals and diets.

LCA studies of food items increasingly address nutritional and environmental aspects, which requires the consideration of additional methodological aspects. Until relatively recently, for example, LCAs have predominantly focused on quantifying the environmental impacts based on mass or volumebased quantities of foods. Yet the nutrition provided by different food items varies widely on a mass/ volume basis, and nutrition is the most fundamental function of food systems in human societies. Therefore, it is necessary to further consider how LCA can best support the decision-making - which is concerned particularly with the provision of nutrition and related environmental impacts - undertaken by different stakeholders.

\subsection{Overview of the project}

FAO, with the financial support of the Government of Ireland and the Government of New Zealand, commissioned a project to further the debate over the use of LCA to support decision-making about future food systems and their nutritional functions. Given the complexity of the topic, the project's designers decided to focus on food items and defer consideration of wider food systems, meals and diets for future initiatives. The objectives for the project included:

- identify the key LCA methodology limitations and contentions that are limiting the ability of policymakers, researchers and food system actors from capturing and comparing the environmental and nutrition impacts of food items; and

- propose ways to develop a more robust, multidimensional and comparable environmental and nutritional LCA methodology for food items, which will better inform the sustainability and health decisions of food system actors and policymakers.

The project was undertaken between May and November 2021, involving 30 LCA and nutritional experts from 18 countries. This report is the outcome of the project. Chapter 2 describes the consensusbuilding process and explains how it led to the structure of this report. Chapter 3 outlines the different decision situations where LCAs of food systems may be undertaken, and Chapter 4 discusses key LCA modelling issues for food items. An overview of nutritional aspects is provided in Chapter 5 , and their potential use in defining the functional unit for an LCA study is explored in Chapter 6. Chapter 7 summarizes the state-of-the-art impact assessment methods in LCA including the assessment of the nutritional value of food items. Chapter 8 synthesizes the insights from the previous chapters to present a summary of key outstanding methodological issues, and it presents a pragmatic approach to undertaking the environmental and nutritional LCA of food items, together with identified future research needs. Finally, Chapter 9 provides a list of recommendations for undertaking these studies. 


\section{A brief overview of food life cycle assessment and the context for this project}

\subsection{A brief history of food life cycle assessment}

LCA was originally developed at the end of the 1980s, building on the resource and energy studies of the previous two decades. Early on, it was realized that LCAs of products derived from agricultural production had specific characteristics that required further methodological consideration. A seminal project, Harmonisation of Environmental Life Cycle Assessment for Agriculture (Audsley et al., 1997), led to the first set of guidelines on LCA of agricultural production systems. A few years later, the biannual LCA Food international conference series became known as the "reference event for the LCA food scientific community" (Notarnicola, 2011). In the 2000s, research on LCA of agricultural and food systems continued to intensify, alongside growing public concerns about biodiversity loss, air, water and soil pollution, climate change and the (mis)management of limited resources such as freshwater, productive agricultural land, and some minerals and metals. Periodic review articles have charted the progress of this research effort, including Andersson, Ohlsson and Olsson (1994), Roy et al. (2009), Heller, Keoleian and Willett (2013), Nemecek et al. (2016), Sala et al. (2017) and Notarnicola et al. (2017).

Further comprehensive guidelines on LCA methodology for agricultural products were produced as part of the World Food LCA Database project initiated in 2012, and have been updated more recently (Nemecek et al., 2019). Meanwhile, interest in assessing both the nutritional and environmental aspects of food items, meals and diets continued to grow (Heller, Keoleian and Willett, 2013). Most food LCA studies used a defined mass/volume-based unit of analysis called the functional unit (FU) but some began to experiment by using nutrient-based FUs; these included FUs based on single nutrients (such as protein) and on multiple nutrients via the use of nutrient indices. More recently, researchers began to consider the nutritional effects of specified food items at impact assessment as part of the human health impact category (e.g. Stylianou et al., 2016). Today, a diverse range of approaches are used to study the life-cycle-based nutritional and environmental impacts of food systems, and research is providing valuable insights into the trade-offs between alternative agricultural processing, distribution and consumption behaviours associated with food systems. However, the downside of this diversity of approaches is that comparability between studies is compromised, and there is the potential for misinterpretation and bias both in undertaking LCA studies and using their results to support decisionmaking.

Methodological issues related to both nutritional and environmental aspects that are currently debated in food LCA research include:

- Definition of an appropriate FU - while a food item is usually represented as a mass/volume-based quantity, other options include quantities of one or more nutrients, energy content and serving size (Chapter 6).

- Quantification of the nutritional value of a food item in an LCA study - a wide variety of nutrients are required in different quantities in the human diet. These nutrients may be more or less bioavailable depending upon the chemical matrix of the food item and other food items consumed in a meal. The nutrient requirements of individuals also vary depending upon their age, sex and life stage (Chapter 5).

- How to account for food preparation in a food LCA study - LCA studies typically assume specific food preparation and cooking processes. However, these activities are widely variable across different households and may have a significant impact on the final nutritional profile of a food item at the point of consumption (Section 5.3.1).

- Quantification of food loss and waste - food may be lost or wasted at all life cycle stages, making a 
significant contribution to the environmental impacts associated with most food items (Section 4.8).

- Data availability and quality - due to the inherent variability of agricultural systems, food supply chains and food preparation methods, it is challenging to make representative datasets available for use in food LCA studies (Section 4.7).

Several other outstanding methodological issues are common to most LCA studies but are particularly relevant in food LCA studies because methodological choices can make a significant difference to the final results. These issues include:

- Suitability of generic LCA methodology for different applications - there is relatively little research on the relationship between an application area (labelling of food products, new product development, evaluation of alternative agricultural systems, providing support for food policymaking, etc.) and how that may, or should, influence methodological choices.

- Attributional versus consequential modelling approaches - the purpose of an LCA study varies from developing a better understanding of a particular food item along its life cycle, to identifying environmental hotspots (i.e. processes with the highest environmental impacts), to understanding the consequences of marginal or incremental changes in the life cycle of a studied food system. These different purposes may require different modelling approaches; this topic is often described as the "attributional versus consequential debate" in LCA.

- Assessment of specific impacts:

- Climate change - choice of metrics such as global warming potential (GWP), global temperature potential (GTP) or GWP* (Section 7.2) lead to different relative weightings of greenhouse gases, and this is particularly pronounced when evaluating short- versus long-lived GHGs le.g. methane versus carbon dioxide). Relevance to food systems - both livestock systems and rice paddies are major sources of global methane emissions. Furthermore, biogenic carbon storage in long-lived products (e.g. timber in buildings), soil carbon sequestration, and a net increase in biomass on agricultural land have the potential to mitigate climate change through ongoing carbon storage. - Water use - use of water can affect both ecosystems and human health. There are various methods for quantifying these impacts, but it is a challenge to find sufficiently disaggregated data at different geographical and temporal scales. Relevance to food systems - irrigation of agricultural land is the single largest source of water consumption in the world.

- Land use - land use is usually subdivided into assessment of land occupation and land transformation. Methods primarily involve modelling the potential impacts on biodiversity, and on soil and above-ground carbon stocks, and allocating these impacts over a specified time period after a change in land use. Data availability is a challenge and methods involve choosing an appropriate time period over which to allocate impacts. Relevance to food systems - 38 percent of the global land surface is used for agricultural production (FAO, 2020a).

- Eutrophication - the impact of emitting nutrients (primarily nitrogen and phosphorus) into water bodies is dependent upon the sensitivity of the receiving environment. Thus, the challenge for modelling eutrophication is the degree to which the site-specific conditions of the receiving environment(s) can be represented. Relevance to food systems - agriculture is one of the main sources of nitrogen and phosphorus emissions to water (due to their use of inorganic or organic fertilizers).

- Ecotoxicity - lack of data on the toxic impacts of substances is an ongoing issue in LCA. Relevance to food systems - agricultural systems use pesticides that are designed to deter or kill living organisms and, hence, are toxic.

- Ecosystem services - integration of the concept of ecosystem services (ES) (representing the benefits that people derive from functioning ecosystems) into LCA has only been considered in 
the last decade and is still at a relatively early stage of methodological development. Relevance to food systems - ES includes an assessment of provisioning services, which include agricultural systems.

- Communication of LCA results - it is challenging for LCA practitioners to efficiently and effectively communicate the relevance of assumptions, variability in input data, and outstanding uncertainties in both data and methodological choices when communicating LCA results to decision-makers.

Therefore, to increase the relevance of LCA to support decision-making around future food systems, it is important to continue research on these outstanding methodological issues, with the aim of reaching consensus about best practice. This has led to FAO's support for this project as a step towards developing a more comprehensive suite of decision-support tools for defining future sustainable food systems.

\subsection{FAO project on environmental and nutritional life cycle assessment}

The overall purpose of this project was to bring together LCA and nutrition experts to identify opportunities for standardizing environmental and nutritional LCA methodology, make recommendations about best practice, build consensus about preferred methodology and to propose future research needs.

To meet the objectives of the project, it was necessary to carefully consider the process of building both the content and the consensus around the content of the report. As a first step, FAO selected 30 environmental and nutritional LCA researchers to join the project group from a long list of more than 70 researchers who replied to a call for participants in a project on "developing a best practice multidimensional LCA to assess the environmental and nutritional impacts of food items." These individuals were selected to maximize (as far as possible) country, gender and age diversity as well as research expertise across both LCA and nutritional assessments of food items (see Appendix 1 Project Group Members for short biographies of project members). The project was launched on 19 May 2021, and it included breakout sessions where participants were asked to identify key issues that need to be addressed in environmental and nutritional LCA. These issues were then synthesized into topics, and subgroups were formed to address these topics. These subgroups focused on writing each of Chapters 3 to 7 of this report. Four virtual project meetings were organized plus several coordination sessions with the subgroup leaders; the subgroups also met regularly to develop their chapters. Chapters 1 , 2, 8 and 9 were written in the last half of the project, building on the content in Chapters 3 to 7 and discussions in the online meetings and via email. The final draft report underwent an extensive review process mediated by FAO, and the report was subsequently revised and approved by the group.

The purpose of this report is to discuss and provide guidance on how to perform a combined environmental and nutritional LCA of food items in order to support decision-making in different decision situations. This type of study is termed a nutritional LCA (nLCA), a phrase used to describe an LCA study where the provision of nutrient(s) is considered as either the main function or one of the main functions of a food item. For the purposes of this report, a food item is defined as a substance that contributes in whole or in part, or following further preparation (typically in a home or restaurant situation), as a source of nourishment when consumed by humans.

${ }^{1}$ Food items may sometimes be used as ingredients in other food items. For example, a beef steak may be considered a food item if it is served alone, or it may be considered an ingredient if it is diced and used as one ingredient in a stew. Substances that require subsequent industrial processing prior to consumption (such as pasteurization, sterilization, homogenization, extrusion) are not considered food items in this report. For example, sugar beet undergoes further industrial processing to produce sugar prior to human consumption; therefore, sugar beet is not considered a food item in this report, though sugar is a food item. 
In writing this report, the authors kept in mind the following:

- The primary audience for this report is policymakers with some understanding of LCA and its role, and LCA practitioners. As for LCA practitioners, this report is intended for those who work primarily with food items, and more specifically those with a particular interest in the food-environment nexus. This means that some terminology may be unfamiliar to readers who are new to LCA; these readers are encouraged to visit the United Nations Environment Programme (UNEP) Life Cycle Initiative website (www.lifecycleinitiative.org/resources-2/e-learning-modules) for access to introductory learning materials on LCA. This report also has a glossary that defines commonly used nutrition terms.

- In some decision contexts, the most obvious function of a food item is not the provision of nutrition. Other considerations include monetary value, hedonic enjoyment, and/or socio-cultural functions. These other functions are not explicitly addressed in this report. However, much of the detail provided in this report may still be useful in LCA studies of food items that focus on these other functions, and study commissioners may wish to consider including consideration of nutritional value in these other LCA studies.

- A pragmatic approach is needed in nLCA due to data limitations. This means the authors have made recommendations about future nLCA practices that are relatively achievable given current constraints on the availability of data. Concurrently, the aim of the project has been to create a conceptual platform that supports future research efforts by developing a common framework and language, and to identify methodological and data issues that require further attention.

- In many cases, additional value will be gained from existing nLCA studies of food items through adapting and/or reusing them in future meal and dietary LCA studies. Therefore, this report provides guidance for undertaking nLCA studies that will facilitate the future use of their results in other nLCA studies.

Regarding the role of this report in relation to the work of international standard-setting, this project is intended to contribute to consensus-building about the use of environmental and nutritional LCA for food items ( $\mathrm{LLCA}$ ) in specific decision situations. The recommendations are based on, and in line with, international standards and current best scientific practices. As well as policymakers and LCA practitioners, standardization bodies may wish to make use of the recommendations in this report. 


\section{A typology of decision situations}

\subsection{Introduction}

There is no one purpose or use for LCA. At the commencement of an LCA study, before any work is undertaken, the commissioner (the person or organization wanting the LCA) and the practitioner (the person or organization doing the LCA work), who can be the same actor in certain cases (e.g. research LCA), discuss the purpose and use of the LCA study and agree on a goal statement. This includes an explanation of the reason for the study (why it is being conducted), the intended application (how it will be used), the audience (to whom it is primarily aimed, see Section 3.5), and whether it will be used for product comparison to be disclosed to the public (ISO, 2006a, 2017). This chapter discusses the types of applications for LCA studies of food items (as distinct from raw materials, meals and diets) that include consideration of nutrient content or nLCA.

Going back to the 1990s, Weidema (1998) defined six generalized application areas for LCA (Figure 1): hot-spot identification (i.e. where in the system the impacts are concentrated); consumer information; market claims; product standards and labelling; product legislation and performance; and societal or product development plans. The purpose of an LCA study is usually influenced by the decisionmaking context - loosely categorized in Figure 1 as operational, tactical or strategic management. Operational management relates to activities dictated by specific situations based on recent or current data. Tactical management relates to activities that will happen in the near future, based on how things currently work. Strategic management relates to changes in activities that will happen in the future. While these application areas and purposes have remained relevant over the subsequent years, the LCA community has developed more detailed ideas about applications in the context of food systems, and more specifically nutrients and nutrition. This chapter explores the use of LCA in different types of applications, recognizing that the high-level classification in Figure 1 does not necessarily capture all application types. Subsequent chapters discuss how the application type influences methodological choices (Chapter 4), selection of the functional unit (Chapter 6), and data requirements (Chapter 5 for nutritional aspects and Chapter 7 for the environmental impact assessment).

Figure 1: Six application areas and their relationship with data specificity, timescale and management



Note: Examples of these and other common application types addressed in the literature are listed in Table 1. This Figure has been redrawn from Weidema, 1998. 
The International Organization for Standardization (ISO) LCA standard (ISO, 2006a, 2017) requires that the intended application be specified. The International Reference Life Cycle Data System (ILCD) Handbook (ILCD, 2010) elaborates on this requirement by suggesting some common applications (Table 1, left column), all of which can be related to food systems in some way (Table 1, right column) - although these are not necessarily nLCA-related. The ILCD Handbook also recommends defining the decision-context, which relates to whether the intended application of LCA is envisaged to cause changes to the system or merely account for what has already happened. The process of defining the goal of the study is, therefore, an essential step in undertaking an nLCA study as it influences decisions about the scope of the study and the subsequent use of its results.

This chapter uses a series of hierarchical questions to help the reader understand what is meant by the term "food item" and how it differs from related food concepts that are also relevant to human nutrition (Section 3.2). It then looks at the difference between a comparison that is part of the study as defined by the ISO standard (an intrinsic comparison, Section 3.3) and the possibility of bringing together a number of different studies for comparison once they have been published lan extrinsic comparison, Section 3.3). One of the purposes of this report is to help ensure that future nLCA studies can be used together to better understand meals and diets, which will require sufficient compatibility to facilitate extrinsic comparisons. To really understand the nutritional implications of food items, they have to be assessed in the context of diets (Chapter 5). This chapter also looks more closely at the decision context (Section 3.4), and the type of audience, which can be food chain actors and/or other stakeholders (Section 3.5). Based on this information, a set of common nLCA application types is defined (Section 3.6).

Table 1: Common applications of LCA with examples for food systems (not necessarily nLCA-related)

\section{Common application type}

Key performance indicators for ecodesign

Weak points (or hotspots) analysis (i.e. identification of key drivers of impacts)

Ecodesign/design for recycling

Comparison of specific goods or services

Benchmarking against a group average

Green public or private procurement

Development of Type 1 ecolabels

Development of product category rules or similar guides

Development of Type III environmental declarations for a specific good or service

Development of "footprint" indicators

Greening the supply chain

\section{Examples for food systems}

Identify major contributors to diet carbon footprint, e.g. Thrane and Flysjö (2010).

Identify environmental hotspots in various school meals, e.g. De Laurentiis et al. (2019).

Food packaging optimization, e.g. Camps-Posino et al. (2021).

Comparison of locally hunted versus imported meat, e.g. Ziegler et al. (2021).

Identify differences due to production system, e.g. Asem-Hiablie et al. (2019).

School meal procurement, e.g. De Laurentiis et al. (2019).

Understand the role of ecolabels in the food supply chain, e.g. Goossens et al. (2017a).

Define standard approaches for assessment of food products, e.g. Schau and Fet (2008).

Environmental product declarations for the food industry, e.g. Del Borghi, Moreschi and Gallo (2020).

Understand the impact of cooking on carbon and energy, e.g. Arrieta and González (2019).

Understand the impact of logistics on the food supply chain, e.g. Helo and Ala-Harja (2018). 


\begin{tabular}{|l|l|}
\hline Common application type & Examples for food systems \\
\hline Data for environmental technology verification & $\begin{array}{l}\text { Improve food process wastewater treatment, e.g. } \\
\text { Chen et al. (2020). }\end{array}$ \\
\hline $\begin{array}{l}\text { Clean development mechanisms and loint im- } \\
\text { plementation }\end{array}$ & $\begin{array}{l}\text { Evaluation of clean development mechanisms in } \\
\text { the tapioca starch industry, e.g. Wimolrattanasil et } \\
\text { al. (2018). }\end{array}$ \\
\hline Policy development (forecasting) & $\begin{array}{l}\text { Evaluation of value of public payments for organic } \\
\text { production, e.g. Zimmermann et al. (2011). }\end{array}$ \\
\hline Policy information (basket of products) & $\begin{array}{l}\text { Evaluation of household consumption in Europe, } \\
\text { e.g. Castellani, Beylot and Sala (2019). }\end{array}$ \\
\hline Policy information (ranking product groups) & $\begin{array}{l}\text { Eco-efficiency benchmarking of products, e.g. Kon- } \\
\text { stantas, Stamford and Azapagic (2020). }\end{array}$ \\
\hline $\begin{array}{l}\text { Monitoring impacts of a nation, sector, product } \\
\text { group or product }\end{array}$ & $\begin{array}{l}\text { Compare the impact of different national dietary } \\
\text { guidelines, e.g. Kovacs et al. (2021). }\end{array}$ \\
\hline Corporate or site environmental reporting & $\begin{array}{l}\text { Environmental footprint of the Knorr brand, e.g. } \\
\text { Milà i Canals et al. (2011). }\end{array}$ \\
\hline Fixed guarantee certification & $\begin{array}{l}\text { Determine the climate impact of food for the desi- } \\
\text { gn of a climate-tax, e.g. Moberg et al. (2019). }\end{array}$ \\
\hline
\end{tabular}

Source: ILCD, 2010

\subsection{Defining a food item}

The word "food" can represent a range of objects in the food supply chain. Formal definitions are presented in ISO (2016) and FAO and WHO (1985), but the simple classification outlined in Table 2 makes it possible to distinguish among nested objects, namely "food source" or "raw material", "simple food”, “ingredient”, “complex food”, “meal” and "diet”. These do not replace formal scientific definitions (see FAO and WHO, 2001) but are plain language terms that can be used by a wider audience of stakeholders. Each is associated with one or more stages in the food supply chain: "production", "processing" or "consumption". A food object can be described by more than one term, depending on the perspective of the user or audience. A food object could be a food source, an ingredient, a simple food, and part of a complex food, meal or diet. To give an example, corn/maize is a typical food object that can be a simple food (eaten as a snack or vegetable as part of a meal), but it is also a food source (processed into a breakfast cereal), an ingredient (for making a stir fry dish), or as part of a complex food (a frozen ready meal) or meal (as a side serving). It will also be part of a diet. Therefore, in nLCA studies it is important to define the nature of the food object and the stages in the food supply chain that are considered, since this determines which goals, impact assessment methods and interpretations are appropriate. For the purposes of this report, the term "food item" is used to refer to simple and complex foods that are ready to be consumed (with or without cooking). 
Table 2: Definition of terms relating to objects studied in food LCA research

\begin{tabular}{|c|c|}
\hline Term & Definition \\
\hline $\begin{array}{l}\text { Food source or raw } \\
\text { material }\end{array}$ & $\begin{array}{l}\text { - An object, intended to be food, considered only in the production stage, and } \\
\text { becomes one or more food items. } \\
\text { - A food source can become an ingredient, a simple food with little processing, a } \\
\text { simple food with more processing, or a complex food with multiple processes. } \\
\text { Examples: an animal, manioc, raw milk, soybeans, sorghum. }\end{array}$ \\
\hline Simple food & $\begin{array}{l}\text { - A food item is available in the market, ready for human consumption and requi- } \\
\text { ring either no or minimal preparation before eating (perhaps only cooking). } \\
\text { - A food item can be the same as an ingredient or food source, so the definition } \\
\text { is context specific. If considered as an ingredient, further processing through } \\
\text { combining it with other ingredients is required before consumption. } \\
\text { Examples: a potato, pitaja, a chicken breast, basmati rice. }\end{array}$ \\
\hline Ingredient & $\begin{array}{l}\text { - A food object available in the market that is intended to be blended or proces- } \\
\text { sed with other items to make a complex food. } \\
\text { - An ingredient can be the same as a simple food, and so the definition is context } \\
\text { specific. An ingredient will require more processing (whether industrial or by the } \\
\text { consumer) before becoming a food item. } \\
\text { - A food additive is a type of ingredient added to food that results in it - or its } \\
\text { by-products - becoming a component or otherwise affecting the characteristics } \\
\text { of that food. } \\
\text { Examples: cooking banana (could also be a simple food), tamarind, coconut milk, } \\
\text { flour, herbs and spices. }\end{array}$ \\
\hline Complex food & $\begin{array}{l}\text { - A food item available in the market, ready for human consumption, composed of } \\
\text { multiple ingredients. } \\
\text { - A complex food is created from multiple ingredients in a domestic or commer- } \\
\text { cial kitchen. } \\
\text { - A complex food is usually a discrete, nameable product or serving. } \\
\text { Examples: maize porridge, flatbread, fermented beverage. }\end{array}$ \\
\hline Meal & - Combination of multiple food items consumed in one sitting or event. \\
\hline Diet & $\begin{array}{l}\text { - Compilation of food items eaten over an extended period. } \\
\text { - Representative of the food intake of an individual or wider community. }\end{array}$ \\
\hline
\end{tabular}

To help the reader identify which term best describes the food object they are interested in, and whether it can be considered a food item, a hierarchy of questions (Q1 to Q6) is provided in Figure 2. The rationale underpinning each of the questions is detailed below. 
Figure 2: Decision tree to guide in scoping nutritional LCA (nLCA) for selection of the most suitable approach in relation to a food item

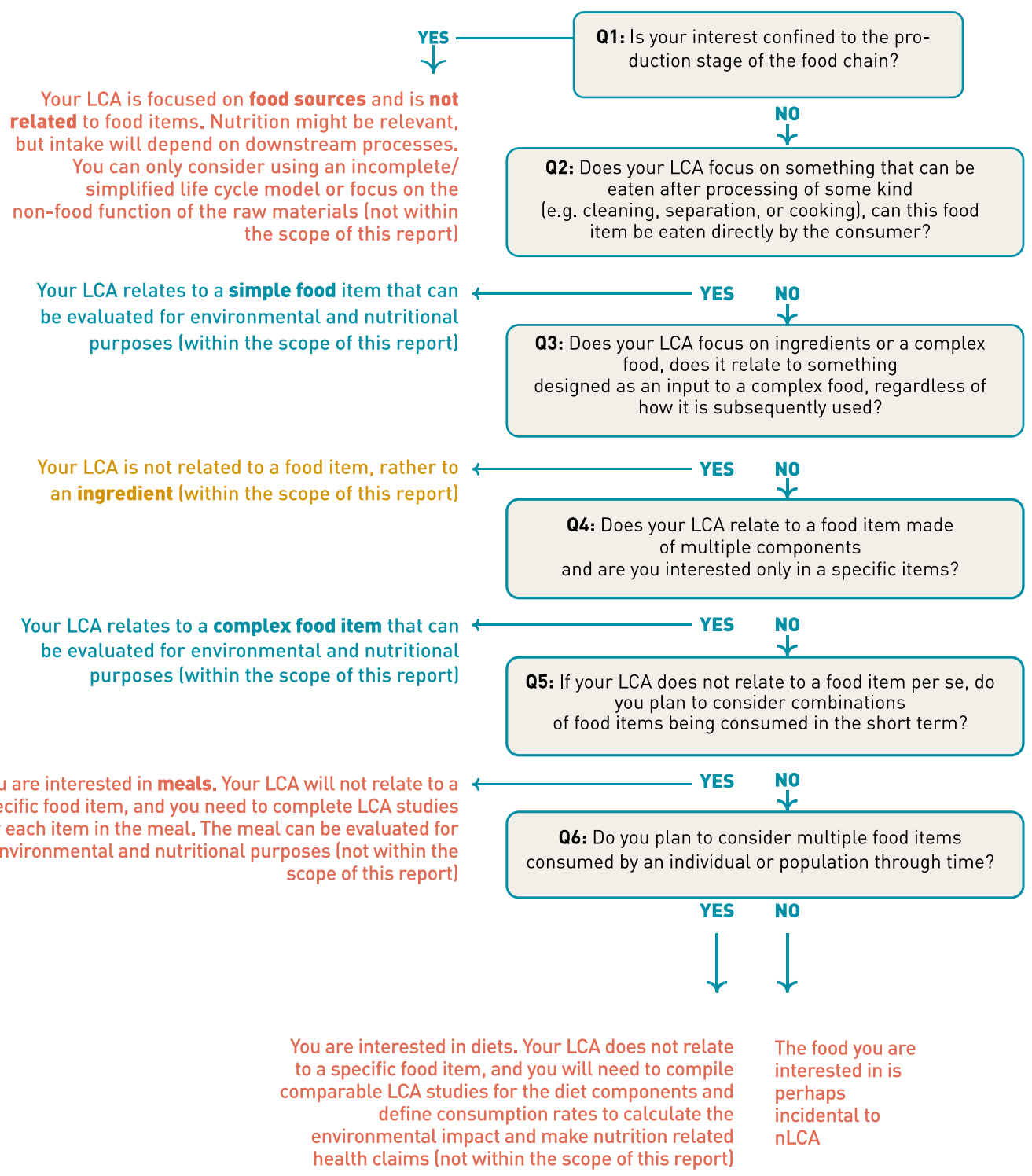

Note: The main focus of this report is food items (green), but the recommendations can also be applied to ingredients (orange). Studies that finish at the producer gate or are extend to meals and diets (red) are not within the scope of this report.

\section{Q1: Is the stakeholder's interest confined to the production stage of the food chain?}

YES
The LCA will be focused on food sources
up to the processor gate and is not related
to food items. The nutrient content of
subsequent food items will depend on
downstream processes.

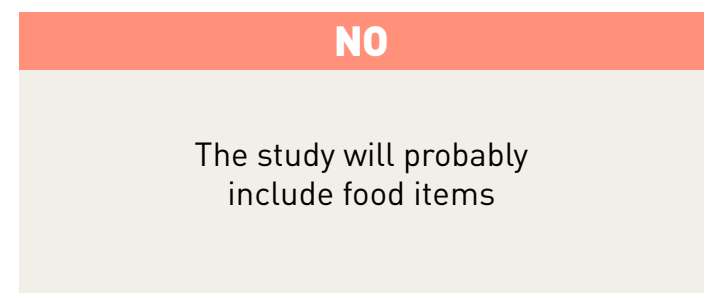

Many LCA studies have been published over the last 20 years focusing on food sources, e.g. milk to the farm gate (e.g. Bartl, Gómez and Nemecek, 2011; Baldini, Gardoni, and Guarino, 2017) and live weight output of animals (Roop et al., 2014). These studies are not necessarily useful for considering nutritional aspects of food items because they do not always convey nutrient content information and, therefore, the nutrient content of the resulting food items will be unknown. 


\section{Q2: Does the LCA focus on something that will be eaten directly by the consumer?}
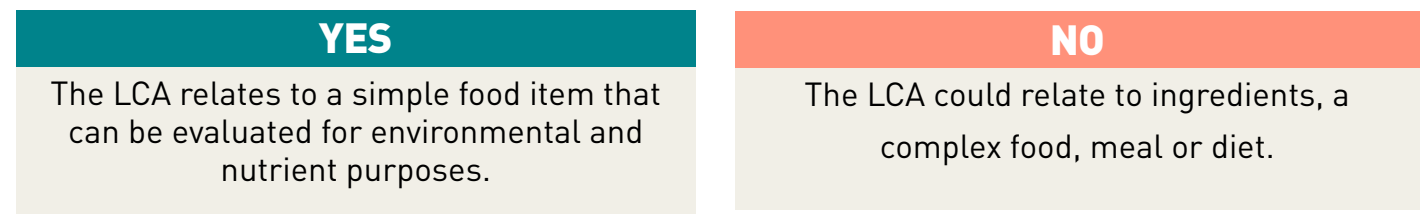

LCA studies have been published about simple food items, like rice (Xu et al., 2020), meat products (McAuliffe, Takahashi and Lee, 2018), and seafood (Hallström et al., 2019). Some studies have declared nutrient contents, expressed the function of the system using nutrient content, or have addressed nutrition.

Q3: Does the LCA relate to something designed as an input to a complex food, but not the nutrient content or nutrition of the resulting food item?

\section{YES}

The LCA is related to an ingredient.

\section{NO}

The LCA relates to a complex food item.

LCA studies have been published about simple food items, like rice (Xu et al., 2020), meat products (McAuliffe, Takahashi and Lee, 2018), and seafood (Hallström et al., 2019). Some studies have declared nutrient contents, expressed the function of the system using nutrient content, or have addressed nutrition.

\section{Q3: Does the LCA relate to something designed as an input to a complex food, but not the nutrient content or nutrition of the resulting food item?}

\section{YES}

The LCA relates to a complex food item that can be evaluated for environmental and nutrient purposes.

\section{NO}

The LCA does not relate to a food item per se.

LCA studies have been published about ingredients, such as olive oil (Fernández-Lobato et al., 2021), skimmed milk powder (Yan and Holden, 2018) (also a simple food item in some contexts), aged vinegar (Bartocci, Fantozzi and Fantozzi, 2017), raw sugar (Renouf et al., 2011). While a simple food and an ingredient can be the same thing, or made from the same food source, they can have very different implications for nLCA.

\section{Q4: Will the LCA consider a complex food item alone?}

\section{YES}

The LCA relates to meals rather than specific food items. nLCA studies will be required for each food item in the meal, which can then be evaluated for environmental and nutrient purposes.

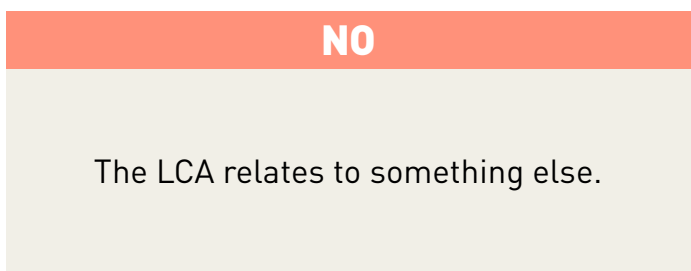

A number of LCA studies have been published about complex foods, such as bread (Notarnicola et al., 2017) and chocolate (Bianchi et al., 2021). 
Q5: Will the LCA consider complex (or simple) food items when consumed with other foods in one sitting or event?

YES
The LCA relates to meals rather than
specific food items. nLCA studies will
be required for each food item in the
meal, which can then be evaluated for
environmental and nutrient purposes.

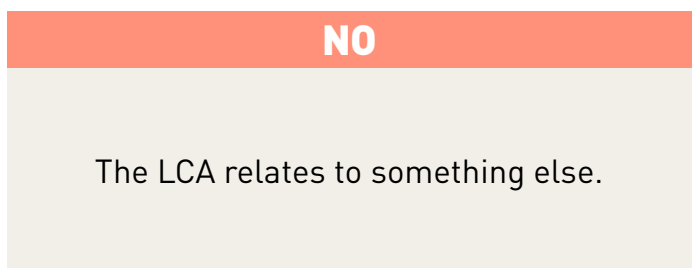

A number of LCA studies have been published about meals, for example, university canteen meals (Cooreman-Algoed et al., 2020), low-carbon meals in public schools (Batlle-Bayer et al., 2021) and compiling existing LCA results into datasets that permit meal-based calculations for catering to dependent senior citizens (Saxe et al., 2019). It is also possible to use the meal as the function with an appropriate functional unit (Ernstoff et al., 2019a; García-Herrero, De Menna and Vittuari, 2019).

\section{Q6: Will the LCA consider food items as part of the wider consumption of foods?}

\section{YES}

The study is interested in diets. The LCA will not relate to a specific food item. It will be necessary to compile comparable nLCA studies for the food item components of the diet.

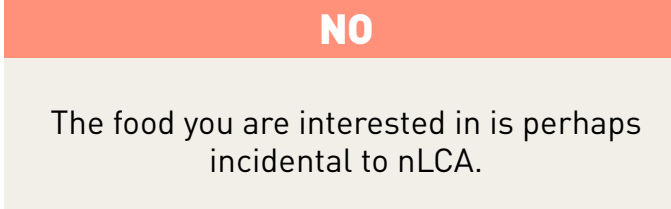

A number of LCA studies have been published about diets, like the Atlantic dietary pattern (EsteveLlorens et al., 2019a), multiple dietary scenarios worldwide (González-García et al., 2018).

\subsection{What are valid comparisons?}

The idea of intrinsic comparison (defined by the goal of the study) and extrinsic comparison (compilation of unconnected studies) was introduced in Section 3.1. Intrinsic comparisons relate to functionally equivalent food items that can be described using the same functional unit (ISO, 2006a, 2017) (Chapter 6). Examples of such studies include Greek yoghurt supply chains (Houssard et al., 2020) and substituting animal-based proteins with oat protein concentrate (Mogensen et al., 2020). Other valid comparisons could be made using packaging types as the functional unit (Banar and Çokaygil, 2009), mass and energy comparison along the food supply chain (Bianchi et al., 2020), national dietetic profile (Batlle-Bayer et al., 2020b), and serving size (Heard et al., 2019). There are also applications where LCA data are used to help individuals choose between food items, such as carbon footprint labels on food (Bellassen et al., 2021) or the carbon footprint of diets (Bruno et al., 2019).

Extrinsic comparisons occur when different studies are compiled to provide a representation of a diet (González-García et al., 2018) or other purpose. Such comparisons are more likely to be valid when the primary LCA studies have similar scopes, but nutritional functional equivalence is not required. A review of poultry production chains (Costantini et al., 2021) that gave particular attention to the different methodological approaches applied to functional units, system boundaries, inventory data collection and multifunctionality management, explains some of the issues, as do Yan and Holden (2018) for raw milk. One of the purposes of this report is to encourage a degree of standardization of nLCA to facilitate extrinsic comparisons. 


\subsection{The decision context}

While it can be argued that all LCA studies are undertaken with the intention that something happens as a result of the work (the application defined in the goal), a distinction can be made between those applications that are concerned with the state of the system (someone purchasing a food because of its declared nutrient content and carbon footprint), and those that are concerned with change (development of policy to encourage consumption of particular food items). These two contexts are explored with Q7.

\section{Q7: Will the LCA results directly or immediately influence future demand for a food item, and/or how the food item is made in the future, and/or changes in the materials used to make it, and/or a new policy environment in which the food item is sold, and/or change in consumer choices?}

\section{YES}

This is a decision context where something is expected to change as a direct outcome of the study. The LCA might be expected to capture the impacts of that change.

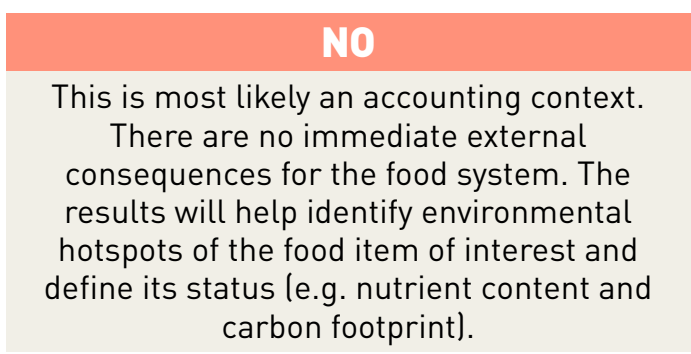

Accounting contexts (Situation C using the ILCD (2010) classification) are typically associated with uses such as footprints, labels and hotspot identification (and use attributional modelling). According to the ILCD Handbook (ILCD, 2010), they are not used directly for decision support. However, this is inconsistent with two uses identified in more recent literature: development of environmental labels that inform food item choices (Dai et al., 2017), and identification of hotspots so that improvement options can be evaluated using consequential modelling (Brander, Burritt and Christ, 2019). More information about the use of different modelling approaches in LCA to support accounting and decision contexts is provided in Chapter 4.

\subsection{Target audience}

The goal defines the target audience for an LCA study, and reporting the LCA results should reflect the audience interests. There are various classifications of stakeholders and actors in food supply chains. The European Environment Agency (EEA, 2017) has defined eight relevant groups of key actors (Table 3); it should be noted that this is very much focused on developed countries, even though it can be applied to food chains dominated by small scale producers, fishers and pastoralists. It is reasonable to think that the underlying data for all audiences might be the same, but the assessment and presentation of results, and associated meaning, could be different for each group.

Table 3: Relevant key actors/stakeholders in the food chain

\begin{tabular}{|l|l|}
\hline Term & Definition \\
\hline Production & (1) Input industry (seed producers, fertilizer manufacturers, energy suppliers) \\
\hline \multirow{2}{*}{ Processing } & $\begin{array}{l}\text { (2) Farmers and fisheries (primary producers of raw materials for food items, including pastoralists, } \\
\text { fishers) }\end{array}$ \\
\hline \multirow{2}{*}{ Logistics } & (4) Food and drink manufacturers (enterprises that make processed foods for distribution in the food chain) \\
\cline { 2 - 3 } & (5) Retail and services (end point logistics) \\
\hline Consumption & (6) Consumers \\
\hline Oversight & (7) Regulation, governance, policy (public sector) \\
\cline { 2 - 2 } & (8) NGOs \\
\hline
\end{tabular}

Source: adapted from EEA, 2017

Note: Alternative classifications of stakeholders will overlap with those listed, such as workers, local community, value chain actors, consumers, society and children (UNEP, 2020). 


\subsection{Types of applications}

Table 1 lists generic applications identified in ILCD (2010) for LCA and provides some examples for food systems. Based on this list and other literature, nine types of applications specifically related to nLCA can be identified:

1. benchmarking (comparing against agreed baselines) of foods (e.g. Batlle-Bayer et al., 2020a; Schaubroeck et al., 2018);

2. process improvement (e.g. Thomas et al., 2020; Vidergar et al., 2021);

3. planning (different by actor/stakeholder group) (e.g. Sonesson et al., 2017; Takacs and Borrion, 2020);

4. labelling and product advice le.g. De Camillis et al., 2012; Food SCP RT, 2013; Jungbluth et al., 2012; Van Der Werf and Salou, 2015);

5. meal planning/offerings (e.g. Saget et al., 2020);

6. food choices (e.g. Bianchi et al., 2020; Bohnes, 2019; Potter and Roos, 2021);

7. diet advice (e.g. Esteve-Llorens et al., 2019b);

8. monitoring (e.g. Ziegler et al., 2018); and

9. food system assessment (e.g. Hessle et al., 2017; McAuliffe, Takahashi and Lee, 2020).

These application types can be correlated with the eight stakeholder groups (listed in Table 3) as shown in Table 4. From the literature search conducted for this report, it seems there are a general lack of LCA studies on monitoring life-cycle-based environmental impacts associated with food intake or food consumption behaviours over time and space. This gap could be addressed in the future using nLCA studies.

\subsection{Towards best practice recommendations}

The recommendations in this report may be of interest for studies considering food sources, but the nutrient content and nutritional aspects will not necessarily be applicable if the study does not consider processing, logistics, preparation and consumption las the nutritional value of food sources may change during these activities). If working with simple or complex food items, the recommendations presented in this report will make it easier for extrinsic comparison, and for compiling environmental and nutrient results into meal or dietary related information. The report recommendations also support assessing ingredients. Ultimately, moving from nutrient content to nutritional value requires an assessment of an individual or population diet because it is the nexus of food items, environmental impact, nutrient content, human nutrition and human health.

One of the purposes of this report is to ensure that future nLCA studies are conducted in such a way as to facilitate the data on individual food items to be compiled for public health and personal diet assessment. While the goal agreed upon between the commissioner and the practitioner, with a specific audience in mind, will always be prioritized when undertaking a food-related LCA study, following the recommendations in this report should ensure that more food item data are interoperable for dietary assessments based on comparable nLCA results. 
The analysis in this chapter leads to the following recommendations:

- Prioritize the goal determined by the commissioner, application and audience for nLCA studies, and present it when reporting the results of an nLCA study. The goal should define: (1) the reason for the nLCA study; (2) the intended application; (3) the intended audience; and (4) any comparison that is intended for public declaration. Follow these recommendations to ensure future food item $\mathrm{nLCA}$ studies can be used for extrinsic comparison and be readily compiled into information about meals and diets.

- Clarify the actor/stakeholder group that is the primary audience for the nLCA. This can guide the nLCA practitioners scoping the nLCA study according to specific application criteria to satisfy enduser requirements.

- Clearly define the food item of interest for the nLCA study. This helps determine the LCA approach to be adopted and the selection of the most suitable functional unit for the study.

- In most cases, identifying environmental hotspots and monitoring should work in an accounting context with attributional LCA. Policy evaluation, strategy development, marketing and future planning should work in a decision context using attributional and consequential LCA as appropriate. 
Table 4: Most common nLCA applications organized by different actors/stakeholders in the food system

\begin{tabular}{|c|c|c|c|c|c|c|c|c|c|c|}
\hline \multirow[b]{2}{*}{ Interest field/ party } & \multirow{2}{*}{$\begin{array}{c}\text { Actors/ stakeholders } \\
\text { in the food system }\end{array}$} & \multicolumn{9}{|c|}{ nLCA applications } \\
\hline & & Benchmarking & $\begin{array}{c}\text { Process } \\
\text { improvement }{ }^{1}\end{array}$ & Planning $^{2}$ & Labelling & Meal offerings & Food choice & Diet advice & Monitoring & $\begin{array}{l}\text { Food system } \\
\text { assessment }\end{array}$ \\
\hline \begin{tabular}{|l|} 
Industry organization \\
\end{tabular} & (1) Input industry & $\begin{array}{l}\text { By product or life } \\
\text { cycle stage }\end{array}$ & $\begin{array}{c}\text { Optimization and } \\
\text { impact/cost mini- } \\
\text { mization/ reduction }\end{array}$ & $\begin{array}{l}\text { For type of product/ } \\
\text { demand }\end{array}$ & & & & & & \\
\hline $\begin{array}{c}\text { Business/ } \\
\text { food companies }\end{array}$ & $\begin{array}{l}\text { (2) Farmers and } \\
\text { fisheries }\end{array}$ & $\begin{array}{c}\text { By process activity } \\
\text { and technology// } \\
\text { management prac- } \\
\text { tice }\end{array}$ & $\begin{array}{l}\text { Process optimiza- } \\
\text { tion }\end{array}$ & $\begin{array}{l}\text { What to produce and } \\
\text { how to do it }\end{array}$ & $\begin{array}{l}\text { Promotion and market } \\
\text { share }\end{array}$ & & & & Legal compliance & \\
\hline $\begin{array}{l}\text { Business/ } \\
\text { food companies }\end{array}$ & $\begin{array}{l}\text { (3) Food and drink } \\
\text { companies }\end{array}$ & $\begin{array}{l}\text { Specific product } \\
\text { comparison }\end{array}$ & $\begin{array}{l}\text { Process optimiza- } \\
\text { tion }\end{array}$ & $\begin{array}{c}\text { Capacity, markets, pur- } \\
\text { chases, new products }\end{array}$ & $\begin{array}{l}\text { Promotion and market } \\
\text { share }\end{array}$ & & $\begin{array}{l}\text { Promotion and mar- } \\
\text { ket share }\end{array}$ & & Legal compliance & \\
\hline $\begin{array}{c}\text { Business/ } \\
\text { industry organization }\end{array}$ & \begin{tabular}{|c|} 
(4) Wholesalers and \\
suppliers
\end{tabular} & & & $\begin{array}{c}\text { Logistics and other } \\
\text { supply-chain require- } \\
\text { ments to maintain } \\
\text { quality } \\
\end{array}$ & $\begin{array}{l}\text { Promotion and market } \\
\text { share }\end{array}$ & & & & & \\
\hline $\begin{array}{c}\text { Business/ } \\
\text { industry organization }\end{array}$ & $\begin{array}{l}\text { (5) Retail and ser- } \\
\text { vices }\end{array}$ & & & $\begin{array}{l}\text { Retail requirements } \\
\text { and promotional ac- } \\
\text { tivities }\end{array}$ & $\begin{array}{l}\text { Promotion and market } \\
\text { share }\end{array}$ & $\begin{array}{l}\text { Promotion and } \\
\text { market share }\end{array}$ & $\begin{array}{l}\text { Promotion and mar- } \\
\text { ket share }\end{array}$ & $\begin{array}{l}\text { Promotion and } \\
\text { market share }\end{array}$ & & \\
\hline Consumption & (6) Consumers ${ }^{3}$ & Regulations & & $\begin{array}{l}\text { Choosing meals and } \\
\text { diets }\end{array}$ & Choosing food items & $\begin{array}{l}\text { Choosing meals } \\
\text { and servings } \\
\text { Portion control }\end{array}$ & $\begin{array}{c}\text { Choosing meals and } \\
\text { servings } \\
\text { Portion control }\end{array}$ & $\begin{array}{l}\text { Adjusting dietary } \\
\text { pattern }\end{array}$ & & \\
\hline Policy making & $\begin{array}{l}\text { (7) Regulation, gov- } \\
\text { ernance and policy }\end{array}$ & & & $\begin{array}{l}\text { Definition of dietary } \\
\text { guidelines }\end{array}$ & Standards setting & & $\begin{array}{c}\text { Production, distribu- } \\
\text { tion and consumption } \\
\text { policies }\end{array}$ & $\begin{array}{c}\text { National/regional } \\
\text { policies protecting/ } \\
\text { regulating local } \\
\text { diets }\end{array}$ & $\begin{array}{l}\text { Establishing regulatory } \\
\text { procedures/criteria }\end{array}$ & $\begin{array}{l}\text { Based on defined proce- } \\
\text { dures/criteria }\end{array}$ \\
\hline $\begin{array}{c}\text { Consumption/ } \\
\text { industry organization }\end{array}$ & (8) NGOS & & & $\begin{array}{l}\text { Definition of dietary } \\
\text { guidelines }\end{array}$ & & $\begin{array}{c}\text { Promotion of } \\
\text { eco-friendly meals } \\
\text { and consumption } \\
\text { practices }\end{array}$ & $\begin{array}{l}\text { Food marketing and } \\
\text { consumption influ- } \\
\text { ence }\end{array}$ & $\begin{array}{l}\text { Advice and mainte- } \\
\text { nance of diets le.g. } \\
\text { local foods }\end{array}$ & Activity and assistance & $\begin{array}{l}\text { Providing decision } \\
\text { support }\end{array}$ \\
\hline
\end{tabular}

1. This largely refers to operational and tactical management.

3. Consideration of community tradition and local culture is also important for $n L C A$ aimed at consumers. 



\section{Modelling issues for a nutritional life cycle assessment}

\subsection{Introduction}

When undertaking an LCA study, it is important to consider how a food item and its life cycle (the system) are defined and represented, the analysis perspective taken, the data used, and how uncertainty and variability of data and results are managed. This chapter summarizes the guidance that is already available to LCA practitioners on these aspects and provides additional guidance for understanding and undertaking the nLCA of food items more specifically.

\subsection{Scope definition}

\section{Functional unit}

The object of the LCA study is influenced by the question of interest, which in the context of this report is related to food items la simple or composite food or ingredient as described in Section 3.2). The FU describes the function of the food item(s) of interest (ISO, 2006a, 2017). It is a fundamentally important part of the LCA, as it defines the basis on which results will be reported and compared. It will depend on the decision context (Section 3.4), the audience for the results (Section 3.5), and the application of the results (Section 3.6).

For nLCA, the FU needs to emphasize the nutritional function of the food item(s). This is a point of difference from the general food LCA, which generally focuses on food provision as the function in terms of mass or volume. Chapters 5 and 6 , respectively, discuss defining the nutritional function(s) of food items and establishing the FU. In summary, there are careful choices to be made about how to represent the nutritional function in the $\mathrm{FU}$, and how to capture nutritional implications in the impact assessment.

The important thing to note in terms of modelling a food system in nLCA is that the function and the FU need to be defined early in the LCA process. This is because it influences the subsequent choices about system boundaries, the modelling perspective and data sources las described further in this section).

\section{System boundaries}

The system boundary defines what is and is not included in an LCA. It will depend on the research question and the FU, as well as on whether an attributional and consequential approach is being taken (Section 4.3). For studies of food items, it is common for the system boundary to include many or all stages of the food item's life cycle. This includes agricultural production, primary and secondary processing, packaging, transport, retail and distribution, and end user consumption.

In the more traditional attributional approach, it has been most common for studies to have "cradle to farm gate" or "cradle to factory gate" system boundaries, which predominantly include the upstream stages of primary agricultural production (fishing in the case of marine products, or growing crops) and processing (canning fruit, milling wheat, vegetable packing). Some aspects of upstream stages may be omitted due to a lack of information and data, for example the nursery production of seedling plants such as fruit trees, grape vines, asparagus, etc. Obtaining nursery stage data has proven to be challenging due to the existence of monopolies or oligopolies at the corporate level (Goossens et al., 2017b). 
Studies with more comprehensive system boundaries of "cradle to plate" or "cradle to grave" are not common in the existing LCA literature, and hence downstream activities or stages (distribution, retail, consumption) are less commonly represented. However, the use of these extended system boundaries has been increasing in recent years due to growing interest in meal- and diet-related environmental impacts (Henriksson et al., 2021).

For nLCA studies, it is preferable for system boundaries to extend to the consumption stage ("cradle to plate"). This is because the nutrient characteristics and their bioavailability may change up to the point of consumption, due to processes such as home storage and cooking. An alternative approach is to define a system boundary up to a point prior to consumption la food item on the supermarket shelf) but take into account the nutrient characteristics at the eventual point of consumption. For the latter perspective, however, it must be noted that excluding household handling and cooking food products may provide a limited assessment in nLCA, as selected cooking methods may - or may not-facilitate the retention of the nutritional value and the biological and functional properties of foods (Zhao et al., 2019).

An aspect to consider is fortifying foods with added nutrients (Omega fatty acids, vitamin D, iron, iodine, etc.) and animal feed fortified with micro-nutrients. In conventional food LCA studies, practitioners commonly exclude these aspects from the system boundaries on the basis of small amounts not significantly influencing the LCA results or lack of data. In nLCA studies, such fortification of food items to increase nutrient density should be considered as part of the nutritional function. Nutritional supplements such as vitamin tablets are not food items and so are outside the scope of what is being considered here.

As food loss and waste (FLW) has been shown to be an important hotspot for nutrient loss (Section 4.8), it should be included in the system boundary (Omolayo et al., 2021).

\section{Data quality}

An important aspect for any LCA is the quality of the data in terms that accurately represent the production system being evaluated. This includes the technological specificity, temporal and geographical correlation (ISO, 2006a, 2017).

In relation to technical specificity, there are differences in the ways food is produced and prepared, which ideally needs to be reflected in how the assessed system is represented. For example, seafood shows very high heterogeneity in relation to the ocean where it is captured, the equipment used, and the way in which it is consumed (Parker et al., 2018). As an example, hake (Merluccius spp.), which is consumed in large volumes in Spain and France, can be caught by bottom trawlers, midwater trawlers, long liners or by small scale artisanal vessels. Each ship uses equipment with different fuel use intensities resulting in a high variability in environmental impacts (Avadí et al., 2020). Consequently, different products (molluscs, crustaceans, fish) should have life cycle inventory (LCI) data that reflect these specificities (Avadí et al., 2020). Variations also extend to how food items are processed, stored or cooked (Bastias et al., 2017) and potentially wasted. For the above example, different processes may result in different rates of food loss. These variations affect the nutritional content of food items and may influence the FU and/or reference flow (RF) in nLCA.

In relation to temporal and geographic representation, it is important that the modelled system and the data used reflect the region and the timeframe relevant to the question of interest. For example, 
good quality data may be available for cheese production in the Netherlands, but it may not adequately represent cheese production in South Africa, which follows different practices. Consequently, researchers often need to develop their own data relevant to the geographic, temporal and technical specificity of the product being assessed.

It can be difficult to represent realistically the exact nature of the product life cycle being assessed. Therefore, the limitations must be reported and assessed clearly, for example the Pedigree matrix may be used (Section 4.5) and/or the uncertainty may be tested (Ciroth et al., 2016) (Section 4.7).

\subsection{Attributional versus consequential perspectives}

Over the past two decades, two alternative modelling perspectives have been developed and extensively discussed in LCA.

Attributional LCA (ALCA), also known as the accounting or descriptive approach, has become predominant for partitioning the production system in such a way that the average energy and material input and output are assigned to the process or service under evaluation. ALCA is mostly used in a retrospective context, considering the status quo of a certain process or product system. The results are usually aimed at understanding the current situation and can be used to compare food items, and to identify hotspots and potential improvement options within a static context. There have also been some attempts outside the food sector to use ALCA with prospective data (Frischknecht and Stucki, 2010; Choma and Ugaya, 2017).

ALCA has been widely used for food products in many regions of the world (Thomassen et al., 2008), as well as for assessing inputs to food production, such as fertilizers or pesticides. These ALCA studies have served as a basis to date for understanding the environmental sustainability and hotspots of hundreds of aquatic and terrestrial food products. More recently, thanks to increasing data availability and more comprehensive databases, ALCA studies have also been aggregated to provide environmental assessments of meal plans and national diets (Henriksson et al., 2021).

Although ALCA studies are extensively used to support decisions about mitigation strategies, the results of such studies on food items do not generally account for linkages with the wider food system (van Zanten et al., 2018). For example, the environmental footprint of a vegetarian diet including milk products may not consider the environmental impact of the production of associated meat from slaughtered milking cows and surplus male calves. However, if the demand for milk changes, the production of the associated meat changes as well. ALCA assessment does not generally, therefore, fully represent the environmental implications of potential mitigation strategies. In effect, it lacks a market perspective, in which marginal or incremental changes may induce domino-effect changes in other markets (Schaubroeck et al., 2021).

On the other hand, consequential LCA (CLCA), also known as the change-oriented modelling approach, considers the environmental implications of changed physical flows in a production system due to the marginal change in production of the food item of interest (Larrea-Gallegos et al., 2019). As CLCA does not focus solely on environmental flows affected by the change in a system but also considers affected flows outside the system, the system boundary of a CLCA study is, therefore, substantially different from an ALCA study. Performing a CLCA involves a prediction of the future consequences of a certain action, and, hence, it requires a deeper understanding of both the economic market in which 
the product or service is situated and its interactions with other production systems. CLCA is mainly applied as a prospective or predictive approach, to address "what if" questions that arise in policy and strategy development, in which an expected meaningful change in a particular sector or system is evaluated to assess the potential change in associated environmental impacts. It was rarely used at the beginning of the century due to factors such as its added complexity, the lack of robust databases, and computational capacity at the time. Through time it has become more popular and is considered by some researchers to be the preferred modelling approach to support future policies (Weidema et al., 2018; Brander, Burritt and Christ, 2019). However, the inherent uncertainties associated with predictive scenarios warrant more attention being given to uncertainty analysis (Section 4.7).

Though certain methodological challenges persist in ALCA, as discussed in Section 4.4, there is wide consensus in the LCA community regarding its scope and utility. However, although some common pillars have been established in CLCA lthe need to model an incremental or marginal change in a production system), a fervent debate is still ongoing regarding what actually constitutes a consequential perspective (De Camillis et al., 2013; Plevin, Delucchi and Creutzig, 2014; Suh and Yang, 2016; Yang, 2016; Zamagni et al., 2012). This has led to the proposal of multiple pathways for consequential modelling, including the use of agent-based models (Querini and Benetto, 2014), technology choice (Kätelhön, Bardow and Suh, 2016), system dynamics (Yao et al., 2018), food system models (Van Selm et al., 2021), and economic equilibrium (Rege et al., 2015) models. Interestingly, according to Palazzo, Geyer and Suh, 2020, the use of only one of these modelling approaches in CLCA would limit the potential of CLCA studies since different models are more adequate in different social and/or economic contexts.

Beyond the heterogeneity of models applied to conduct CLCA studies, LCA practitioners recurrently report wider uncertainties than in ALCA, as well as challenges for policymakers and other stakeholders in understanding the inherent complexities of CLCA. However, at the same time, CLCA offers a more flexible framework in which LCA practitioners are subject to a lower number of methodological restrictions (Schaubroeck et al., 2021).

The choice of modelling approach will significantly influence the final results, as ALCA uses average data and CLCA uses marginal data for the production system under analysis. Practitioners can perform scenario and sensitivity analyses to generate a prospective approach with ALCA, but this generates different domino-effects than would be generated by a CLCA approach, influencing the final results and their interpretation. In the food sector, the use of CLCA has been scarce. Some early studies in Denmark used it to assess food versus biofuel-food competition (Searchinger et al., 2008; Tonini et al., 2012). Since then, most studies have been carried out in response to a specific research problem (Larrea-Gallegos et al., 2019) or as a way to test the consequential modelling perspective (Chalmers et al., 2015; Sacchi, 2018). As far as we can ascertain, CLCA is yet to be applied in the food sector beyond the land use change or market implications of a particular food product. It may be a promising modelling perspective for assessing the environmental consequences of adapting meal plans and diets to meet global dietary guidelines within environmental limits. However, current computational tools for CLCA limit the number of parameters that can be changed in the market, and a new generation of CLCA studies will be needed to develop a more complex and change-oriented modelling framework. 


\subsection{Allocation in multi-product systems}

When ALCA modelling is undertaken, allocation is a methodological challenge that arises for many, but not all, LCAs. It occurs when a studied process inevitably and unavoidably results in two or more products or services simultaneously. Such multi-functional activities in food production and processing are common, including:

- Fisheries - multiple species are caught simultaneously and landed for sale, and fish processing concurrently produces fish meal and fish oil.

- Cereal crops - plant stalks and leaves are also harvested for use as animal bedding or fuel.

- Livestock processing - hides, bones, feathers, etc. are used in products such as clothing and horticultural or feed amendments, alongside the meat for human consumption.

Although well known in LCA research, this issue is not unique to LCA, and is known by other names (such as the joint production problem) in other forms of economic and biophysical modelling.

The topic of allocation, and more specifically the basis upon which allocation should occur, is one that has given rise to considerable debate among LCA practitioners (Pelletier et al., 2015). This is because different approaches can result in markedly different results for a given individual product (e.g. Parker et al., 2018).

Given this effect, and the long historical and ongoing debate regarding the most suitable allocation basis(es), it is not surprising that there is formal guidance on allocation in the ISO 14044 LCA standard. The standard recommends a hierarchy with the following order of preference (ISO, 2006a, 2017):

- to avoid allocation by:

- dividing the process giving rise to co-products into sub-activities that deliver one or more unique co-products and analysing inputs and outputs to these activities discretely, and

- expanding the scope of analysis (system expansion) to consider one or more separate, parallel processes that yields a functionally equivalent product to the co-products and subtracts the impacts of the co-produced product from the determining product. (Note: when performing a CLCA, a system expansion is used by default, therefore, allocation is also avoided by default.);

- to allocate inputs and outputs between co-products on the basis of an underlying physical causality/relationship between them; and

- to allocate inputs and outputs between co-products in relation to some other relationship between them. One such relationship could be their economic value lalthough the basis upon which economic value should be determined is not indicated).

The first preference of the ISO standard is for allocation to be avoided where possible. In practice, where it cannot be avoided, it is to be based on an underlying physical causality or relationship between the products/co-products. This is usually done on the basis of relative mass, economic value or, less frequently, the energy content. Allocation based on the economic value of co-products or functions is less preferred. Despite this, it has been used based on the justification that it reflects the primary motivation for most food production systems (e.g. profit-seeking by producers).

Table 5 summarizes some of the main strengths and limitations of the three main bases upon which allocation occurs in practice in LCA. 
Table 5: Summary of strengths and limitations of three frequently employed bases of allocation used in food LCls

\begin{tabular}{|c|c|c|}
\hline $\begin{array}{l}\text { Basis for } \\
\text { allocation }\end{array}$ & Strengths & Limitations \\
\hline $\begin{array}{l}\text { Economic } \\
\text { value }\end{array}$ & $\begin{array}{l}\text { - nominally reflects one motivation for } \\
\text { activity that results in multi-functional } \\
\text { outputs } \\
\text { - in some instances, relative prices of } \\
\text { co-products are readily, publicly available }\end{array}$ & $\begin{array}{l}\text { - does not reflect a physical relationship between inputs } \\
\text { and co-products/functions } \\
\text { - does not align with biophysically based FUs used in most } \\
\text { LCAs } \\
\text { - prices of co-products are subject to diverse and highly } \\
\text { variable influences (taxes, subsidies, changes in market } \\
\text { demand) that are usually unrelated to the underlying } \\
\text { biophysical processes } \\
\text { - consequently, relative co-product values vary over time } \\
\text { independently of any potential change in the underlying } \\
\text { biophysical realities, rendering life cycle impact asses- } \\
\text { sment (LCIA) outcomes of limited temporal durability or } \\
\text { comparability } \\
\text { - basis of determining which prices (wholesale, retail, } \\
\text { fraction of total revenue, fraction of profits generated, etc) } \\
\text { to use is unclear and ultimately arbitrary } \\
\text { - potentially preferred co-product relative economic } \\
\text { values (e.g. fraction of profits) are frequently unavailable } \\
\text { resulting in default to those that are available but that } \\
\text { provide poorer representation of relative economic value } \\
\text { - cannot be applied in situations where co-products are } \\
\text { not bought and sold (e.g. subsistence systems or when } \\
\text { bartered) } \\
\text { - biases LCIA results to align with high value co-products }\end{array}$ \\
\hline Mass & $\begin{array}{l}\text { - frequently aligns with biophysically } \\
\text { based FU } \\
\text { - mass of co-products usually easily de- } \\
\text { termined using publicly available data } \\
\text { - where variability of relative mass of } \\
\text { co-product production over time or space } \\
\text { exists, variance can frequently be quanti- } \\
\text { fied and incorporated in analyses } \\
\text { - results in temporally stable LCIA out- } \\
\text { comes when LCI data are stable } \\
\text { - LCIA outcomes are independent of the } \\
\text { relative subjective social utility of co-prod- } \\
\text { ucts }\end{array}$ & $\begin{array}{l}\text { - mass reflects a physical attribute of co-products but } \\
\text { one that may or may not reflect an underlying relationship } \\
\text { between inputs and outputs } \\
\text { - in some instances, relative mass of co-products does } \\
\text { not align with one or more functions of co-products (e.g. } \\
\text { use of crop residues as a heat source) }\end{array}$ \\
\hline $\begin{array}{l}\text { Energy } \\
\text { content }\end{array}$ & $\begin{array}{l}\text { - frequently aligns with biophysically } \\
\text { based FU } \\
\text { - energy content of co-products usually } \\
\text { easily determined using publicly available } \\
\text { data } \\
\text { - where variability of relative energy con- } \\
\text { tent of co-product production over time or } \\
\text { space exists, variance can be quantified } \\
\text { and incorporated in analyses } \\
\text { - results in temporally stable LCIA out- } \\
\text { comes when LCI data are stable } \\
\text { - LCIA outcomes are independent of the } \\
\text { relative subjective social utility of co-prod- } \\
\text { ucts }\end{array}$ & $\begin{array}{l}\text { - energy content reflects a physical attribute of co-pro- } \\
\text { ducts but one that may or may not reflect an underlying } \\
\text { relationship between inputs and outputs } \\
\text { - in some instances, relative energy content of co-pro- } \\
\text { ducts does not align with one or more functions of } \\
\text { co-products (e.g. use of crop residues as livestock bedding } \\
\text { material because the energy content is not the basis for } \\
\text { using it as bedding) } \\
\text { - choice of energy carrier upon which to base allocation } \\
\text { (protein only, total macro-nutrient energy, etc.) is ultima- } \\
\text { tely arbitrary but can be chosen to align with the FU }\end{array}$ \\
\hline
\end{tabular}


The latest amendments to the ISO 14044 standard list some arguments in favour of and against economic allocation. Among the limitations (Table 5) is the high degree of price variability, even over very short time periods, that can affect one or more co-products of a given system. As an example, Figure 3 illustrates the monthly price variability of the co-products of soybean milling - meal and oil over a ten-year period. This variability, even affecting only a single co-product of a system, means that LCA results based on economic allocation may have very limited temporal relevance.

For food LCA studies that use nutrient quantities as the underlying physical causality/relationship between multiple products/functions, economic allocation becomes even more difficult to justify. When using or adapting existing $\mathrm{LCl}$ data, the perspective and allocation approach underlying the $\mathrm{LCl}$ should be critiqued to check that it is consistent with the perspective and approach for the study in question. For more detailed critiques of different approaches to allocation in LCA research, see Pelletier and Tyedmers (2011), Weinzettel (2012) and Pelletier et al. (2015).

Figure 3: Change in monthly nominal price of soybean meal and oil (in USD) over a ten-year period (July 2011-June 2021)

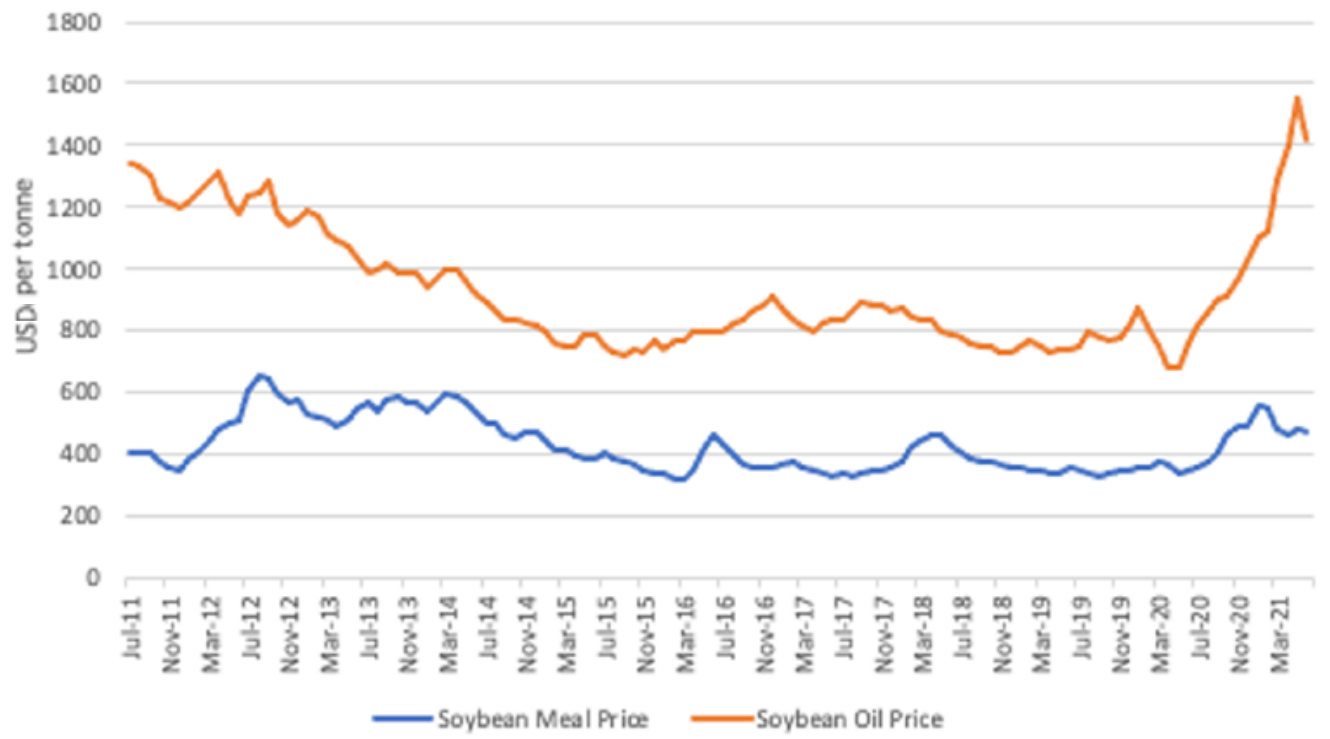

Source: Mundi, 2021

Importantly, the basis upon which allocation is conducted can, in theory, be very flexible and depart from the historically popular attributes of co-products that have come to dominate food LCA research (relative mass or energy content, or some measure of economic value of co-products). In this regard, Chen et al. (2017) proposed a novel, yet highly principled basis for allocation in the future-oriented LCAs of primary food production systems. Specifically, they describe using metabolic energy requirements for growing different tissues as a highly stable, relatively easily determined, and biophysically rigorous basis upon which to base an allocation that aligns well with the preferred physical basis of the allocation in the ISO 14044 standard. For example, Chen et al. (2017) employ known relationships between metabolic energy demand and tissue growth in cattle, but the same approach could not only be applied across livestock systems but also across cropping systems, aquaculture, etc.

Finally, as food LCA research evolves to better reflect the nutritional attributes of food and potentially the specific functional needs of human consumers, methods should similarly evolve. This would include aligning the basis of allocation, where it is required, to the purpose of the study and ideally to 
the chosen FU. For example, an nLCA focused on addressing Omega-3 deficiency among a specific population may have an FU based on the Omega-3 fatty acid content available for consumption in the food item(s). In this context, it might be appropriate to allocate impacts between products and coproducts on the basis of relative Omega-3 fatty acids content or concentration.

\subsection{General data requirements for a food life cycle assessment}

Data availability and quality is an important aspect for LCA studies. In this section, we discuss data issues for food LCA generally across the four topics of: il foreground or primary data; ii) background or secondary data; iii) emissions modelling; and iv) data quality statement. nLCA studies also require additional data for characterizing the nutritional attributes of food items, which is discussed in Section 4.6. For nLCA studies extending to endpoint modelling of human health impacts, additional data requirements related to health impacts may also be required and are discussed in Chapter 7 .

In terms of the foreground data required for food LCA generally, the inherent variability of food systems makes it especially important to use data that adequately represent the system being modelled. This is particularly the case for the agricultural stage of the food item life cycle. It is common for different sources of data to be used for building the LCl, from statistics to surveys, pilot trials, extension services and archetype scenarios (Nemecek et al., 2005). As the attributes of these data sources vary (specificity of operation techniques, inputs applied, geographical scale, allocation assumptions, etc.), consistency and standardization are an issue.

Furthermore, the data used to represent the processes of interest need to consider the inherent variability. For example, data for a single, specific year may not adequately represent the process being modelled depending upon the decision situation. Recommendations for accounting for variability include representing an average over a range of years (EC-JRC, 2018) and excluding single or rare events. In fact, representing variability in food LCA studies necessitates specific methodology guidelines, particularly for agricultural inventories (Notarnicola et al., 2017).

In terms of background data required for food LCA generally, several studies have considered the role of secondary agricultural datasets. For example, Corrado et al. (2018) aimed to understand similarities and differences in datasets of arable crop cultivation and the extent to which the differences may affect life cycle impact assessment (LCIA) results. They identified that the exclusion of infrastructure, machinery, and the production of plant protection products and seeds from system boundaries can significantly influence the outcomes of the study.

Section 4.4 discussed the significance of the allocation basis used in the LCA study. It is equally important to critique the allocation basis of the data that is sourced/selected for a study to ensure it is consistent with the allocation basis chosen for the study. This is often overlooked when sourcing secondary data for a study.

Although some initiatives have emerged to build national $\mathrm{LCl}$ data from a range of world regions (GLAD, 2018), there is still bias in LCls that represent conventional production in Europe loften based on practices in France and Switzerland). Therefore, there is a need for a broadening of available data to make it more representative of agrifood production processes globally. For example, even though the United States of America, India and China together produce more than two-thirds of the world's milk, European milk production is assumed in more than 90 percent of datasets (Teixeira, 2014). 
Considering the post-agricultural stages in food supply systems, reviews have highlighted the need for better data for the food processing (Ahmad, Yew Wong and Ahmad, 2019) and consumption stages (Virdegar et al., 2021). Furthermore, most of the food LCA studies are in the context of high-income countries rather than low/medium-income countries. A lack of specific studies and proper databases are two of the main reasons.

Emissions modelling may involve different methodological assumptions and disparities in approaches. This could hamper the interpretation of LCA results, mainly in comparative studies or when mixing datasets from different databases (Montemayor et al., 2021). In particular, agricultural emissions are often major contributors to impacts, and most of them are estimated rather than measured using various models or default factors (EC-JRC, 2018; Nemecek et al., 2015). Since agricultural emissions are influenced by site-specific conditions, emission factors or emission modelling should represent specific regions and climatic conditions wherever possible (Corrado et al., 2018). This applies particularly to methods and factors used for pesticides, fertilizers and livestock emissions (OLCAPest, 2020; IPCC, 2019a).

The established way to deal with variability, lack of knowledge and uncertainty is described in the ISO standards (ISO, 2006a, 2017). LCAs should be transparent and include a description of data quality, so that the audience can understand the reliability of the study results and properly interpret the outcome. However, how to define data quality represents another challenge for LCA studies.

Weidema et al. (2013) established the pedigree matrix to deal with data quality. This matrix lists five indicators: reliability, completeness, temporal correlation, geographical correlation and further technological correlation. Based on this work, Nemecek et al. (2015) suggest a simplification and adaptation for agricultural datasets, assuming default qualifications, which usually gives high values of quality as foreground datasets, but they would need to be adjusted when they are used as background datasets. As another example, in the European Commission's Product Environment Footprint, the data quality ratio for each dataset and for the LCA study is calculated based on four data quality criteria: technological, geographical, time representativeness and precision/uncertainty (ECJRC, 2018). Other data quality schemes include efforts by the United States Environmental Protection Agency (Edelen and Ingwersen, 2018) and the Global Life Cycle Data Access Network (GLAD) (Ciroth et al., 2017, synthesized in Ciroth et al., 2021).

Information and data about the nutrient characteristics or nutrition implications of food items are rarely documented in existing LCA studies and LCl databases. When using or interpreting existing LCA studies and data for nLCA purposes, it will be necessary to complement it with information about nutritional attributes at various stages of the food supply chain (Chapter 5). It will also be important to critique the appropriateness of the data in terms of representing the production of a food item with the required nutrient characteristics. For example, how and where an agricultural commodity is grown and subsequently processed may influence its nutrient characteristics.

\subsection{Nutrient data requirements for a nutritional life cycle assessment}

Unlike general food LCA studies, an nLCA requires additional layers of data related to the nutritional value of food items. However, the nLCA is a burgeoning sub-field of LCA which currently lacks standardization in this regard. 
Existing nLCA studies have addressed questions related to the environmental impacts of nutrient or nutritional provisions from individual food items (e.g. McAuliffe Takahashi and Lee, 2020, Werner, Flysjö and Tholstrup, 2014), through to whole diets (e.g. Castañé and Antón, 2017). Some ALCA studies have used new models to account for nutritional aspects of food items, meals and diets, such as linear programming models (Larrea-Gallegos and Vázquez-Rowe, 2020) and the nutrient-rich food (NRF9.3) model (Castañé et al., 2017; McAuliffe, Takahashi and Lee, 2020; Vázquez-Rowe et al., 2020) (Chapters 5 and 6). Some of these studies have also aligned their optimization targets with environmental sustainability boundaries (Lucas, Guo and Guillén-Gosálbez, 2021; Van Selm et al., 2021) and global dietary guidelines (Ritchie, Reay and Higgins, 2018; Van Selm et al., 2021).

With such a diverse range of possible uses, nLCA studies often rely on a more eclectic range of data sources than standard food LCA studies. Nutritional information and data are required to define the FU (Chapters 5 and 6), and possibly also to inform nutrition-related health impacts (Chapter 7). Examples of the additional layers of nutritional and/or health-related data that may be needed include:

- Nutrient composition of the food items studied - Ideally this includes data on food composition collected in the country or place of origin of the food considered, and food composition data specific to the different production systems involved, for example, wild salmon tend to have higher levels of vitamin $D$ than farmed salmon, while long-chain Omega-3 fatty acid levels can be increased in the meat of monogastric animals by feeding them linseed (as reported by Coehlo et al., 2016). Locally relevant food composition data is required for composite foods that are unique to a country le.g. pho in Viet Nam) or when recipes or the manufacturer's ingredients differ depending on geographical location (the same food brands can have different compositions in the different countries where the food is marketed). However, these data may be lacking in low- and middle-income countries. In some cases, food composition data can be used from other sources (food composition data from other, comparable countries and/or food products) but the quality and applicability of the data should be carefully considered.

- Nutrient intake recommendations - If an nLCA study aims to evaluate the nutrient composition of a food item in the context of recommended daily intake (RDI) or allowances (RDA) for nutrients, locally relevant nutrient intake recommendations should be used when available. For example, they may be accessed from national reference nutrient intakes established by health agencies and governments, ideally using recommendations for relevant population subgroups defined by age and sex (including estimated energy requirements when considering caloric intake).

- Food matrix effects, and interaction with other foods in the diet - As discussed in Section 5.3, the nutritional value of food items may be influenced by the combined effects of individual nutrients in a single food item or by other foods eaten concurrently in a meal. The lack of data means that addressing this aspect in an nLCA is challenging, but its potential significance can be discussed in an $\mathrm{nLCA}$ report.

- Food processing and preparation - As discussed in Section 5.3.1, both industrial processing and at-home food preparation may affect the nutritional value of food items. Therefore, it is important to consider the life cycle of foods up to the plate in nLCA.

The most common additional data requirement for nLCA is food composition data. Examples of freely available food composition tables are shown in Box 1. This list is not exhaustive, is mostly for high-income countries, and not all databases are available in English. There are also commercial, subscription-based options which collate all available nutritional data into a single platform. For example, EuroFir (2021) offers the datasets in Box 1 plus others. Commercial websites often allow users to delve deeper into nutritional composition of food items by enabling them to calculate the 
nutrient density of multiple individual ingredients which comprise a single product, thus allowing subscribers to assess food items that contain multiple ingredients (ketchup, which contains tomatoes, sugar, salt, in addition to many other minor ingredients that may originate in multiple countries, as demonstrated recently by Wohner et al., 2020).

Many low- and middle-income countries have a limited availability of reliable food composition data for foods eaten locally. For example, in Viet Nam, the food composition data currently available is measured on uncooked foods only; this is an issue for nLCA studies when the studied foods are cooked rather than uncooked items. FAO's INFOODS initiative aims to improve the global availability of locally relevant food composition data (e.g. FA0, 2019b).

It is important to be aware of the level of variability in the completeness and level of detail provided by food composition databases. For example, the United States Department of Agriculture (USDA) database, arguably one of the most complete databases in English, provides standard deviations for some nutrients in some food items. However, there are many food items where no data are provided on variability in nutrient content. Indeed, the food composition data that underlie the nutrition composition values in national databases are often based on a very small sample of the particular food item purchased and analysed locally. Values are sometimes imputed from other international databases when local data are not available.

When the same food composition data are used for comparing different food items within one study, such variability is less of an issue because the same database informs the comparisons made. However, when foods are compared between different studies, and different food composition databases are used for the foods being compared, caution should be exercised and possible differences due to variations in underlying food composition data should be identified.

For example, in the United Kingdom of Great Britain and Northern Ireland nutritional database (known nationally as the McCance and Widdowson database) there are no variations provided, which hinders uncertainty assessments related to the choice of a nutritional FU or nutritional impact assessment. This is an issue for nLCA because the nutritional value of food items can vary depending on aspects such as climatic conditions during agricultural production, farm management and soil types, and products of varying quality (for example, the protein content of wheat grain). However, LCA data scientists, mathematicians and nutritional/health scientists across the globe are increasingly working in multidisciplinary groups to better-understand uncertainties pertaining to the food-environment nexus and to produce novel primary data that can be incorporated into the nLCA framework.

\section{BOX 1. NUTRITIONAL TABLES FOR DIFFERENT COUNTRIES}

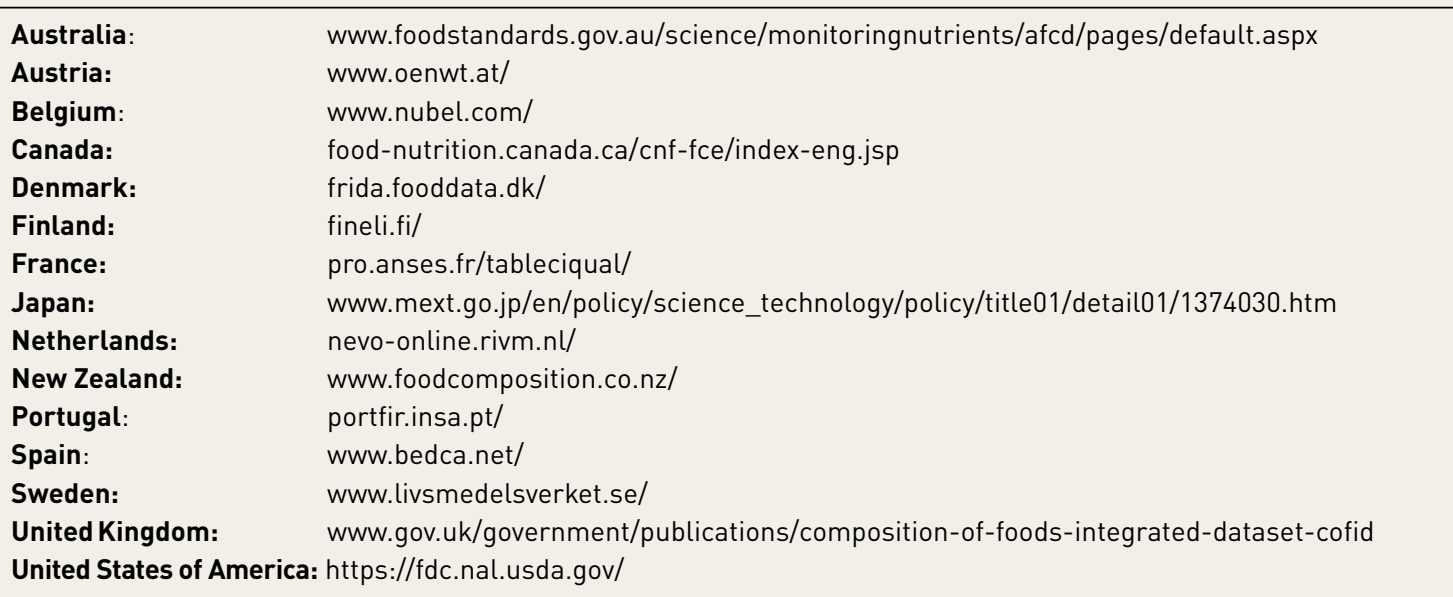

Source: FAO, 2019b 


\subsection{Uncertainty and variability}

Uncertainty and variability can make the interpretation of LCA results challenging, and even make the comparison of products and scenarios misleading. Uncertainty can be due to random and systematic errors, and a lack of scientific knowledge (Rosenbaum, Georgiadis and Fantke, 2018). Variability, on the other hand, refers to inherent differences present in a sample or population. See Table 6 for the characteristics of both uncertainty and variability. Although both are rarely evaluated in LCA, there are examples of agricultural LCAs that consider them (Henderson et al., 2017). Unlike uncertainty, variability cannot be decreased but only better estimated (Groen et al., 2016). Examples of variability in agricultural systems are discussed in Section 4.5.

Uncertainty analysis can be a challenge due to a lack of information or data for defining the statistical distribution (type and standard deviation) for inputs and outputs in the $\mathrm{LCl}$, and the lack of knowledge about correlations between parameters (Huijbregts, 1998). Groen and Heijungs (2017) highlighted that ignoring correlations between input parameters during uncertainty propagation may even lead to under- or over-estimation of output uncertainty and incorrect conclusions. When two food items are compared, Monte Carlo simulations might be performed to determine the probability of one alternative being better than the other. For example, the output variance of greenhouse gas emissions of one alternative might be overestimated due to ignoring correlations between input parameters (such as carbohydrate concentration and energy content). As the actual variance is lower, this could lead to the incorrect conclusion that one alternative performs better than another.

Methodology and dataset choices made by the LCA practitioner are another important source of uncertainty in LCA practice. In research conducted by Scrucca et al. (2020), the same LCI data for a bottle of Italian red wine was used by six experienced practitioners to independently calculate cradleto-grave environmental impacts for six impact categories. The practitioners could independently select the most appropriate datasets, system boundaries, allocation procedures and some modelling choices. The LCA results were analysed in terms of reproducibility and repeatability and were found to be significantly different for the different practitioners, although the differences reduced markedly when further information was supplied about the wine bottle.

It is particularly important to assess the uncertainty associated with the chosen modelling perspective (i.e. attributional versus consequential, see Section 4.3) and the chosen allocation basis (see Section 4.4). For this, scenario and/or sensitivity analysis can be conducted using different perspectives and allocation methods to test how they influence the conclusions drawn from the results.

Table 6: Summary of uncertainty and variability characteristics in LCA

\begin{tabular}{|l|l|}
\hline Uncertainty & Variability \\
\hline $\begin{array}{l}\text { Parameter uncertainty: measurement or estimation } \\
\text { errors, sampling errors, lack of knowledge on the data }\end{array}$ & $\begin{array}{l}\text { Temporal variability: variations over time (seasons, } \\
\text { years) }\end{array}$ \\
$\begin{array}{l}\text { Model uncertainty: related to information loss when } \\
\text { modelling reality within the LCA structure lassumption } \\
\text { of linear relationships) }\end{array}$ & $\begin{array}{l}\text { Spatial variability: variations across locations (regional } \\
\text { differences in emission factors) }\end{array}$ \\
$\begin{array}{l}\text { Uncertainty due to choices: uncertainty caused by } \\
\text { choices in LCAs (FU, allocation, etc.) }\end{array}$ & $\begin{array}{l}\text { Variability between objects/sources: inherent } \\
\text { differences in a product system (different } \\
\text { characteristics in considered food products) }\end{array}$ \\
$\begin{array}{l}\text { Epistemological uncertainty: lack of scientific } \\
\text { knowledge on system behaviour lignorance about how } \\
\text { food systems will react to changes) }\end{array}$ & \\
$\begin{array}{l}\text { Mistakes (e.g. using wrong units) } \\
\text { Relevance uncertainty: related to the representation of } \\
\text { the used indicators for the decision at hand }\end{array}$ &
\end{tabular}


Analysis of uncertainty and variability are recommended to understand how they influence conclusions. Uncertainty and variability can be assessed using probabilistic methodologies, Monte Carlo simulations and sensitivity analysis. These should be integrated into the study from the outset, during $\mathrm{LCl}$ development, and not left until the end of the assessment. The feasibility of uncertainty analysis will be improved if default uncertainty estimates are provided in LCI databases. Uncertainties in LCIA should also be considered, as the models and characterization factors underlying LCIA methods come with uncertainties. Neglecting these uncertainties may lead to incorrect interpretation of impacts and thus biased decision support (Verones et al., 2017). Communicating uncertainty and variability to the end user of the LCA data is also important, including guidance on how to account for uncertainty and variability in decision-making processes.

\subsection{Quantifying food loss and waste in the life cycle inventory}

Food loss and waste (FLW) makes a significant contribution to the environmental impacts of food (FAO, 2013). Corrado et al. (2017) provide a useful list of the most important food losses that occur across all stages of the food life cycle lagriculture, food processing, distribution, retail and home consumption). Food loss refers to all food originally destined for human consumption that is lost along the supply chain, and food waste is considered a subset of food loss (FAO, 2019a). The term food loss generally describes losses that occur in the production, post-harvest, processing and distribution stages of the food supply chain, whereas food waste describes the losses that take place at the retail and consumer stages (Corrado et al., 2017).

Food LCA studies that have accounted for food waste have been concerned with understanding how food losses contribute to the environmental impacts of food items and assess the benefits of food waste prevention or valorization opportunities (Omolayo et al., 2021; Bernstad and Cánovas, 2015). In their comprehensive review of how FLW has been accounted for in LCA studies, Corrado et al. (2017) found:

- In primary production, flood losses have been accounted for by including impacts from the decomposition of food losses, and by giving credits for the nutrient input to soil from food losses left in the fields.

- In processing, avoidable losses are explicitly reported in only a few studies, and unavoidable losses are accounted for in more studies as a reduced output per unit of raw produce input.

- In distribution and consumption, there is hardly any consideration of food loss mostly because few studies extend from cradle to plate and so these phases are not included in the system boundary.

- Over-consumption as another dimension of food waste has not been considered in many LCA studies (Sundin et al., 2021), but may be a hotspot of future interest.

Consideration of FLW in food LCA studies appears to deteriorate in the downstream stages of food supply chains. Ironically, these are the stages where the environmental impacts of FLW are typically the greatest (Tonini, Albizzati and Astrup, 2018) due to the large amount of avoidable food waste generated in the consumption stage. Furthermore, in terms of FLW data, Xue et al. (2018) found that most data sources relate to a few industrialized countries (in particular, the United Kingdom of Great Britain and Northern Ireland and the United States of America), and more than half are based only on secondary data. This suggests that existing FLW data for use in LCA has high uncertainty and is not fully representative of different national and cultural contexts. Accounting for FLW in the LCl of all phases in the supply chain is recommended (Omolayo et al. 2021) but is currently a challenge. Furthermore, differentiating the type of food that is wasted or lost is important so that the environmental impacts can be accurately calculated. 
Some LCA studies have recently managed to shed light on this issue by estimating some trends at a national level. For instance, Hallström et al. (2021) estimated that FLW accounted for approximately 18 percent of total dietary climate impacts in Sweden, whereas Vázquez-Rowe et al. (2021) estimated a range of 24 to 29 percent in some of the main cities in Peru. Both studies focused on climate impacts, meaning that the environmental trade-offs across a wider range of impact categories remains unexplored in LCA.

Vázquez-Rowe et al. (2020) studied the nutritional value of FLW and found that vegetables and cereals were the food categories where the most nutrient losses occur, and that agricultural production and household consumption were the stages in which these nutrient losses were mostly occurring.

Consideration of FLW in the supply chain also requires consideration of its fate. This may involve modelling the waste treatment process (e.g. landfilling) or, if the food is beneficially used (for animal feed, biogas production, etc.), modelling these co-production processes using system expansion and substitution or allocation. The distinction between FLW that is disposed of, versus being beneficially used is also an important consideration. Each will trigger a different approach for assigning impacts, and so will influence the magnitude of the environmental impacts associated with the food item represented in the FU (Vázquez-Rowe et al., 2020, 2021). FLW that is rescued and provided to charities, especially those generated at the retail or service end of the supply chain, also need to be accounted for, but there is less guidance available on this.

\subsection{Best practice recommendations}

Other chapters address in more detail some of the methodological issues that have been briefly mentioned in this chapter (in particular, Chapter 6 discusses the selection of the FU and Chapter 7 addresses impact assessment). For this chapter, best practice recommendations for modelling are consistent with general LCA best practice and ISO standards:

- The perspective of the study (attributional versus consequential) should be appropriate for the LCA study goal, scope and objectives.

- The chosen basis for allocating impact between multiple products/co-products, where it is used, should be justified based on the LCA study goal, scope and objectives.

- When using or adapting existing LCl data, the perspective and allocation approach underlying the $\mathrm{LCl}$ should be critiqued to check that it is consistent with the perspective and approach for the study in question.

- Data quality parameters should be transparently reported.

- Uncertainty and variability of the LCI data and the LCIA methods should be quantified and reported.

In addition, best practice recommendations relevant to nLCA in particular:

- The nutritional function and the FU need to be defined early in the LCA process as they underpin all subsequent methodological choices.

- Nutritional information and data about the food item being assessed should be used to inform the FU and to inform nutrition-related health impacts.

- For nLCA studies that omit the processing, storage and/or preparation life cycle stages, the assumed nutrient content and associated nutrition/health impacts (if considered) may be different for the final consumer depending upon how the food item is stored and prepared for 
final consumption. This also includes the potential fortification of foods with added nutrients. Such potential differences should be noted in the nLCA report as they affect the interpretation of results. - The processes modelled and the LCl data used should be as representative as possible of the food item assessed, including its nutritional characteristics.

- Given that production processes can vary within a food type and across regions, reliance solely on readily available LCI data (which commonly represents production in a limited number of countries) should be avoided and effort taken to source or develop context-specific data.

- Given that agricultural emissions are influenced by site-specific conditions, emission factors or emission modelling should represent specific regions and climatic conditions where possible.

- An nLCA study report should document any enrichment of foods with additional nutrients.

- Fortification of food items to increase nutrient density should be accounted for as part of the nutritional function, but nutritional supplements such as vitamin tablets are not food items and are out of scope. When using food composition data to inform the nutritional characteristics of food items, critique the completeness and detail of the data.

- If an nLCA study evaluates nutrient composition of a food item in the context of RDI or RDA, locally relevant nutrient intake recommendations should be used where available.

- The potential of future mitigation strategies is currently mainly assessed with static attributional LCA data based on the current situation; however, the use of more complex predictive models using a consequential approach should be further investigated.

- Food loss and waste - at all life cycle stages - should be included in the system boundary including their end-of-life fates. 



\section{Assessing nutritional value in life cycle assessment of food items}

\subsection{Introduction}

The primary biological purpose of food consumption is to sustain proper functioning of the body through the assimilation of nutrients (Burgess and Glasauer, 2004). Other reasons for food consumption include the social dimension, providing gustative pleasure as well as an occasion to gather with others. Nutrition provided through food plays a key role in maintaining health, which can be defined as an individual having an "optimal function, well-being, and quality of life" (Saylor, 2004). SDG 2 aims to guarantee "access to safe, nutritious, and sufficient food for all people all year round", and to end malnutrition (United Nations, 2021). Ending hunger and achieving adequate nutrition are, therefore, key challenges for the food sector (FAO, 2020b); however, it is crucial that food production occurs within environmental limits. To balance these factors, nutritional aspects can be integrated into LCA methodology to assist decision makers to identify which food items and/or diets have the potential to comply with SDG 2 while having a lower environmental footprint.

Nutritional and health aspects, and environmental aspects of food items have traditionally been distinct scientific disciplines. However, in the past two decades, an increasing number of studies have assessed the combined nutrition or health and environmental aspects of food ingredients, food items or diets. As an example, according to Scopus, LCAs that concurrently address health and/or nutrition have risen from 56 publications in 2000 to 693 publications in 2020, demonstrating a substantial increase both in interest and, more importantly in the current context, data availability (Figure 4). Nutrition and health aspects have been included in environmental assessments of food using different approaches and methods le.g. Grigoriadis, Nugent and Brereton, 2021; Guo et al., 2021; Green et al., 2020; McAuliffe, Takahashi and Lee, 2020; Eme et al., 2019; Hallström et al., 2018; Mertens et al., 2017; Saarinen et al. 2017; Springmann et al., 2018). These approaches can be divided into nutrition-based and disease-risk-factors-based assessment methods and are used to analyse either specific foods items, meals or complete diets.

Nutrient-based methods analyse the nutritional value of food, based on the content of individual nutrients or metrics describing nutritional quality based on several nutrients, often in relation to a reference pattern (Chapter 6 ). Disease-risk-factors-based methods analyse the dietary health effects, for example, by using health metrics to estimate the dietary impact on a specific health outcome (Chapter 7). Both methods have advantages and challenges and can therefore complement each other and be suitable for different purposes (Table 7).

Figure 4: Number of studies per year since 2000 combining LCA with nutrition or health

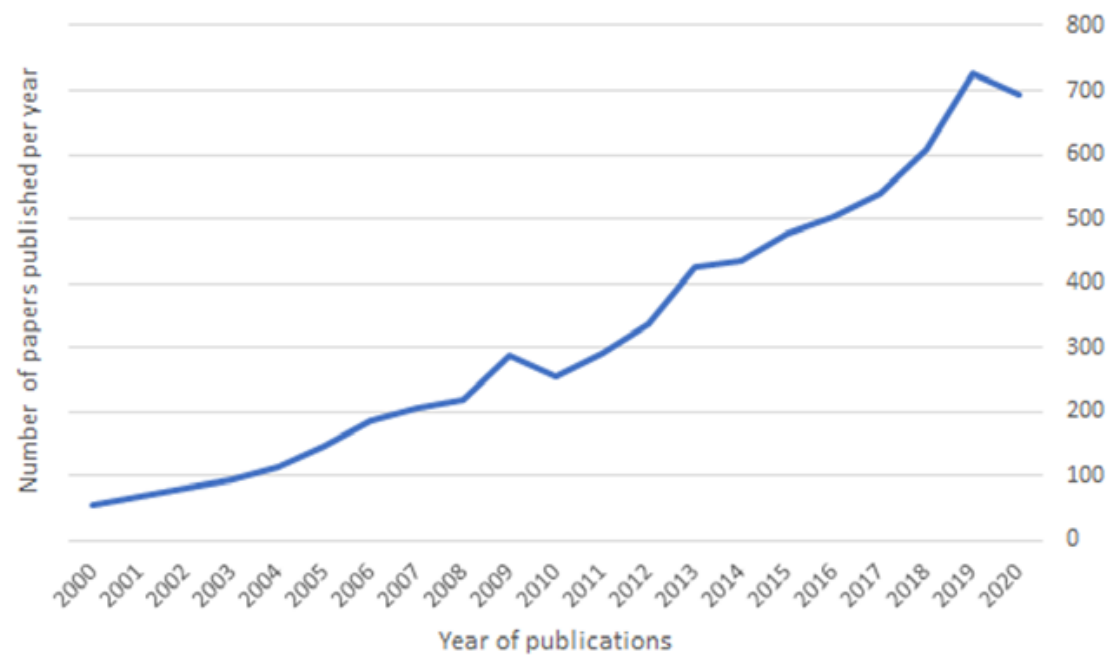

Source: Scopus (www.scopus.com) using search terms "Life cycle assessment" AND "nutrition" OR "health" 
Many aspects need to be considered when assessing the nutritional and health effects of food either alone or in combination with other effects, such as environmental effects. In particular, the choice of method and underlying data affect the reliability and uncertainty of the results as well as their suitability for different purposes (Chapter 4 for a general discussion about data and uncertainty in LCA). This chapter provides an overview of key aspects to consider in relation to nutrients and nutrition (Sections 5.2 to 5.4 ) and discusses how these could be applied in LCA studies on food items (Section 5.5); it also highlights important aspects for best practice (Section 5.6). Assessment of health impacts in food item LCAs and associated strengths and uncertainties are addressed in Chapter 7.

Table 7: Overview of differences in context suitability between nutrition-based methods and disease-risk-factor-based methods

\begin{tabular}{|l|l|l|}
\hline & Term & Definition \\
\hline $\begin{array}{l}\text { Nutrition-based } \\
\text { methods }\end{array}$ & $\begin{array}{l}\text { - assessments of single food } \\
\text { items, meals, and complete diets } \\
\text { - assessments at individual and } \\
\text { population level }\end{array}$ & $\begin{array}{l}\text { - account for nutritional bioavailability and } \\
\text { other food matrix* aspects } \\
\text { - account for aspects beyond nutrient com- } \\
\text { position ldegree of satiety) } \\
\text { - predict dietary-related health outcome }\end{array}$ \\
\hline $\begin{array}{l}\text { Disease- risk- fac- } \\
\text { tor-based methods }\end{array}$ & $\begin{array}{l}\text { - prediction of dietary health } \\
\text { outcomes } \\
\text { - assessments of complete } \\
\text { diets or dietary patterns } \\
\text { - assessments at population } \\
\text { level }\end{array}$ & $\begin{array}{l}\text { - assess health outcom } \\
\text { items } \\
\text { - assess health outcomes of an individual }\end{array}$ \\
\hline
\end{tabular}

*Food matrix effects are described in Section 5.3.2.

Note: Based on Guo et al., 2021

\subsection{Defining nutrients and nutrition}

\subsubsection{Nutrients versus nutrition}

Although food items may be consumed by people for different reasons, the most important biological reason is as a source of nutrients and for the purpose of nutrition. In this context, it is important to distinguish between nutrients and nutrition, as described in Box 2. Based on these descriptions, it is clear that nutrients are a prerequisite for nutrition, but nutrients alone do not automatically lead to nutrition; in other words, the ingestion of sufficient quantities of nutrients is no guarantee of nutrition. To contribute nutrition, nutrients need to be released from their product matrix, be absorbed into the gastro-intestinal tract, and subsequently be metabolized or utilized in processes to support growth, development and health. Nutrients need to be bioavailable to be able to provide nutrition; this starts with being bioaccessible (Box 2), but bioavailability entails more than bioaccessibility.

\section{BOX 2. TERMINOLOGY USED IN NUTRITIONAL STUDIES}

Nutrient: a substance of food that after absorption can be used by the human body to support normal growth, development and maintenance of health.

Nutrition: the process by which an organism uses food to support its normal growth, development and maintenance of health via ingestion, absorption, assimilation, biosynthesis, catabolism and excretion.

Bioaccessibility: the proportion of a nutrient that is released from its matrix in the gastrointestinal tract and has become available for absorption.

Bioavailability: the proportion of a nutrient that is digested, absorbed and metabolized via normal pathways. 


\subsubsection{Essential versus non-essential nutrients}

Within the group of nutrients, distinctions can be made on their various aspects, most notably whether they can or cannot be synthesized by the body and the quantities that are required of each nutrient on a daily basis. The distinction between essential, non-essential and conditionally essential nutrients as well as between macro- and micronutrients is shown in Box 4. Dietary recommendations (Section 5.5) focus on essential nutrients, and in cases for specific target populations, can also include some conditionally essential nutrients (specific amino acids such as arginine and cysteine that cannot be produced by the human body in sufficient amounts in persons with injury or illness).

Nutrient recommendations typically do not take into account the bioavailability of nutrients; for instance, the bioavailability of elements such as calcium, zinc and iron varies widely between different classes of food items. Likewise, for protein, which is the dietary source of the nine essential amino acids, protein quantities alone are often insufficient, as two other key factors should be considered: (1) the digestibility of the protein, and (2) the level and ratio at which the essential amino acids occur in the protein. Typical recommendations for protein intake are $\sim 0.8 \mathrm{~g}$ of protein per kilogram of bodyweight per day for adults, but these are based on a protein that is (1) fully digestible, and (2) contains all the essential amino acids at the desired concentration and ratio of essential amino acids (EFSA NDA Panel, 2012). This can be summarized in a protein quality parameter called the digestible indispensable amino acid score (DIAAS), see Box 4 (FAO and WHO, 2013). For proteins with a DIAAS score lower than 100 , higher intake than the recommended $0.8 \mathrm{~g} / \mathrm{kg} /$ day would be required to meet the nutritional demands. The application of protein quality measures, like DIAAS, in assessing nutritional value is highly encouraged but is challenged by a lack of available data. Currently, DIAAS data are available for only a limited number of food items. Likewise, application bioavailability data for minerals in a nutritional assessment is highly encouraged but is also hampered by the lack of available data. For example, calcium is one of the most widely studied minerals in this respect but, even for calcium, the amount of food items for which reliable calcium bioavailability data are available does not exceed 50 , and extrapolation of data from one food item to another is not readily possible.

\section{BOX 3. NUTRIENT CLASSES}

Macronutrient: A calorie-containing component of food (i.e. fat, protein, carbohydrate) that is needed in significant quantities (typically $>10 \mathrm{~g}$ per day) for normal growth, development and maintenance of health.

Micronutrient: Nutrient required by the body in small amounts (typically $<2 \mathrm{~g}$ per day) for normal growth, development and maintenance of health; for example, vitamins and minerals. Essential nutrient: a nutrient required by the human body that cannot be synthesized by the human body, for example:

- amino acids (Phe, Val, Thr, Leu, Ile, Lys, His, Met, Trp);

- fatty acids ( $\alpha$-linolenic acid, linoleic acid);

- vitamins $(A, B 1, B 2, B 3, B 5, B 6, B 7, B 9, B 12, C, D, E, K$; note vitamin $D$ is considered conditionally essential);

- minerals (K, Cl, Na, Ca, Mg, P, Fe, Zn, Mn, Cu, I, Cr, Mo, Se, Co); and

- choline.

Conditionally essential nutrients: nutrients that are ordinarily produced by the body in sufficient amounts to meet physiological requirements, but for which intake via food may be essential under certain conditions when biosynthesis is inadequate.

Non-essential nutrients: a nutrient required by the human body that can be synthesized by the human body under normal conditions:

- amino acids (Ala, Arg, Asn, Asp, Cys, Gln, Glu, Gly, Pro, Ser, Tyr);

- all digestible carbohydrates; and

- all fatty acids except for $\alpha$-linolenic acid, linoleic acid. 


\section{BOX 4. DIETARY INDISPENSABLE AMINO ACID SCORE}

- Standardized ileal digestibility (SID) of individual amino acids in food items is determined in humans, pigs or rats and expressed as digestible amino acid per gram of ingested protein.

- Values of digestible amino acids for each indispensable amino acid are compared to the recommended reference pattern for a specific age group.

- The amino acid with the lowest ratio compared to the reference pattern is considered the first limiting amino acid.

- Dietary indispensable amino acid score (DIAAS) value is expressed as the percentage of the first limiting amino acid that can be supplied by $1 \mathrm{~g}$ of protein compared to the reference pattern.

- DIAAS values >100: all indispensable amino acids can be supplied by the food item at levels above the reference pattern.

- DIAAS values <100: at least one of the indispensable amino acids cannot be supplied by the food item at levels in the reference pattern due to:

- insufficient levels of the amino acid present in the protein; or

- low digestibility of the protein.

Source: FAO and WHO, 2013

\subsubsection{Non-nutrient components in food items}

In addition to nutrients, food items also contain components that are not classified as nutrients but may still impact nutrition or human health positively or negatively. Examples of non-nutrient components of food items that positively impact human health are dietary fibre and phytochemicals (Box 5); though dietary fibre is often included in dietary intake recommendations as well. Likewise, polyphenols are not classified as nutrients. Though they can affect human health, they do not contribute directly to the basic biochemical processes in nutrition (Williamson, 2017). In addition, food products can contain non-nutrient compounds that interfere with the digestion of nutrients. These are referred to as antinutritional compounds or anti-nutritional factors, and they include compounds that interact with elements and limit their absorption, that interact with macronutrients and limit their digestion, or that inhibit the enzymes that digest the macronutrients (Box 5).

\section{BOX 5. NON-NUTRIENT COMPONENTS AND ANTI-NUTRITIONAL FACTORS}

Non-nutrient components: any component present in a food product that is not classified as a nutrient, for example, fibre or phytochemicals. The fact that such compounds are not classified as nutrients does not mean they do not affect human health. Typically, no estimated average requirement or recommended dietary allowance is established for these compounds, though an adequate intake may be established.

Anti-nutritional compounds/anti-nutritional factor: compounds in food that interfere with the absorption of nutrients. Examples include:

- phytic acid (binding of elements, e.g. Ca, Zn, Fe)

- oxalic acid (binding of elements, e.g. $\mathrm{Ca}, \mathrm{Zn}, \mathrm{Fe}$ )

- glucosinolates

- protease inhibitors

- lipase inhibitors

- amylase inhibitors

- tannins

- lectins

- saponins 
Overall, when considering the nutritional aspects of food items, it is important to remember that nutrition goes beyond nutrient content and requires nutrients to be bioavailable to ensure that they can be absorbed and utilized via metabolic processes in the body. Other constituents of food items, such as anti-nutritional factors, should also be considered. However, these are not typically included in food composition databases, making it more challenging to consider them in nutritional LCAs. Furthermore, the effects of food processing, food matrix effects and interactions between food products are important considerations, and they are discussed in Section 5.4 .

\subsection{Influence of food processing methods on nutrients and nutritional value}

\subsubsection{Food processing}

Most food items that are consumed undergo at least some processing steps before consumption. In the very mildest way, this may be simply washing and/or cutting some fruits prior to consumption. However, in many cases, more extensive processing is required for reasons of food safety, for prolonging shelf-life of products, culinary purposes, or for creating desirable properties in the food products, such as sensory properties. Processing may also be applied to improve certain product properties in relation to nutritional properties and health, to increase protein digestibility, for example (Drulyte and Orlien, 2019), or to reduce the content of compounds such as phytate and oxalate, which inhibit the absorption of iron and calcium, for example (Hurrell, 2002; Hurrell et al., 2002). Processing may also have negative effects on nutrients. Applying heat can modify amino acid residues in proteins, via the Maillard reaction, for example, thereby reducing digestion, absorption and metabolic utilization (Van Lieshout et al., 2019). Furthermore, it can destroy vitamins. A broader overview of the potential processing effects is shown in Box 6. Processing effects may also occur during industrial processing and when food is prepared at home. With a few exceptions (such as the destruction of vitamins during heat treatment in industrial preparation), many of the effects of processing are factors that are typically not captured in food composition databases. This could have a large impact in relation to protein quality. In cereal-based products, for example, high levels of lysine (in some cases even more than 50 percent) have been found to be non-available due to amino acid modifications (Torbatinejad, Rutherfurd and Moughan, 2005). When considering that lysine is already the limiting amino acid in wheat proteins, this means that the metabolic utilization of amino acids from wheat protein can be strongly impaired by process-induced modifications. A loss of vitamins, particularly water-soluble vitamins during typical food preparation steps such as boiling, can reach up to 100 percent (Lee et al., 2018). This highlights the need to consider not only the impact of industrial processing, but also the effects of at home preparation on the nutritional value of foods.

\section{BOX 6. EFFECT OF PROCESSING AND FOOD PREPARATION ON NUTRIENTS AND NUTRITIONAL VALUE - SOME EXAMPLES}

Accessibility of nutrients in product matrices:

- comminution of food items during milling

- destruction of cell walls during cooking

Inactivation and destruction of anti-nutritional compounds:

- destruction of oxalates during boiling

- inactivation of enzyme inhibitors

Interactions between food constituents:

- protein-carbohydrate interactions - Maillard reaction

- amino acid primary structure modifications in cooked meat 


\subsubsection{Food matrix effects and meal effects}

When considering the absorption and utilization of nutrients from food items, the product matrix can also have a notable effect. This can be related to the physical accessibility of the nutrients in the food matrix, but also to the combined effects of nutrients on human health. Such food matrix effects have been researched widely in the past decade and have highlighted, for example, that metabolic markers that are linked to cardiovascular disease are considerably lower after consuming red meat, dairy and dark chocolate, and are considerably lower than would be expected solely on the basis of saturated fat content, which has often been seen as a link between food items and cardiovascular disease (Astrup et al., 2020). Likewise, glycaemic responses to food items are in many cases notably lower than would be expected solely based on the concentration and type of carbohydrate present in the products (Wolever, 1990). Box 7 outlines further areas in which such food matrix effects have been reported.

\section{BOX 7. EXAMPLES OF REPORTED FOOD MATRIX EFFECTS ON PHYSIOLOGICAL AND METABOLIC MARKERS}

\section{Glycemic responses}

- processing apples into puree or juice affects glycemic responses negatively (Haber et al., 1977)

- processing affects glycemic responses of lentils (Jenkins et al., 1983)

- glycemic responses of bread strongly dependent on food matrix

\section{Cardiovascular disease markers}

- red meat (0'Connor, Kim and Campbell, 2017; Astrup et al., 2020)

- chocolate (Gianfredi et al., 2018; Astrup et al., 2020)

- dairy products (Guo et al., 2017; Astrup et al., 2020)

\section{Post-prandial aminoacidemia}

- faster postprandial rise in blood amino acid levels after consumption of minced beef compared to steak (Pennings et al., 2013)

- faster postprandial rise in blood amino acid levels after consumption of yoghurt than milk and slower again for cheese (Horstman et al., 2021)

Another important consideration in relation to food, nutrition and health is that in many cases food items are not consumed on their own but as part of a meal. In that case, synergistic or antagonistic effects between food items can occur. This can be considered in relation to proteins, for example, where deficiencies in amino acid composition for one protein in a meal may be compensated by another protein source in the same meal, for example, the combination of cereal and milk in a typical breakfast (Fanelli et al., 2021). Also, consuming milk together with rice increases the bioavailability of zinc from the latter (Talsma et al., 2017). Consuming tea with a meal, however, has been shown to have a negative effect on the digestibility of protein (Kashyap et al., 2019) and on iron absorption (Hurrel et al., 1999). Such "meal effects" are often important for understanding the nutritional properties of food items in a realistic setting, though they have not received sufficient attention in research to date.

Overall, it is clear that capturing the true nutritional value of food items goes beyond the nutrient content of the individual food items. Both industrial processing and at-home food preparation can affect various nutrients, and so can the overall matrix of food items affect nutritional value and have health impacts. Food matrix effects also clearly highlight the need for a holistic view of food items. 
it is necessary to consider the entire food item, with all its constituents and interactions, rather than taking the more reductionist single-nutrient view. Even food matrix views may be too limited, as most food items are consumed in meals where complementary, synergistic or antagonistic effects can occur. Unfortunately, however, the broadscale application of such factors in nutritional LCAs is difficult at present due to the absence of sufficiently large datasets.

\subsection{Nutrient requirements}

\subsubsection{Definition of nutrient requirements}

Nutrients are required for the healthy growth, maintenance and repair of the human body. Some nutrients play a role in preventing disease, while overconsuming nutrients and energy from foods can have detrimental health effects. Even though the first discovered vitamin (thiamine) was isolated less than 100 years ago, modern nutrition science has provided a high level of evidence for the intake levels of vitamins, minerals and other food compounds required to maintain health and avoid disease.

Nutrient requirements are typically formulated as reference nutrient intake values. Nutrient requirements can vary between age groups due to the reduced absorption in older age (e.g. calcium), for example. It also varies between men and women (higher iron intake requirements in women due to menstrual losses). Nutrient reference values are usually developed based on estimated requirements for healthy people (disease states can alter nutrient requirements; Stover, 2020).

For desirable nutrients, an estimated average requirement (EAR) is commonly decided upon, which is the intake level of a nutrient that is estimated to meet the requirement of half of all healthy individuals of a particular age, sex or life stage. EAR values are useful for estimating the number of people likely to have inadequate intakes within a group, but they are not designed for setting intake targets for individuals. An RDI or RDA indicates a level of intake that is expected to meet the requirements for 97 to 98 percent of all healthy individuals in a particular age/sex/life-stage group, and these targets can be used when making recommendations for individuals and when evaluating the dietary intake of a specific nutrient (for example, the proportion of intake towards the RDA provided by the serving size of a specific food).

Some countries (Australia, the United States of America) have established acceptable macronutrient distribution ranges for macronutrients (protein, fat, carbohydrate) and specific fatty acids (the essential fatty acids, i.e. linoleic acid and $\alpha$-linolenic acid). These provide recommended target intake levels that are thought to reduce chronic disease risk (between 15 percent and 25 percent of total energy intake to come from protein).

\subsubsection{The purpose and the process of establishing reference nutrient intake values}

Reference nutrient intake values serve many different purposes including the assessment of nutritional adequacy of food supplies. They also aid in developing food and nutrition policies and dietary guidelines. Nutrient reference values are used in dietary planning, such as for the military or residential institutions, for planning food fortification initiatives, and they are commonly incorporated in food labelling laws and health claim regulations. nLCA studies can complement these applications by adding data on the environmental impacts of foods consumed - this is when considering nutrient requirements, by using a nutrient density score in the nLCA, for example, can be particularly useful.

National and international agencies establish reference nutrient intake levels after reviewing human and animal studies providing evidence on the intake levels required to maintain health and 
avoid deficiency and subsequent disease. Globally, only a relatively small number of countries have developed their own reference nutrient intake levels by reviewing all the scientific evidence because this is very time consuming and costly. Many countries have, therefore, adopted their national nutrient reference values from other well-resourced countries, or from sources such as FAO and/or the World Health Organization (WHO) (Lewis, 2019). Documentation from relevant national agencies needs to be consulted to assess the reference nutrient intake levels appropriate for people in a particular country.

To help consumers evaluate the relative contribution of individual food products to a healthy total diet, and to facilitate comparisons between products, Codex Alimentarius has published its Codex nutrient reference values (where nutrient reference values are based on the daily intake value that is estimated to meet the nutrient requirement of 98 percent of an apparently healthy individual, thus the RDI or RDA) for the general population, identified as individuals older than 36 months. An example of the Codex Alimentarius nutrient reference values is shown in Table 8 . Thus, while RDI or RDA values are typically provided for specific population groups defined by sex, age and life stage in a country or region, the Codex Alimentarius nutrient reference values summarize these into one estimate for any healthy person older than 36 months.

Table 8: Codex Alimentarius nutrient reference values for the general population older than 36 months

\begin{tabular}{|c|c|c|c|}
\hline \multicolumn{2}{|l|}{ Vitamins } & \multicolumn{2}{|l|}{ Minerals } \\
\hline Vitamin A & $800 \mu \mathrm{g} / \mathrm{d}$ Retinol Equivalents & Calcium & $1000 \mathrm{mg} / \mathrm{d}$ \\
\hline Vitamin D & $\begin{array}{l}5-15 \mu \mathrm{g} / \mathrm{d} \text { (depending on sunlight } \\
\text { exposure) }\end{array}$ & Magnesium & $310 \mathrm{mg} / \mathrm{d}$ \\
\hline Vitamin C & $100 \mathrm{mg} / \mathrm{d}$ & Iron & $\begin{array}{l}14 \mathrm{mg} / \mathrm{d} \text { (if } 15 \% \text { dietary absorption*); } 22 \\
\mathrm{mg} / \mathrm{d} \text { (if } 10 \% \text { dietary absorption**) }\end{array}$ \\
\hline Vitamin K & $60 \mu \mathrm{g} / \mathrm{d}$ & Zinc & $\begin{array}{l}11 \mathrm{mg} / \mathrm{d} \text { (if } 30 \% \text { dietary absorption***); } 14 \\
\mathrm{mg} / \mathrm{d} \text { (if } 22 \% \text { dietary absorption****) }\end{array}$ \\
\hline Vitamin E & $9 \mathrm{mg} / \mathrm{d}$ & lodine & $150 \mu \mathrm{g} / \mathrm{d}$ \\
\hline Thiamine & $1.2 \mathrm{mg} / \mathrm{d}$ & Copper & $900 \mu \mathrm{g} / \mathrm{d}$ \\
\hline Riboflavin & $1.2 \mathrm{mg} / \mathrm{d}$ & Selenium & $60 \mu \mathrm{g} / \mathrm{d}$ \\
\hline Niacin & $15 \mathrm{mg} / \mathrm{d}$ niacin equivalents & Manganese & $3 \mathrm{mg} / \mathrm{d}$ \\
\hline Vitamin B6 & $1.3 \mathrm{mg} / \mathrm{d}$ & $\begin{array}{l}\text { Molybde- } \\
\text { num }\end{array}$ & $45 \mu \mathrm{g} / \mathrm{d}$ \\
\hline Folate & $400 \mu \mathrm{g} / \mathrm{d}$ dietary folate equivalents & Phosphorus & $700 \mathrm{mg} / \mathrm{d}$ \\
\hline Vitamin B12 & $2.4 \mu \mathrm{g} / \mathrm{d}$ & Potassium & $3500 \mathrm{mg} / \mathrm{d}$ \\
\hline Pantothenate & $5 \mathrm{mg} / \mathrm{d}$ & $\begin{array}{l}\text { Sodium } \\
\text { (level not to } \\
\text { exceed) }\end{array}$ & $2000 \mathrm{mg} / \mathrm{d}$ \\
\hline Biotin & $30 \mu \mathrm{g} / \mathrm{d}$ & & \\
\hline \multicolumn{4}{|l|}{ Macronutrients } \\
\hline \multicolumn{2}{|l|}{ Protein } & \multirow{2}{*}{\multicolumn{2}{|c|}{$\begin{array}{l}50 \mathrm{~g} / \mathrm{d} \\
20 \mathrm{~g} / \mathrm{d}\end{array}$}} \\
\hline \multicolumn{2}{|c|}{ Saturated fatty acids (level not to exceed) } & & \\
\hline
\end{tabular}

* Diversified diets, rich in meat, fish, poultry and/or rich in fruit and vegetables.

** Diets rich in cereals, roots or tubers, with some meat, fish, poultry and/or containing some fruit and vegetables.

$* * *$ Mixed diets, and lacto-ovo vegetarian diets that are not based on unrefined cereal grains or high extraction rate (>90\%) flours.

**** Cereal-based diets, with $>50 \%$ energy intake from cereal grains or legumes and negligible intake of animal protein.

Source: FAO and WHO, 2017 
When reference nutrient intake values are established, all relevant scientific evidence is systematically searched and reviewed. This ideally includes data from systematic reviews and meta-analyses of randomized trials (if available), and from longitudinal cohort studies. Standardized protocols are then used to assess the quality of evidence le.g. the Grading of Recommendations, Assessment, Development and Evaluations [GRADE] approach used by WHO; Guyatt, 2011) for each nutrient. This process is usually completed for men and women separately and for prespecified age groups and life stages (pregnancy, lactation).

Globally, different national agencies decide on reference nutrient intake values suitable for the specific population in their country or region. This means reference nutrient intake values can sometimes differ between countries. For example, countries can consider the local food supply, which may influence the absorption of nutrients in food, or they can consider the relative age and sex distribution of their population.

\subsubsection{Using reference nutrient intake values in a nutritional life cycle assessment}

As requirements for nutrients vary by age, sex, life stage and physical activity level (as discussed above), the most optimal choice of reference intake for use in an nLCA is a reference developed for the specific target group that would consume the foods assessed. However, in nLCA studies, and also in other applications (food labelling), this is not always feasible. Global nutrient references values have been developed by the Codex Committee on Nutrition and Foods for Special Dietary Uses for the purpose of informing food regulators about the standardization of food labelling, and to create provisions for developing nutrition-related health claims (Lewis, 2019). Codex distinguishes NRV-Rs, which indicate nutrient requirements for vitamins, minerals and protein, and NRV-NCDs, which are intake levels associated with a reduction in the risk of diet-related non-communicable diseases, which are defined for fat, sodium and potassium. These global Codex nutrient reference intakes can be used in nLCA studies, for example when considering nutrient density (Section 5.6) when local recommendations are not available (Drewnowksi et al., 2021).

\subsubsection{Link between nutrient reference values and dietary recommendations}

Nutrient reference values are one of the main pillars of support for food-based national dietary guidelines. For example, in developing national dietary guidelines for the Netherlands, one of the core principles was that the recommended amounts of food would deliver 100 percent of the essential nutrients for males and females in different age groups (Brink, 2019). Cultural acceptability, current consumption patterns and sufficient choices for consumers are other factors that are typically considered in developing dietary guidelines in addition to nutrient requirements.

In the past, requirements for single nutrients have been a main basis for developing dietary guidelines in many countries. This stems from an era when undernutrition and nutritional deficiencies were predominant causes of nutrition-related disease. More recently, and particularly in high-income countries where chronic diseases associated with overnutrition are now causing a larger health burden than nutritional deficiencies, there is an increasing awareness that the reductionist singlenutrient focus of the past has been unhelpful (Tapsell, 2016). For example, the principle that diets are more than the intake of nutrients was one of the guiding principles in developing the 2014 food-based dietary guidelines for Brazil (Tetens, 2020). Identifying healthy dietary patterns, rather than focusing on specific foods and nutrients, is increasingly being adopted as a focus when developing foodbased dietary guidelines (Section 5.4.5). Also, Benin's dietary guidelines promoted the importance of preserving the traditional cuisine and ensuring that it continues into the next generation as a way 
to promote health (FAO, 2021). It should be noted, however, that some specific foods may remain of particular interest because they contain a single nutrient that plays a role in preventing or causing a health condition (folate-containing foods for preventing neural tube defects).

\subsubsection{Food-based dietary guidelines}

Globally, more than 100 different countries have food-based national dietary guidelines that inform the promotion of health activities and consumer choice (see Box 8). Guidelines vary depending on the specific health priorities of each country. For example, in Guatemala meat intake is promoted as preventing iron deficiency anaemia (Herforth, 2019), whereas in the Netherlands, the recommendation to limit red meat intake is based on the evidence of its association with the risk of colorectal cancer, diabetes and cardiovascular diseases (Health Council of the Netherlands, 2015).

\section{BOX 8. FOOD-BASED DIETARY GUIDELINESMETABOLIC MARKERS}

Following the 1996 publication of FAO and WHO recommendations for preparing and using food-based dietary guidelines, FAO assisted member countries to develop their own foodbased dietary guidelines in line with the current scientific evidence. National food-based dietary guidelines for more than 100 countries are available in a repository that is continuously updated by FAO (FAO, 2021) and that includes helpful summary reviews (Herforth, 2019).

The recommendations in food-based dietary guidelines are usually developed to meet the nutrition requirements for healthy people of different age, sex and life-stages (pregnancy, lactation, ageingl in a country or region. There are no single foods that can provide all the required nutrients (apart from breast milk for infants), thus the combination of different foods that are consumed in a diet need to be considered. Recommendations should be based on diets that are culturally acceptable and that reflect the diets of different socio-economic and cultural groups in a country, with the concept of dietary variety incorporated in most foodbased dietary guidelines (Herforth, 2019). Thus, from the perspective of promoting health and informing consumer choice, the focus is typically not on individual foods but rather on food groups ("Eat legume-based dishes regularly and choose unsalted nuts and seeds" in the WHO Dietary Guidelines for the Eastern Mediterranean Region [WHO, 2012]) or whole diets (the Mediterranean diet). Food-based dietary guidelines in most countries recommend limiting the consumption of certain foods or food components, usually with a message to avoid foods that are high in fat, sugar or salt (Herforth, 2019).

One of the limitations of focusing on food items, rather than whole diets, is that the importance to an individual's health of the amount of a nutrient contained in a food consumed, depends on the other foods that individual has eaten. For example, milk may be a main contributor to total calcium intake of a person who consumes few other foods that contain calcium. In contrast, for a person who consumes many other foods that contain calcium (almonds, calcium-fortified drinks or cereals), the calcium contained in the milk they consume may only represent a small proportion of their total calcium intake. This means that summarizing the nutritional value of a food, for example based on its nutrient density, ignores the fact that this food is part of the whole diet. With dietary patterns being highly variable within countries and between countries (Afshin, 2019), it becomes difficult to assess the relative importance of nutrients contained in a food item against an individual's total nutrient intake and health. 


\subsection{Methods for assessing nutritional value in food life cycle assessment studies}

In LCA, the nutrition aspects of food can either be assessed in parallel with the environmental impacts or by using methods that integrate the two dimensions (Strid et al., 2021; Guo et al., 2021). The different approaches have both benefits and drawbacks that influence the purposes for which they are best suited (Table 9).

\subsubsection{Parallel approaches - assessment of nutrition at impact assessment}

Parallel assessments imply reporting of the environmental impact of a food, a meal or a diet lobtained from an LCA), and separate reporting of the nutritional value as an additional impact in the impact assessment. Nutrition-based methods analyse the nutritional value of food items based on the content of individual nutrients or on the nutritional quality of several nutrients. A variety of different approaches have been used, including a focus on individual nutrients, nutrient density (such as the different versions of the Nutrient Rich Food [NRF] index) (Chapter 6), and approaches that consider nutrient density, quality of nutrients contained in the food (such as protein quality), as well as methods that use indicators of the quality of a total diet lusing established and validated diet quality indices, such as the Mediterranean diet quality index) (see reviews by Grigoriadis, Nugent and Brereton, 2021, and Hallström et al., 2018). Correlations between nutrition and environmental impacts, assessed in parallel, may be examined to provide further insights.

Other approaches to capture nutrition aspects in environmental assessments of food include comparisons of food items, meals or diets with equivalent nutrient content, and assessments of meals or diets fulfilling nutritional or dietary recommendations. Nutrition and environmental effects assessed as separate impact categories may also be translated into a common unit, such as an economic measure, by using scaled assessment methods (Green et al., 2020; Guo et al., 2021). Functional units relating to the nutritional value are described in further detail in Chapter 6, and the impact assessment is described in Chapter 7.

\subsubsection{Integrated approaches - nutrition-based functional units}

Developing a method to mathematically integrate aspects of nutrition into the LCA methodology has mainly been focused on nutrition-based functional units (Saarinen et al., 2017; McAuliffe, Takahashi and Lee, 2020; Weidema and Stylianou, 2020; Hallstrom et al., 2018). Nutrition-based functional units (nFUs) are defined in this report as FUs that represents some nutritional aspect(s). As a complement to the traditional mass/volume-based FUs often used in food LCAs, nFUs may be useful to account for differences in nutritional content and quality between foods, meals and diets (Chapter 6).

Table 9: Overview of the methodological advantages and challenges of parallel and integrated approaches for the combined assessment of the environmental and nutrition effects of food

\begin{tabular}{|l|l|l|}
\hline & Advantages & Challenges \\
\hline $\begin{array}{l}\text { Parallel approa- } \\
\text { ches: nutrition as- } \\
\text { sessed in an impact } \\
\text { assessment }\end{array}$ & $\begin{array}{l}\text {-straightforward method: easy to } \\
\text { use and interpret } \\
\text {-transparent method: specify va- } \\
\text { riability in environmental impact } \\
\text { and nutritional value separately } \\
\text { and where improvements are } \\
\text { most needed }\end{array}$ & $\begin{array}{l}\text {-limited ability to provide guidance based } \\
\text { on the combined environmental impact and } \\
\text { nutritional value }\end{array}$ \\
\hline $\begin{array}{l}\text { Integrated ap- } \\
\text { proaches: nFUs }\end{array}$ & $\begin{array}{l}\text {-suitable for use in applications } \\
\text { requiring an integrated score } \\
\text { that captures both environmen- } \\
\text { tal impact and nutritional value } \\
\text {-suitable for relative compari- } \\
\text { sons of foods }\end{array}$ & $\begin{array}{l}\text { less transparent method: does not specify } \\
\text { tional value separately and where improve- } \\
\text { ments are most needed } \\
\text {-challenging to compare absolute values due } \\
\text { to lack of established threshold values }\end{array}$ \\
\hline
\end{tabular}

Note: Based on Strid et al., 2021 


\subsection{Towards best practice recommendations}

Although many different approaches in nLCA are referred to as nutrition-based, it is important to recognize that nutrition, by definition, goes beyond just the concentrations of nutrients present in food items and includes crucial aspects such as digestibility and bioavailability. Hence, approaches that consider only concentrations of nutrients should technically be referred to as nutrient-based approaches. It is well known, for instance, that there are large differences in protein quality among food items (consider amino acid composition and digestibility) as well as bioavailability of micronutrients like calcium, zinc and iron. While including these values could be justified in nLCAs based on their nutritional relevance, their widespread application will be hampered by the simple fact that the availability of data thus far is limited and requires large research efforts and investments to attain it. Likewise, considerations of the effects of processing, food matrix effects and synergistic/antagonistic effects at the meal level for food items ideally would be considered but is limited by the availability of data. As such, nutrient-based approaches appear to be most applicable, particularly in the short term as they depend on chemical analysis and do not require in vivo studies land can also be applied to new products under development and recently introduced into markets).

In summary, the best practice recommendations are that nutritional aspects in LCA should:

- clearly report whether approaches are nutrient-based or whether they also include nutritional aspects (bioavailability of nutrients, digestibility, product matrix effects or meal effects);

- consider non-nutrient components of food items where possible in addition to nutrients;

- consider potential losses in nutrients and nutritional value during food preparation steps where possible; and

- consider nutrient concentrations in food items in relation to the recommended intake values of the appropriate target populations when using a nutrient index. 


\section{Defining the functional unit}

\subsection{A brief history of the functional unit in life cycle assessment studies of food items}

International standards govern the practice of LCA. ISO 14040, describing the principles of and the framework for a life cycle assessment, and ISO 14044, describing the requirements and guidelines, are of particular relevance (ISO, 2006a, 2006b, 2017). As stated in the ISO standards, LCA adopts a relative approach whereby results are expressed relative to an FU; defining the FU is an important part of the goal and scope definition phase of a study. As the name implies, an FU is based on the purpose that a product is intended to fulfil in the study (Section 6.2.1).

To illustrate how to define an FU, ISO 14040 uses the example of drying hands using a paper towel system or an electric air-dryer system. These two systems could be compared by defining the FU as an identical number of pairs of dried hands. However, as is widely appreciated by LCA scientists and practitioners, the functions of many products are often difficult to define exhaustively and unambiguously. Even in this simple hand drying example, paper towels are not completely described by their ability to dry hands. Paper towels may vary in strength, softness and thickness, and they may have patterns or embossing that fulfil other sensory and aesthetic functions. In addition, electric hand dryers vary in terms of their hand-drying speed, noise level, and size, among other features. Some of these characteristics may affect the function chosen as the basis for the FU, others certainly would not (see Section 6.2.3 for examples related to food items).

Usually, there are only a subset of all the functions and characteristics of a studied product that can be described in the FU at the same time. The essential characteristics of a product are termed its obligatory properties and are an appropriate basis for determining the FU, as opposed to positioning properties that may influence consumer preferences ${ }^{2}$ but are not essential and therefore should not be the sole basis of an FU (Weidema et al., 2004). As such, in LCA studies of food items the FU is often interpreted narrowly as a product unit or declared unit las described in ISO 14067, the international standard for product carbon footprint assessment). However, the ISO 14040 and 14044 standards emphasize that the FU must be chosen so that it is consistent with the goal and scope of the study; hence the definition of obligatory properties should also be consistent with the goal and scope of the study.

As LCA has become more common in the environmental impact assessment of food items in recent decades, a mass- or volume-based FU has been adopted as common practice (Schau and Fet, 2008; Clune, Crossin and Verghese, 2017). The vast majority of food product LCAs still use a mass/volumebased FU, although alternative methods to suit different information needs and assessment goals have been developed, tested and presented in the literature (Green et al., 2020; Grigoriadis, Nugent and Brereton, 2021; McAuliffe, Takahashi and Lee, 2020; Strid et al., 2021). A mass/volume-based FU is also recommended in some LCA guidelines, for example in the ENVIFOOD Protocol that is linked with the European Commission's Product Environmental Footprint initiative (Food SCP RT, 2013). It recommends that the FU be aligned with European Union regulations about nutrition facts, and hence be based on weight or volume $(100 \mathrm{~g} \text { or } \mathrm{ml})^{3}$

2Obligatory and positioning properties may also be related to objectives other than addressing the immediately obvious consumer requirements and preferences, depending on the goal and scope of the study. For example, an $\mathrm{nLCA}$ study may aim to produce environmental and nutrition information on food that is explicitly intended to influence consumer choices by raising awareness through providing new information that would otherwise remain invisible to consumers. Thus, in the context of the nLCA, it may be relevant to consider consumer preferences more widely than they currently appear in the marketplace.

${ }^{3}$ Alternatively, the FU can be expressed in another way (per portion, per consumption unit or per unit sold) if this is stated in the relevant product category rules. 
The mass/volume-based FU is so widely used that one could argue that it provides a good basis for comparison between different studies, and this idea may even be used as a justification for choosing it as an FU. However, comparability is significantly weakened by the fact that a mass/volume-based FU does not express food functionality. If providing nutrients to the body is considered to be the primary function of food land thus the obligatory property), it is not represented in a mass/volume-based FU. This is why other options have been developed so vigorously in recent years (see Table 10). However, a mass/volume-based FU can facilitate enhanced comparisons in so far as such FUs can easily be translated into other FUs that better reflect the functionality of food. When using an nFU, the same opportunity for translation into other FUs can be guaranteed by reporting the product flow required to meet the selected FU. This flow is known as the RF in LCA methodology (ISO, 2006a, 2006b, 2017; Food SCP RT, 2013), and it is a key concept in discussions about FUs (Saarinen et al., 2017) (Section 6.2.2).

Early developments in this field were based on considerations of the energy or protein content of food in the FU (Masset, Vieux and Darmon, 2015; Oonincx et al., 2012; Smetana et al., 2015). The intake of other individual nutrients, groups of nutrients, or bioactive compounds from the product has also been addressed in a few studies, such as phenolic compounds in vegetables (Martinéz-Blanco, 2011) or Omega-3 fatty acids in meat (McAuliffe, Takahashi and Lee, 2018). These studies have often involved comparing production methods or technologies. However, the applications are still controversial. For example, the most bioactive compounds include some compounds that promote health but some reduce the bioavailability of nutrients. Proposed measures of bioavailability have sought to incorporate an understanding of how nutrients are metabolized in the body in different ways, providing more nuance to nutrient-based comparisons across foods (Berardy et al., 2019; Smetana et al., 2015).

In recent years, more consumer-oriented approaches have also been developed, with the FU typically describing the more general nutritional quality of a product (Saarinen et al., 2017; Sonesson et al., 2019). These FUs contain several nutrients and are typically based on nutrient indices (Section 6.3.2). Methods have been developed to fit either across-the-board or food group-specific assessments.

In addition, other approaches for analysing the relationship between the nutritional quality of foods and their environmental impacts have been developed. These include a two-dimensional analysis of a product's environmental impacts and nutritional quality through LCA and nutrient profiling (i.e. presenting the nutrient index alongside the FU on a mass or energy basis) (Strid et al., 2012), nutrient intake in relation to environmental impact (i.e. transposing the usual presentation of LCA results) (e.g. Chaudhary et al., 2018), and including nutritional quality in the impact assessment as a health impact category or as part of it (e.g. Clark et al., 2019) (see also Section 5.5). This chapter focuses on options for the FU; health impact assessment methods are discussed in Chapter 7.

\subsection{Key considerations in defining the functional unit}

\subsubsection{Principles in defining the functional unit}

As described in Section 6.1, an LCA is a relative approach that is structured around an FU. This FU defines a unit of measurement of the function that describes the purpose of the product studied in an LCA. In performing an LCA, all subsequent analyses are then undertaken, and the results are presented, relative to that FU.

According to the ISO LCA methodology, the FU is intended to be used as a reference unit and a basis for possible comparisons between products. It is defined as part of the goal and scope definition phase of an LCA study and, according to the ISO LCA standards, the scope - and thus also the FU - should be 
defined in relation to the stated goal. In an $\mathrm{nLCA}$, the goal is related to the simultaneous consideration of environmental impacts and nutrition/health aspects, but there are many ways to implement it. This chapter discusses different options for defining the FU relative to the goal of an nLCA study.

\subsubsection{Reference flow}

In addition to the FU, the RF is another key concept related to the basic nature of LCA as a relative approach. The RF is a measure of the output(s) from a given product system required to fulfil the function expressed in the FU.

In traditional food LCA studies, where a mass/volume-based FU is used, the RF is usually equal to the FU. In an nLCA study where the FU is defined on the basis of the nutritional quality of the product, the RF indicates the amount of a food item needed to deliver the nutritional FU (i.e. the selected function represents some nutritional aspect[s]]. As nutritional quality metrics are not always easy to understand intuitively, unlike mass/volume measurements used in everyday life (kilogram and litre), mass/volume-based RFs can provide an important role in supporting the interpretation of nLCA results. For example, when using a nutrition index score as the $\mathrm{nFU}$ (Section 6.3.2), the results do not directly indicate the quality of the source of nutrients in the product because the portion size is not (necessarily) represented in the FU (Saarinen et al., 2017). In these situations, the RF indicates how much product is needed to provide a unit of the nutrient index. This quantity can vary greatly between foods and, therefore, is relevant information when considering the potential for substituting different food items in the diet.

Declaring the RF also facilitates future use of the nLCA results by other LCA practitioners in studies on meal plans and diets because it enables translation into different food quantities.

\subsubsection{Complexity of food functionality}

As outlined in Section 6.1, the function(s) of many products are often difficult to define, and this is also the case for foods. Foods can provide nutrients, but they can also provide satiety and pleasure. Foods also play a role in social and cultural exchange. Some foods are conveniently ready to eat, whereas others require elaborate preparation. On the other hand, it is not necessary, and indeed not possible, to include all functions in one FU.

The function(s), as well as characteristics (properties) of food items are more diverse than those of, for example, hand-drying systems (Section 6.1), because "food item" is a very broad and varied group whose products have various functions and characteristics. This broad food group is often divided into subgroups based on different criteria and depending on the particular purpose of the food items, such as raw material basis or meal functionality (Box 9). However, the characteristics of food items such as taste, mouthfeel, scent, overall attractiveness and nutritional value vary even within subgroups. For example, a side dish for lunch could be a portion of pasta, rice or potatoes, which are all food items having quite different characteristics. And the food group "breads" includes different kinds of breads (such as wheat bread or crispbread), each potentially being consumed in a different situation.

Out of all the different functions and properties of food, this report focuses on the nutritional aspects. Even if the nutritional aspects of food items only are considered, foods are inherently multi-functional, whether considered as a whole or even when considering a specific food group. A complete diet requires many different types of foods, but foods rich in one nutrient may be lacking in another, and vice versa. Furthermore, meat is not simply a source of protein; fruit is not simply a source of vitamins; 
dairy products are not simply a source of calcium. Food items in these food groups provide several of the nutrients needed for a nutritious and healthy diet. Some food items or food groups may also be crucial as a source of some nutrients in a particular dietary context. However, in the end, the relative contribution of each nutrient supplied by each food item is determined by the composition of the whole diet. Thus, the nutritional value of any one food item is dependent on the dietary context.

Therefore, LCA practitioners should avoid simplistic assumptions about the nutritional value of food items. Instead, nLCA studies must openly address these challenges. The appropriate definition of an $\mathrm{nFU}$ for an nLCA study, relative to the study goal, is one of the potential ways forward alongside other methodological choices (such as assessing nutrition/health impacts in the impact assessment (Chapter 7) and providing additional descriptions about the bioavailability of nutrients when quantitative data are not available (Section 5.6).

\section{BOX 9. FOOD GROUPS FOR nLCA}

Food is a very broad and varied product group that must often be sub-grouped for different purposes. In an nLCA, the grouping is often related to comparisons between food items (see also Box 10).

The key questions in defining a food group are: What kind of comparison makes sense? and, On what is the comparison based? These questions are, of course, closely related to the goal and scope of the study. nLCA studies can have a wide range of goals and application areas (Table 4 and Table 13). The appropriate food grouping for an individual comparative study may well be different from the creation of broader principles and knowledge bases for consumer choice tools, for example.

Aspects that may be considered when choosing a food group include:

- the perceived nutritional role of the food items in the overall diet lcustomary source of protein in a meal);

- the functionality of the food items in meals (protein sources, carbohydrate sources, protective nutrient-sources);

- raw material basis (dairy foods); and

- consumer choices (snack, sweet treat, vegetables in a meal).

An example of a food categorization system is the CODEX/FAO food category system (FAO, 2019c). This hierarchical system includes all foodstuffs and is often used in nutrition science. However, it is not intended for labelling purposes. There is little discussion of food classification in the nLCA literature and further research is needed on this topic

\subsection{Key methodological issues in defining a nutritional functional unit}

\subsubsection{Should nutritional quality be included in the functional unit and to what extent?}

Despite the growing discussion on including nutrition in food LCA studies, there is no agreed upon and established method for defining an nFU. Table 10 provides a summary of the different FUs that have been used in food LCA studies, including LCAs with a particular focus on nutritional aspects. In short, there is no one single FU that has been used systematically, or should obviously be used, across all food LCA studies.

In Table 10, the benefits and drawbacks associated with each type of FU have been assessed from the perspective of using these FUs in nLCA studies at a general level. Most of the LCA studies listed as 
examples in Table 10 address at least some nutritional aspect, and some have mass-based FUs; it is important to note that the chosen FUs may be well justified in the example LCA studies based on their specific goals.

Table 10: Overview of functional units used in food LCA studies and their benefits and drawbacks when interpreted in the context of $n L C A$

\begin{tabular}{|c|c|c|c|c|}
\hline FU & $\begin{array}{l}\text { Benefits of FU when used } \\
\text { in nLCA }\end{array}$ & Drawbacks when used in nLCA & Implications & $\begin{array}{l}\text { Examplesof } \\
\text { studies }\end{array}$ \\
\hline Mass & $\begin{array}{l}\text { Widely used as an FU in LCA. } \\
\text { Widely used in nutrition educa- } \\
\text { tion, such as food labelling and } \\
\text { dietary guidelines. } \\
\text { Simple and easy to under- } \\
\text { stand. } \\
\text { Easily translated to other FUs. }\end{array}$ & $\begin{array}{l}\text { Doesn't describe any functions of food, } \\
\text { nor capture nutrition. } \\
\text { Seldom reflects the substitutive relation } \\
\text { between food products. } \\
\text { In terms of LCA methodology, mixes the } \\
\text { concepts of reference flow and functional } \\
\text { unit. }\end{array}$ & $\begin{array}{l}\text { Can be converted } \\
\text { to other FUs for } \\
\text { more appropriate } \\
\text { comparisons be- } \\
\text { tween products. } \\
\\
\text { Can be used when } \\
\text { analysing environ- } \\
\text { mental impacts } \\
\text { and other sustain- } \\
\text { ability aspects as } \\
\text { separate issues in } \\
\text { parallel, or when } \\
\text { evaluating diets. }\end{array}$ & $\begin{array}{l}\text { Nijdam, Rood } \\
\text { and Westhoek } \\
\text { 2012) } \\
\text { Poore and } \\
\text { Nemecek } \\
\text { (2018) } \\
\text { Berardy et al. } \\
\text { (2019) } \\
\text { Berardy et al. } \\
\text { (2020) } \\
\text { Green et al. } \\
\text { (2021) }\end{array}$ \\
\hline $\begin{array}{l}\text { Serving } \\
\text { size }\end{array}$ & $\begin{array}{l}\text { Customarily acknowledged. } \\
\text { Widely used in health impact } \\
\text { assessment studies and die- } \\
\text { tary guidelines. } \\
\text { Linked with the purchase be- } \\
\text { haviour of consumers and with } \\
\text { food labelling. } \\
\text { Simple and easy to under- } \\
\text { stand. }\end{array}$ & $\begin{array}{l}\text { May vary between recommended and } \\
\text { typical doses. } \\
\text { May vary due to different consumption } \\
\text { patterns in different regions. } \\
\text { Does not always reflect the substitutive } \\
\text { relation between food products. } \\
\text { Standardized portion sizes are only avail- } \\
\text { able to a limited extent for different food } \\
\text { ingredients or items. }\end{array}$ & $\begin{array}{l}\text { Requires transpar- } \\
\text { ency in the defi- } \\
\text { nition (reference } \\
\text { flow) and justifica- } \\
\text { tion of the service } \\
\text { size le.g. regional } \\
\text { coverage). } \\
\text { Can be converted } \\
\text { to other FUs for } \\
\text { more appropriate } \\
\text { comparisons be- } \\
\text { tween products. } \\
\text { Can be used when } \\
\text { analysing environ- } \\
\text { mental impacts } \\
\text { and other sustain- } \\
\text { ability aspects as } \\
\text { separate issues in } \\
\text { parallel. }\end{array}$ & $\begin{array}{l}\text { Heller, Keoleian } \\
\text { and Willett } \\
\text { (2013) } \\
\text { Espinoza-Orias } \\
\text { and Azapagic } \\
\text { (2018) } \\
\text { Chaudhary et al. } \\
\text { (2018) } \\
\text { Poore and } \\
\text { Nemecek } \\
\text { (2018) } \\
\text { Clark et al. } \\
\text { (2019) } \\
\text { Berardy et al. } \\
\text { (2019) }\end{array}$ \\
\hline Calories & $\begin{array}{l}\text { Customarily acknowledged. } \\
\text { Widely used in nutrition educa- } \\
\text { tion, such as food labelling and } \\
\text { dietary guidelines. } \\
\text { Simple and easy to under- } \\
\text { stand. }\end{array}$ & $\begin{array}{l}\text { Does not describe nutrition more broadly } \\
\text { than in terms of energy intake. } \\
\text { Seldom reflects the substitutive relation } \\
\text { between food products. }\end{array}$ & $\begin{array}{l}\text { Focus on caloric } \\
\text { intake may help } \\
\text { address obesity } \\
\text { and overconsump- } \\
\text { tion issues. }\end{array}$ & $\begin{array}{l}\text { Masset et al. } \\
\text { (2015) } \\
\text { Xu et al. (2018) }\end{array}$ \\
\hline Protein & $\begin{array}{l}\text { Simple and easy to under- } \\
\text { stand. } \\
\text { Facilitates comparison of } \\
\text { typically high environmental } \\
\text { impact products (e.g. livestock) } \\
\text { to alternatives (e.g. plant, } \\
\text { insect, or cultured protein). }\end{array}$ & $\begin{array}{l}\text { Does not describe nutrition more broadly } \\
\text { than in terms of protein intake. } \\
\text { Does not reflect the substitutive relation } \\
\text { between other food products than pro- } \\
\text { tein-rich products. }\end{array}$ & $\begin{array}{l}\text { Contributes to the } \\
\text { assumption that } \\
\text { protein deficiency } \\
\text { is a major issue, } \\
\text { which is not the } \\
\text { case on a country } \\
\text { level in affluent } \\
\text { countries but } \\
\text { can be for many } \\
\text { sub-populations } \\
\text { and developing } \\
\text { countries; should } \\
\text { only be used in the } \\
\text { proper context. }\end{array}$ & $\begin{array}{l}\text { Oonincx et al. } \\
\text { (2012) } \\
\text { Saarinen et al. } \\
\text { (2017) } \\
\text { Xu et al. (2018) }\end{array}$ \\
\hline
\end{tabular}




\begin{tabular}{|c|c|c|c|c|}
\hline $\begin{array}{l}\text { Single } \\
\text { nutrient } \\
\text { lother } \\
\text { than } \\
\text { protein) }\end{array}$ & $\begin{array}{l}\text { Simple and easy to under- } \\
\text { stand when applied to one } \\
\text { nutrient linstead of a range of } \\
\text { nutrients). } \\
\text { Broadens the perspective by } \\
\text { raising non-protein issues } \\
\text { in the current context where } \\
\text { protein-focused research is } \\
\text { prevalent. }\end{array}$ & $\begin{array}{l}\text { When applied to one nutrient linstead of } \\
\text { a range of nutrients) does not describe } \\
\text { nutrition more broadly. } \\
\text { When applied to a range of individual } \\
\text { nutrients, the overall result is difficult to } \\
\text { interpret. }\end{array}$ & $\begin{array}{l}\text { When applied } \\
\text { to one nutrient, } \\
\text { contributes to the } \\
\text { assumption that } \\
\text { deficiency of that } \\
\text { nutrient is a major } \\
\text { issue. This may be } \\
\text { an issue for some } \\
\text { sub-populations } \\
\text { or counties. Thus, } \\
\text { this should only be } \\
\text { used in the proper } \\
\text { context, or for } \\
\text { product develop- } \\
\text { ment in specific } \\
\text { situations. }\end{array}$ & $\begin{array}{l}\text { Saarinen et al. } \\
\text { (2017) } \\
\text { McAuliffe, } \\
\text { Takahashi and } \\
\text { Lee (2018) } \\
\text { Xu et al. (2018) } \\
\text { Salazar et al. } \\
\text { (2019) }\end{array}$ \\
\hline $\begin{array}{l}\text { Nutrient } \\
\text { quality } \\
\text { le.g. } \\
\text { protein } \\
\text { qualityl }\end{array}$ & $\begin{array}{l}\text { Improves the consideration } \\
\text { of nutritional quality for } \\
\text { important details of individual } \\
\text { nutrients, such as protein } \\
\text { digestibility and amino acid } \\
\text { composition/intake/ adequacy. } \\
\text { When applied to proteins, } \\
\text { facilitates fairer comparison } \\
\text { of typically high environmental } \\
\text { impact products (e.g. livestock) } \\
\text { to alternatives (e.g. plant, } \\
\text { insect, or cultured protein). }\end{array}$ & $\begin{array}{l}\text { Complex calculation. } \\
\text { Requires dietary and food composition } \\
\text { data that is often difficult to obtain. } \\
\text { Does not describe nutrition more broadly } \\
\text { than in terms of the intake of the nutrient } \\
\text { in question. } \\
\text { Does not reflect the substitutive relation } \\
\text { between food products other than pro- } \\
\text { tein-rich products. }\end{array}$ & & $\begin{array}{l}\text { Sonesson et al. } \\
\text { (2017) } \\
\text { Moughan (2021) }\end{array}$ \\
\hline $\begin{array}{l}\text { NRF9.31 } \\
\text { and var- } \\
\text { iations, } \\
\text { such as } \\
\text { NRF22-21 }\end{array}$ & $\begin{array}{l}\text { Commonly used as nutritional } \\
\text { FU and thus results would } \\
\text { be comparable to many or, at } \\
\text { least, some other studies. } \\
\text { Moderate simplicity. } \\
\text { Applicable to all food items las } \\
\text { a nutritional quality measure). } \\
\text { Describes the nutritional qual- } \\
\text { ity of a product more broadly } \\
\text { than a single nutrient. } \\
\text { Validated for nutritional pur- } \\
\text { poses (in the United States of } \\
\text { America). } \\
\text { Can be tailored to reflect the } \\
\text { nutritional needs or status of } \\
\text { specific population groups by } \\
\text { changing RDI9 or by applying } \\
\text { weighting of nutrients }\end{array}$ & $\begin{array}{l}\text { Harder to understand. } \\
\text { Often produces a negative value (particu- } \\
\text { larly to food items) that is not suitable for } \\
\text { use as an FU. } \\
\text { Includes added sugars, for which it is } \\
\text { difficult to gather data. } \\
\text { Increase in the number of nutrients in the } \\
\text { index impairs the resolution of the index } \\
\text { and requires more data. } \\
\text { Does not distinguish products from the } \\
\text { point of view of product choice within the } \\
\text { product group. } \\
\text { May refer to impact rather than quality. }\end{array}$ & $\begin{array}{l}\text { As an FU, can } \\
\text { only be applied to } \\
\text { ingredients and } \\
\text { food items to which } \\
\text { it does not produce } \\
\text { negative values } \\
\text { (without additional } \\
\text { rules to be set, } \\
\text { such as the one in- } \\
\text { troduced by Green } \\
\text { et al. [2021]). }\end{array}$ & $\begin{array}{l}\text { Doran-Browne } \\
\text { et al. (2015) } \\
\text { Hallström et } \\
\text { al. (2019) } \\
\text { Green et al. } \\
\text { (2021) } \\
\text { Strid et al., } \\
\text { (2021) } \\
\text { Originally } \\
\text { developed for } \\
\text { nutritional } \\
\text { education to } \\
\text { compare the } \\
\text { nutritional } \\
\text { quality of prod- } \\
\text { ucts by Fulgoni, } \\
\text { Keast and } \\
\text { Drewnowski } \\
\text { (2009) }\end{array}$ \\
\hline
\end{tabular}




\begin{tabular}{|c|c|c|c|c|}
\hline $\begin{array}{l}\text { NRF21.21 } \\
\text { (variation } \\
\text { of NRF } \\
\text { index } \\
\text { family) }\end{array}$ & $\begin{array}{l}\text { Commonly used as nutritional } \\
\text { FU and thus results would } \\
\text { be comparable to many or, at } \\
\text { least, some other studies. } \\
\text { Moderate simplicity. } \\
\text { Applicable to all food items las } \\
\text { a nutritional quality measure). } \\
\text { Describes the nutritional qual- } \\
\text { ity of a product more broadly } \\
\text { than a single nutrient. } \\
\text { Validated for nutritional pur- } \\
\text { poses (in the United States of } \\
\text { America). } \\
\text { Can be tailored to reflect the } \\
\text { nutritional needs or status of } \\
\text { specific population groups by } \\
\text { changing RDI9 or by applying } \\
\text { weighting of nutrients. }\end{array}$ & $\begin{array}{l}\text { Harder to understand. } \\
\text { Often produces a negative value (particu- } \\
\text { larly to food items) that is not suitable for } \\
\text { use as an FU. } \\
\text { Includes added sugars, for which it is } \\
\text { difficult to gather data. } \\
\text { Increase in the number of nutrients in the } \\
\text { index impairs the resolution of the index } \\
\text { and requires more data. } \\
\text { Does not distinguish products from the } \\
\text { point of view of product choice within the } \\
\text { product group. } \\
\text { May refer to impact rather than quality. }\end{array}$ & $\begin{array}{l}\text { As an FU, can } \\
\text { only be applied to } \\
\text { ingredients and } \\
\text { food items to which } \\
\text { it does not produce } \\
\text { negative values } \\
\text { (without additional } \\
\text { rules to be set, } \\
\text { such as the one in- } \\
\text { troduced by Green } \\
\text { et al. [2021]). }\end{array}$ & $\begin{array}{l}\text { Doran-Browne } \\
\text { et al. (2015) } \\
\text { Hallström et al. } \\
\text { (2019) } \\
\text { Green et al. } \\
\text { (2021) } \\
\text { Strid et al., } \\
\text { (2021) } \\
\text { Originally } \\
\text { developed for } \\
\text { nutritional } \\
\text { education to } \\
\text { compare the } \\
\text { nutritional } \\
\text { quality of prod- } \\
\text { ucts by Fulgoni, } \\
\text { Keast and } \\
\text { Drewnowski } \\
\text { (2009) }\end{array}$ \\
\hline $\mathrm{NR9}^{2}$ & $\begin{array}{l}\text { Moderate simplicity. } \\
\text { Applicable to all food items. } \\
\text { Describes the nutritional qual- } \\
\text { ity of a product more broadly } \\
\text { than a single nutrient. } \\
\text { Can be tailored to reflect the } \\
\text { nutritional needs or status of } \\
\text { specific population groups by } \\
\text { changing RDI9 or by applying } \\
\text { weighting of nutrients }\end{array}$ & $\begin{array}{l}\text { Needs a complementary measure for } \\
\text { nutrients to limit (index or health impact } \\
\text { assessment) because it addresses only } \\
\text { nutrients to encourage. } \\
\text { Does not distinguish among products } \\
\text { from the point of view of product choice } \\
\text { within the product group. }\end{array}$ & & $\begin{array}{l}\text { Saarinen et al. } \\
\text { (2017) } \\
\text { Originally } \\
\text { introduced by } \\
\text { Drewnowski } \\
\text { and Fulgoni, } \\
\text { (2014) }\end{array}$ \\
\hline $\mathrm{NBC}^{3}$ & $\begin{array}{l}\text { Addresses energy intake in } \\
\text { addition to nutrients; favours } \\
\text { products with a high nutrient } \\
\text { density (amount of nutrients } \\
\text { per energy content). } \\
\text { Applicable to all food items. } \\
\text { Describes the nutritional qual- } \\
\text { ity of a product more broadly } \\
\text { than a single nutrient. }\end{array}$ & $\begin{array}{l}\text { A more complex calculation method, } \\
\text { harder to understand. } \\
\text { More data/time needed. } \\
\text { Not validated. } \\
\text { (In LCA application (Chaudhary et al. } \\
\text { 2018) not initially used as FU but NBC3/ } \\
\text { carbon footprint.) } \\
\text { Does not distinguish among products } \\
\text { from the point of view of product choice } \\
\text { within the product group. } \\
\text { May refer to impact rather than quality } \\
\text { (as includes both nutrients to encourage } \\
\text { (27) and nutrients to limit (6) and energy } \\
\text { intake). }\end{array}$ & & $\begin{array}{l}\text { Fern et al. } \\
\text { (2015) } \\
\text { Chaudhary et al. } \\
\text { (2018) }\end{array}$ \\
\hline Nu21 & Moderate simplicity. & $\begin{array}{l}\text { Nutrients to limit are included using } \\
\text { the same procedure as nutrients to } \\
\text { encourage. } \\
\text { Increase in the number of nutrients in the } \\
\text { index impairs the resolution of the index } \\
\text { and requires more data. }\end{array}$ & & Xu et al. (2018) \\
\hline WNDS $^{4}$ & $\begin{array}{l}\text { Selects nutrients based on } \\
\text { which ones explain variation } \\
\text { in the Healthy Eating Index. } \\
\text { Uses this algorithm to apply } \\
\text { weightings to nutrients. } \\
\text { Easy to apply. } \\
\text { Partially validated. }\end{array}$ & $\begin{array}{l}\text { Due to weightings, index produces dras- } \\
\text { tically negative values for certain food } \\
\text { products. } \\
\text { Includes added sugars, for which it is } \\
\text { difficult to gather data. } \\
\text { Nutrients to limit are included using } \\
\text { the same procedure as nutrients to } \\
\text { encourage. }\end{array}$ & & $\begin{array}{l}\text { Arsenualt et al. } \\
\text { (2012) }\end{array}$ \\
\hline
\end{tabular}




\begin{tabular}{|c|c|c|c|c|}
\hline FNIprot7 5 & $\begin{array}{l}\text { Moderate simplicity. } \\
\text { Includes nutrients selected to } \\
\text { suit the product group in the } \\
\text { context of a particular diet. } \\
\text { Linked with the purchase } \\
\text { behaviour of consumers. } \\
\text { Describes the nutritional qual- } \\
\text { ity of a product more broadly } \\
\text { than a single nutrient. } \\
\text { Can be tailored to reflect the } \\
\text { nutritional needs or status of } \\
\text { specific population groups by } \\
\text { changing RDI9 or by applying } \\
\text { weighting of nutrients. }\end{array}$ & $\begin{array}{l}\text { May require a complementary measure } \\
\text { for nutrients to limit (index or health im- } \\
\text { pact assessment) because it addresses } \\
\text { only nutrients to encourage. } \\
\text { Not validated (but selection of nutrients } \\
\text { based on consumption data analysis). }\end{array}$ & $\begin{array}{l}\text { Suitable for distin- } \\
\text { guishing products } \\
\text { from the point of } \\
\text { view of product } \\
\text { choice within the } \\
\text { product group, i.e. } \\
\text { products used as } \\
\text { protein sources. }\end{array}$ & $\begin{array}{l}\text { Saarinen et al. } \\
\text { (2017) }\end{array}$ \\
\hline $\begin{array}{l}\text { UKNI } \\
\text { prot } \\
7^{6}, \\
\text { UKNI } \\
\text { prot } \\
10^{6} \\
\text { (vari- } \\
\text { ations } \\
\text { from } \\
\text { FNI7prot }{ }^{5} \text { ) }\end{array}$ & Validated & Validated & Validated & Validated \\
\hline $\begin{array}{l}\text { UKNI } \\
\text { prot } \\
7-2^{6} \\
\text { UKNI } \\
\text { prot } \\
10-2^{6}\end{array}$ & $\begin{array}{l}\text { Moderate simplicity. } \\
\text { Includes nutrients selected to } \\
\text { suit the product group in the } \\
\text { context of a particular diet. } \\
\text { Linked with the purchase } \\
\text { behaviour of consumers. } \\
\text { Describes the nutritional qual- } \\
\text { ity of a product more broadly } \\
\text { than a single nutrient. }\end{array}$ & $\begin{array}{l}\text { Applied only to meat as a food ingredient, } \\
\text { not for food items. } \\
\text { Not validated. }\end{array}$ & & $\begin{array}{l}\text { McAuliffe, } \\
\text { Takahashi and } \\
\text { Lee (2018) }\end{array}$ \\
\hline Nu11 & $\begin{array}{l}\text { Moderate simplicity. } \\
\text { Linked with the purchase } \\
\text { behaviour of consumers. } \\
\text { Describes the nutritional qual- } \\
\text { ity of a product more broadly } \\
\text { than a single nutrient. }\end{array}$ & $\begin{array}{l}\text { Addresses only nutrients to encourage. } \\
\text { Larger number of nutrients in the index } \\
\text { may impair the resolution of the index, } \\
\text { and requires more data. } \\
\text { Not validated. }\end{array}$ & $\begin{array}{l}\text { Suitable for distin- } \\
\text { guishing products } \\
\text { from the point of } \\
\text { view of product } \\
\text { choice within the } \\
\text { product group. }\end{array}$ & Xu et al. (2018) \\
\hline $\mathrm{NQI}^{7}$ & $\begin{array}{l}\text { Reflects the dietary context of } \\
\text { a protein food item in a gener- } \\
\text { al manner. } \\
\text { Moderately to highly specific to } \\
\text { the dietary context }\end{array}$ & $\begin{array}{l}\text { Requires extensive dietary data. } \\
\text { Time intensive and complex. } \\
\text { May be hard to understand. }\end{array}$ & $\begin{array}{l}\text { Allows users to } \\
\text { assess protein food } \\
\text { items within the } \\
\text { context of a whole } \\
\text { diet in a general } \\
\text { manner. }\end{array}$ & $\begin{array}{l}\text { Sonesson et al. } \\
\text { (2019) }\end{array}$ \\
\hline $\begin{array}{l}\text { NRFpro- } \\
\text { tein-sub }\end{array}$ & $\begin{array}{l}\text { Reflects the dietary context of } \\
\text { a protein food item in a gener- } \\
\text { al manner. }\end{array}$ & $\begin{array}{l}\text { Requires knowledge about dietary defi- } \\
\text { ciencies. } \\
\text { Specific to protein-rich food alternatives. }\end{array}$ & $\begin{array}{l}\text { Allows users to } \\
\text { assess protein food } \\
\text { items within the } \\
\text { context of a whole } \\
\text { diet in a fairly } \\
\text { simple manner. }\end{array}$ & $\begin{array}{l}\text { Green et al. } \\
\text { (2021) }\end{array}$ \\
\hline
\end{tabular}

${ }^{1}$ nutrient rich foods (NRF);

${ }^{2}$ nutrient rich (NR);

${ }^{3}$ balance concept (NBC);

${ }^{4}$ weighted nutrient density score (WNDS);

${ }^{5}$ finnish nutrient Index for protein sources ( $\mathrm{FNI}_{\text {prot }}$ );
${ }^{6}$ British nutrient Index for protein-rich foods (UKNI ${ }_{\text {prot }}$ );

${ }^{7}$ nutritional quality index (NQI);

${ }^{8}$ nutrient rich (for) protein sources (NRprotein-sub);

${ }^{9}$ recommended daily intake (RDI) 
Utilization of nutrient profiling has rapidly become widespread (Hallström et al., 2018; Green et al., 2020; Grigoriadis, Nugent and Brereton, 2021), but an important outstanding question is whether providing nutrients is the primary function of food in the sense required by the FU (Weidema and Stylianou, 2020). It has been suggested, for example, that the "pursuit of satiety" better reflects the purpose of consuming food than the intake of nutrients, and so "inducing satiety" would be an appropriate FU (Weidema and Stylianou 2020). So far, however, methodologically valid FUs based on "satiety" have not been reported in the literature, and in fact it is not a nutritional concept; therefore, if used as an FU, the study should include a nutrition/health impact assessment to be considered nLCA. An acknowledgement of additional drivers of consumer food choice such as food culture, affordability and enjoyment is also lacking in nutrient-based definitions of the FU. In any case, this discussion highlights the relevance of the choice of FU to the purpose and scope of the study.

Another basic question concerns the extent to which nutritional value should be included in the FU and to what extent in the impact assessment, and how these interact. This topic has received little attention in the literature, but it is related to the questions of (a) how to treat nutrients to limit when $\mathrm{nFUs}$ are based on several nutrients (Section 6.3.2.4), and (b) how to combine non-nutritional FUs such as serving size or other mass/volume quantities, and nutrition/health impact assessment. Regarding the latter question, mass/volume-based FUs have typically been used in food LCA studies where no attention is paid to nutrition (often targeting raw materials, for example) but when an FU based on serving size is used, it is usually used to account for nutrition and/or consumer behaviour (e.g. Berardy et al., 2019; Chaudhary et al., 2018), as it potentially reflects consumers' eating patterns or purchasing behaviours. However, standardized serving sizes may vary between typical and recommended portions in different applications. As with other FUs, the serving size has its strengths and weaknesses (Table 10).

Some LCA studies use individual nutritional factors such as caloric intake or protein content (sometimes corrected for protein quality) as a basis for the FU (Table 10). Such FUs are typically easy to use, but their range of use is often limited and specific. For example, an FU based on caloric intake may help address obesity and overconsumption issues but may also result in some inappropriate comparisons because nutrient content varies independently from energy content (Xu et al., 2018). Another example is protein; protein is one of the macronutrients and its deficiency causes major health concerns. However, although protein deficiency is an issue in some countries, protein availability in affluent countries meets adequacy requirements - although it can still be an issue for certain sub-populations (Schmidhuber et al., 2018)..$^{4}$ The same types of issues relate to the use of any single nutrient as the basis of the FU: they inherently assume that a deficiency of that nutrient is a major issue. In some situations, this may be the case and then such an FU is appropriate lif it is also consistent with the goal and scope of the study). However, such FUs are not suitable as a general reference basis across different food items (Saarinen et al., 2017; Green et al., 2021).

To illustrate the significant role of selection of the FU, Table 11 shows some example GHG emission intensities $\left(\mathrm{kg} \mathrm{CO}_{2} \mathrm{e}\right)$ for 33 food items available in the Netherlands. The results are presented for different FUs: $100 \mathrm{~g}$ product, typical serving size, $100 \mathrm{~g}$ dry matter, $100 \mathrm{kcal}, 100 \mathrm{~g}$ protein, and $100 \mathrm{mg}$ $\mathrm{Ca}$. The ranking within each column is indicated by different colours. Overall, it is clear that each FU alters the ranking of the food items and, therefore, also the potential choices that could be made based on this information. For example, when expressing the results based on a typical serving size rather than a mass-based FU, for liquid products (milk, juices and wine) the serving size FU gives higher

${ }^{4} \mathrm{An}$ additional issue for protein is that many protein-rich foods also provide a diverse range of other nutrients, but this nutrient content is highly variable between foods. In these comparisons, protein quality has also been raised as a key issue (see, for example, Sonesson et al., 2017). 
results than the mass-based FU, whereas for other food items (nuts, meat products or cheese) the use of the serving size FU gives lower results than the mass-based FU. When expressing the results using a dry matter content FU, the differences between milk and cheese are reduced compared with using a mass-based FU (due to the difference in water content between these food items). When considering these food items primarily as a source of energy, protein or calcium, the ranking changes markedly according to which one is considered; for example, boiled mushrooms are ranked high (i.e. relatively high GHG emissions) when using an energy or calcium FU but are middle-ranked when using a protein FU; Gouda cheese is ranked low when using a calcium FU but is middle-ranked using an energy or protein FU.

In summary, when nutritional quality is included in the FU, the choice of the function to be represented and its quantified representation markedly influences the ranking of different food items. Nutrient profiling is an evolving approach that accounts for a greater number of nutrients, and methods consistent with different goals and scopes of LCA studies are being developed. 
Table 11: Examples of greenhouse gas emissions ( $\left.\mathrm{kg} \mathrm{CO}_{2} \mathrm{e}\right)$ of food items across a selection of functional units

\begin{tabular}{|c|c|c|c|c|c|c|c|}
\hline Food item & Type of food & $\begin{array}{c}\mathrm{kg} \mathrm{CO} \\
\mathrm{e} / \\
100 \mathrm{~g} \\
\text { product }\end{array}$ & $\begin{array}{c}\mathrm{kg} \mathrm{CO} \\
\text { eq/ } \\
\text { serving } \\
\text { size }\end{array}$ & $\begin{array}{c}\mathrm{kg} \mathrm{CO}_{2} \\
\mathrm{e} / \\
100 \mathrm{~g} \text { dry } \\
\text { weight }\end{array}$ & $\begin{array}{l}\mathrm{kg} \mathrm{CO}_{2} \mathrm{e} / \\
100 \text { kcal }\end{array}$ & $\begin{array}{c}\mathrm{kg} \mathrm{CO}_{2} \\
\mathrm{e} / \\
100 \mathrm{~g} \\
\text { protein }\end{array}$ & $\begin{array}{c}\mathrm{kg} \mathrm{CO} \\
\mathrm{e} / \\
100 \mathrm{mg} \\
\text { calcium }\end{array}$ \\
\hline Ham shoulder medium fat boiled & Red meat & 1.08 & 0.16 & 3.95 & 0.81 & 6.60 & 9.04 \\
\hline Beef rump steak prepared & Red meat & 3.13 & 2.35 & 9.01 & 2.15 & 10.70 & 21.46 \\
\hline Potatoes w/o skins boiled average & Starchy vegetables & 0.09 & 0.05 & 0.42 & 0.11 & 4.86 & 1.24 \\
\hline Eggs (chicken) boiled average & Eggs & 0.43 & 0.22 & 1.82 & 0.34 & 3.51 & 0.53 \\
\hline Chicken with skin prepared & Poultry & 1.36 & 1.02 & 3.17 & 0.59 & 5.25 & 4.53 \\
\hline Milk whole & Dairy & 0.21 & 0.52 & 1.68 & 0.34 & 6.32 & 0.28 \\
\hline Milk skimmed & Dairy & 0.20 & 0.49 & 2.03 & 0.56 & 5.32 & 0.44 \\
\hline Cheese Gouda 48+ average & Dairy & 1.31 & 0.26 & 2.16 & 0.36 & 5.74 & 0.04 \\
\hline Shrimps Dutch peeled boiled & Fish & 1.54 & 0.15 & 6.39 & 1.64 & 7.78 & 1.22 \\
\hline Herring salted & Fish & 0.28 & 0.21 & 0.84 & 0.16 & 1.59 & 0.32 \\
\hline Kale curly boiled & Vegetables & 0.16 & 0.08 & 1.14 & 0.35 & 4.00 & 0.19 \\
\hline Mushrooms boiled & Vegetables & 0.52 & 0.26 & 5.21 & 2.48 & 13.71 & 49.60 \\
\hline Pineapple & Fruit & 0.10 & 0.10 & 0.70 & 0.18 & 20.11 & 1.47 \\
\hline Banana & Fruit & 0.08 & 0.08 & 0.31 & 0.08 & 6.88 & 1.33 \\
\hline Beans French boiled & Legumes & 0.11 & 0.05 & 1.34 & 0.42 & 5.89 & 0.79 \\
\hline Peas frozen boiled & Legumes & 0.11 & 0.06 & 0.44 & 0.12 & 1.90 & 0.38 \\
\hline Bread wholemeal average & Cereals & 0.10 & 0.04 & 0.17 & 0.04 & 0.93 & 0.13 \\
\hline Bread white water based & Cereals & 0.12 & 0.04 & 0.19 & 0.05 & 1.32 & 0.17 \\
\hline Cashew nuts unsalted & Nuts & 0.43 & 0.09 & 0.44 & 0.07 & 2.01 & 0.16 \\
\hline Peanuts unsalted & Nuts & 0.74 & 0.15 & 0.75 & 0.12 & 2.92 & 0.21 \\
\hline $\begin{array}{l}\text { Apple pie Dutch w shortbread w } \\
\text { margarine }\end{array}$ & Sweets & 0.23 & 0.23 & 0.39 & 0.08 & 6.53 & 0.35 \\
\hline Almond paste filled tarts average & Sweets & 0.39 & 0.20 & 0.46 & 0.10 & 6.31 & 0.27 \\
\hline Crisps potato average & Snacks & 0.48 & 0.05 & 0.49 & 0.09 & 7.67 & 0.33 \\
\hline Wine red & Alcoholic beverage & 0.20 & 0.30 & 1.74 & 0.25 & $N A^{*}$ & 3.08 \\
\hline Wine white dry & Alcoholic beverage & 0.23 & 0.34 & 1.64 & 0.34 & 227.67 & 2.83 \\
\hline Peanut butter & Spreads & 0.87 & 0.13 & 0.88 & 0.13 & 3.87 & 0.26 \\
\hline Sauce for chips $25 \%$ oil & Spreads & 0.29 & 0.06 & 0.70 & 0.10 & 58.44 & 1.23 \\
\hline Juice apple & Juice & 0.15 & 0.22 & 1.31 & 0.33 & 149.50 & 4.06 \\
\hline Juice orange pasteurized & Juice & 0.07 & 0.10 & 0.59 & 0.15 & 10.89 & 1.24 \\
\hline Sausage cooked & Meat & 1.52 & 0.23 & 2.98 & 0.43 & 13.44 & 2.36 \\
\hline Bacon rashers streaky & Meat & 1.10 & 0.16 & 2.21 & 0.35 & 7.00 & 4.40 \\
\hline Oil olive & Oils & 0.72 & 0.07 & 0.72 & 0.08 & NA* & NA* \\
\hline Oil sunflower seed & Oils & 0.50 & 0.05 & 0.50 & 0.06 & 167.02 & NA* \\
\hline
\end{tabular}

$*^{*}=\mathrm{NA}=$ Not available as nutrient level listed as 0

Note: Values in each column are coloured based on ranking from red (highest) to green (lowest). Food composition data were obtained from the Dutch Food Composition Database (NEVO) (RIVM, 2019). These example $\mathrm{CO}_{2}$ e values for food items were published by RIVM (2021) and are calculated on a cradle-to-consumer basis. 


\subsubsection{Use of nutrient profiling in nLCA studies}

Types of nutrient indices

Since foods are not only a source of calories or a single nutrient, some recent studies have explored integrating nutrient indices as FUs for food items (Table 10). One of the most used nutrient indices is the NRF index (Box 10) which is intended to be used for all types of food items. It considers a combination of nutrients to encourage (between 6 and 20) and nutrients to limit (between 0 and 3) (Drewnowski, Maillot and Darmon, 2009; Fulgoni, Keast and Drewnowski, 2009). The term "nutrients to encourage" refers to nutrients that are essential or important for human health and for the prevention of disease, and that are not normally supplied in harmful quantities in diets. The term "nutrients to limit" refers to nutrients that have the potential to be harmful in typical diets and thus should be consumed in moderation (to minimize the risk of health impacts). It is worth noting that the classification of a nutrient into one of these two groups is basically dependent on the whole diet - which varies in different parts of the world and between different target populations. For example, in a Western diet, the nutrients to limit are typically saturated fatty acids, sodium and added sugar for all target populations.

The use of NRF or other comparable indices requires information on: (1) concentrations of the different nutrients in the food item; and (2) RDI values for each of the nutrients. As RDI values can differ between population groups (Section 5.4), nLCA studies should report the population group used as a basis for the NRF index.

\section{BOX 10. NUTRIENT RICH FOOD INDEX}

The NRF score is calculated based on the nutrient content of a food item relative to its RDI values for nutrients to encourage or the recommended maximum intake (or daily allowance) values for nutrients to limit. NRF scores may be calculated considering different amounts of nutrients and are expressed as NRFx.y, where $x=$ the amount of nutrients to encourage that are considered (between 6 and 20 ), and $y$ is the number of nutrients to limit that are considered (between 0 and 3).

Nutrients to encourage that are considered in NRF calculations are:

NRF6 - protein, dietary fibre, vitamin A, vitamin C, Ca and Fe

NRF9 - NRF6 plus vitamin E, Mg and $K$

NRF11 - NRF9 plus vitamin B12 and Zn

NRF15 - NRF9 plus monounsaturated fat, vitamin D, vitamin B1, vitamin B2, folate but excluding $\mathrm{Mg}$

NRF20 - NRF15 plus linoleic acid, -linolenic acid, EPA+DHA, vitamin B6, Mg

Nutrients to limit are saturated fat, $\mathrm{Na}$ and added or total sugar.

The score for NRFx is the average of the relative nutrient contents for encouraged nutrients. The score for nutrients to limit is calculated in the same way. As a separate index, it is usually abbreviated as LIM. In NRFx.y, the score for nutrients to limit is subtracted from the score for encouraged nutrients. There are also applications of NRF that account for only nutrients to encourage or nutrients to limit.

NRF scores for food items may be expressed on various bases, for example, weight or volume, serving size or calories. 
To illustrate the use of different types of NRF scores as FUs, variants were applied to the same food items listed in Table 11, and results are shown in Table 12. Table 12 includes both NRF values based solely on nutrients to encourage (NR6.0, NRF11.0), and also includes nutrients to limit (NRF9.3, NRF15.3, NRF20.3). In addition, for NRF9.3, a distinction is made based on sugars, where both added sugars and total sugars are included in the FU. While added sugars were included in the definition of NRF9.3, total sugars have subsequently also been used in NRF9.3 calculations. Added sugars - sugars that are added during the food processing step - were estimated as 80 percent of the total sugar in sweets, and all mono- and di-saccharides in the sauce for chips. No added sugars were considered for the other food items, meaning that all sugars were considered to be present as natural sugars. The concept of added sugars, in general, is difficult because, unlike for other nutrients included in NRF calculations, added sugars are not easily distinguished from other sugars in food items and are difficult to quantify without knowing the full formulation of a food item. Table 12 shows that the ranking of food items changes depending upon the chosen NRF index. 
Table 12: Examples of greenhouse gas emissions ( $\mathrm{kg} \mathrm{CO}_{2} \mathrm{e}$ ) of various food items across a selection of functional units based on NRF indices

\begin{tabular}{|c|c|c|c|c|c|c|c|}
\hline Food item & Type of food & $\begin{array}{c}\mathrm{kg} \mathrm{CO} \\
\mathrm{e} / \mathrm{NRF} \\
6.0\end{array}$ & $\begin{array}{c}\mathrm{kg} \mathrm{CO} \\
\text { e/NRF } \\
9.3\end{array}$ & $\begin{array}{c}\mathrm{kg} \mathrm{CO}_{2} \mathrm{e} / \\
\mathrm{NRF} 9.3 \\
\text { (all } \\
\text { sugars) }\end{array}$ & $\begin{array}{l}\mathrm{kg} \mathrm{CO} \\
\mathrm{NRF} 11.0\end{array}$ & $\begin{array}{c}\mathrm{kg} \mathrm{CO}_{2} \\
\mathrm{e} / \mathrm{NRF}^{2} \\
15.3\end{array}$ & $\begin{array}{c}\mathrm{kg} \mathrm{CO}_{2} \\
\text { e/NRF } \\
20.3\end{array}$ \\
\hline Ham shoulder medium fat boiled & Red meat & 1.52 & 2.71 & 2.80 & 0.79 & 0.79 & 0.68 \\
\hline Beef rump steak prepared & Red meat & 4.15 & 2.76 & 2.76 & 1.29 & 1.20 & 1.02 \\
\hline Potatoes w/o skins boiled average & Starchy vegetables & 0.07 & 0.06 & 0.06 & 0.06 & 0.05 & 0.05 \\
\hline Eggs (chicken) boiled average & Eggs & 0.59 & 0.44 & 0.44 & 0.22 & 0.15 & 0.14 \\
\hline Chicken with skin prepared & Poultry & 2.41 & 2.76 & 2.76 & 1.22 & 1.15 & 0.74 \\
\hline Milk whole & Dairy & 0.82 & 0.83 & 1.37 & 0.35 & 0.38 & 0.34 \\
\hline Milk skimmed & Dairy & 0.87 & 0.62 & 0.94 & 0.35 & 0.33 & 0.30 \\
\hline Cheese Gouda 48+ average & Dairy & 0.70 & 1.70 & 1.70 & 0.41 & 0.52 & 0.47 \\
\hline Shrimps Dutch peeled boiled & Fish & 2.91 & 2.19 & 2.20 & 0.19 & 0.20 & 0.19 \\
\hline Herring salted & Fish & 0.56 & 1.34 & 1.34 & 0.06 & 0.05 & 0.05 \\
\hline Kale curly boiled & Vegetables & 0.08 & 0.07 & 0.07 & 0.07 & 0.06 & 0.05 \\
\hline Mushrooms boiled & Vegetables & 2.59 & 1.51 & 1.53 & 1.36 & 0.78 & 0.65 \\
\hline Pineapple & Fruit & 0.15 & 0.13 & 0.20 & 0.13 & 0.18 & 0.15 \\
\hline Banana & Fruit & 0.32 & 0.15 & 0.46 & 0.14 & 0.36 & 0.15 \\
\hline Beans French boiled & Legumes & 0.30 & 0.18 & 0.19 & 0.17 & 0.12 & 0.10 \\
\hline Peas frozen boiled & Legumes & 0.16 & 0.13 & 0.13 & 0.12 & 0.09 & 0.08 \\
\hline Bread wholemeal average & Cereals & 0.16 & 0.14 & 0.15 & 0.09 & 0.10 & 0.07 \\
\hline Bread white water based & Cereals & 0.34 & 0.44 & 0.54 & 0.22 & 0.27 & 0.20 \\
\hline Cashew nuts unsalted & Nuts & 0.40 & 0.23 & 0.25 & 0.15 & 0.12 & 0.08 \\
\hline Peanuts unsalted & Nuts & 0.80 & 0.36 & 0.38 & 0.27 & 0.20 & 0.14 \\
\hline $\begin{array}{l}\text { Apple pie Dutch w shortbread w } \\
\text { margarine }\end{array}$ & Sweets & 0.71 & NA & NA & 0.37 & 0.80 & 0.51 \\
\hline Almond paste filled tarts average & Sweets & 0.97 & NA & NA & 0.48 & 11.05 & 0.95 \\
\hline Crisps potato average & Snacks & 0.78 & 0.43 & 0.44 & 0.27 & 0.21 & 0.13 \\
\hline Wine red & Alcoholic beverage & 3.82 & 1.81 & 4.50 & 1.69 & 4.75 & 2.23 \\
\hline Wine white dry & Alcoholic beverage & 3.82 & 1.86 & 2.09 & 1.78 & 2.31 & 1.69 \\
\hline Peanut butter & Spreads & 0.99 & 0.54 & 0.57 & 0.37 & 0.25 & 0.17 \\
\hline Sauce for chips $25 \%$ oil & Spreads & 3.25 & NA & NA & 0.51 & 0.53 & 0.14 \\
\hline Juice apple & Juice & 7.91 & 1.79 & NA & 1.73 & NA & NA \\
\hline Juice orange pasteurized & Juice & 0.15 & 0.11 & 0.17 & 0.11 & 0.12 & 0.11 \\
\hline Sausage cooked & Meat & 4.25 & NA & NA & 1.55 & 1.41 & 1.03 \\
\hline Bacon rashers streaky & Meat & 3.35 & NA & NA & 1.17 & 1.06 & 0.67 \\
\hline Oil olive & Oils & 143.44 & NA & NA & 1.67 & 0.21 & 0.16 \\
\hline Oil sunflower seed & Oils & 95.20 & 0.09 & 0.09 & 0.08 & 0.07 & 0.04 \\
\hline
\end{tabular}

NA = Not available as nutrient level listed as 0

Note: Values in each column are coloured based on their ranking from red (highest) to green (lowest). Food composition data were obtained from the Dutch Food Composition Database (NEVO) (RIVM, 2019). The example $\mathrm{CO}_{2}$ e for food items were published by RIVM (2021) and are calculated on a cradle-to-consumer basis. 
In general, nutrient indices have a history of use in regulating health claims, regulating food marketing and advertising and in consumer nutrition education; therefore, their suitability for use in nLCA studies must be considered carefully (Hallström et al., 2018). The key methodological issues that have been identified in the literature on the use of nutrient profiling in nLCA studies are discussed in Sections Food group-specific vs across-the-board nutrient indices to Weighting or not.

\section{Food group-specific vs across-the-board nutrient indices}

The NRF indices were originally developed to apply to all food items - thus they are across-the-board indices. More recently, food group-specific indices have also been developed (Drewnowski and BurtonFreeman, 2020) for application to a specific food group, such as protein sources or fruits. In such indices, the basis for determining the nutritional quality of a food item is related to the role of its food group in overall nutrition but otherwise the calculation logic is the same as in across-the-board indices (Saarinen et al., 2017).

Saarinen et al. (2017) showed that across-the-board and food group-specific nutrient indices provide different results for both the nutrient index scores and the results of the LCA when these indices are used in the nFU. According to the results by Saarinen et al. (2017) for protein sources, both approaches identified the most obvious cases, but between the extremes they ranked food items differently. The food group approach in principle takes better account of consumer behaviour than the general approach, but further research is needed on the performance of both approaches in relation to the different goals of LCA studies (Table 13).

Food group-specific indices can compare substitute products within a food group on a more representative basis because they align with the substitution method (Scarborough et al., 2010). For this, one food is produced or consumed rather than another one within a food group. Across-theboard indices, in contrast, align with the displacement approach (Scarborough et al., 2010) wherein one food item is produced or consumed in place of another from a different food group (for example, plant-based protein is consumed in place of animal-sourced food protein). These considerations are, of course, very sensitive to the grouping of foods, whether the grouping is based on raw materials or a meal functional perspective (such as protein provision) (Table 10).

\section{Choice of nutrients and nutrient intake recommendation included}

In line with the original purpose of nutrient indices to act as nutrition education tools, a nutrition index should contain the most critical nutrients that distinguish those food items that improve the quality of the diet of the reference population relative to other food items (Drewnowski and Fulgoni, 2014). Similarly, the nutrient intake recommendation, recommended daily intake, and/or RDI for nutrients is selected based on the reference population. These criteria are also reasonable to apply when a nutrient index is used in an nLCA.

According to Drewnowski and Fulgoni (2014) and Fulgoni, Keast and Drewnowski (2009), a nutrient index consisting of a reasonably limited number of nutrients (about seven) to encourage and three main nutrients to limit is, in principle, the best performing across-the-board nutrient index in relation to a healthy diet. A larger number of nutrients, in general, reduces the explanatory power of the index; it tends to even out the differences between different food items. However, which nutrients are included depends largely on the dietary context in which the nutrient index is to be used (Drewnowski and Fulgoni, 2014) and whether it is an across-the-board or food group-specific index (Saarinen et al., 2017; McAuliffe, Takahashi and Lee, 2018; Drewnowski and Burton-Freeman, 2020). Again, the most critical nutrients should be included, but probably not, for example, all those with high intake. 
Nutrients to encourage vs nutrients to both encourage and limit

The inclusion of nutrients to limit is a contentious subject in nLCA (Hallström et al., 2018; Green et al., 2020). Both nutrients to encourage and nutrients to limit undeniably affect the nutritional quality of food items. Thus, the presence of both types of nutrients is widely emphasized in nutrition science and public health messages.

The issue is more complicated in nLCA. Firstly, some argue that the FU is not a measure of harm and, therefore, should only include nutrients to encourage (Saarinen et al., 2017). It can also be argued that a measure combining nutrients to encourage and to limit may in fact be closer to a representation of nutritional impact rather than functionality. Secondly, the inclusion of nutrients to limit could lead to a negative nutrient index score and thus also to negative environmental scores. This is problematic in LCA because negative scores in the impact assessment represent positive environmental outcomes - and these are not actually happening in these systems (Saarinen et al., 2017). Even a nutrient index score of zero makes assessing environmental impacts impossible. ${ }^{5}$ Others have argued to include nutrients to limit in the FU, in nLCA studies where nutritional value is not assessed in the impact assessment, because excluding these nutrients would mean that only part of the nutritional quality of the food items is represented, and that can bias results in favour of energy-dense foods (Green et al., 2020).

In general, subtracting the score for nutrients to limit from the score for nutrients to encourage in these indices might not make sense in an nFU, as the "unit effect" of these nutrients is not the same: one unit of a nutrient to limit index may not reduce the nutritional value of a food item in the same way or by the same amount as one unit of a nutrient to encourage index increases the nutritional value of that food item. Although it may be a reasonable basis for assessing foods in nutrition education, in an LCA the assessment should be based on a common FU that describes functionality. This has so far been incompletely discussed in the literature.

In any case, nutrients to limit affect the nutritional quality of food items and thus they need to be accounted for in the nLCA. Alternative approaches proposed to account for nutrients to limit, instead of including them in the $\mathrm{nFU}$, provide a separate index of these nutrients in the LCA study report (Saarinen et al., 2017), or address them in the impact assessment las part of the assessment of human health impacts). If nutrients to limit are included in the $\mathrm{nFU}$, Green et al. (2021) propose a method in which a bottom threshold of 1 is set to avoid negative impact scores. This undercuts the relative nutrient density of foods close to 1 ; however, with the nLCA the interpretation phase is critical and a score of 1 means that foods receive no benefit (i.e. the environmental score is not decreased with an $\mathrm{nFU}$ ) because the food is so energy-dense (Green et al., 2021). In general, this method is best applied to identify hotspots (Green et al., 2021).

\section{Choice of reference amount for the calculation of nutritional quality}

Nutrient density scores can be calculated based on different reference amounts, typically $100 \mathrm{kcal}$ or $100 \mathrm{~g}$. Fulgoni, Keast and Drewnowski (2009) showed that the best performance as a measure of nutritional quality, against the healthy eating index, was calculated on the basis of $100 \mathrm{kcal}$. However, when using a nutrient index as an nFU in an nLCA, it does not matter whether the nutrition score is based on mass (e.g. per $100 \mathrm{~g}$ ) or energy (e.g. per $100 \mathrm{kcal}$ ) because emissions and nutrition content are calculated from the same amount of product and so the relation will always be the same (Saarinen et al., 2017). ${ }^{6}$

It is also worth noting that nutrients to encourage and limit are functionally distant from each other, so the method of calculation based on subtracting the score of nutrients to limit from the score of nutrients to encourage is questionable in the context of use in an FU. As an index of nutritional quality in nutrition education they work well, but the FU in an LCA must be both contextually and mathematically sensible and this has not yet been scientifically proven.

'In contrast, in the approach where nutritional and environmental impacts are assessed in parallel, different reference amounts can sometimes be used for the nutrient index and LCA. In this case, the choice of the reference amount for the nutrient index has a significant impact on the results of the joint nutrition and environmental impact assessment as Strid et al. (2021) showed. 


\section{Capping or not}

Capping refers to cutting off nutrient scores at 100 percent of daily recommended intake values. The highest score an index can receive is 100 . The primary reason for capping is to ensure that foods do not receive higher index scores because they have an excess of nutrients to encourage compared to an individual's RDI (if they provide more than 100 percent of RDI). Consuming nutrients in excess does not create additional health benefits and can be detrimental (Fern et al., 2015). However, the limit values for detrimental impacts are usually quite high. Capping would be justified if RDIs were the upper limit for intake of the nutrient or near it, because then there would be the risk of an excessive intake of the nutrient (Saarinen et al., 2017). Normally, RDI is the lowest recommended intake and far from an amount that would be harmful to health. The rationale for capping at the food item level is further diminished by the fact that nutrients in one food item can compensate for a lack of nutrients in other food items in the diet. In summary, based on current knowledge, the arguments for capping are not very strong at the product item level (Hallström et al., 2018) and so its possible application needs to be justified on a case-by-case basis. In particular, if the use of nutrient indices becomes more widespread, especially in consumer communications, non-capping may provide an incentive for the food industry to unnecessarily supplement food products with nutrients (Arsenault et al., 2012), which may make it appropriate to consider introducing capping or restrictions on including supplements in the calculation of the nutrient index score.

\section{Weighting or not}

Most nutrient indices used in LCAs give the same weighting to all the nutrients they contain (Green et al., 2020), and to the nutrient index and the environmental impacts (Hallström et al., 2018). There have been some attempts in the literature to develop weighted indices and related weighting methods based on relationships between nutrients and health outcomes (Arsenault et al., 2012). However, there is no scientific consensus on a method to give different weightings to (some of the) nutrients, or even on the basis of weighting la specific nutrient deficiency or excess in the diet, bioavailability, or caloric density/ energy). Further research is needed, including on how weighting could be applied when using the food group-specific approach.

Energy standardization is frequently used as a type of weighting. Food items have different caloric densities and can be standardized to energy content to make them more comparable (Green et al., 2021). Some indices choose to standardize against energy content while others do not. Energy standardization, and the point at which it is applied, influences nutrient index scores and the nLCA results based on them (Green et al., 2021) but the issue has so far received little attention in the literature.

\subsection{Functional unit options in relation to the goal(s) of a nutritional life cycle assessment}

According to the ISO LCA standards, the goal of an LCA study is defined in the goal and scope definition and states the reasons for carrying out the study, the intended application, the intended audience (to whom the results are intended to be communicated), and whether the results are intended to be used in comparative assertions intended to be disclosed to the public. Thus, as discussed in Chapter 3, different food LCA study application areas have different goals, although simultaneously considering environmental impacts and nutrition/health aspects is a common feature of nLCA studies. Each application has its own perspective which influences the choice of FU and other methodological details. Table 13 provides an indicative list of the interest areas and related goals of food LCA studies, applications and potentially compatible FU options.

In summary, the nLCA is appropriate for many, but not all LCA applications (see also Chapter 3). 
In addition, an FU based on nutritional characteristics can be appropriate in many cases while in some it is better to use mass/volume or serving size as the basis of the FU and include nutrition in the impact assessment as a nutrition/health impact. Nutrition and health impact assessments may in principle also be performed with an $\mathrm{nFU}$, but there are no practical examples yet. Also, for broader applications such as sustainability science and policy making, it may be appropriate to use several methods in parallel to provide an overview. More research is needed to develop a better understanding of the suitability of different FUs for the wide range of situations where an nLCA can be used to support decision-making. 
Table 13: Interest areas and related goals of food LCA study applications, and potentially compatible FU options

\begin{tabular}{|c|c|c|c|}
\hline $\begin{array}{l}\text { Interest } \\
\text { field/ party }\end{array}$ & $\begin{array}{l}\text { Characteris- } \\
\text { tics/scale }\end{array}$ & LCA application/interest areas/goals & Possible types of FU in nLCA \\
\hline \multirow[t]{2}{*}{ Science } & \multirow{2}{*}{$\begin{array}{l}\text { - all scales } \\
\text { from produc- } \\
\text { tion-chain-wise } \\
\text { products to } \\
\text { global }\end{array}$} & $\begin{array}{l}\text { - knowledge on and understanding of envi- } \\
\text { ronmental impacts and wider sustainability }\end{array}$ & - different FUs and methodological approaches \\
\hline & & $\begin{array}{l}\text { - methodological development and valida- } \\
\text { tion }\end{array}$ & - as above \\
\hline \multirow[t]{3}{*}{$\begin{array}{l}\text { Policymaking/ } \\
\text { regulation, } \\
\text { governance, } \\
\text { policy }\end{array}$} & \multirow[t]{3}{*}{$\begin{array}{l}\text { national and } \\
\text { international } \\
\text { - governmental }\end{array}$} & $\begin{array}{l}\text { - societal development plans } \\
\text { - general and sectoral policy guidelines, } \\
\text { e.g. agricultural, food lincluding dietary } \\
\text { guidelines), environmental and climate } \\
\text { policy } \\
\text { - policy instruments targeted to produc- } \\
\text { tion chain actors or consumers (such as } \\
\text { taxes) }\end{array}$ & $\begin{array}{l}\text { - different FUs and methodological approaches: } \\
\text { - if guidance affects nutritional quality of food, mass- } \\
\text { based or serving size with health impact assessment } \\
\text { and/or nFU such as a product group specific or across } \\
\text { the board nutrient indices } \\
\text { - if guidance affects nutritional quality of food or con- } \\
\text { sumer nutrient intake, mass-based or serving size with } \\
\text { health impact assessment and/or nFU such as a product } \\
\text { group specific or across the board nutrient indices }\end{array}$ \\
\hline & & - product legislation & $\begin{array}{l}\text { - not known/nLCA not relevant/suitable method is } \\
\text { lacking }\end{array}$ \\
\hline & & - product labelling, e.g. EU PEF & $\begin{array}{l}\text { - nFU as above or a criteria-based label based on var- } \\
\text { ied information (currently EU PEF, or any labelling or } \\
\text { LCA initiatives, does not include nutritional aspects) }\end{array}$ \\
\hline \multirow[t]{4}{*}{$\begin{array}{l}\text { Consumption/ } \\
\text { consumers }\end{array}$} & \multirow{4}{*}{$\begin{array}{l}\text { - all scales } \\
\text { from produc- } \\
\text { tion-chain-wise } \\
\text { products to } \\
\text { global }\end{array}$} & $\begin{array}{l}\text { - general consumer education, food-based } \\
\text { dietary guidelines }\end{array}$ & $\begin{array}{l}\text { - mass-based or serving size with health impact } \\
\text { assessment and/or nFU as below }\end{array}$ \\
\hline & & - food selection & $\begin{array}{l}\text { - } \mathrm{nFU} \text { such as a product group specific or across the } \\
\text { board nutrient indices }\end{array}$ \\
\hline & & $\begin{array}{l}\text { - food package labelling, e.g. front of pack- } \\
\text { age labels }\end{array}$ & $\begin{array}{l}\text { - } \mathrm{nFU} \text { as above or a criteria-based label based on } \\
\text { varied information }\end{array}$ \\
\hline & & $\begin{array}{l}\text { - other tools, e.g. food basket/diet carbon } \\
\text { calculators }\end{array}$ & - any of the above depending on how the tool works \\
\hline \multirow[t]{3}{*}{ NGO } & \multirow[t]{3}{*}{$\begin{array}{l}\text { - national to } \\
\text { global }\end{array}$} & $\begin{array}{l}\text { - knowledge on and understanding of envi- } \\
\text { ronmental impacts and wider sustainability }\end{array}$ & - different FUs and methodological approaches \\
\hline & & $\begin{array}{l}\text { - general communication and consumer } \\
\text { education }\end{array}$ & $\begin{array}{l}\text { - mass-based or serving size with health impact as- } \\
\text { sessment and/or nFU such as a product group specific } \\
\text { or across the board nutrient indices }\end{array}$ \\
\hline & & - political lobbying & - as above \\
\hline \multirow{6}{*}{$\begin{array}{l}\text { Business/ } \\
\text { input industry, } \\
\text { farmers and } \\
\text { fisheries, food } \\
\text { and drink, } \\
\text { wholesalers and } \\
\text { suppliers, retail } \\
\text { and service }\end{array}$} & \multirow{6}{*}{$\begin{array}{l}\text { - from sectoral } \\
\text { to company- } \\
\text { and produc- } \\
\text { tion-chain-wise }\end{array}$} & - hot-spot identification & $\begin{array}{l}\text { - nLCA not relevant le.g. mass-based FU in traditional } \\
\text { LCA) }\end{array}$ \\
\hline & & - process improvements/optimization & $\begin{array}{l}\text { - not relevant unless includes raw material choices } \\
\text { that affect nutritional quality, then nFU such as a prod- } \\
\text { uct group-specific or across-the-board nutrient indices }\end{array}$ \\
\hline & & $\begin{array}{l}\text { - product performance (consumer phase as } \\
\text { scenarios) }\end{array}$ & - as above \\
\hline & & - product development & $\begin{array}{l}\text { - } \mathrm{nFU} \text { such as a product group-specific or across-the- } \\
\text { board nutrient indices }\end{array}$ \\
\hline & & $\begin{array}{l}\text {. market claims (environmental, not nutri- } \\
\text { tion/health) }\end{array}$ & $\begin{array}{l}\text { - } \mathrm{nFU} \text { such as a product group-specific or across-the- } \\
\text { board nutrient indices }\end{array}$ \\
\hline & & - product labelling & $\begin{array}{l}\text { - } \mathrm{nFU} \text { as above or a criteria-based label based on } \\
\text { varied information }\end{array}$ \\
\hline \multirow[t]{3}{*}{$\begin{array}{l}\text { Industry } \\
\text { organizations }\end{array}$} & \multirow[t]{3}{*}{$\begin{array}{l}\text { - national and } \\
\text { international }\end{array}$} & - product standards & $\begin{array}{l}\text { - not known/nLCA not relevant/suitable method is } \\
\text { lacking }\end{array}$ \\
\hline & & - product labelling & $\begin{array}{l}\text { - nFU such as a product group-specific or across-the- } \\
\text { board nutrient indices as above or a criteria-based } \\
\text { label based on varied information }\end{array}$ \\
\hline & & - political lobbying & $\begin{array}{l}\text { - Mass-based or serving size with health impact as- } \\
\text { sessment and/or nFU as above }\end{array}$ \\
\hline
\end{tabular}




\subsection{Towards best practice recommendations}

\subsubsection{Selecting a functional unit for a nutritional life cycle assessment}

The FU should be carefully chosen to be compatible with the goal and scope of a food LCA study, taking into account the reasons for conducting the study, the intended application and the audience. Figure 5 provides some guidance on selecting the FU. Although an $\mathrm{nFU}$ is often useful, nutrients do not have to be part of the FU in an nLCA study, as different functions of food items can be considered in an LCA study. However, for all nLCA studies the nutritional value of food items should be reported.

Figure 5: A decision tree for selecting the functional unit

Functional unit selection

(the basis for the comparison]

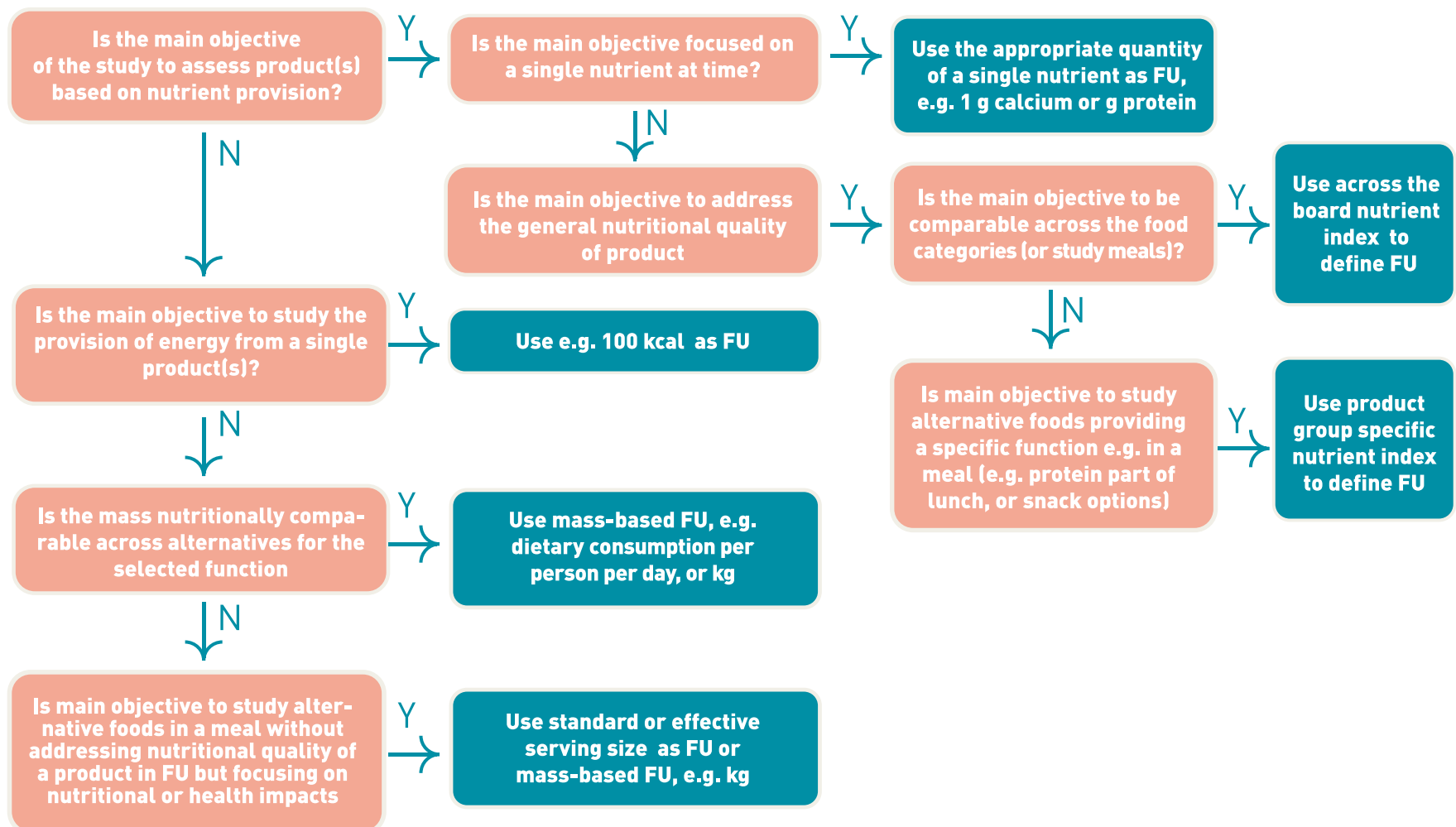

\subsubsection{Comparisons across food groups}

In general, comparisons between food items should be limited to those within the same food group, although it is possible to extend comparisons beyond by using a carefully defined FU (Box 11). In any case, it is important to base the comparison on a common function. In an nLCA, comparisons can be based on a common $\mathrm{nFU}$ or an $\mathrm{FU}$ coupled with a nutrition/health impact assessment. It is important in such cases that the nutritional value of these food items is stated and compared in the nLCA report. 


\section{BOX 11. FOOD GROUP-SPECIFIC OR ACROSS-THE-BOARD APPROACH IN DEFINING THE METHODOLOGY FOR AN $\mathrm{nLCA}$}

The question of food group specificity or coverage of all food items is related to: 1) the comparison between food items in general

From a practical point of view, it does not make sense to compare food items that are not intended for the same use or that do not provide the same functionality. The ISO LCA standards require that comparisons between product systems are made on the basis of the same function (as represented in the FU). The nLCA results describe the environmental impact of compared food items in terms of their shared functionality regardless of how efficiently the food items fulfil this function. For example, the climate impact of alternative food items may be assessed in terms of providing a particular amount of calcium that is specified in the nFU.

\section{2)the choice of whether to use a food-specific or across-the-board nutrient index in the nFU} Most nLCA studies that use nutrient profiling as the basis of the nFU currently apply an acrossthe-board approach - and the most commonly used nutrient indices belong to the NRF index family. They are intended to reflect the overall nutritional quality of any food item in relation to nutritional recommendations. They rank different foods as a source of nutrients in general. The food-group-specific approach, on the other hand, seeks to distinguish the importance of different food groups as sources of specific nutrients. The approach is still under development, but Saarinen et al. (2017) and McAuliffe, Takahashi and Lee (2018), for example, considered food items used as sources of protein within certain dietary contexts.

\subsubsection{Handling nutrients to limit}

Nutrients to limit affect nutritional quality and consequently the nutrition/health impacts of food items. They should be addressed in the nLCA. However, these nutrients should be treated with care in defining an nFU. Based on the current knowledge, it may be better to assess nutrients to limit in the impact assessment as part of the broader nutritional impact assessment or by using a separate index of nutrients to limit. When using a nutrient index based on both nutrients to encourage and to limit, the way that nutrients to limit are handled can yield negative scores. Further research on this aspect is needed. Some proposals have recently been presented - but are not yet established - on methods in which indices are adapted to be used in the nFU (Box 12).

\section{BOX 12. SOLVING THE NEGATIVE SCORE PROBLEM OF COMMONLY USED NUTRIENT INDICES.}

Commonly used nutrient indices in nutritional education (e.g. NRF9-3) that assess both nutrients to encourage and to limit often confer negative values, particularly for food items that are in edible form for consumption (prepared). This is problematic for use as an FU in an nLCA. In these nutrient indices, an average portion of nutrients to limit from the daily allowance is subtracted from an average portion of nutrients to encourage from the recommended daily intake. When the scores of the subset of nutrients to limit are higher than those of the nutrients to encourage, the overall score is negative. The amount of a nutrient to limit is compared with the daily upper value; however, below this value the nutrient is within the limit of the recommendations and thus is not necessarily regarded as detrimental.

Green et al. (2021) suggest a threshold method through where the risk of negative scores is eliminated as explained in Section 6.3.2.4.

Another way to deal with nutrients to limit is to evaluate them separately, for example through a separate limited-nutrients index (Saarinen et al., 2017) or as part of a human health impact assessment (Chapter 7). 


\subsubsection{Nutrient indices as a nutrition-based functional unit}

When the nutritional function of a food item is being studied with a focus on several nutrients, it may be appropriate to use a nutrient index score as an nFU; however, it should be used with care because the approach is still evolving. The benefit of including nutritional quality in an $\mathrm{nFU}$ is the fact that environmental impacts can be expressed in relation to (at least partially to) nutritional quality. However, there are many issues associated with nutrient indices that need to be addressed, justified and discussed transparently in an nLCA report. These include, in addition to the previously mentioned issues of managing nutrients to limit and food group coverage, a basis for selecting the nutrients, possible energy standardization, weighting and capping. Energy standardization may be used to make food items more comparable in relation to caloric values and nutrient densities, particularly in acrossthe-board assessments, if applicable in the study. However, weighting and capping require further research before any recommendation can be made about their use. In general, the validity of using nutrient indices in defining FUs should be investigated further in LCA studies, as they have been developed so far for application in nutrition science and education.

\subsubsection{Other recommendations}

- Clearly identify the target audience in the goal and scope and use an FU that is justified on the basis of the needs of the target population and the goal of the study because different population segments have different needs and priorities.

- According to the standardized LCA methodology, comparisons should only be performed across food items based on the same function as represented in the FU. Such functions are not limited to nutrients or serving sizes due to the diversity of reasons that people eat foods. However, an nLCA requires consideration of nutritional value as part of the analysis.

- Always declare the mass/volume-based reference flow in addition to the FU lif the FU is not mass/ volume-based) to enable subsequent use in dietary studies and to facilitate the interpretation of the results.

- When a quantity (or quality-corrected quantity) of nutrients to encourage are represented in the FU, quantities of nutrients to limit should be listed and/or assessed in the impact assessment.

- When nutrients to limit are the only basis for assessing nutrition/health impacts in the impact assessment, nutrients to encourage should be represented in the nFU.

- When only a selection of nutrients to encourage is represented in the $\mathrm{FU}$, the remaining nutrients to encourage may be addressed in the impact assessment.

- The limitations of an nFU or nutrition/health impact assessment method should be discussed when they are used. 


\section{Assessing environmental and human health impacts relevant to life cycle assessment of foods}

\subsection{Introduction}

The LCIA quantifies the environmental impacts due to the emissions and extraction of resources that are quantified during the inventory analysis phase of an LCA. It generally consists of several, or all, of the following steps (ISO, 2006a, 2006b, 2017):

- Classification - the emissions and resources are associated with different environmental impact categories (global warming, human toxicity, ecotoxicity, resource use, etc.).

- Midpoint characterization - characterizes and aggregates the emissions into midpoint impact categories.

- Damage (endpoint) characterization - a second natural science-based step that assesses the contribution of each midpoint impact category to damage at the level of a main area of protection (damage to human health, ecosystem quality, resources, etc.). The damage scores may be kept separate or aggregated for each area of protection.

- An additional normalization (e.g. using total world scores) or a weighting step may be carried out to show the contribution of the studied product relative to a reference value (e.g. global impact) in a given impact category and to weight these normalized scores to bring them in line with a comparable metric, or eventually a single score.

Verones et al. (2017) describe the latest LCIA framework established by the UNEP (United Nation Environment Programme)-SETAC (Society of Environmental Toxicology and Chemistry) Life Cycle Initiative. This chapter focuses on those impact categories that are particularly relevant to agricultural production and food preparation, looking first at climate change (Section 7.2) and water use (Section 7.3) as two main areas of concern. It then considers the food-relevant impact categories affecting two main areas of protection: a) biodiversity and ecosystem quality (Section 7.4 - land use, eutrophication impacts of fertilizers and ecotoxicity impacts of pesticides); and b) human health (Section 7.5 - the impact of fine particulates on human health, human toxicity and dietary impacts on humans associated with food consumption). This is followed by a section on ecosystem services as a third area of concern (Section 7.6). A final section addresses general impact categories to which food will also contribute as well as the increase in antimicrobial resistance, an emerging issue (Section 7.7).

This chapter provides a state-of-the art review of each food-related impact category, and its recommendations, mostly built on FAO recommendations (water) and the Life Cycle Initiative GLAM project that provides guidance for global LCIA methods. In particular, Section 7.5.4 summarizes the present status and provides recommendations on how to account for dietary impacts on human health, one of the dominant factors influencing the human burden of disease.

\subsection{Climate change/greenhouse gas impacts}

\subsubsection{Brief review}

GHG emissions are a long-standing concern, and in many cases the climate change impact of GHG emissions is the only component of a life cycle-based impact assessment that is assessed or reported las a carbon footprint). As public awareness of global warming has grown and policy developed to mitigate climate change, the methods used to estimate GHG emissions have become increasingly detailed, and the results of carbon footprints have been applied to an increasingly broad range of purposes. 
Globally, it is estimated that around one-third of annual anthropogenic GHG emissions las commonly aggregated using the 100-year Global Warming Potential, discussed below) result from food systems (Tubiello et al., 2021), and so food system emissions are an important policy concern. There is also significant attention on product-level emissions associated with food systems, with recent LCA review papers highlighting the significant variation in emissions across different types of foods and within the same products based on location and production methods (Clune, Crossin and Verghese, 2017; Poore and Nemecek, 2018).

Unsurprisingly, given the level of interest in using LCAs to assess climate impacts, there are wellestablished and continuously refined methods for estimating GHG emissions, as well as standard and widely used indicators for impact assessment. The key challenges relate to the level of detail and specificity that can be required for the most rigorous emission calculation methods, and to the appropriate selection and interpretation of impact indicators.

\subsubsection{Important issues in assessment of food items}

GHG emissions associated with food systems result from a number of processes across supply chains. The challenge of generating detailed emission estimates is not unique to food production, but the key roles of variability in biological processes and level of spatial specificity (particularly relevant for methane emissions from animal husbandry and for land-use related carbon fluxes, discussed further below) are particularly notable for the agricultural sector.

Life cycle inventory databases can often provide detailed emission estimates differentiated by production location and production details, or at least more generic emission estimates, for upstream activities such as fertilizer manufacture, and there are continuing initiatives to provide greater supply chain transparency and more complete data. However, at the primary agricultural production stage, simple models are generally used to estimate emissions directly rather than relying on inventory databases. More detailed models may be used for the most important emission sources (for example, to estimate methane emissions resulting from the enteric fermentation of ruminant livestock). There are standard guidelines for these calculations provided by the Intergovernmental Panel on Climate Change (IPCC, 2019a), with a tiered approach representing increasingly detailed methodologies for estimating emissions. Tier 1 is the least specific and simplest to compute, requiring only broad activity data le.g. at the level of animal species and high-versus low-intensity production systems). Tier 2 uses narrower livestock categories (potentially including, for example, animal age, sex and breed) and incorporates more detailed modelling of emission factors. A number of major global LCA studies and platforms use tier 2 methodologies, including FAO's recent interactive version of the Global Livestock Environmental Assessment Model (GLEAM-i - https://gleami.apps.fao.org). Tier 3 methods are generally countryspecific models that may take alternative, more specific approaches than the default IPCC guidelines, verified through peer-reviewed scientific research. Emissions should be estimated using as high a tier as feasible where the relevant data are available and where the methods have been shown to be appropriate for the system of interest.

There are several carbon calculators now available that simplify emission estimation, where end-users input the required data (numbers and types of livestock, fertilizer inputs) and the emission estimates are generated automatically. These emission estimates may be calculated either directly using the methods outlined above or by incorporating nationally/regionally specific emission factors derived from them. Given the level of detail required for the most accurate/precise emission estimates, however, even these tools can present a significant data input burden. Therefore, there is potential for more integrated agricultural assessment tools to reduce the level of individual/bespoke data input by users. 
A separate source of GHG emissions is deforestation and habitat loss. This results in significant carbon loss as the carbon in native biomass and soil carbon are emitted as $\mathrm{CO}_{2}$, and land transitions to agriculture with generally lower carbon stocks. As of 2019, land-use change emissions accounted for around 16 percent of the total anthropogenic $\mathrm{CO}_{2}$ (1.8 of 11.5 total Gt C. Friedlingstein et al., 2020). However, agricultural land use also has the potential to provide some carbon sequestration itself, through agronomic practices that increase carbon stocks (soil carbon) and/or land-sharing type practices (silvopasture). There is currently particular interest in the potential for increasing agricultural soil carbon to provide significant climate change mitigation. While there are ultimate biophysical limits as soil carbon levels reach saturation and gains may be reversed (Sykes et al., 2019), emerging agricultural practices such as the addition of biochar (Matuštík, Hnátková and Kočí, 2020) and enhanced weathering (addition of crushed silicate rocks, Beerling et al., 2018) may further increase the potential for soil carbon sequestration. There are established methods for estimating soil carbon stocks and flows, and FAO's Livestock Environmental Assessment and Performance (FAO LEAP) partnership has recently provided a guidance document (FAO, 2019d). But challenges remain in using consistent modelling approaches and standardizing LCA implementation (Bessou et al., 2020). Some have argued that the potential carbon sequestration that may be achieved by reducing agricultural land use (for example, by freeing land for afforestation or other carbon-sequestering activities) should be incorporated in environmental footprints as a carbon opportunity cost (Searchinger et al., 2018). Including opportunities foregone is outside the scope of attributional LCA, but the concept could instead be applied to explore land-use related carbon fluxes from a simple consequential perspective.

Land use also exerts climatic impacts beyond GHG fluxes, with biogeochemical and biogeophysical effects on climate, where effects may be predominantly local (transpiration of plants) or global (change in land surface albedo). While these may be significant, there is currently no standardized method for including them in life cycle inventories or impact assessments, with spatially and temporally specific information being required (Bright, 2015).

Once a GHG emission inventory is compiled, different gases are commonly converted to and/or aggregated as $\mathrm{CO}_{2}$ equivalents to provide an overall climate impact indicator across all gases. As noted above, choices must be made about which GHG emission metric(s) to use as a total climate impact indicator. This is discussed in Section 7.2.3.

\subsubsection{Impact assessment methods}

\section{Midpoint impact characterization}

Once a GHG emission inventory is compiled, a critical methodological issue relates to the indicators used to aggregate and/or compare different GHG emissions to report total climate change impacts, clearly defining the impact being compared and the time horizon over which it is assessed, which entails value judgments (IPCC, 2014). Different GHG emissions are typically reported as carbon dioxide equivalents $\left(\mathrm{CO}_{2} \mathrm{e}\right)$, whereby an emission quantity of a non- $\mathrm{CO}_{2}$ gas is scaled and described as an equivalent quantity of $\mathrm{CO}_{2}$. In the context of agricultural production, choices made here are particularly relevant because agriculture is a dominant source of anthropogenic methane $(\mathrm{CH} 4)$, accounting for around 50 percent of global annual emissions (Chang et al., 2019; Mbow et al., 2019; FAO, 2020c, Tubiello et al., 2021); and anthropogenic nitrous oxide $\left(\mathrm{N}_{2} \mathrm{O}\right)$, accounting for around 75 percent of global annual emissions (Mbow et al., 2019; FAO, 2020c, Tubiello et al., 2021).

The most commonly used and de facto standard emission metric is the 100-year Global Warming Potential, or $\mathrm{GWP}_{100}$. This metric is based on the radiative forcing (the change in atmospheric energy budget) resulting from an idealized pulse emission of a GHG, integrated over a 100-year 
period following the emission. Different gases are equated to $\mathrm{CO}_{2}$ on a per-mass basis. The $\mathrm{GWP}_{100}$ is the required metric in a number of LCA standards and is also used for certain policy purposes, such as emission reporting under the United Nations Framework Convention on Climate Change (UNFCCC). As different GHGs can vary significantly in their atmospheric lifetimes, their GWP valuation can change dramatically depending on the time horizon, with decreases in the valuation of relatively short-lived methane relative to more persistent $\mathrm{CO}_{2}$, when increasing the GWP time horizon.

Global warming potential is not the only means of comparing climate impacts. The second most common metric, the global temperature change potential (GTP), bases the comparison on temperature change resulting from an individual emission at the end of the time horizon used (i.e. the $\mathrm{GTP}_{100}$ is the temperature change occurring 100 years after an idealized pulse emission, relative to a mass-equivalent idealized pulse emission of $\mathrm{CO}_{2}$ ), rather than an integrated measure attempting to report impacts over all points within the time horizon. As LCA is fundamentally concerned with representing the entire cumulative impacts of a product or activity over all time periods, and not just impacts at a certain point, the GWP metric conceptually fits best with the LCIA framework. Other integrated emission metrics, such as the integrated GTP, may also be justified based on this reasoning. However, the GTP might be of interest when GWPs are not available for longer time horizons, as an available proxy for very long-term impacts on climate change.

To try and account for the variation in metrics and capture the differences across GHGs, the UNEP Life Cycle Initiative has recently provided guidance that climate change impacts should be reported as two complementary categories covering long-term impacts using the GTP 100 (recognizing that this is a proxy for $\mathrm{GWP}_{800}$ ), and shorter-term impacts, using the GWP ${ }_{100}$, with the $\mathrm{GWP}_{20}$ considered for sensitivity analysis of very short-term impacts (Jolliet et al. 2018). There continues to be a discussion of how best to handle temporal elements in LCA, and dynamic approaches and/or further elaboration of LCA choices have been suggested that may help communicate and resolve issues relating to GHG lifetime, but there are implementation challenges, and further development is required (Beloin-Saint-Pierre et al., 2020).

A further recommendation from the UNEP Life Cycle Initiative regarding climate impact indicators is to include climate-carbon (cc) feedbacks for all gases in emission metrics (Jolliet et al., 2018), as previous metric values had included cc feedbacks for $\mathrm{CO}_{2}$ but not other gases. The most recent (6th) IPCC Assessment Report (AR6) resolves this concern and includes cc feedbacks for all gases in the updated emission metrics it provides (Table 14). It is also worth noting that $\mathrm{CO}_{2}$ respired by livestock and the degradation of non-fossil $\mathrm{CH}_{4}$ into $\mathrm{CO}_{2}$ is not included in any standard emission accounting framework; this carbon has always come from atmospheric $\mathrm{CO}_{2}$ recently fixed as plant biomass and hence does not represent an addition to atmospheric $\mathrm{CO}_{2}$. 
Table 14: Global warming potential for a time horizon of 20 (GWP ${ }_{20}$ ) and 100 (GWP ${ }_{100}$ ) years and Global temperature potential 100 years $\left(\right.$ GTP $_{100}$ ) for the most relevant agricultural GHGs, as provided by the (6th) IPCC Assessment Report (AR6)

\begin{tabular}{|c|c|c|c|}
\hline & $\begin{array}{l}\mathrm{GWP}_{20} \\
\mathrm{kgCO}_{2} \mathrm{e} 20 \text { years }\end{array}$ & $\begin{array}{l}\mathrm{GWP}_{100} \\
\mathrm{Kg} \mathrm{CO}_{2} \text { e shorter term }\end{array}$ & $\begin{array}{l}\mathrm{GTP}_{100} \\
\mathrm{~kg} \mathrm{CO}_{2} \text { e long term }\end{array}$ \\
\hline $\mathrm{CH}_{4}$ (non-fossil) & 79.7 & 27.0 & 4.7 \\
\hline $\mathrm{CH}_{4}$ (fossil) & 82.5 & 29.8 & 7.5 \\
\hline $\mathrm{N}_{2} \mathrm{O}$ & 273 & 273 & 233 \\
\hline
\end{tabular}

Source: Forster et al., 2021

\section{Progress towards an endpoint damage assessment and novel indicator approaches}

There are several challenges in moving towards an endpoint damage assessment in the assessment of climate impacts in an LCA. As climate change is a global concern with multifaceted impacts, it exerts human, environmental and economic damage through multiple effects. There is considerable uncertainty in the damage functions, i.e. the relationship between climate change and resulting negative impacts, and there is potential for non-linear damage functions (Tol et al., 2012), with further research required to improve the climate-damage assessment across a range of impact pathways.

Nevertheless, within LCA, both the ReCiPe (https://www.rivm.nl/en/life-cycle-assessment-lca/recipe) and the IMPACT World+ (Bulle et al., 2019) LCIA methods calculate the endpoint damage of climate change on human health (in Disability Adjusted Life Years - DALYs) and on ecosystems (in Potentially Disappeared Fraction of species over a unit area and for a year - PDF $\mathrm{m}^{2} \mathrm{yr}$ ), based on de Schryver et al. (2009). This work is being updated and improved as part of the UNEP Life Cycle Initiative's work on global guidance for LCIA. Due to the lifetime differences between gases, as described above, these endpoint damage assessments still require a time horizon to be specified. IMPACT World+ (Bulle et al., 2019) solves - or rather avoids - the question of selecting or recommending a particular time horizon by reporting both the cumulative damages for the first 100 years, and the impacts between 100 and 500 years, that can then be potentially summed up. Rather than making an a priori choice of a time horizon, it enables the practitioner to interpret the results based on knowledge of the impacts over the different time-horizons provided. IMPACT World+ also follows the life cycle initiative recommendations to report both GWP $_{100}$ and GTP $_{100}$ as mid-point indicators.

In recent years, there has been a move towards setting overall temperature limits (Knutti et al., 2017) as a primary climate change policy objective, with a general assumption that most climate damages can be related to global mean temperature increase. Specified global temperatures can also be related directly to emission limits in a straightforward manner because cumulative emissions of $\mathrm{CO}_{2}$ show a direct linear relationship with their contribution to increasing temperatures. Staying under any temperature limits thus requires keeping cumulative total $\mathrm{CO}_{2}$ emissions within cumulative carbon budgets (Matthews et al., 2018). The GWP100 can also be used to include other relatively long-lived gases, such as nitrous oxide, in cumulative emission budgets. This approach, however, does not apply to individual methane emissions. Due to their short atmospheric lifetime, methane emissions do not exert cumulative impacts, with most of the temperature elevation resulting from a methane emission experienced over the first few decades post-emission and then automatically undone as the methane emission breaks down. One means of reporting methane emissions in $\mathrm{CO}_{2}$-equivalent terms that could reflect these differences is to use a dynamic application of the GTP, where the time horizon is determined by the anticipated date at which a predetermined temperature limit will occur. Using the 
time-dependent GTP as a climate impact indicator in this way would result in the carbon footprint of methane-dominated products (such as beef) scaling dramatically over time and increasing rapidly as the temperature threshold is approached. This could pose significant implementation challenges (Persson et al., 2015) but is consistent with valuing the role of methane emissions with respect to $\mathrm{CO}_{2}$ in terms of peak warming (Bowermen et al., 2013).

Alternative means of comparing short- and long-lived GHG emissions have recently emerged where, instead of taking individual emissions as the point of comparison, an indefinite emission flow lor change in emission rate) of short-lived gases is equated to individual emission pulses of long-lived gases (or, specifically, $\mathrm{CO}_{2}$ ). This is based on the relative dynamics of methane and $\mathrm{CO} 2$ (Lauder et al. 2013) and also expressed as emission metrics in GWP* (Allen et al. 2016; Cain et al., 2019) and the combined global warming potential (CGWP), or combined GTP (CGTP) (Collins et al., 2020).These steppulse metrics allow short-lived GHG emissions to be included in cumulative emission budgets, and can be linked directly to contributions to temperature change (Cain et al., 2019; Lynch et al., 2020). This also overcomes the need to use a predetermined time horizon into the future over which to compare impacts. Basing the comparison on changes in emission rates does, however, necessitate a dynamic perspective or assessment of an emissions scenario over time, rather than simple characterizing of individual emissions, posing challenges in applying it in the same manner in an attributional climate change impact assessment.

There remain, therefore, a number of potential methods to overcome time-horizon dependence and link greenhouse gas emissions to end-point impacts and/or specified policy targets Iglobal temperature limits), and different approaches may suit different objectives. Reporting the cumulative damages differentiated for different periods (first 100 years and longer term), or providing multiple indicators to describe the impact of emissions over different times las recommended by ReCiPe and IMPACT World+l, are the most straightforward means of reporting marginal impacts as commonly provided by an attributional LCA while still providing some dynamic insight; however, users are limited to the time horizons provided and cannot reliably infer impacts at different points within them. This limitation also prevents a reliable assessment of how a given set of emissions contribute to overall climate targets based on global temperature increase, where a more dynamic approach will be required. For these applications, users may prefer the dynamic GTP for a fully temporally resolved assessment of marginal contribution to global temperature change, or step-pulse metrics (GWP*, CGWP, CGTP) to assess global climate targets in terms of cumulative emissions budgets. These concerns are not unique to climate impact indicators, and there is wider discussion of the use and development of dynamic LCA methods (Beloin-Saint-Pierre et al., 2020). Nevertheless, the issue is perhaps especially salient for climate assessments, as damages and overarching policy objectives are predominantly understood and framed in terms of a global impact (specifically, temperature increase). Assessing a global temperature increase requires an understanding of the temporal evolution of individual emissions and cannot be derived using time-integrated indicators.

\subsubsection{Recommendations and further research needs}

We reiterate the UNEP Life Cycle Initiative recommendation that multiple complementary climate impact categories are reported: long-term impacts are reported with the GTP ${ }_{100}$ and shorter-term impacts using the $\mathrm{GWP}_{100}$, and sensitivity to very short-term impacts are explored using the $\mathrm{GWP}_{20}$ (Jolliet et al., 2018). In addition, at the endpoint damage level, overall cumulative impacts can be decomposed into impacts for different periods (methane will only have substantial impacts in the first 50 years, whereas $\mathrm{CO}_{2}$ and $\mathrm{N} 2 \mathrm{O}$ have impacts over longer periods). 
It should be recognized that the $\mathrm{GWP}_{100}$ remains the default metric and is used as the primary emission indicator for policy purposes such as the UNFCCC reporting. The recommendation for multiple metric reporting then provides insight into dynamic behaviours without requiring judgment over which to prefer, and the $\mathrm{GWP}_{20}, \mathrm{GWP}_{100}$ and GTP 100 largely cover the range of possible emission valuations that can be justified for different subjective or practical purposes. It is important to note that the multiple climate impact indicators should be reported together so that any potential trade-offs can be made apparent land not simply to present the worst-case metric to highlight concerns) (Balcombe et al., 2018). It should also be highlighted that these different indicators cannot be summed: the $G_{W} P_{20}$ and $\mathrm{GWP}_{100}$ are both integrated metrics capturing relative gas-specific scaling over time; the $\mathrm{GWP}_{100}$ also includes impacts over the first 20 years and attempting to sum with $G_{W} P_{20}$ would double-count this period. Meanwhile, the GTP ${ }_{100}$ provides fundamentally different information lor if considered a proxy for a very long-term GWP, has the same issue with double-counting earlier periods).

A range of alternative and emerging metrics may also prove useful for other purposes, including different LCA applications (e.g. consequential and dynamic LCA), or be used to address questions that employ LCA data but ultimately go beyond LCA methodologies (for example, environmental modelling and absolute sustainability assessment, Bjørn et al., 2020). Further research should continue to develop and identify potential applications of novel metric concepts (e.g. step-pulse equivalence) in LCA contexts.

For the clearest communication of GHG emissions, particularly for research purposes, individual GHG emissions should be reported separately, in addition to reporting using any aggregated climate impact indicator. This will allow assessments to be kept up to date as emission metrics are updated over time, and also retains the opportunity for researchers to explore alternative metrics or climate modelling approaches. This is not yet standard practice, and most agricultural LCAs in the scientific literature only report total GWP ${ }_{100} \mathrm{CO}_{2}$ e emissions (Lynch, 2019), from which it is not possible to work back to individual gases.

For land-use related climate impacts, FAO LEAP guidance (FAO, 2016a) recommends separate reporting of any land-use change related $\mathrm{CO}_{2}$ loss, and it would be advisable to maintain clear and separate reporting of any other land-use related carbon fluxes llosses or sequestrations, particularly soil sequestration) until there is greater standardization of land-use modelling methods and incorporation in LCA. Further development and standardization are also required before any non-GHG related climate effects of land use and/or land-use change can be included as standard. Similar consideration should also be given to land-use carbon opportunity costs and how or whether they should be included as standard in LCA.

\subsection{Water use impacts}

\subsubsection{Brief review}

Water is an extremely valuable and life-sustaining resource. However, many regions across the world experience water scarcity. Consideration of water use is especially relevant for the agriculture sector, as this sector is a major consumer of water (FAO, 2019d).

Allan (1998) considered water embodied in products through the virtual water concept he introduced. Building on that, Hoekstra et al. (2009) used the term water footprint as a volumetric water use indicator. However, early life cycle impact assessment methods initially did not consider water use 
as an impact category (Eco-indicator 99, CML 2001 and IMPACT 2002+) or only considered water use inventories without any impact assessment (ReCiPe, 2008). Frischknecht, Steiner and Jungbluth (2008) were the first to consider water use impacts in LCA through water scarcity in their Ecoscarcity method, but with a limited set of characterization factors. Soon afterwards, Pfister, Koehler and Hellweg (2009) developed a set of characterization factors assessing water scarcity at the global scale through a proxy midpoint indicator, which does not lie along an impact pathway, and endpoint impacts on three areas of protection (human health, ecosystem quality and resources). In 2014, an international standard on water footprints, building on the principles of LCA, was formalized by the ISO (ISO 14046). It clarified that different types and locations of water extraction should not be summed at the inventory level, and that a water footprint should go beyond water volumes and assess the potential impacts of water use.

Water can be categorized into blue, green and grey water (Hoekstra et al., 2009). Blue and green water are related to actual freshwater use, while grey water represents a hypothetical volume of freshwater needed to dilute water pollution. Since LCAs already consider water pollution in separate impact categories, such as freshwater eutrophication and freshwater ecotoxicity, grey water footprints are not used in an LCA to avoid double counting (Food SCP RT, 2013; Pfister et al., 2017). Green water includes soil moisture and is only accessible to plants at the respective location. It is an important water source in agriculture. However, only the net consumption is relevant for an environmental assessment in an LCA. The net green water consumption, i.e. the difference in evapotranspiration between the anthropogenic vegetation, such as cultivated crops, and the natural vegetation used as a reference, can even be negative, meaning that the crops require less green water than the natural vegetation would in a particular area (Núñez et al., 2013; Quinteiro et al., 2015). Therefore, less attention has been given to green water in LCA - but green water is still considered in some studies le.g. Lathuillière, Bulle and Johnson, 2019).

\subsubsection{Important issues in the assessment of food items}

Water use impacts in LCA typically focus on water that is withdrawn from surface or groundwater, differentiating between consumptive and non-consumptive uses. While early water scarcity indicators were based on water withdrawal (e.g. Pfister, Koehler and Hellweg, 2009), more recent versions are based on water consumption (e.g. Pfister and Bayer, 2014). Water withdrawal is a term used to refer to all the water extracted from a water body, of which a part might be returned to the environment. Water withdrawal is more commonly reported in statistics and is, therefore, easier to access. However, it does not represent the fact that some water may be returned, and does not differentiate water quantity and quality aspects, as any returned water might be degraded. Water consumption refers to the water withdrawn and not returned to the environment but is either lost to the atmosphere through evaporation or incorporated into the product. Water consumption is preferred as a basis for assessing the impacts of water use in LCA, as it isolates the water quantity aspect and facilitates assessment of its quality in separate impact categories (freshwater eutrophication, freshwater ecotoxicity).

The water use inventory of agricultural products is sometimes limited to irrigation, as it usually dominates the total water use. For livestock products, this implies that most of the water use comes from feed production. The Technical Advisory Group organized by FAO LEAP recommended considering all water use across the different life cycle stages (Boulay et al., 2021). This includes, for example, drinking and servicing water on livestock farms and water use for food processing and energy production, as these stages may also be relevant. 
Major LCl databases, such as ecoinvent, only cover a limited set of agricultural products and a limited set of regions. Regionalization in water related $\mathrm{LCl}$ and LCIA is crucial, as water demand and availability varies greatly across space (Kounina et al., 2013). Pfister et al. (2011) provide additional, simulated water consumption data for crop (and feed) production for 160 crops and 160 countries. With a focus on blue water, it makes a big difference if agriculture is rainfed or irrigated. However, it is not always known if irrigation takes place or not. Therefore, Pfister et al. (2011) provided two estimates, one assuming full irrigation and another considering areas known to be equipped for irrigation, as well as aggregated values considering both estimates (Pfister and Bayer, 2014). The type of water used for irrigation is also relevant, as reclaimed water used for irrigation would also reduce the pressure on freshwater resources. Although not distinguishing specific crops, Leão et al. (2018) provide the water supply mix of 93 countries for different water users, including as agricultural users irrigation, livestock, aquaculture (off-stream) and planted forestry.

The time of water withdrawal can also matter, especially when using naturally flowing rivers and lakes (the use of stored water or groundwater has impacts that are less sensitive to timing). Both water availability and demand vary throughout the year. Water availability reflects seasonal fluctuations in precipitation while, for example, irrigation water requirements depend on the growing seasons of specific crops. Annual water scarcity indices hide this variability and more often underestimate water scarcity. Therefore, more recent water scarcity indices are provided at a monthly scale le.g. Pfister and Bayer, 2014). If the time of water withdrawal is unknown, aggregated monthly water scarcity indices can be used, which are multiplied by the total monthly water consumption at the location.

\subsubsection{Impact assessment methods}

As mentioned above, Pfister, Koehler and Hellweg (2009) were the first to develop a set of characterization factors for freshwater use at both the midpoint and endpoint levels. Their water scarcity indices were based on the water withdrawal-to-availability ratio, which were later updated to use a water consumption-to-availability ratio (Pfister and Bayer, 2014). Water use led to human health impacts through a lack of water for agricultural production and associated malnutrition. Water use also led to impacts on terrestrial ecosystem quality where net primary production is limited by water availability. Finally, although water is renewable, it can also be depleted, thereby affecting resources. This aspect of water use was assessed through the surplus energy needed for a backup technology where seawater desalination would be applied to compensate for resource depletion (Pfister, Koehler and Hellweg, 2009).

Multiple additional methods at the midpoint and endpoint levels have been developed subsequently, as reviewed by Kounina et al. (2013) and listed in Annex 6 of the FAO LEAP guidelines on water use assessment (FAO, 2019d), with continued development of further methods. Some of these methods offer alternative water scarcity indices as proxy midpoint indicators, and others offer complementary pathways to areas of protection. An example of a more recently developed water scarcity index is the Available WAter REmaining (AWARE) method developed by Boulay et al. (2018) in a consensus-building effort as part of the UNEP Life Cycle Initiative (Boulay et al., 2015). It is based on the basin's water availability remaining after having met human and ecosystem water demands per area relative to the world average.

The UNEP Life Cycle Initiative working group also recommended a method for water use impacts on human health. Compared to the method proposed by Pfister, Koehler and Hellweg (2009), this method also follows the pathway through malnutrition, but additionally considers international trade 
effects that affect the adaptation capacity (Motoshita et al., 2014). However, caution is advised when interpreting the results for food systems, as they at least partly reduce malnutrition (Jolliet et al., 2018). A complementary pathway to human health impacts is through domestic water use and the spread of diseases (Boulay et al., 2011).

For the other areas of protection, there are also alternative pathways, but none is consensus-based and recommended yet. Complementary pathways to ecosystem quality impacts are through the species-discharge relationship (Hanafiah et al., 2011; Tendall et al., 2014) or habitat change (Damiani et al., 2021) affecting freshwater species. For resources, Milà i Canals et al. (2009) focus on groundwater resources and assess its depletion through the abiotic depletion potential, as used for other abiotic resources (minerals and fossil fuels), with antimony $(\mathrm{Sb})$ as the reference resource.

For green water use, Quinteiro et al. (2018) developed scarcity indicators. As for blue water scarcity, they are spatially explicit and provide global coverage. They considered two types of impacts: either on blue water availability or on moisture recycling within a basin. These impacts can be assessed through two separate indicators or one aggregated indicator.

FAO LEAP has also extensively discussed how to assess water use in livestock systems. Three scientific networks were involved: the UNEP Life Cycle Initiative, the Water Footprint Network and the Water Productivity community. The three communities agreed that blue scarcity water footprint assessment needs to use at least two methods, namely AWARE and the Blue Water Scarcity Index lor an alternative method from Appendix 6 of the FAO LEAP guidelines on water use assessment, or from the literature). Should an alternative method be chosen, the deviation is to be justified with reasoning (FAO, 2019). Further to developing the FAO LEAP guidelines (2019), a literature review of livestock water productivity studies was conducted. Among others, it was acknowledged that classifying water flows into blue and green can be omitted in water productivity studies, while it remains a requirement for blue water scarcity footprint assessments (Drastig et al., 2021).

\subsubsection{Recommendations and further research needs}

We advise following the recommendations of the UNEP Life Cycle Initiative and FAO LEAP, where relevant. They recommend applying AWARE and a second method, such as the Blue Water Scarcity Index, for water scarcity assessments (relating water use to availability) at the midpoint level of the cause-effect chain. At the endpoint level, the UNEP Life Cycle Initiative recommends a revised version of the method by Motoshita et al. (2014) for human health impacts (Jolliet et al., 2018). While the impacts of blue water use are more commonly assessed, ideally, practitioners also assess the impacts of green water use and report them separately.

For further research, the method for human health impacts is being revised in the current phase of the UNEP Life Cycle Initiative, which will lead to an updated recommendation. The UNEP Life Cycle Initiative task forces are also working on an improved method for ecosystem quality impacts as another endpoint. Until it becomes available, the method by Hanafiah et al. (2011) can be used, although it does not provide full global coverage. Likewise, other members of the UNEP Life Cycle Initiative are working on a recommendation for water use impacts on natural resources as an endpoint, building on the framework by Pradinaud et al. (2019). Until then, the method for resource depletion developed by Pfister, Koehler and Hellweg (2009) can be used.

For transparency, both the water use inventory - including the location of its extraction - and the water use impact assessment results should be reported. Such transparent reporting has multiple benefits. 
First, the practitioner can verify, based on the water use inventory, if there is room for improving the water use efficiency to reduce impacts. Second, impact assessment results can differ based on the choice of characterization model; therefore, reporting the water use inventory enables others to subsequently use the same inventory data coupled with a different characterization model. It is also best to use a second characterization model to test the robustness of the results, as recommended by FAO LEAP for blue water scarcity assessments (FAO, 2019).

The further development of water-related characterization models depends on the data available in global hydrological models. Such models are uncertain, and this uncertainty propagates to the characterization models and their water scarcity indices (Scherer and Pfister, 2016). Furthermore, climate change and growing populations with different consumption patterns drive changes in water availability and scarcity over time. It also affects the water supply mix (Leão et al., 2019). Consequently, inventory data and characterization models require regular updates.

Following the development of volumetric water use indicators and water scarcity indicators, Núñez et al. (2018) advocate for a third generation of water use indicators. Many water scarcity indicators consider watersheds as a single water compartment or possibly distinguish water from surface water bodies and aquifers but without connections between the two. Núñez et al. (2018) recommend considering multiple water compartments, most importantly including also soils, and the flows between such compartments and regions. Additionally, they recommend assessing impacts at the endpoint las is sometimes already done, as previously noted), but following a mechanistic characterization factor structure that accounts for multiple steps along the cause-effect chain through fate, exposure or sensitivity, effect, and damage factors. Water use impact indicators of this third generation are not yet operational. Further research is required to develop new indicators and the use of case studies to test their applicability in practice (Núñez et al., 2018).

\subsection{Biodiversity impacts associated with land use, fertilizers (eutrophication) and pesticides (ecotoxicity)}

\subsubsection{Biodiversity impacts associated with land use}

\section{Brief review}

Agriculture is among the sectors with the highest impact on biodiversity. Around 38 percent of global land surface is used for agricultural purposes (FAO, 2020a), which causes natural habitat loss and degradation and, consequently, biodiversity loss at local, regional, and global scale. While preventing global biodiversity loss (permanent extinctions) is imperative for preserving the Earth's tree of life, biodiversity loss at the local (farm-level) and regional (species extirpations) scale can jeopardize the ecosystem services in the region. Earlier land use-driven biodiversity assessment methods such as ReCiPe (Goedkoop et al., 2008) were based on local characterization factors derived from plotscale field surveys by dividing the number of species of vascular plants found at a human-modified site (cropland) with those at the reference (natural, undisturbed) site of the same region (often Europe). De Baan, Alkemade and Koellner (2013) expanded this approach and provided local characterization factors specific to 14 biomes and for other taxonomic groups. They later provided regional and global characterization factors for broad land use types (managed forests, urban, agriculture and pasture) per terrestrial ecoregions using a species-area relationship (SAR) model (de Baan et al. 2013). Chaudhary et al. (2015) updated these characterization factors, representing potential species loss per $\mathrm{m}^{2}$ of different land use types in different ecoregions using improved input data and adopting a countryside SAR model. 
Important issues in assessment of food items

Several crucial issues determine the impact of agricultural land use on biodiversity. These include: the exact geographical location of land use (tropical, temperate); its management intensity level lannual crops, permanent crops, permanent pastures); level of land fragmentation; the pre-human potential natural vegetation and the original biodiversity that existed before the land was converted for agriculture; the ability of existing species in the region to live in the modified (agricultural) settings; the land use matrix surrounding the agricultural farm; and on-farm measures for biodiversity conservation (buffer zones, number of trees).

\section{Impact assessment methods}

Many methods have been proposed that quantify the agricultural land use-driven biodiversity impacts (Curran et al., 2016; Woods et al. 2018). Example indicators include: changes in species abundance (Alkemade et al., 2013), functional diversity (Maia de Souza et al. 2013, Scherer et al., 2020), phylogenetic diversity (Chaudhary, Pourfaraj and Mooers, 2018; Chaudhary and Mooers, 2018), species composition/ biodiversity intactness (Newbold et al. 2015), species threats (Lenzen et al., 2012; Mair et al., 2021), local species richness (de Baan, Alkemade and Koellner 2013), and regional/global species richness (Chaudhary and Brooks, 2018; Kuipers, May and Verones, 2021).

In the UNEP Life Cycle Initiative, all existing LCA methods were reviewed, and a revised version of the land occupation and land transformation characterization factors (CFs) calculated by Chaudhary et al. (2015) was interim recommended for use in LCA within an earlier phase of the initiative (UNEP, 2017). These CFs were also adopted by the recently launched LC-Impact methodology for assessing land use impacts on biodiversity (Verones et al., 2020). These CFs represent potential species loss (PSL) per $\mathrm{m}^{2}$ for five taxa (mammals, birds, amphibians, reptiles, and plants) caused by a unit area of six different land use types lannual crops, permanent crops, pasture, intensive forestry, extensive forestry, and urban land) in the 804 terrestrial ecoregions. These CFs were calculated by combining the countryside species-area relationship model with the vulnerability score $(0<\mathrm{VS}<1)$ of the species group that represents species' International Union for Conservation of Nature (IUCN) status and their endemicity. The countryside species-area relationship model quantifies changes in species richness because of the loss or degradation of natural habitat and takes into account the ability of species to live in both altered and natural habitats (Pereira, Ziv and Miranda, 2014).

Chaudhary and Brooks (2018) then addressed several limitations of the above old CFs calculated by Chaudhary et al. (2015). They provided updated CFs per ecoregion for five broad land use types (managed forests, plantations, pasture, cropland and urban) under three management intensities (minimal, light and intense use). Unlike a limited number of local site-comparison data from literature used in the old CFs, they used the IUCN Habitat Classification database (IUCN, 2015) to derive the affinity (habitat preference) of individual species to different human land use types. This reduced the uncertainty intervals around the CFs and resulted in more accurate CFs compared to the old CFs. This was demonstrated by their validation exercise where the model predicting species loss using the new CFs came out closer to the documented (observed) number of species threatened with extinction on the IUCN Red List compared with the case when the old CFs were used.

Note that using the taxa-specific CFs (in PSL/m²), one can also calculate the CFs for each land use type aggregated across five taxa in the units potentially disappeared fraction $\left(\mathrm{PDF} / \mathrm{m}^{2}\right)$ by different weighting schemes of their choice (see Verones et al., 2015). The taxa-aggregated CFs provided in the 
supplementary materials provided by Chaudhary and Brooks (2018) adopt one out of the many available value choices (weighting schemes) and use the median of all 804 values of vulnerability scores per taxon as the weighting factor. However, this might not be compatible with the weighting choice used in previous LCA methods such as LC-Impact where a different weighting choice was used. The user should, therefore, be careful while applying taxa-aggregated CFs to their case study and ensure such compatibility across impact categories (such as water use) and other methods.

A more recent method (Kuipers, May and Verones, 2021) considered habitat fragmentation but disregarded land use intensities. They provide marginal and average characterization factors and cover four animal vertebrate taxa but not plants. Instead of vulnerability scores, they consider global extinction probabilities, which build on a similar concept but are implemented such that they globally sum to 1. In the GLAM project, such global extinction probabilities are foreseen to be recommended for scaling local/regional to global species loss. However, further development of the method for use in LCA is required, including carrying out validation against documented threatened species per ecoregion, extending the coverage of land intensity and ecoregions, including more taxonomic groups (such as plants) and providing uncertainty ranges.

\section{Recommendations and further research needs}

The UNEP Life Cycle Initiative and FAO LEAP have recommended the use of CFs by Chaudhary and Brooks (2018) for assessing land use impacts of food systems and identifying hot spots (UNEP, 2017; FAO, 2020d]. We also recommend using these factors at present and suggest that they should be updated in future to address additional aspects. Future studies should attempt to include further land use classes (annual crops, permanent crops, organic farms). New global high-resolution, harmonized, and validated land use maps with more land use and intensity classes are needed to reduce the uncertainty in characterization factors. More field effort is needed to enable the calculation of CFs for other species groups (invertebrates, fungil as well as to help expand the IUCN habitat classification database to include more land use classes differentiated by management intensity levels so that more accurate species affinities to human land use can be calculated. Developing more sophisticated methods for use in an LCA that account for habitat fragmentation, global extinction probabilities (Kuipers, May and Verones, 2021; Larrey-Lassalle et al., 2018) and land-use intensity (Chaudhary and Brooks, 2018), alongside additional indicators of biodiversity loss (functional, phylogenetic), represent important future research topics. The choice of reference state has also important implications on LCA results and it should be clearly reported and discussed.

\subsubsection{Biodiversity impacts associated with eutrophication or fertilizers}

Brief review

Eutrophication refers to the process in which freshwater, marine and terrestrial systems receive surplus amounts of nutrients (typically nitrogen or phosphorus), leading to the excessive growth of plants and algae and, therefore, to alterations in species composition, biomass or productivity. In the case of agricultural systems, the application of fertilizers is the source of these nutrients. Eutrophication does occur naturally, but anthropogenic emissions of nutrients and organic matter have generally interfered with the natural cycling of nutrients. Coupled with changes in hydrologic regimes Igenerally resulting in longer residence times in water bodies), human activity leads to conditions favourable for eutrophication and harmful algal blooms (Paerl and Barnard, 2020). These perturbations of natural cycles have been identified as high risk in the context of planetary boundaries (Bouwman, Beusen and Billen, 2009; Steffen et al., 2015). 
The response of terrestrial ecosystems to nutrient supply was documented in the mid-nineteenth century (von Liebig, 1855). Freshwater responses to nutrients, based on changes in appearance and macroinvertebrates, were documented in the early twentieth century (Weber, 1907). As anthropogenic nutrient loading increased and the occurrence of oxygen-limited dead zones increased, concern about eutrophication intensified in the middle of the last century (MEA, 2005a; Tilman, 1999; Vitousek et al., 1997). There was uncertainty about the causes of aquatic eutrophication into the 1960s, with a variety of substances, including $P$ and $N$, carbon, vitamins, amino acids and trace elements identified as possible causes (NAS, 1969). Experiments in temperate, freshwater lakes identified $P$ as a limiting nutrient (Carpenter et al., 1998; Schindler, 1977), and there was a general understanding that freshwaters were limited by $\mathrm{P}$, and marine systems by $N$ (Jørgensen and Richardson, 1996). The idea of a limiting nutrient is drawn from the Redfield ratio concept, based on a global analysis that set stoichiometric requirements for carbon, hydrogen, oxygen, nitrogen and phosphorus in biomass (Redfield, 1958); nitrogen $(N)$ and phosphorus $(P)$ are often less available than carbon, hydrogen and oxygen. For example, if freshwaters are P-limited, then additional $\mathrm{N}$ will not cause eutrophication. However, both systems are complex, and $\mathrm{P}, \mathrm{N}$, iron and trace elements may limit planktonic growth, with the limiting paradigm changing seasonally and spatially (Conley et al., 2009; Grouzet et al., 2000; Schindler, 2006; Sterner, 2008).

LCIA methods initially focused on site-generic biomass production potential, based on the Redfield ratio (Udo de Haes et al., 2002). The Environmental Design of Industrial Products 2003 method introduced spatially explicit fate modelling (in Europe) for $N$ and P (Hauschild and Potting, 2005). Effect models have recently incorporated spatial differentiation in impact on species occurrence, rather than biomass production (Azevedo et al., 2013). Henderson (2015) provides an overview of these LCIA developments. Recently, the UNEP Life Cycle Initiative created consensus recommendations for eutrophication models, recommending models with global coverage and spatial differentiation in fate and effect (Payen et al., 2019).

\section{Important issues in assessment of food items}

In the impact assessment of agricultural systems, there are challenges for both the inventory (LCI) and impact assessment (LCIA) phases. The assessment is further complicated because different methods may treat the agricultural field itself as part of the technosphere (the human/agricultural or industrial system) or the ecosphere (the environmental system).

Inventory Analysis

The agricultural field itself is a complex system, and often the inventory data is limited to the mass of fertilizer applied, sometimes without information about the nutrient content of these fertilizers. As an additional complicating factor, historical phosphorus inputs may be the main driver for current phosphorus emissions (Sabo et al., 2021). Taking this into account, the UNEP Life Cycle Initiative (Payen et al., 2019) recommends a tiered approach to addressing eutrophication impacts from the application of agricultural fertilizers:

- The least detailed approach is to assume a default emission fraction defined as 10 percent of applied nutrients leaving the agricultural field and reaching receiving waters. This assumption is used in LC-Impact (Verones et al., 2020) and ReCiPe 2016 (Huijbregts et al., 2017), which refers to the work of Bouwman, Beusen and Billen (2009), which itself is based on the NEWS2 models (Seitzinger et al., 2010).

- A more detailed approach is based on FAO (2017), which provides guidelines to estimate inventory, 
accounting for a number of interacting flows for nutrients including both inputs (from atmospheric deposition, biological nitrogen fixation, phosphorus from weathering, irrigation water, synthetic or organic fertilizer) and outputs (from biomass harvest, volatilization, denitrification, burning of residues, soil erosion, leaching, runoff).

- The most detailed approach requires field-specific modelling, using nutrient cycling models and/ or soil models, such as a Universal Soil Loss Equation approach (Scherer and Pfister, 2015).

For agriculture, nutrient surpluses are a major challenge, and may be encouraged by intensification that appears efficient from an environmental footprint (environmental intensity of production) perspective. Some authors have argued that area-based functional units should be used alongside product-based functional units for farming systems to reflect such pressures (Salou et al., 2017).

Impact Assessment

The fate and effect models recommended by the Global Life Cycle Impact Assessment Method (GLAM, 2020) project of the UNEP Life Cycle Initiative incorporate spatial modelling, which allows for differentiation between points of emission. However, temporal (seasonality), co-limitation, and nitrate transport in groundwater aspects have not yet been captured well in LCIA fate modelling. Regarding effects, there are ongoing efforts in the GLAM project to better connect nutrient exposure to species changes.

As eutrophication CFs show strong spatial gradients, country averages may not represent local conditions (Payen et al., forthcoming) and so it is critical to differentiate the location of eutrophication emissions and impacts. Several impact methods use the spatially differentiated phosphorus model (Helmes et al., 2012) and nitrogen models (Cosme and Hauschild, 2017) recommended by the UNEP Life Cycle Initiative (Payen et al., 2019): IMPACT World+ (Bulle et al., 2019), LC-Impact (Verones et al., 2020), and ReCiPe 2016 (Huijbregts et al., 2017).

None of these methods has yet included the pathway of atmospheric nitrogen emissions to marine eutrophication, although these factors are available (Payen et al., forthcoming). Also, with respect to resource depletion, the use of phosphorus should be assessed in the context of the limited global supply of phosphorus ore.

Recommendations and further research needs

Consistent with the recommendations of the UNEP Life Cycle Initiative (Payen et al., 2019), we highlight the following points:

- The complex processes occurring at field scale can affect the release of fertilizer nutrients from the field to the surrounding areas. Therefore, practitioners should work to improve inventory data through the use of field scale modelling when possible.

- The global, spatially explicit models identified above should be used for assessing the fate and impacts of emissions.

In addition, future impact models can be refined in terms of spatial resolution and hydrological data, but conceptual changes are needed as well:

- The current limiting nutrient paradigm of LCIA is itself limited. Modelling of phosphorus, nitrogen and possibly other contaminants (such as silica) should be conducted in parallel, and current 
conditions should be considered, in order to reflect the possibility of co-limitation.

- Biological oxygen demand and chemical oxygen demand are commonly reported inventory metrics. The eutrophication impact of these compounds is modelled generically at present, but their fate and impact should be included (in a way that avoids double counting the nutrients in these compounds). - Effect factors should be based on existing concentrations of relevant nutrients when possible and be made compatible with the species vulnerability approach of Kuipers, Hellweg, S., Verones (2019) on global extinction probability.

\subsubsection{Biodiversity impacts associated with ecotoxicity or pesticides}

\section{Brief review}

Concern about pesticides or other toxic substances, and their distribution in different environmental compartments, is long-standing. Many organic pesticides are amenable to treatment in multimedia fugacity models (Mackay, 1979), and such models were incorporated into early LCIA methods, such as CalTOX (McKone, 1993) and the Uniform System for the Evaluation of Substances (Guinée et al., 1996). These models and others were part of the consensus-building effort that created the LCA model USEtox (Hauschild et al., 2008; Rosenbaum et al., 2008), which continues to be updated, for example, through the addition of environmental compartments such as freshwater sediments, and region-specific parametrizations for various subcontinents. USEtox is now incorporated into many LCIA methods.

Despite the utility of multimedia models, the fate of pesticides in the environment is complex and is challenging to model in an LCA. A 2013 workshop to identify key issues related to pesticides addressed the boundary between inventory and impact modelling; it provided guidance on spatial and temporal considerations, and components of fate needed for emission impacts (runoff, leaching, drainage systems, etc.) (Rosenbaum et al., 2015). The requirements for inventory datasets to appropriately capture pesticide applications are numerous: the mass of active ingredients, the crops to which they are applied, the method of application, the timing between application-growth-harvest, and the presence of buffer zones, and the status of the agricultural field as part of the ecosphere or the technosphere (Rosenbaum et al., 2015).

The fate, and thus impact, of pesticides is affected by the application method and other factors. There have been efforts to develop models that predict the distribution of pesticides and environmental compartments based on the application method, timing, etc. While it has been common practice to assume that all pesticide application to a field is applied directly to the soil, modelling using PestLCl 2.0 shows this is likely a mischaracterization and that local climate and soil conditions can affect fractions to receiving compartments (Dijkman, Birkved and Hauschild, 2012). For example, in the case of 2,4-D applied to corn, standard databases such as ecoinvent and the USDA digital commons assume 100 percent emission to soil; the US LCl assumes 96 percent to air (and 4 percent to surface water); and PestLCl 2.0 calculates that 98.7 percent is degraded or incorporated into plants (Rosenbaum et al., 2015). A study of pesticide application in the midwest area of the United States of America, using PestLCl modified for conditions in the United States of America (Birkved and Hauschild, 2006) and USEtox (Rosenbaum et al., 2008), showed that fate and inherent toxicity drive most of the differences among pesticides (five orders of magnitude); application timing, soil properties and climate can lead to differences of up to two orders of magnitude (Xue et al., 2015). Clearly, this range of possible outcomes presents challenges for LCIA.

Currently, USEtox characterization factors are mostly available for freshwater ecotoxicity and more research is needed to provide reliable data for terrestrial and marine ecotoxicity. 
Important issues in the assessment of food items

As noted above, there are many factors that influence the fate of a pesticide emission. An ongoing challenge for LCA is to adequately capture these factors, both in the inventory and in the impact assessment. For example, recent studies have emphasized the differences between temperate and tropical applications due to differences in climate, soils and microbial activity (Gentil et al., 2020; Gentil-Sergent et al., 2021). PestLCI can inform such inventory, but it is restricted to a European context (Dijkman, Birkved and Hauschild, 2012), although it can be modified for other climates and soil types (Xue et al., 2015). Other research has built upon PestLCl; for example, PestTox adds washoff, photodegradation and mortality rates to the distribution calculations (Felix, Holst and Sharp, 2019).

\section{Impact assessment methods}

Most inventory databases still make coarse assumptions about the application of pesticides to agricultural fields. Therefore, practitioners should be careful to understand the nature of $\mathrm{LCl}$ data, and, if possible, supplement it with distribution modelling, as described in Section 7.4.3.4. Most LCIA methods have incorporated the USEtox model into their toxicity fate and effect modelling. Therefore, there are not strong differentiators among LCIA methods, although there is need for future improvements.

\section{Recommendations and further research needs}

Where possible, following the recommendations of Rosenbaum et al. (2015), inventory data should specify the mass of active ingredients, the crops to which they are applied, the method of application, the timing between application-growth-harvest, and the presence of buffer zones, etc. If inventory databases can be supplemented by a distribution model, such as PestLCI 2.0 (Dijkman, Birkved and Hauschild, 2012), then this is recommended, using the updated version based on Rosenbaum et al. (2015): "Consensus Pesticide Emission Model for LCA" (see DTU, 2021). For fate and effect, the USEtox model is recommended.

The UNEP Life Cycle Initiative consensus effort recently addressed the state of ecotoxicity modelling, making several recommendations that remain to be implemented broadly in LCIA methods (Frischknecht and Jolliet, 2019). The ecotoxicity recommendations that apply to pesticides include the following:

- to incorporate coastal seawater, freshwater sediment, and soil compartments;

- to exclude biotic removal from exposure factors;

- to use liquid-phase speciation for metals, and free ion activity models; and

- to set working points for SSD curves at relevant concentrations (typically the 20th percentile) and to use chronic effect concentrations for 10 percent as a reference, rather than 50 percent of species (EC10 or NOEC, rather than EC50).

Finally, in future studies the ecotoxicity factors should be combined with the species vulnerability approach of Kuipers, Hellweg and Verones (2019) on the global extinction probability so that they can be compared consistently to other impact categories. This is being pursued by the ecosystem quality task force of the UNEP Life Cycle Initiative GLAM project. 


\subsection{Human health impacts}

\subsubsection{Brief review}

For food systems, human health impacts are mostly associated with the following impact categories:

- Fine particulate impacts on human health - emissions of fine particulates smaller than $2.5 \mu \mathrm{m}$ (PM2.5) occur from mechanization (e.g. tractor use) and transportation, and are more substantially due to the formation of secondary particulates (ammonium nitrates and ammonium sulfates) mainly from ammonia emissions associated with fertilizer applications or manure management.

- Human toxicity and troposheric ozone formation - direct leaching of nitrates from fertilizer applications, for example, contribute to human toxicity impacts via water consumption or bioconcentration in plants. Pesticide applications can lead to both intakes of residues via plants, and more indirect environmentally mediated exposure of the general population to active ingredients via inhalation or ingestion via water consumption. Also, methane and other volatile organic compound emissions are increasing tropospheric ozone pollution, which is an important cause of premature deaths annually.

- Dietary impacts: recently developed impact categories include dietary impacts and benefits of foods on human health.

As far as possible, human health impacts are calculated for each of these impact categories separately at the midpoint level, but then also assessed and compared at the endpoint or damage level. The following sections discuss the specific issues, methods and research needs for each of these impact categories.

\subsubsection{Fine particulate impacts on human health}

Important issues in the assessment of food items

Three key issues are related to agricultural production in rural areas. The first is the need for reliable inventory data for the direct fertilizer-related emissions on farms, for which uncertainty is high. The most common emissions from agriculture are ammonia $\left(\mathrm{NH}_{3}\right)$ emissions that then combine with industrial or transportation emissions of $\mathrm{NOx}$ or $\mathrm{SO}_{2}$ to create secondary PM2.5, i.e. ammonium nitrate and ammonium sulfate particles.

The second key issue is that most primary and secondary precursor emissions occur in rural areas with lower-than-average population density and related exposures. However, fine particulates can travel typically up to $500 \mathrm{~km}$ for primary PM2.5, and up to several thousand kilometres for secondary particulates; thus, it is important to use region-specific characterization factors. Ideally, the impact of secondary particulates should be differentiated between primary and secondary PM2.5; however, currently epidemiological data do not enable this degree of differentiation.

A third key issue is that indoor cooking - without appropriate stoves - might create substantial indoor exposure to fine particulates. This is especially relevant in developing countries.

\section{Impact assessment methods}

To address the key issues identified above, it is important to use LCIA methods that are either spatialized or that differentiate between rural and urban archetypes, account for both primary and secondary PM2.5, and use epidemiologically based dose-response information. The main available methods include ReCiPe (Huijbregts et al., 2017, from Van Zelm et al., 2016), IMPACT World+ (Bulle et al., 2019, 
building on Humbert et al., 2011 and Gronlund et al., 2015) and LC-Impact (Verones et al. 2020). The latest development and recommendation of the UNEP Life Cycle Initiative GLAM project expand these approaches, providing archetypes and intake fraction specific data for $3000+$ cities (Fantke et al., 2017 and 2019). These also provide characterization factors for indoor emissions during cooking processes, for example. In addition, Oberschelp et al. (2019) present a plume-based spatialized approach valid worldwide with relatively high resolution. For agriculture-specific studies and archetypes, Stylianou et al. (2018) build on the inMAP model (Tessum, Hill and Marshall, 2017) and combine it with doseresponse data from the Global Burden of Disease to show for North America that the United States of America's agricultural sector average NH3 intake fraction (iF) of $0.37 \mathrm{ppm}$ is close to the United States of America rural iF of $0.44 \mathrm{ppm}$, a factor 7 to 10 below the urban iF for PM 2.5 .

\section{Recommendations and further research needs}

For food systems, the first recommendation is that the impact of fine particulates on human health should be systematically considered; this is based on reliable epidemiological studies and intake fraction modelling. For agricultural production, it is also important to consider a rural or agriculturebased archetype beyond national averages, even for secondary PM2.5 formation from $\mathrm{NH}_{3}$. Several initiatives (IMPACT World+, ReCiPe or the Product Environmental Footprint implementation) (EU, 2013; Zampori and Pant, 2019) are working on developing applicable methods. Among the above-mentioned methods, the easiest to apply is the UNEP Life Cycle Initiative GLAM project recommendation for the continent-specific rural archetype (Fantke et al., 2017, 2019).

\subsubsection{Human toxicity impacts}

\section{Important issues in the assessment of food items}

For human health, three main exposures are likely to be especially important for foods. The first is pesticide exposure, and primarily exposure to pesticide residues in the food itself. The second is the chemical migration from food contact materials (e.g. packaging, as addressed by Ernstoff et al., 2019b), and the third is the potential bioconcentration in the food of legacy persistent organic pollutants and metals that are ubiquitous in the environment due to their persistence. In addition, other toxic exposures can occur along the food life cycle. Exposure to food contaminants, fungi, microbial issues or contaminants such as benzopyrene due to grilled cooking might also be relevant, but no LCA approach considers these at present.

\section{Impact assessment methods}

Many of the studies on pesticides in LCA focused on environmentally mediated exposure and thus fail to address pesticide exposures via food. The USEtox model version 2 and 3 (Fantke et al., 2021), as implemented in IMPACT World+, enables consideration of these residues based on the dynamiCrop model from Fantke, Friedrich and Jolliet (2012) and Fantke and Jolliet (2015), in a consistent way with environmental exposures, with exposure to chemicals in food contact materials and with exposures to other toxic chemicals emitted along the entire food life cycle.

\section{Recommendations and further research needs}

The USEtox model and its extension according to the latest guidance of the Life Cycle Initiative (Fantke et al., 2021) is recommended as a default screening model to identify most relevant exposures over the food life cycle. Work is still needed to connect food production to specific additional human health impacts. Although the work described above captures pesticide residues in food and other drinking water impacts, methods should be developed to assess at least orders of magnitude of typical impacts of active pesticide ingredients on workers and on nearby populations (Ryberg et al., 2018; Teysseire et al., 2020), in a compatible way with other exposures in order to enable LCAs to analyse potential trade-offs. 


\subsubsection{Dietary impacts on human health}

Important issues in the assessment of food items

The realization of the importance of both beneficial and detrimental dietary impacts on health has led LCA researchers to advocate for the creation of a new and specific impact category for dietary impacts on human health. For individual food items, it applies the marginal approach that is inherent to LCA and LCIA, looking at a marginal increase in impact within the context of overall impacts (for example, the impact of an additional gram of fine particulate emitted over the current PM background concentration). This means that, for a considered food item, we consider its marginal dietary impact within the context of an overall diet.

Impact assessment methods for dietary impacts on human health

Recently developed approaches have applied morbidity and mortality related risk ratios to foods. These risk ratios have been established by the Global Burden of Disease (GBD) study and other epidemiologically based studies for cardiovascular disease, diabetes and cancer related health outcomes, for multiple age- and gender-specific risk ratios. The GBD study considered dietary risks not only associated with nutrients (calcium, sodium, Omega-3 fatty acids) but also with foods from various food groups (vegetables, legumes, processed meat, red meat). Consumption of sugar sweetened beverages was also linked to DALY, mediated by the Body Mass Index, and sodium intake to hypertension. In two complementary approaches, Stylianou et al. (2016) and Stylianou, Fulgoni and Jolliet, 2021) used the GBD risk ratios to develop epidemiology-based indicators of health impacts. These indicators determine marginal effects of food items on health, providing for the $15 \mathrm{GBD}$ dietary risks LCIA, as dietary characterization factors expressed in DALY/g risk component (e.g. DALY/g sodium or DALY/g processed meat), and account for both beneficial and detrimental risk factors. These are then multiplied by the considered food item composition for each of this risk factors (e.g. grams of sodium per $100 \mathrm{~g}$ ) to give the impacts in DALY per $100 \mathrm{~g}$, per serving size or per functional unit (see Table 15 for an illustrative example). Walker et al. (2019) also used dietary risk factors from the GBD, but at the diet level or for diet changes accounting for the multiplicative nature of dietary risks. 
Table 15: GBD maximum theoretical limits, dietary risks characterization factors, and determination of dietary human health impacts: illustrative application to a chicken wing consumed in the United States of America

\begin{tabular}{|c|c|c|c|c|}
\hline Dietary risk & $\begin{array}{l}\text { TMLR and effective } \\
\text { intake }{ }^{1} \\
\text { g/person/d }\end{array}$ & $\begin{array}{l}\text { DRF' } \\
\text { (pDALYs/g) }\end{array}$ & $\begin{array}{l}\text { Inventory of risk } \\
\text { component }{ }^{3} \\
\text { [g/serving }_{\text {chicken wing }} \text { J }^{\text {s. }}\end{array}$ & $\begin{array}{l}\text { Dietary health } \\
\text { impacts } \\
\text { (pDALYs/ } \\
\text { serving }_{\text {chicken wing }}\end{array}$ \\
\hline Omega-3 (seafood) & $<0.25$ & -81 & - & 0 \\
\hline Calcium & $<1.25$ & -5.1 & 0.028 & -0.1 \\
\hline Nuts and seeds & $<20.5$ & -1.5 & - & 0 \\
\hline Fibre $_{\text {other }}$ & $<23.5$ & -0.99 & - & 0 \\
\hline Polyunsaturated fatty acids (PUFA) & $\begin{array}{l}<11 \% \text { total energy } \\
\text { intake }\end{array}$ & -0.60 & 1.85 & -1.1 \\
\hline Whole grains & $<125$ & -0.34 & - & - \\
\hline Legumes & $<60$ & -0.23 & - & - \\
\hline Fibre $_{f, v, l, w}$ & $<23.5$ & -0.19 & - & - \\
\hline Fruits & $<250$ & -0.18 & - & - \\
\hline Vegetables $^{4}$ & $<360$ & -0.083 & - & - \\
\hline Milk & $<435$ & -0.0077 & - & - \\
\hline Sugar-sweetened beverages & $>2.5$ & 0.066 & - & - \\
\hline Red meat & $>22.5$ & 0.099 & - & - \\
\hline Processed meat & $>2$ & 0.86 & - & - \\
\hline Trans fatty acids & $\begin{array}{l}>0.5 \% \text { total energy } \\
\text { intake }\end{array}$ & 4.4 & 0.139 & 0.6 \\
\hline Sodium $^{5}$ & $>3.49$ & 13.9 & 0.49 & 6.8 \\
\hline Total net damage & - & - & $140 \mathrm{~g} / \mathrm{serving}_{\text {chicken wing }}$ & 6.2 \\
\hline
\end{tabular}

$\mathrm{DRF}=$ dietary risks characterization factors

TMLR = ??

${ }^{1}$ Maximum theoretical intake limits for each dietary risk component of the GBD laverage of the reported range as in Stylianou et al., 2021, Table S1), representing the effective range a) above which there is no additional benefits (e.g. no benefit above $250 \mathrm{~g}$ fruit consumed per day) or b) below which intakes are not detrimental (e.g. no impact of sodium below $3.49 \mathrm{~g} / \mathrm{d}$ ). For the United States of America, the average consumption are all within the effective ranges of intake. 2 Dietary risk factors calculated for the United States of America by Stylianou, Fulgoni and Jolliet (2021, Table S3) based on an adult population weighted average of 6000 risk, gender, age, outcome specific DRFs. Factors for Switzerland are also available in Ernstoff et al. (2020, Table S2), typically a factor two lower than in the United States of America due to lower disease incidence rates.

${ }^{3}$ Inventory flows representing the amount of each of the relevant risk components contained in a serving of $140 \mathrm{~g}$ of chicken wing.

${ }^{4}$ Starchy vegetables such as potatoes and corn are excluded by the GBD from the beneficial vegetable (Fulgoni et al., 2018).

${ }^{5}$ The sodium contribution to the net damage is calculated by multiplying the DRF of $13.9 \mu \mathrm{DALY} / \mathrm{g}_{\text {sodium }}$

by the $0.49 \mathrm{~g}_{\text {sodium }} / 140 \mathrm{~g}_{\text {serving size }}$ of the chicken wing, that is $6.8 \mu \mathrm{DALY} / \mathrm{g}_{\text {chicken wing }}$.

Source: Stylianou, Fulgoni and Jolliet, 2021

\section{Recommendations and further research needs}

Our recommendations for the use and development of a dietary impact category include:

- The impact category should account for both the benefits and the negative dietary impacts of foods on human health.

- These benefits or negative impacts can only be excluded if they are fully equal between alternative scenarios in a food LCA study. For example, if the functional unit is 1000 milligrams calcium, the health benefits of calcium can be discounted only if all the scenarios have equal bioavailability and impacts associated with this calcium.

- Epidemiology-based factors derived from the Global Burden of Disease represent a sound initial basis for deriving dietary response factors expressed in DALY/g of the risk factors that include both nutrients and food groups (see illustrative example in Table 15). These are multiplied by the inventory of food content in each of these risk factor components, ensuring consistency with the GBD defined categories (Fulgoni et al., 2018). 
- The marginal human health impact of individual food items should be considered in the context of an overall diet. This enables accounting for maximum theoretical limits above or below which there is no benefit or impact as defined by the Global Burden of Disease (see, for example, Stylianou, Fulgoni and Jolliet, 2021, Table S3). For substantial changes in diet, a multiplicative approach should be used (see, for example, Walker et al., 2019).

- The dietary human health impacts on the consumer associated with food consumption should be reported separately from the human health impacts on the general population associated with other activities in the life cycle of food items (due to fine particulate emissions, for example).

- Further research is needed to account for specific mortality rates in different countries in the world and to make dietary evaluation at the diet level easier to perform and represent.

\subsection{Ecosystem services assessment}

\subsubsection{Brief review}

Ecosystem services (ES) can be defined as "the ecological characteristics, functions, or processes that directly or indirectly contribute to human wellbeing: that is, the benefits that people derive from functioning ecosystems" (Costanza et al., 2017). To some extent, ES can be interpreted as the outputs of natural capital, which Guerry et al. (2015) define as "the living and non-living components of ecosystems - other than people and what they manufacture - that contribute to the generation of goods and services of value for people." Rather than an area of protection, the UNEP Life Cycle Initiative defines ES as an area of concern that can affect several intrinsic areas of protection (human health, biodiversity) as well as having instrumental value to humans (UNEP, 2021).

According to FAO (2016a), some ecosystem services are more evident than others: "Those that we consume directly, such as food and raw materials, are valued in markets. On the other hand, services, such as pollination and nutrient cycling, are less easily quantifiable though they play vital life-supporting roles. This lack of appreciation threatens the long-term provision of such services."

Research in the field of ES has grown enormously over the last 20 years (Torres, Tiwari and Atkinson, 2021). The release of the Millennium Ecosystem Assessment in the early 2000s (MEA, 2005) represented a first global milestone for the harmonization of ES-related concepts and indicators into an internationally acknowledged classification system. According to the Common International Classification of Ecosystem Services (CICES) (Haines-Young and Potschin, 2018), one of the most recent ES classification systems, there are three main ES categories:

- provisioning services (food, water, bio-resources);

- maintenance and regulation services (air purification, climate regulation, pollination); and

- cultural services Inon-material ecosystem outputs that have symbolic, cultural or intellectual significance).

In this sense, ES are produced in all types of ecosystems, from the intensively managed (e.g. agroecosystems) to those where human intervention is minimal (Guerry et al., 2015).

Progress in ES research areas led the LCA community towards an explicit consideration of ES in LCA approximately ten years ago (Zhang et al., 2010). Over this timeframe, LCA researchers have explored several ways to integrate ES in LCA, finding clear overlap in the environmental sustainability objectives between the two research areas (Rugani et al., 2019; VanderWilde and Newell, 2021). Nevertheless, as of today there is still a general lack of a methodological consensus on how to comprehensively integrate ES accounting in LCA. 
A recent systematic critical review of the literature highlights that approximately 19 LCA studies have attempted to integrate biotic ES in various meaningful ways (VanderWilde and Newell, 2021). As reflected in this and other previous literature analyses (Maia de Souza et al., 2018; Othoniel et al., 2016; Rugani et al., 2019), three main schools of thought essentially took hold so far, which regroup almost 300 peer-reviewed studies, the majority of which were published since 2010. Rugani et al. (2019) regrouped them into three lines of research: (1) "UNEP/SETAC branch of frameworks and methods for land use impact assessment (LULCIA)"; (2) "analysis of ES in the framework of LCA, alternative to UNEP/SETAC LULCIA branch studies"; and (3) "models developed outside the conventional LCA framework," Likewise, Vander Wilde and Newell (2021) clustered the LCA-ES literature into three main sets: "biodiversity and ES clusters", "land use cluster" and "dynamic modelling". Despite minor differences, these categorizations show considerable overlap and reach a similar general conclusion, that is current LCIA paradigms extended with an ES approach can guide towards a complementary evaluation both of detrimental impacts on ES and of their beneficial contribution to well-being.

\subsubsection{Important issues in the assessment of food items}

The two research areas of LCA and ES still speak different languages and have different assessment paradigms. With some adjustments, however, most of the LCA impact categories can be used to assess the detrimental impacts on the supply of ecosystem functions (those ES that typically fall under the umbrella of the "maintenance and regulation" services). However, the same approach cannot be used for other ES, such as those in the "cultural" and "provisioning" categories. Also, while most LCIA impact categories measure only negative impacts, some agricultural activities may have benefits when assessed using ES and practitioners should be aware of the possibility for such benefits.

Provisioning services represent resources and commodities crucial for the functioning of human societies, for which an economic market value already exists, such as crops and livestocks. The CICES framework, for instance, includes in this ES section all the cultivated and wild terrestrial and aquatic plants, as well as the reared and wild animals used for human nutrition, either directly or after processing. All these may already represent product units in LCA, for which a characterization model to evaluate impacts on their supply cannot be explicitly formulated using the conventional LCA practice (Rugani et al., 2019). Furthermore, when using an established ES assessment paradigm, such as that offered by the so-called "cascade model" (Haines-Young and Potschin, 2010), it is possible to capture the whole cause-effect chain underpinning the interaction between humans and ecosystems. The cascade model, indeed, explains the linkages between ecological structures, functions/processes, as well as the derived benefits and values to humans. This type of evaluation paradigm does not currently exist in LCA. Therefore, there is a timely research need to develop methodologies capable of capturing the beneficial value of ES for human wellbeing, in a way that goes beyond the mere accounting of their physical and/or economic value.

\subsubsection{Impact assessment methods}

A first and widespread effort in merging ES into LCA was performed by the UNEP Life Cycle Initiative in the project "Operational Characterization Factors for Land Use Impacts on Biodiversity and Ecosystem Services in the Life Cycle Impact Assessment-Compatible with the Framework of the UNEP-SETAC Life Cycle Initiative" (LULCIA). This initiative aimed to identify and characterize detrimental impacts generated by human processes (mainly driven by land use) on the provision of ES. This resulted in the development of an initial selection of characterization factors (CFs) for some ES (Koellner and Geyer, 2013). The LULCIA initiative was therefore specifically oriented towards developing CFs for land use impacts on biodiversity and ES in LCIA (Koellner et al., 2013; Koellner and Geyer, 2013; Teixeira et al., 2016). A common approach in all the LULCIA studies was to quantify and deliver CFs compatible 
with existing $\mathrm{LCl}$ datasets, including information on land use and land use change. These efforts led to the implementation of CFs for assessing impacts on a few provisioning, and maintenance and regulation services: biotic production potential (Brandão and Mila i Canals, 2013), climate regulation potential (Müller-Wenk and Brandäo, 2010), and freshwater regulation, erosion regulation and water purification potentials (Saad et al., 2013). These CFs were developed for a midpoint impact assessment using physical units and were then converted into an ES damage potential at the endpoint level. Further research efforts proceeded to designate endpoint CFs in monetary terms (Cao et al., 2015). Indicators of impacts on functional diversity (de Souza et al., 2013) and species richness (de Baan et al., 2013) were also implemented with the aim of translating direct impacts on species habitats into a biodiversity damage potential. While CFs developed within and in accordance with the LULCIA initiative still represent the most compatible and "ready-to-use" values to perform ES-LCA analyses, their implementation in LCA practice is very limited. One reason might be their inability to link ES with the final value and actual benefits to human society.

Such methodological limitations led to a second effort of the LCA community to account for ES in LCA (Arbault et al., 2014). In this case the goal was to use integrated modelling frameworks (implemented outside the LCA field) as impact characterization models for ES in order to capture complex ecological dynamics in the CFs. More specifically, such research included methodologies, applications and tools developed ad hoc to assess the impact of life-cycle-based activities on the provision of specific ES. Different models and impact drivers were implemented and considered, but they were usually not comparable with each other, as they were not harmonized under an umbrella approach like the LULCIA initiative le.g. Alejandre, van Bodegom and Guinée, 2019; Bulle et al., 2019; Jeswani et al., 2018; Othoniel et al., 2019; Schaubroeck et al., 2013; van Zelm et al., 2018). The common approach across these studies was the quantification of CFs for possible application in existing LCIA frameworks, and/or development of new impact characterization solutions that match the current LCA calculation structure. These approaches could bring more sophistication and diversity in: (i) the calculation of CFs (e.g. higher spatial resolution, and/or time-dependency and/or wider and deeper geographical distribution) (Life Cycle Initiative, 2021), and (ii) the choice of the impact drivers (not only land use was considered, but also other stressors like the extraction of natural resources; Rugani et al., 2019). Despite these improvements, as for the previous group of studies, the application of one or another of those models remains very limited and case-specific, most probably because of the lack of harmonization into one or another methodological solution.

Finally, a few proposals of LCA-ES integration were developed outside the typical LCIA framework le.g. Chaplin-Kramer et al., 2017; Liu and Bakshi, 2019; Liu et al., 2020). All of them made use of existing ES modelling and assessment tools in order to account for damages on ES applying specific life cycle data or inventory models, or simply adopting life cycle thinking but without developing and using CFs. Some insights from those novel computational frameworks for LCA-ES integration, which make use of, for example, integrated system dynamics-based models or other deterministic tools (Rugani et al., 2019), may inspire the future development of a new generation of impact characterization models to assess ES in LCA.

\subsubsection{Recommendations and further research needs}

An assessment of ES can include the supply of ES, the demand for ES, or both. However, the valuation of ES must consider both supply and demand of ES in order to deploy LCA consistently as a decisionsupport tool for nutritional LCA (e.g. a demand for high quality soils can be determined). To this end, the literature analysed in this chapter suggests that theory and practice to account for ES in LCA are still at their initial stage of development, proving that more and more sophistication in integrating these two areas of research exists but methodological and procedural consensus is also a challenge. 
The relevance of assessing life cycle impacts on ES is nowadays well documented by numerous studies characterizing impacts on ecosystem processes and functions, such as increase/decrease in carbon sequestration (Ingram et al., 2018), loss/gain in pollination services (Arzoumanidis et al., 2021), changes in soil quality (Tang et al., 2018), etc. It is worth noting that most of the literature on ES-LCA also focuses on topics related to agricultural and food systems. This is well shown by the thematic foci of the emerging "ES accounting in LCA" area of research identified by VanderWilde and Newell (2021), i.e. bioenergy/biofuels, livestock, general methodologies, agriculture, forestry and soils. A general bias of these studies, however, is the lack of an assessment for the typical beneficial value of the ES for human well-being.

In this regard, the UNEP Life Cycle Initiative GLAM project has recently created several working groups to discuss ES as a priority issue for impact assessments in LCAs (Antón et al., 2016; Verones et al., 2017). The general ambition of this work is to determine effective strategies to assess impacts, either beneficial or detrimental, on the provision of ES associated with the life cycle of production systems.

\subsection{Other impacts and the emerging issue of microbial resistance}

Some additional impact categories deserve attention for specific agriculture process and related inventory flows. For mineral resource use, the use of phosphorous as a limited resource could be a relevant aspect to consider, as has been addressed by the GLAM project of the Life Cycle Initiative (Sonderegger et al., 2020, Berger et al., 2020). Ozone depletion and photochemical ozone formation are other impact categories that can be heavily influenced by post-harvesting and post processing activities, in particular by the logistic and refrigeration of food items, as highlighted in a recent technical report on the European Consumer Footprint (Castellani, Fusi and Sala, 2017, Tables 18 and 19). Finally, the impact of fisheries and aquaculture on biodiversity also need to be further developed and included in assessment methods.

Other food-related processes such as the use of materials for packaging and of fuels in the food chain logistics will more generally affect the use of fossil resources but can be treated as currently applied in more general LCAs that are not food-specific. Similarly, the optional normalization and weighting steps of an LCA will be important to put food LCA results in perspective when comparing different products and analysing trade-offs between different impact categories. Such normalization and weighting factors are, however, not food specific since they can be applied to all types of products; the GLAM project provides further guidance for their development and application (Verones et al., 2017).

The rest of this section focuses on antibiotic resistance as an emerging concern.

\subsubsection{Background and problems for antibiotic resistance}

The use of antimicrobials (in particular, antibiotics - this text uses the two terms interchangeably, given the relatively generic discussion) in food-producing animals, subsequent selection of antimicrobial resistance in bacteria among food-producing animals, then transfer of those antimicrobial resistant bacteria from food-producing animals to humans via food, is an important food safety issue (WHO, 2017). The World Health Organization characterizes antimicrobial resistance as a global public health crisis that must be managed with the utmost urgency and has issued a global action plan on anti-microbial resistance (AMR) (WHO, 2015). It highlights the necessity of adopting a "One Health" approach, with the involvement of public health and veterinary authorities, the food and agriculture sectors, financial planners, environmental specialists and consumers. 
Estimates of the total annual global consumption of antimicrobials in agriculture vary considerably. This is due to poor surveillance and data collection in many countries. For example, only 42 countries in the world have systems to collect data on the use of antimicrobials in livestock (FA0, 2016a). FAO (2016a) estimated that 63151 tonnes of antimicrobials were used in the livestock sector in 2010. In some countries, approximately 80 percent of total consumption of medically important antibiotics is in the animal sector (WHO, 2017). However, animals cannot metabolize all the antibiotics: 30 to 90 percent of ingested antibiotics are excreted in their original form with antibiotic-resistant bacteria through urine and faces (Andersson and Hughes, 2014); they can also enter the food chain (Zhou et al., 2019). The misuse of antimicrobials will lead to an AMR problem. Also, the misuse of feed additives might lead to developing resistances. In addition, AMR build-up can also be a major issue for aquaculture production, with fishponds becoming potential reservoirs of antibiotic resistance genes (Xiong et al., 2015). The consequences of AMR include the failure to successfully treat infections, leading to increased mortality, production losses and reduced livelihoods and food security. It is estimated that deaths attributable to AMR every year will be 4.73 million in Asia and 10 million in the world by 2050 (0'Neill, 2014).

\subsubsection{Recommendations and further research needs}

So far, established life cycle impact assessment methods and models have not accounted for the development and spread of AMR due to antibiotic emissions into the environment.

Nyberg et al. (2021) recently proposed a novel approach to characterize the potential for AMR enrichment in the environment as a midpoint indicator, and another conceptual approach to directly link the total use of antibiotics in a given region to human health impacts at the endpoint damage level (DALY/kg antibiotic used). Similarly, Emara et al. (2021) derive minimum selective concentrations from widely available antibiotic susceptibility data and determine hazardous concentrations (HCs) for more than 140 antibiotics that reflect an antibiotic-specific threshold for resistance selection in the environment. Based on $\mathrm{HCs}$, characterization factors for the spread of resistance in the environment due to antibiotic emissions and exposure can be easily derived and integrated into LCIA. While links between antibiotic emissions and AMR development in the environment are fairly well characterized with such approaches, a connection between the environmental resistome and human health impacts is still difficult to establish given current data limitations (e.g. transmission rates from environmental bacteria to pathogens) (Manaia, 2017). Furthermore, none of the existing approaches includes the direct emission of, or exposure to, already resistant bacteria.

Novel LCIA methods will thus have to be developed to evaluate fate, human exposure and effects of these emerging biological pollutants.

\subsection{Integration of recommendations in existing global LCIA methods}

Several of the recommendations in this chapter have already been implemented in different comprehensive LCIA methods that cover both midpoint and damage levels with a global scope. In particular, ReCiPe (Huijbregts et al., 2016) integrates the land use, fine particulate impacts and climate change impacts in a consistent way for midpoint and endpoint assessment. IMPACT World+ (Bulle et al., 2019) provide an implementation of USEtox ecotoxicity and human toxicity factors, integrates the AWARE approach for water use, and enables differentiation between short- and long-term climate change impacts. The product environmental footprint method represents an implementation at the midpoint level for European use. LCIMPACT (Verones et al., 2020) provides a high level of spatial differentiation for several impact categories (EC-JRC, 2019). Current developments underway in the GLAM project should provide a major step forward in most of these agriculture-specific impact categories. 


\section{Towards an agreed upon methodology for nutritional life cycle assessment}

\subsection{Outstanding issues in assessing nutritional value in nutritional life cycle assessment studies of food items}

Throughout the project, several key outstanding methodological issues were identified that were particularly relevant to assessing nutritional value in an $\mathrm{nLCA}$. They are summarized in Sections 8.1.1 to 8.1.9.

\subsubsection{Terminology}

In research, a shared understanding of the meaning of terms is fundamental to progressing research ideas and achieving consensus. In this project, we agreed on the following terms:

- Nutritional LCA (nLCA) - an LCA study where the provision of nutrient(s) is considered as either the main function or one of the main functions of a food item.

- Nutritional functional unit (nFU) - an FU that represents at least one nutritional aspect.

- Nutrition impact category - midpoint impact assessment category that accounts for the benefits or impacts of nutrition on human health.

- Nutrients to encourage - nutrients that are essential or important for human health and for the prevention of disease, and that are not normally supplied in harmful quantities in diets.

- Nutrients to limit - nutrients that have the potential to be harmful in typical diets and should be consumed in moderation (to minimize the risk of health impacts).

Regarding the last two terms, it is important to note that the classification of a nutrient as encouraged or limited is dependent upon the intake quantities in the diet of an individual or target population (Section 5.4). For example, sodium is usually a nutrient to limit but could be a nutrient to encourage if it is only present in very small amounts in the diet of a target population.

\subsubsection{Assessment of one nutrient versus many nutrients}

Humans require a variety of nutrients for healthy growth, maintenance and repair of the human body (Chapter 5). This raises the question of whether there should be a requirement to assess a specified minimum number of nutrients in an nLCA. Such a requirement would avoid potential bias in the presentation of nLCA results that could occur by cherry-picking one, or a limited number of, nutrients for assessment that are present in relatively larger quantities in some food items.

Theoretically, defining a minimum number of nutrients for assessment in an nLCA would support standardization and facilitate integration into future nLCA studies. However, it is unlikely to be workable across all food items due to a lack of data. In the meantime, an nLCA study should provide information about as many essential nutrients as possible.

\subsubsection{Assessment of non-nutrients}

As discussed in Section 5.2.3, a number of components in food items are not classified as nutrients but affect nutrition and/or human health. These include dietary fibre, polyphenols and anti-nutritional factors (Box 5). These aspects should be considered when assessing the nutritional value of food items; however, data on these components is rarely included in food composition databases and makes assessment in an nLCA difficult. Therefore, in the absence of quantitative data, nLCA reports should qualitatively discuss the potential role of non-nutrient components in assessing the nutritional value of food items. 


\subsubsection{Distinguishing between nutrients and nutritional value}

Nutrients are a prerequisite for nutrition, but nutrients alone do not automatically lead to nutrition. This is because nutrients need to be absorbed and metabolized in the human body to provide nutritional value. The term bioavailability is used to describe the degree to which a nutrient is available to be absorbed and metabolized in the human body (Section 5.2.1).

In nLCA, obviously it is preferable to assess nutrients based on their bioavailability in a food item. However, this is challenging because there is limited data on the bioavailability of nutrients in food items (Section 5.2), and because the bioavailability of nutrients in a single food item may be markedly influenced by other food items consumed at the same time (so-called "meal effects") (Section 5.3.2). Therefore, in the absence of quantitative data, nLCA reports should note the potential role of the bioavailability of nutrients in assessing the nutritional value of food items.

\subsubsection{Use of nutrient indices in a nutritional life cycle assessment}

Nutrient indices provide an existing method for assessing, at least partly, the nutritional value of food items. A nutrient index scores a food item in relation to national or international recommended reference intake values and may include both nutrients to encourage and to limit. It can be designed to be applied to all food items (e.g. the Nutrients Rich Food Index (Fulgoni, Keast and Drewnowski, 2009) or to a specific food group (e.g. protein sources) (Saarinen et al., 2017; McAuliffe, Takahashi and Lee, 2018) (Section 6.3.2).

Reference intake values vary for individuals and target populations according to characteristics such as age, life stage, sex, weight and level of physical activity. In the case of individuals, food intolerances and allergies can also affect adequate intake values. Therefore, if a nutrient index is used, it should justify the choice of reference intake values in relation to the goal and scope of the study. As a default, global nutrient reference intake values developed by the Codex Committee on Nutrition and Foods for Special Dietary Uses may be used (Section 5.4.3).

Furthermore, the different types of nutrient indices have different strengths and weaknesses. Also, additional methodological issues arise when using nutrient indices in the context of an nLCA, for example, capping (or not) of nutrients at 100 percent of reference intake value, energy adjustment of nutrient content, weighting of different nutrients (Section 6.3.2). A number of methods have been proposed, or are being developed, to adapt nutrient indices to use in an nLCA (Section 6.3.2). This is a topic that requires further research attention.

\subsubsection{Treatment of nutrients to limit}

Certain nutrients are commonly discouraged as they are typically overconsumed in quantities that are detrimental to human health (added sugar, sodium). These nutrients affect the nutritional value of food items and so they should be addressed in an nLCA.

However, there are a number of methodological issues associated with the consideration of nutrients to limit in an nLCA (Section 6.3.2.4). These include whether it is appropriate to assess nutrients to limit in the FU, and the possibility of a negative score when a nutrient index is used to represent the nutritional value of a food item. Several methods have been proposed, or are being developed, to adapt nutrient indices so that nutrients to limit can be included in the nutritional assessment in an $\mathrm{nLCA}$ (Section 6.5.3, Box 12). This is a topic that requires further research attention.

\subsubsection{Nutritional value addressed in functional unit versus in the impact assessment}

As discussed in Chapter 6 and Chapter 7 (Section 7.5.4), food LCA studies have addressed nutrients and/ or nutrition in both the FU and in human health-related impact categories in the impact assessment. 
We do not recommend one or the other approach here; instead, we suggest that the choice depends upon the type of application. Indeed, in some applications, particularly in nLCA studies supporting policymaking, it may be appropriate to use several methods in parallel.

The decision about how to address nutritional value should be based on careful consideration of the goal, purpose, scope and audience for an nLCA study (Chapters 3 and 4). In all cases, nLCA studies should report the nutrient profile of the food item in the nLCA report. If the nutritional value is reported in the impact assessment, it should be reported separately from the contribution of other activities to human health impacts (in a nutrition impact category, see Section 7.5.4).

\subsubsection{Role of system boundaries in affecting nutritional value}

Food processing and preparation may affect the nutritional value of food items - either positively or negatively (Section 4.2, Section 5.3.1). However, if an nLCA study does not extend to the point of consumption of the food, these nutritional effects may not be represented in the nLCA study.

It is preferable that system boundaries extend to the consumption stage (cradle to plate) in nLCA. An alternative approach is to define a system boundary up to a point prior to consumption le.g. a food item on the supermarket shelf), but take into account the nutrient characteristics at the eventual point of consumption. This is a topic that requires further research to define best practice.

\subsubsection{Comparisons between alternative foods}

In general, nLCA comparisons between food items are undertaken for food items within the same food groups, and with similar FUs meeting similar needs. ${ }^{7}$ However, when using an nFU, the nutritional function is represented in the FU and it forms a basis for comparison, not food grouping. In these cases, comparisons are basically possible between any products, but in practice they are usually undertaken within the same food group.

The definition of appropriate food groups that are relevant for $n L C A$ studies requires further investigation (Box 9). Also, it may be advisable to define critical components associated with specific food groups, such as calcium in dairy foods or vitamin $D$ in seafood, that should always be included in the nutritional assessment of food groups using $\mathrm{nLCA}$. This is a topic for further research.

\subsection{Additional methodological issues of particular relevance to food life cycle assessment studies}

As well as the nutritionally focused issues addressed in Section 8.1, this project has identified other methodological issues that are particularly relevant for nLCA studies. These include:

- quantification of food loss and waste (Section 4.8);

- data availability and quality (Sections 4.5 and 4.6);

- representation of data variability and uncertainty (Section 4.7);

- attributional versus consequential modelling approaches (Sections 4.3 and 4.44.4); and

- suitability of "generic" LCA methodology for different application areas (Chapter 3).

In addition, some existing impact assessment categories are particularly relevant for food systems and require further research attention. These are: climate change (Section 7.2), water use (Section 7.3), land use (Section 7.4.1), eutrophication (Section 7.4.2), ecotoxicity (Section 7.4.3), ecosystem services (Section 7.6) and antimicrobial resistance (Section 7.7).

${ }^{7}$ ISO 14044 (Section 4.2.3.2) states that compared alternatives must have the same FU and provide the same function. The term "similar" is used here to make clear that the function for alternatives studied in the nLCA may be defined fairly generically as a serving size of a recognized component of a meal (protein source, carbohydrate source). Alternatively, the FU may be defined as a specified quantity of one or more nutrients, or a nutrient index score, in which case the FU is, in fact, quantitatively the same for the alternatives in the nLCA study. 
Lastly, Chapter 3 emphasizes that an nLCA study should be shaped by the application area and, more specifically, the goal, purpose, scale of the studied system(s), and intended audience (decision situation). This report provides examples of how different application areas and decision situations relate to the choice of FU (Table 4 and Table 13).

\subsection{Operationalizing methodology for nutritional life cycle assessment}

Application areas for use of an nLCA include benchmarking, identifying process improvements, and/ or evaluating the environmental trade-offs between different food items (Section 3.6). In each of these application areas, decision makers have different priorities and motivations for undertaking an LCA, and these factors shape the goal and scope of a given LCA, and also the choice of FU.

When a decision maker has decided to undertake an nLCA, there are two main ways in which nutritional value can be incorporated (at least partly) in the LCA framework: 1) nutritional effects can be considered in the impact assessment (i.e. effects due to food consumption during the use phase of food items) (Section ); and/or 2) nutritional value can be incorporated in the FU (Section 8.3.2). Guidance on choosing an approach is provided in Section 8.3.3.

\subsubsection{Nutritional effects considered in the impact assessment}

Food items may have beneficial and/or detrimental potential human health impacts related to the use phase of the life cycle of a food item. These effects should be assessed separately, but alongside, the human health effects arising from other activities in the life cycle of a food item (e.g. due to pesticide emissions during agricultural production or particulate matter emissions during truck transport) (Section 7.5.4).

The potential human health impacts may be assessed at the midpoint in a nutrition impact category (e.g. using a nutrient-based index such as the NRF) or at the endpoint in the impact assessment (e.g. using DALYs) (Section 7.5.4).

\subsubsection{Nutritional value as (part of) the functional unit}

For nLCA studies, the nFU may be defined in terms of (Section 6.3.1):

a) a quantity of a particular nutrient (such as $200 \mathrm{mg}$ calcium); and/or

b) nutrient density, i.e. a quantity of several different nutrients expressed in terms of a nutrient index; and/or c) a quality-corrected quantity of one or more nutrients laccounting for bioavailability or digestibility, or considering amino acid surpluses and/or deficiencies in a specific dietary context); and/or d) other properties such as energy content (kJ).

For $\mathrm{nFUs}$ expressed as one or a limited number of nutrients, the nLCA report should also list the quantities of as many other essential nutrients as possible.

Alternatively, the FU may also be expressed as a serving size or, in the limited situation where the compared food items have similar serving sizes, as a mass/volume quantity. However, in these cases, the main function of the food item(s) being investigated in the LCA study is nevertheless the provision of nutrition.

\subsubsection{Guidance on undertaking a nutritional life cycle assessment}

Figure 6 provides a decision tree to support the process of deciding on the type of nutritional assessment, and whether to represent nutritional value in the FU and/or in the impact assessment in nLCA studies of food items based on the best practice recommendations given in this report. 
Figure 6: Decision tree to support development of a nutrition life cycle assessment study



Out of scope for this report 


\subsection{Further research needs}

To progress towards a harmonized environmental and nutritional LCA methodology, a number of recommended research priorities were identified in the project and are listed in this section.

Methodology for nLCA of food items:

1. Minimum nutritional data requirements for an acceptable nLCA - research to assess the minimum data needed for including nutrients/nutrition as a (complementary) FU for an acceptable nLCA lacknowledging that an ideal nLCA often cannot be performed due to data limitations). Can this be done based on a single nutrient, or should other nutrients be considered as well and, if so, which one(s) should be prioritized? From an NRF (or other indicator) perspective, what is the minimum needed? Is NRF6.0 good enough in the absence of more data? Or is NRF9.3 or NRF18.3 the minimum? 2. Use of nutrient index scores as nFUs (Sections 6.3.2 and 6.5.4): more research is needed on use of nutrient index scores as nFUs, and in particular on:

a. treatment of nutrients to limit;

b. use of across-the-board vs. group-specific indices - for the latter point particularly, more work should be done to understand and develop guidance for using and creating group-specific metrics for relevant food groups in the context of nLCA;

c. use of energy adjustment of nutrient content (energy standardization);

d. capping and weighting of nutrients in nutrient indices; and

e. choice of reference flow for food items. This issue also relates to validation of the nutrient index scores as nFUs, which is an open question.

3. Multi-functionality of food items - as foods provide much more than just nutritional value (social, cultural, aesthetic, hedonic and economic functions), is it possible (or even desirable) to represent this multi-functionality in food LCA studies?

4. Truncated system boundary for nLCA study - if the system boundary for a food item is set at a life cycle stage prior to consumption (e.g. a food item on the supermarket shelf), what is the best practice with respect to representing further changes in nutrient characteristics that may occur up to the eventual point of consumption?

5. Impact assessment issues with particular relevance to food systems - improved models are needed for non-GHG climate effects of land use, species vulnerability and habitat fragmentation for biodiversity, multi-compartment water use, land use classes, losses from field to environment, co-limitation for eutrophication and more compartments for ecotoxicity. Additional metrics are also needed for step-pulse equivalence for climate change, and ecosystem services assessment.

6. Impact assessment category for nutrition - more research is needed to develop the methodology for this proposed new impact category.

Data for nLCA studies:

7. Representative data for different regions - the dominant representation of data for $n L C A$ is currently of European food systems. This should be extended to region-specific environmental and nutritional data that are representative of food items from more world regions, particularly developing countries.

8. Representative data for life cycle stages downstream of agricultural production - more data are needed, in particular, on processing, retail, distribution and consumption in the home and at food outlets. 9. Data uncertainty - more guidance is required for estimating uncertainty in agrifood databases, and on how to communicate uncertainty and variability in LCA studies. 
10. Nutritional value beyond nutrient content - for nutritional aspects in particular, as discussed in Chapter 5, there is relatively little evidence that can be used to quantify the factors influencing the nutritional value of food items beyond nutrient content. In particular, research is needed to provide quantitative data on bioavailability (e.g. haem iron versus non-haem iron), digestibility (e.g. amino acid uptake), (anti)nutrient interactions (e.g. phytic acid and zinc) and interactions between food items consumed together. In the absence of such understanding, how can the potential relevance of these factors be most objectively represented in nLCA study reports?

11. Food loss and waste - existing available food loss and waste data for use in LCA has high uncertainty, and it is not fully representative of different national and cultural contexts. Therefore, a robust accounting of food loss and waste in life cycle inventories is currently a challenge.

More experience with use of $n L C A$ :

12. More, and more diverse, nLCA case studies - in general, more nLCA case studies should be undertaken that are compliant with the recommendations in this report, and which address a range of food items in different food cultures and diets. For example, the case studies could illustrate how to apply the results of food nLCA studies to identify policy making priorities for populations lor population subgroups, defined by age/sex/life stage/geography) that experience malnutrition, including undernutrition such as micronutrient deficiencies, as well as overnutrition lindicated by a high prevalence of obesity and chronic diseases). How can nLCA methods best incorporate the relative importance of different nutrients in these settings? Should nLCAs even be done in these settings?

13. Prospective attributional/consequential modelling of future mitigation strategies - more futureoriented nLCA case studies should be undertaken to develop a better understanding of the roles of different modelling approaches in evaluating future mitigation strategies.

14. Allocation approaches based on nutritional attributes - where an attributional perspective is used, the use of nutritional attributes as a basis for allocation should be explored.

15. Guidelines for use of nLCA in different applications - based on the different application areas identified in this report (Table 4 and Table 13), as more case studies become available it should be possible to develop guidelines for using an nLCA in different application areas.

16. Reviews and meta-analyses - as more case studies become available, review studies will be useful to bring together the learnings from different case studies and progress toward metaanalyses.

Extension into nLCA studies of meals and diets:

17. Use of nLCA study results at the meal and diet scale - future research efforts should investigate the integration of individual food item nLCA study results into meal and dietary analyses, and "what if" meal and dietary scenarios.

18. Role of fortification - food items can be fortified with different nutrients, such as calcium, iron, and vitamin $\mathrm{C}$, and are commonly added to food items. What is the role of fortification when evaluating future alternative meals and/or diets? 
Wider context for nLCA studies:

19. Assessment relative to environmental limits - assessment of the environmental consequences of adapting meal plans or different types of diets to meet global dietary guidelines within environmental limits may provide useful insights to support policymaking.

20. Sustainability assessment - in the search for more sustainable food system, it will be necessary to integrate complementary methodologies either within or with nLCA to provide a more holistic sustainability evaluation. For example, the use of FUs as the basis for LCA results leads to a greater focus on efficiency at the possible expense of resilience, and so additional methods could help provide a more complete understanding.

\subsection{Limitations in using nutritional life cycle assessment studies to support decision-making about sustainable food systems}

In addition to the future research requirements identified in Section 8.4, it is important to note that nLCA studies of food items do not provide all the information required to support decision-making about sustainable food systems. This is because the sustainability of food systems is dependent upon social, cultural and economic aspects as well as environmental and nutritional aspects. Therefore, nLCA studies should be extended into life cycle sustainability assessment (LCSA) studies if decision makers want to understand the diversity of aspects requiring attention in order to realize sustainable food systems (see, for example, Gava et al., 2018; Valdivia et al., 2021).

Furthermore, as noted throughout the report, ultimately the nutritional value of food items can only be assessed in the context of diets. It is important that nLCA studies communicate information about the nutritional value of a food item or items in the context of diets. This includes discussing any potential interactions between the bioavailability of nutrients in the food item, and other food items in a meal or in the diet. It also includes discussing (or preferably quantifying in a nutrient index) the nutritional requirements of the target population. 


\section{Final recommendations for nutritional life cycle assessment of food items}

This chapter provides a list of recommendations for undertaking an nLCA of food items. The corresponding chapters or sections of the report are provided in brackets after each recommendation, where relevant, to enable readers to refer to the related text in the report.

In making these recommendations, we recognize that the nutritional value of food items should be assessed in the context of diets. Some of the recommendations specifically address the need to define and account for this context in the nLCA. Other recommendations focus on providing information in nLCA studies of food items that will increase their usefulness for future LCA studies of meals and diets.

Also, as people eat foods for a diversity of reasons, the function of a food item or items may not be - and often are not - limited to the supply of nutritional value. For this reason, we include recommendations to reflect on the purpose and scope of an LCA study prior to undertaking it. However, an nLCA involves a consideration of the nutritional value of food items, and an assessment of both environment and nutrition in LCA is the focus of this report and these recommendations.

Undertaking an nLCA study:

1. Multidisciplinary efforts involving the collaboration of experts in related disciplines (e.g. nutritional and health scientists) are needed for nutritional comparisons of different food items in the nLCA research and assessment of nutritional impacts on human health. This multidisciplinary effort will facilitate the integration of the latest understandings in relevant fields, such as the optimal choice of FU and the alignment of transparent and appropriate nLCA methodology with a given decision situation. (Section 8.1.7, Section 8.1.9)

2. Define the reason for the study, the intended application, the intended audience, and whether any comparison is intended for public declaration, at the outset of an nLCA study. This will assist in scoping the nLCA study to satisfy end-user requirements. However, at the same time the recommendations in this report should be followed to ensure future food item nLCA studies can be readily compiled into information about meals and diets. (Chapter 3, Section 6.4, Section 8.1.7, Section 8.1.9)

3. Clearly define the food item of interest for the nLCA study. This will help determine the type of LCA approach to be adopted and to select the most suitable FU for the study. (Chapter 3)

4. The perspective of the study (attributional versus consequentiall should be appropriate for the LCA study goal, scope and objectives. In most cases, identifying environmental hotspots and monitoring should work in an accounting context with attributional LCA. Policy evaluation, strategy development, marketing and future planning should work in a decision context using attributional and consequential LCA as appropriate. (Section 4.3)

Goal and scope:

5. Nutritional LCA should be undertaken when nutrients and/or nutrition are relevant to the decision-maker and decision context, and the goal and scope should be documented accurately and transparently. (Chapter 3)

6. Report the quantities of as many essential nutrients as possible in the nLCA report. (Chapter 5 , Section 8.1.2)

7. Any omissions should be clearly stated, such as missing information about the bioavailability of nutrients and digestibility of the food item. (Chapter 5, Section 8.1.4) 
8. Clearly identify the target audience and decision situation as part of the goal and scope of an nLCA, and justify the FU on the basis of the needs of the target population las well as the goal of the study). (Section 5.4)

9. nLCA studies should provide results in a form that enables subsequent use in dietary studies because nutritional performance is ultimately only realized at the dietary level, despite the specific purpose and scope of an individual nLCA study. In particular, when the FU is not expressed on a mass/volume basis, results should also be reported using a mass or volume-based reference flow. (Section 6.2.2)

10. Comparisons should only be performed across food items based on the same function as represented in the FU. nLCA requires consideration of nutritional value as the main function or as one of the main functions of a food item. (Section 6.5.2, Section 8.1.9)

11. In an $n L C A$, it is preferable that the system boundaries include all stages of the product life cycle that affect nutritional value. An alternative approach is to define a system boundary up to a point prior to consumption (e.g. a food item on the supermarket shelf), but take into account the nutrient characteristics at the eventual point of consumption. (Section 4.2, Section 5.3.1, Section 8.1.8)

The functional unit:

12. The FU should be carefully chosen to be compatible with the goal and scope of a food LCA study. It should be justified based on the needs of the target population because different population segments have different needs and priorities. (Section 5.4, Section 6.3.1, Section 6.4, Section 6.5.1) 13. It may be preferable to assess nutrients to limit in the impact assessment as part of a broader nutritional assessment or by using a separate index of nutrients to limit. If these are the only bases for assessing nutrition and health impacts in the impact assessment, nutrients to encourage should be represented in the FU or listed and discussed in the nLCA report. (Section 6.3.2.4, Section 6.5.3) 14. If some nutrients are addressed in either the FU or in the impact assessment (whether quantity or quality-corrected quantityl, then other nutrients to encourage or limit should be listed and discussed in the nLCA report. (Section 6.3.1, Section 8.1.7)

Modelling approach:

15. The modelling approach used in an nLCA should be justified based on the decision situation, such as the use of a consequential or attributional perspective. If a consequential LCA is performed, the nutritional profile of marginal and/or incremental systems that are affected by the main system should also be reported. (Section 3.4, Section 4.3)

16. The processes modelled and the data used should be as representative as possible of the food item produced/consumed and its nutritional characteristics. (Section 4.5, Section 4.6, Section 4.7)

17. Reliance solely on inventory data from high-income countries (which is usually most readily availablel should be avoided and effort taken to develop context-specific data, given the variability and relevance of local and geoclimatic conditions in agricultural systems. (Section 4.5)

18. Non-nutrient components of food items should be considered, in addition to nutrients, where possible (e.g. fibre). (Section 5.2.3, Section 8.1.3)

19. Assessment of food loss and waste at different life cycle stages, and the end-of-life fate of lost and wasted foods, should be included in nLCA studies. (Section 4.8) 
20. Use of nutrient index scores as nFUs is still evolving and therefore related modelling issues should be discussed transparently in an nLCA report. (Section 6.5.4, Section 8.1.5)

21. When using a nutrient index, consider nutrient concentrations in food items in relation to the recommended intake values of the appropriate target populations. (Section 5.4, Section 8.1.5)

22. Where life cycle stages involve alternative processes that may have different effects on the nutrition value or health impacts (boiling, frying or roasting vegetables at home), these should be represented using scenarios. These scenarios should also include any ingredients that are added during these stages, such as frying fat, salt or sugar. (Section 5.3.1)

23. Sensitivity analysis should be undertaken, where possible, to ensure more robust nLCA results. (Section 4.7)

Reporting results:

24. The $n L C A$ results should always be provided based on the mass/volume-based reference flow as well as the FU, as this will facilitate the interpretation of the results and their use in future studies. (Section 6.2.2)

25. Nutritional quality and/or health impacts should be reported when data are available. (Section 7.5.4)

26. Clearly report whether approaches are nutrient-based or also include nutritional aspects (bioavailability of nutrients, digestibility). (Section 5.2.1, Section 5.2.2, Section 8.1.4)

27. When any nutritional FU or health impact assessment method is used, its limitations are to be discussed in the LCA report. For example, the nutritional benefits (and detriments) as well as associated expected health impacts, may differ for the final consumer based on the bioavailability of nutrients and digestibility of the food item, and on the consumption of other foods in a meal and/or diet. (Section 5.2.1, Section 5.2.2, Section 5.3.2, Section 8.1.4)

28. An nLCA study report should document any enrichment of foods with additional nutrients. (Section 4.2)

29. For nLCA studies that omit the processing, storage and/or preparation life cycle stages, the assessed nutritional value and human health impacts (if considered) may be different for the final consumer depending upon how the food item is processed, stored and prepared for final consumption. This includes the potential fortification of foods with added nutrients. Such potential differences should be noted in the nLCA report. (Section 4.2, Section 5.3.1, Section 8.1.8)

30. nLCA reports should include statements to acknowledge that the nLCA is not sufficient on its own to assess the sustainability of a food item. An nLCA is a decision support tool that is used to assess the environmental profile of food items on the basis of their nutritional value, and/or in relation to their health impacts, using the data and methods available at the time of the study. It does not account for the social (other than health), cultural, aesthetic, hedonic or economic functions of food items, and it does not address food safety risks associated with the consumption of food items. 



\section{References}

Afshin, A., Sur, P.J., Fay, K.A., Cornaby, L. et al. 2019. Health effects of dietary risks in 195 countries, 1990-2017: a systematic analysis for the Global Burden of Disease Study 2017. The Lancet, 393(10184): 1958-1972.

Ahmad, S., Yew Wong, K., \& Ahmad, R. 2019. Life cycle assessment for food production and manufacturing: recent trends, global applications and future prospects. Procedia Manufacturing 34: 49-57.

Alejandre, E.M., van Bodegom, P.M. \& Guinée, J.B. 2019. Towards an optimal coverage of ecosystem services in LCA. Journal of Cleaner Production, 231: 714-722.

Alkemade, R., Oorschot, M., Miles, L., Nellemann, C., Bakkenes, M. \& Brink, B. 2009. GLOBIO3: A Framework to Investigate Options for Reducing Global Terrestrial Biodiversity Loss. Ecosystems 12: 374-390.

Allan, J.A. 1998. Virtual Water: A Strategic Resource Global Solutions to Regional Deficits. Groundwater, 36(4): 545-547. doi.org/10.1111/j.1745-6584.1998.tb02825.x

Allen, M.R., Fuglestvedt J.S., Shine, K.P., Reisinger, A., Pierrehumbert, R.T, \& Forster, P.M. 2017. New Use of Global Warming Potentials to Compare Cumulative and Short-Lived Climate Pollutants. Nature Climate Change, 6(8): 773-776.

Andersson, D.I. \& Hughes, D. 2014. Microbiological effects of sublethal levels of antibiotics. Nature Reviews Microbiology, 12(7): 465-478.

Andersson, K., Ohlsson, T., \& Olsson, P. 1994. Life cycle assessment (LCA) of food products and production systems. Trends in Food Science and Technology, 5(5): 134-138.

Antón, A., Maia de Souza, D., Teillard, F. \& Milà i Canals, L. 2017. Addressing biodiversity and ecosystem services in Life Cycle Assessment. In: D. Geneletti, ed. Handbook on Biodiversity and Ecosystem Services in Impact Assessment. pp. 140-164. Edward Elgar Publishing, Inc. Cheltenham, UK.

Arbault, D., Rivière, M., Rugani, B., Benetto, E. \& Tiruta-Barna, L. 2014. Integrated earth system dynamic modeling for life cycle impact assessment of ecosystem services. Science of The Total Environment, 472: 262-272.

Arrieta, E.M. \& González, A.D. 2019. Energy and carbon footprints of food: Investigating the effect of cooking. Sustainable Production and Consumption, 19: 44-52.

Arsenault, J.E., Fulgoni, V.L., Hersey, J.C., \& Muth, M.K. 2012. A novel approach to selecting and weighting nutrients for nutrient profiling of foods and diets. Journal of the Academy of Nutrition and Dietetics, 112(12); 1968-1975. doi.org/10.1016/j.jand.2012.08.032.

Arzoumanidis, I., Petti, L., Raucci, D. \& Raggi, A. 2021. Multifunctional modelling in the life cycle assessment of honey considering pollination. The International Journal of Life Cycle Assessment, 26: 643-655.

Asem-Hiablie, S., Battagliese, T., Stackhouse-Lawson, K.R. \& Alan Rotz, C. 2019. A life cycle assessment of the environmental impacts of a beef system in the USA. The International Journal of Life Cycle Assessment, 24: 441-455.

Astrup, A., Magkos, F., Bier, D.M., Brenna, J.T., de Oliveira Otto, M.C., Hill, J. O., King, J.C. et al. 2020. Saturated fats and health: a reassessment and proposal for food-based recommendations: JACC state-of-the-art review. Journal of the American College of Cardiology, 76(7): 844-857.

Audsley, A., Alber, S. Clift, R., Cowell, S., Crettaz, P., Gaillard, G., Hausheer et al. 1997. Harmonisation of Environmental Life Cycle Assessment for Agriculture. Final Report for Concerted Action AIR3-CT94-2028. Silsoe, Bedford, Silsoe Research Institute.

Avadí, A., Vázquez-Rowe, I., Symeonidis, A., \& Moreno-Ruiz, E. 2020. First series of seafood datasets in ecoinvent: setting the pace for future development. The International Journal of Life Cycle Assessment, 25(7): 1333-1342. 
Azevedo, L.B., van Zelm, R., Elshout, P.M.F., Hendriks, A.J., Leuven, R.S.E.W., Struijs, J., de Zwart, D. \& Huijbregts, M.A.J. 2013. Species richness-phosphorus relationships for lakes and streams worldwide. Glob. Ecol. Biogeog. 22: 1304-1314. doi.org/10.1111/geb.12080

Balcombe, P., Speirs, J.F., Brandon, N.P. \& Hawkes, A.D. 2018. Methane Emissions: Choosing the Right Climate Metric and Time Horizon. Environmental Science: Processes \& Impacts, 20(10): 1323-1339.

Baldini, C., Gardoni, D. \& Guarino, M. 2017. A critical review of the recent evolution of Life Cycle Assessment applied to milk production. Journal of Cleaner Production 140: 421-435.

Banar, M. \& Çokaygil, Z. 2009. A life cycle comparison of alternative cheese packages. Clean Soil, Air, Water, 37: 136-141.

Bartl, K., Gómez, C.A. \& Nemecek, T. 2011. Life cycle assessment of milk produced in two smallholder dairy systems in the highlands and the coast of Peru. Journal of Cleaner Production, 19: 1494-1505.

Bartocci, P., Fantozzi, P. \& Fantozzi, F. 2017. Environmental impact of Sagrantino and Grechetto grapes cultivation for wine and vinegar production in central Italy. Journal of Cleaner Production, 140: 569-580.

Bastías, J.M., Balladares, P., Acuña, S., Quevedo, R. \& Muñoz, 0. 2017. Determining the effect of different cooking methods on the nutritional composition of salmon (Salmo salar) and Chilean jack mackerel (Trachurus murphyil fillets. PloS One, 12(7): e0180993.

Batlle-Bayer, L., Aldaco, R., Bala, A. \& Fullana-i-Palmer, P. 2020a. Toward sustainable dietary patterns under a water-energy-food nexus life cycle thinking approach. Current Opinion in Environmental Science and Health, 13: 61-67.

Batlle-Bayer, L., Bala, A., Alberti, J., Xifre, R., Aldaco, R. \& Fullana-I-Palmer, P. 2020b. Food affordability and nutritional values within the functional unit of a food LCA. An application on regional diets in Spain. Resources Conservation and Recycling, 160: 104856.

Batlle-Bayer, L., Bala, A., Aldaco, R., Vidal-Mones, B., Colom, R. \& Fullana-I-Palmer, P. 2021. An explorative assessment of environmental and nutritional benefits of introducing low-carbon meals to Barcelona schools. Science of The Total Environment, 756: 143879.

Beerling, D.J., Leake, J.R., Long, S.P., Scholes, J.D., Ton, J., Nelson, P.N., Bird, M. et al. 2018. Farming with crops and rocks to address global climate, food and soil security. Nature Plants, 4 : $138-$ 147. doi.org/10.1038/s41477-018-0108-y

Bellassen, V., Drut, M., Antonioli, F., Brečić, R., Donati, M., Ferrer-Pérez, H., Gauvrit, L. et al. 2021. The Carbon and Land Footprint of Certified Food Products. Journal of Agricultural and Food Industrial Organization, 19: 113-126.

Beloin-Saint-Pierre, D., Albers, A., Hélias, A., Tiruta-Barna, L., Fantke, P., Levasseur, A., Benetto, E., Benoist, A. \& Collet, P.. 2020. Addressing Temporal Considerations in Life Cycle Assessment. Science of The Total Environment, 743: 140700.

Berardy, A., Fresán, U., Matos, R.A., Clarke, A., Mejia, A., Jaceldo-Siegl, K. \& Sabaté, J. 2020 Environmental impacts of foods in the Adventist health study-2 dietary questionnaire. Sustainability, 12: 1-14.

Berardy, A., Johnston, C.S., Plukis, A., Vizcaino, M. \& Wharton C. 2019. Integrating protein quality and quantity with environmental impacts in life cycle assessment. Sustainability, 11: 1-11.

Berger, M., Sonderegger, T., Alvarenga, R., Bach, V., Cimprich, A., Dewulf, J., Frischknecht, R. et al. 2020. Mineral resources in life cycle impact assessment: part II - recommendations on application-dependent use of existing methods and on future method development needs. International Journal of Life Cycle Assessment,25, 798-813 (https://doi.org/10.1007/s11367020-01737-5).

Bernstad, A. \& Cánovas, A. 2015. Current practice, challenges and potential methodological improvements in environmental evaluations of food waste prevention - A discussion paper. Resources, Conservation and Recycling, 101: 132-142. 
Bessou, C., Tailleur, A., Godard, C., Gac, A., Lebas de la Cour, J., Boissy, J. Mischler, P., Caldeira-

Pires, A. \& Benoist, A. 2020. Accounting for Soil Organic Carbon Role in Land Use Contribution to Climate Change in Agricultural LCA: Which Methods? Which Impacts? The International Journal of Life Cycle Assessment, 25(7): 1217-1230.

Bianchi, F.R., Moreschi, L., Gallo, M., Vesce, E. \& Del Borghi, A. 2021. Environmental analysis along the supply chain of dark, milk and white chocolate: a life cycle comparison. The International Journal of Life Cycle Assessment, 26: 807-821.

Bianchi, M., Strid, A., Winkvist, A., Lindroos, A.K., Sonesson, U. \& Hallström, E. 2020. Systematic evaluation of nutrition indicators for use within food LCA studies. Sustainability, 12: 1-18.

Birkved, M. \& Hauschild, M.Z., 2007. PestLCl-A model for estimating field emissions of pesticides in agricultural LCA. Ecological Modelling, 198: 433-451.doi.org/10.1016/j.ecolmodel.2007.05.035

Bjørn, A., Chandrakumar, C., Boulay, A.-M., Doka, G., Fang, K., Gondran, N., Hauschild, M.Z. et al. 2020. Review of life-cycle based methods for absolute environmental sustainability assessment and their applications. Environmental Research Letters, 15(8): 083001. doi.org/10.1088/1748-9326/ab89d7

Bohnes, F.A. 2019. LCA of aquaculture systems: methodological issues and potential improvements. The International Journal of Life Cycle Assessment, 24: 324-337.

Boulay, A.-M., Bare, J., Benini, L., Berger, M., Lathuillière, M.J., Manzardo, A., Margni, M. et al. 2018. The WULCA consensus characterization model for water scarcity footprints: assessing impacts of water consumption based on available water remaining (AWARE). The International Journal of Life Cycle Assessment, 23(2): 368-378. doi.org/10.1007/s11367-017-1333-8

Boulay, A.-M., Bare, J., DeCamillis, C., Döll, P., Gassert, F., Gerten, D., Humbert, S. et al. 2015. Consensus building on the development of a stress-based indicator for LCA-based impact assessment of water consumption: outcome of the expert workshops. The International Journal of Life Cycle Assessment, 20(5): 577-583. doi.org/10.1007/s11367-015-0869-8

Boulay, A.-M., Bulle, C., Bayart, J.-B., Deschênes, L. \& Margni, M. 2011. Regional characterization of freshwater Use in LCA: modeling direct impacts on human health. Environmental Science \& Technology, 45(20): 8948-8957. doi.org/10.1021/es1030883

Boulay, A.-M., Drastig, K., Amanullah, Chapagain, A., Charlon, V., Civit, B., DeCamillis, C. et al. 2021. Building consensus on water use assessment of livestock production systems and supply chains: Outcome and recommendations from the FAO LEAP Partnership. Ecological Indicators, 124 : 107391. doi.org/10.1016/j.ecolind.2021.107391

Bouwman, A.F., Beusen, A. \& Billen, G. 2009. Human alteration of the global nitrogen and phosphorus soil balances for the period 1970-2050. Global Biogeochemical Cycles, 23: GB0A04. doi.org/10.1029/2009GB003576

Bowerman, N.H.A., Frame, D.J., Huntingford, C., Lowe, J.A., Smith, S.M. \& Allen, M.R. 2013. The Role of Short-Lived Climate Pollutants in Meeting Temperature Goals. Nature Climate Change, 3(12): 1021-1024.

Brandão, M. \& i Canals, L. 2013. Global characterisation factors to assess land use impacts on biotic production. The International Journal of Life Cycle Assessment, 18: 1243-1252.

Brander, M., Burritt, R. L. \& Christ, K. L. 2019. Coupling attributional and consequential life cycle assessment: A matter of social responsibility. Journal of Cleaner Production, 215: 514-521.

Bright, R.M. 2015. Metrics for Biogeophysical Climate Forcings from Land Use and Land Cover Changes and Their Inclusion in Life Cycle Assessment: A Critical Review. Environmental Science \& Technology, 49(6): 3291-3303.

Brink, E., van Rossum, C., Postma-Smeets, A., Stafleu, A., Wolvers, D., van Dooren, C., Toxopeus, I., Buurma-Rethans, E., Geurts, M. \& Ocké, M. 2019. Development of healthy and sustainable food-based dietary guidelines for the Netherlands. Public Health Nutrition, 22(13): 2419-35. 
Bruno, M., Thomsen, M., Pulselli, F. M., Patrizi, N., Marini, M. \& Caro, D. 2019. The carbon footprint of Danish diets. Climatic Change, 156: 489-507.

Bulle, C., Margni, M., Patouillard, L., Boulay, A.-M., Bourgault, G., De Bruille, V., Cao, V. et al. 2019. IMPACT World+: a globally regionalized life cycle impact assessment method. The International Journal of Life Cycle Assessment, 24 (9): 1653-1674. doi.org/10.1007/s11367-019-01583-0

Burgess, A. \& Glasauer, P. 2004. Family Nutrition Guide. Rome. FAO. www.fao.org/3/y5740e/y5740e04.htm

Cain, M., Lynch, J., Allen, M.R., Fuglestvedt, J.S., Frame, D.J. \& Macey, A.H. 2019. Improved Calculation of Warming-Equivalent Emissions for Short-Lived Climate Pollutants. NPJ Climate and Atmospheric Science, 2(1).

Camps-Posino, L., Batlle-Bayer, L., Bala, A., Song, G., Qian, H., Aldaco, R., Xifré, R. \& Fullana-IPalmer, P. 2021. Potential climate benefits of reusable packaging in food delivery services. A Chinese case study. Science of The Total Environment, 794: 148570.

Cao, V., Margni, M., Favis, B.D. \& Deschênes, L. 2015. Aggregated indicator to assess land use impacts in life cycle assessment (LCA) based on the economic value of ecosystem services. Journal of Cleaner Production, 94: 56-67.

Carpenter, S.R., Caraco, N.F., Correll, D.L., Howarth, R.W., Sharpley, A.N. \& Smith, V.H., 1998. Nonpoint pollution of surface waters with phosphorus and nitrogen. Ecological Applications, 8: 559-568.

Castañe, S., \& Antón, A. 2017 Assessment of the nutritional quality and environmental impact of two food diets: A Mediterranean and a vegan diet. Journal of Cleaner Production, 167: 929-937.

Castellani, V., Beylot, A. \& Sala, S. 2019. Environmental impacts of household consumption in Europe: Comparing process-based LCA and environmentally extended input-output analysis. Journal of Cleaner Production, 240: 117966.

Castellani, V., Fusi, A. \& Sala, S. 2017. Basket of products indicator on food. JRC Technical Reports. Luxembourg. European Commission. https://eplca.jrc.ec.europa.eu/uploads/ConsumerFootprint_BoP_Food.pdf

Chalmers, N.G., Brander, M. \& Revoredo-Giha, C. 2015. The implications of empirical and 1: 1 substitution ratios for consequential LCA: using a $1 \%$ tax on whole milk as an illustrative example. The International Journal of Life Cycle Assessment, 20(9): 1268-1276.

Chang, J., Peng, S., Ciais, P., Saunois, M., Dangal, S.R.S., Herrero, M., Havlík, P., Tian, H. \& Bousquet, P. 2019. Revisiting Enteric Methane Emissions from Domestic Ruminants and Their $\triangle 13 \mathrm{CCH} 4$ Source Signature. Nature Communications, 10(1).

Chaplin-Kramer, R., Sim, S., Hamel, P., Bryant, B., Noe, R., Mueller, C., Rigarlsford, G. et al. 2017. Life cycle assessment needs predictive spatial modelling for biodiversity and ecosystem services. Nature Communications, 8: 15065.

Chaudhary, A. \& Brooks, T.M. 2018. Land use intensity-specific global characterization factors to assess product biodiversity footprints. Environmental Science \& Technology, 52(9): 5094-5104.

Chaudhary, A., Marinangeli, C.P., Tremorin, D. \& Mathys, A. 2018. Nutritional combined greenhouse gas life cycle analysis for incorporating Canadian yellow pea into cereal-based food products. Nutrients, 10(4): 490.

Chaudhary, A. \& Mooers, A.0. 2018. Terrestrial vertebrate biodiversity loss under future global land use change scenarios. Sustainability, 10(8): 2764.

Chaudhary, A., Pourfaraj, V. \& Mooers, A.0. 2018. Projecting global land-use driven evolutionary history loss. Divers. Diversity and Distributions, 24: 158-167.

Chaudhary, A., Verones, F., de Baan, L. \& Hellweg, S. 2015. Quantifying land use impacts on biodiversity: combining species-area models and vulnerability indicators. Environmental Science and Technology, 49 (16): 9987-9995. 
Chen, W., Oldfield, T.L., Patsios, S.I. \& Holden, N.M. 2020. Hybrid life cycle assessment of agroindustrial wastewater valorisation. Water research, 170: 115275.

Chen, X., Wilfart, A., Puillet, L. \& Aubin, J. 2017. A new method of biophysical allocation in LCA of livestock co-products: modeling metabolic energy requirements of body-tissue growth. The International Journal of Life Cycle Assessment, 22(6): 883-895.

Choma, E.F. \& Ugaya, C.M.L. 2017. Environmental impact assessment of increasing electric vehicles in the Brazilian fleet. Journal of Cleaner Production, 152: 497-507.

Ciroth, A. 2021. Life Cycle Inventory Analysis. In: A. Ciroth and R. Arvidsson, eds. LCA Compendium The Complete World of Life Cycle Assessment. Springer.

Ciroth, A., Arbuckle, P., Cherubini, E., Ugaya, C. \& Edelen, A. 2017 Report from GLAD Task 3: Core meta-data descriptors and guidance on populating descriptors. Working Group 3 of the Global Life Cycle Data Access Network (GLAD).

Ciroth, A., Muller, S., Weidema, B. \& Lesage, P. 2016. Empirically based uncertainty factors for the pedigree matrix in ecoinvent. The International Journal of Life Cycle Assessment, 21(9): 1338-1348.

Clark, M.A., Springmann, M., Hill, J. \& Tilman, D. 2019. Multiple health and environmental impacts of foods. Proceedings of the National Academy of Sciences, 116(46): 23357-23362.

Clune, S., Crossin, E. \& Verghese, K. 2017. Systematic review of greenhouse gas emissions for different fresh food categories. Journal of Cleaner Production, 140: 766-783.

Coelho, C.R.V., Pernollet, F. \& van der Werf, H.M.G. 2016. Environmental Life Cycle Assessment of Diets with Improved Omega-3 Fatty Acid Profiles. PLOS ONE, 11: e0160397.

Collins, W.J., Frame, D.J., Fuglestvedt, J.S. \& Shine, K.P. 2020. Stable Climate Metrics for Emissions of Short and Long-Lived Species-Combining Steps and Pulses. Environmental Research Letters, 15(2): 024018.

Conley, D., Paerl, H., Howarth, R., Boesch, D., Seitzinger, S., Havens, K., Lancelot, C. \& Likens, G. 2009. Controlling Eutrophication: Nitrogen and Phosphorus. Science, 323: 1014-1015. doi.org/10.1126/science.1167755

Cooreman-Algoed, M., Huysveld, S., Lachat, C. \& Dewulf, J. 2020. How to integrate nutritional recommendations and environmental policy targets at the meal level: A university canteen example. Sustainable Production and Consumption, 21: 120-131.

Corrado, S., Ardente, F., Sala, S. \& Saouter, E. 2017. Modelling of food loss within life cycle assessment: From current practice towards a systematisation. Journal of Cleaner Production, 140: 847-859.

Corrado, S., Castellani, V., Zampori, L. \& Sala, S. 2018. Systematic analysis of secondary life cycle inventories when modelling agricultural production: A case study for arable crops. Journal of Cleaner Production, 172: 3990-4000.

Cosme, N. \& Hauschild, M.Z. 2017. Characterization of waterborne nitrogen emissions for marine eutrophication modelling in life cycle impact assessment at the damage level and global scale. The International Journal of Life Cycle Assessment, 1-13. doi.org/10.1007/s11367-017-1271-5

Costantini, M., Ferrante, V., Guarino, M. \& Bacenetti, J. 2021. Environmental sustainability assessment of poultry productions through life cycle approaches: A critical review. Trends in Food Science and Technology, 110: 201-212.

Costanza, R., de Groot, R., Braat, L., Kubiszewski, I., Fioramonti, L., Sutton, P., Farber, S. \& Grasso, M. 2017. Twenty years of ecosystem services: How far have we come and how far do we still need to go? Ecosystem Services, 28: 1-17.

Curran, M., Maia de Souza, D., Antón, A., Teixeira, R. F., Michelsen, O., Vidal-Legaz, B., Sala, S. \& Milà i Canals, L. 2016. How Well Does LCA Model Land Use Impacts on Biodiversity? A Comparison with Approaches from Ecology and Conservation. Environmental Science \& Technology, 50(6): 2782-2795. 
Dai, T., Fleischer, A.S., Wemhoff, A.P. \& Lee, R. 2017. Environmental impact of an industrial kitchen: A case study. American Society of Mechanical Engineers (ASME).

Damiani, M., Roux, P., Loiseau, E., Lamouroux, N., Pella, H., Morel, M. \& Rosenbaum, R. K. 2021. A high-resolution life cycle impact assessment model for continental freshwater habitat change due to water consumption. Science of the Total Environment, 782: 146664. doi.org/10.1016/j.scitotenv.2021.146664

de Baan, L., Alkemade, R. \& Koellner, T. 2013. Land use impacts on biodiversity in LCA: a global approach. The International Journal of Life Cycle Assessment, 18: 1216-1230.

de Baan, L., Mutel, C.L., Curran, M., Hellweg, S. \& Koellner, T. 2013. Land use in life cycle assessment: global characterization factors based on regional and global potential species extinction. Environmental Science \& Technology, 47 16): 9281-9290.

De Camillis, C., Bligny, J.C., Pennington, D. \& Pályi, B. 2012. Outcomes of the second workshop of the Food Sustainable Consumption and Production Round Table Working Group 1: Deriving scientifically sound rules for a sector-specific environmental assessment methodology. The International Journal of Life Cycle Assessment, 17: 511-515.

De Camillis, C., Brandao, M., Zamagni, A. \& Pennington, D. 2013. Sustainability assessment of futureoriented scenarios: a review of data modelling approaches in Life Cycle Assessment. EUR 26088. Luxembourg. Publications Office of the European Union. JRC82804.

De Laurentiis, V., Hunt, D.V.L., Lee, S.E. \& Rogers, C.D.F. 2019. EATS: a life cycle-based decision support tool for local authorities and school caterers. The International Journal of Life Cycle Assessment, 24: 1222-1238.

De Schryver, A.M., Brakkee, K.W., Goedkoop, M.J. \& Huijbregts, M.A.J. 2009. Characterization Factors for Global Warming in Life Cycle Assessment Based on Damages to Humans and Ecosystems. Environmental Science \& Technology, 43: 1689-1695.

de Souza, D., Flynn, D.B., DeClerck, F., Rosenbaum, R., de Melo Lisboa, H. \& Koellner, T. 2013. Land use impacts on biodiversity in LCA: proposal of characterization factors based on functional diversity. The International Journal of Life Cycle Assessment, 18: 1231-1242.

Del Borghi, A., Moreschi, L. \& Gallo, M. 2020. Life cycle assessment in the food industry. In: C. Galanakis, ed. The Interaction of Food Industry and Environment. pp. 63-118. Academic Press.

Dijkman, T.J., Birkved, M. \& Hauschild, M.Z. 2012. PestLCI 2.0: a second generation model for estimating emissions of pesticides from arable land in LCA. The International Journal of Life Cycle Assessment, 17: 973-987. doi.org/10.1007/s11367-012-0439-2

Doran-Browne, N.A., Eckard, R.J., Behrendt, R. \& Kingwell, R.S. 2015. Nutrient density as a metric for comparing greenhouse gas emissions from food production. Climatic Change, 129(1-2): 73-87.

Drastig, K., Vellenga, L., Qualitz, G., Singh, R., Pfister, S., Boulay, A.-M., Wiedemann, S., Prochnow, A., Chapagain, A. \& DeCamillis, C. 2021. Accounting for livestock water productivity: How and why? Land and Water Discussion Papers. Rome, FAO.

Drewnowski, A., Amanquah, D. \& Gavin-Smith, B. 2021. Perspective: How to Develop Nutrient Profiling Models Intended for Global Use: A Manual. Advances in Nutrition, 12(3): 609-20.

Drewnowski, A. \& Burton-Freeman, B. 2020. A New Category-Specific Nutrient Rich Food (NRF9f.3) Score Adds Flavonoids to Assess Nutrient Density of Fruit. Food \& Function, 11 (1): 123-130. doi:10.1039/C9F002344E.

Drewnowski, A. \& Fulgoni, V.L. 2014. Nutrient density: principles and evaluation tools. The American Journal of Clinical Nutrition, 99. doi:10.3945/ajcn.113.073395

Drewnowski, A., Maillot, M. \& Darmon, N. 2009. Should nutrient profiles be based on $100 \mathrm{~g}, 100 \mathrm{kcal}$ or serving size? European Journal of Clinical Nutrition, 63(7): 898-904.

Drulyte, D. \& Orlien, V. 2019. The effect of processing on digestion of legume proteins. Foods, 8(6): 224. 
DTU. 2021. Pesticide consensus in LCA. In: DTU.DK. Cited 3 November 2021. www.sustainability.man.dtu.dk/english/Research/QSA/Research/Pesticide-consensus

EC-JRC. 2018. Product Environmental Footprint Category Rules Guidance Version 6.3. European Comission-Joint Research Center. May 2018. https://eplca.jrc.ec.europa.eu/permalink/PEFCR_guidance_v6.3-2.pdf

EC-JRC. 2019. Environmental Footprint reference package 3.0 (EF 3.0). Joint Research Centre of the European Commission. Ispra, Italy. https://eplca.jrc.ec.europa.eu/LCDN/developerEF.xhtml.

Edelen, A. \& Ingwersen, W.W. 2018. The creation, management, and use of data quality information for life cycle assessment. The International Journal of Life Cycle Assessment, 23(4): 759-772.

EEA. 2017. Actors in the food chain (infographic)- European Environmental Agency. https://uww.eea.europa.eu/media/infographics/actors-in-the-food-chain-2/image/image_view_fullscreen.

EFSA NDA Panel. 2012. Scientific opinion on dietary reference values for protein. EFSA Journal, 10: 2257.

Emara, Y., Jolliet, O., Tudge, L., Kosnik, M., Siegert, M., Finkbeiner, M. \& Fantke, P. (forthcoming). Deriving antibiotic-specific "resistance selection hazard" in different environmental compartments based on predicted bacterial sensitivities to selection pressure.

Eme, P.E., Douwes, J., Kim, N., Foliaki, S. \& Burlingame, B. 2019. Review of Methodologies for Assessing Sustainable Diets and Potential for Development of Harmonised Indicators. International Journal of Environmental Research and Public Health, 16: 1184.

Ernstoff, A.S., Niero, M., Muncke, J., Trier, X., Rosenbaum, R.K., Hauschild, M.Z. \& Fantke, P. 2019 b. Challenges of including human exposure to chemicals in food packaging as a new exposure pathway in Life Cycle Impact Assessment. International Journal of Life Cycle Assessment, 24(3): 543-552.

Ernstoff, A., Stylianou, K.S., Sahakian, M., Godin, L., Dauriat, A., Humbert, S., Erkman, S. \& Jolliet, 0. 2020. Towards win-win policies for healthy and sustainable diets. Nutrients, 12(9): 2745 doi.org/10.3390/nu12092745

Ernstoff, A., Tu, Q., Faist, M., Del Duce, A., Mandlebaum, S. \& Dettling, J. 2019a. Comparing the environmental impacts of meatless and meat-containing meals in the United States. Sustainability, 11.

Espinoza-Orias, N., Stichnothe, H. \& Azapagic, A. 2011. The carbon footprint of bread. The International Journal of Life Cycle Assessment, 16: 351-365.

Espinoza-Orias, N., \& Azapagic, A. 2018. Understanding the impact on climate change of convenience food: Carbon footprint of sandwiches. Sustainable Production and Consumption, 15: 1-15.

Esteve-Llorens, X., Darriba, C., Moreira, M.T., Feijoo, G. \& González-García, S. 2019a. Towards an environmentally sustainable and healthy Atlantic dietary pattern: Life cycle carbon footprint and nutritional quality. Science of The Total Environment, 646: 704-715.

Esteve-Llorens, X., Moreira, M.T., Feijoo, G. \& González-García, S. 2019b. Linking environmental sustainability and nutritional quality of the Atlantic diet recommendations and real consumption habits in Galicia (NW Spain). Science of The Total Environment, 683: 71-79.

EU (European Union). 2013. Commission Recommendation of 9 April 2013 on the use of common methods to measure and communicate the life cycle environmental performance of products and organisations. Text with EEA relevance. 2013/179/EU: OJ L 124, 4.5.2013: 1-210.

EuroFIR. 2021. European Food Information Resource. In: EuroFIR AISBL. Cited 1 November 2021. www.eurofir.org/

Fanelli, N.S., Bailey, H.M., Guardiola, L.V. \& Stein, H.H. 2021. Values for Digestible Indispensable Amino Acid Score (DIAAS) Determined in Pigs Are Greater for Milk Than for Breakfast Cereals, but DIAAS Values for Individual Ingredients Are Additive in Combined Meals. The Journal of Nutrition, 151(3): 540-547. 
Fantke P, Chiu WA, Aylward L, Judson R, Huang L, Jang S, Gouin T, Rhomberg L, Aurisano N, McKone T, Jolliet 0. 2021. Exposure and Toxicity Characterization of Chemical Emissions and Chemicals in Products: Global Recommendations and Implementation in USEtox. International Journal of Life Cycle Assessment, 26,: 899-915. https://doi.org/10.1007/s11367-021-01889-y

Fantke, P., Friedrich, R. \& Jolliet, 0. 2012. Health impact and damage cost assessment of pesticides in Europe. Environment International, 49 : 9-17. doi.org/10.1016/j.envint.2012.08.001

Fantke, P. \& Jolliet, 0. 2015. Life cycle human health impacts of 875 pesticides. International Journal of Life Cycle Assessment, 1-12. doi.org/10.1007/s11367-015-0910-y

Fantke, P., Jolliet, O., Apte, J.S., Hodas, N., Evans, J., Weschler, C.J., Stylianou, K.S., Jantunen, M. \& McKone, T.E. 2017. Characterizing aggregated exposure to primary particulate matter: Recommended intake fractions for indoor and outdoor sources. Environmental Science \& Technology, 51: 9089-9100. doi.org/10.1021/acs.est.7b02589

Fantke, P., McKone, T.E., Tainio, M., Jolliet, O., Apte, J.S., Stylianou, K.S., Illner, N., Marshall, J.D., Choma, E.F. \& Evans, J.S. 2019. Global effect factors for exposure to fine particulate matter. Environmental Science \& Technology, 53: 6855-6868. doi.org/10.1021/acs.est.9b01800

FA0. 2013. Food Wastage Footprint. Impacts on Natural Resources. Summary Report. Rome, FAO.

FAO. 2016a. Principles for the assessment of livestock impacts on biodiversity. Rome, FAO.

FA0. 2016b. The contributions of livestock species and breeds to ecosystem services. Rome, FAO. www.fao.org/documents/card/en/c/25208ece-20f2-44d8-a63e-7d7c84950a9d/

FAO. 2016c. The FAO Action Plan on Antimicrobial Resistance 2016-2020. Rome, FAO. www.fao.org/policy-support/tools-and-publications/resources-details/en/c/459933/

FAO. 2018. Guidelines for environmental quantification of nutrient flows and impact assessment in livestock supply chains. Livestock Environmental Assessment and Performance (LEAP) Partnership. Rome, FAO.

FA0. 2019a. The State of Food and Agriculture 2019: Moving Forward on Food Loss and Waste Reduction. Rome, FAO. www.fao.org/3/ca6030en/ca6030en.pdf

FA0. 2019b. About INFOODS. In: International Network of Food Data Systems INFOOD. FAO/INFOODS Food Composition Table for Western Africa (2019) User Guide and Condensed Food Composition Table. FAO/INFOODS Food Composition Databases. Rome, FAO. www.fao.org/infoods/infoods/en/

FA0.2019c. CodexAlimentarius: Food categories. www.fao.org/gsfaonline/foods/index.html?collapse=0

FA0. 2019d. Measuring and Modelling Soil Carbon Stocks and Stock Changes in Livestock Production Systems: Guidelines for Assessment (Version 1). Report. Livestock Environmental Assessment and Performance (LEAP) Partnership. Rome, FAO. www.fao.org/3/CA2934EN/ca2934en.pdf.

FAO. 2020a. Land use in agriculture by the numbers. In: FAO Sustainable Food and Agriculture. Rome. Cited 29 September 2021. www.fao.org/sustainability/news/detail/en/c/1274219/

FA0. 2020b. The State of Food Security and Nutrition in the World: Transforming Food Systems for Affordable Healthy Diets. Rome, FAO. doi.org/10.4060/ca9692en

FA0. 2020c. The Share of Agriculture in Total Greenhouse Gas Emission. Global, Regional and Country Trends 1990-2017. FAOSTAT Analytical Brief Series No 1. Report. www.fao.org/3/ca8389en/CA8389EN.pdf.

FA0. 2020d. Biodiversity and the livestock sector - Guidelines for quantitative assessment - Version 1. Rome, Livestock Environmental Assessment and Performance Partnership (FAO LEAP). Rome, FAO. doi.org/10.4060/ca9295en

FAO. 2021. Food-based dietary guidelines. In: FAO Nutrition. Rome. Cited 8 July 2021. www.fao.org/nutrition/education/food-dietary-guidelines.

FAO, IFAD, UNICEF, WFP \& WHO. 2018. The State of Food Security and Nutrition in the World 2018: Building 
Climate Resilience for Food Security and Nutrition. Rome, FAO.

FAO, IFAD, UNICEF, WFP \& WHO. 2021. The State of Food Security and Nutrition in the World 2021.

Transforming Food Systems for Food Security, Improved Nutrition and Affordable Healthy Diets for All. Rome, FAO.

FAO \& WHO. 1985. Codex Alimentarius International Food Standards Guidelines on nutrition labelling. CAC/GL 2-1985. Revised 2017. www.fao.org/fao-who-codexalimentarius

FAO \& WHO. 2013. Dietary protein quality evaluation in human nutrition. Report of an FAO Expert Consultation. Food and Nutrition Paper No.92. Rome, FAO.

FAO \& WHO. 2001. Codex Alimentarius Commission. Procedural Manual. 12th edition. Rome, Joint FAO/ WHO Food Standards Programme. Rome, FAO. www.fao.org/3/y2200e/y2200e00.htm\#Contents

Felix, M., Holst, N. \& Sharp, A. 2019. PestTox: An object oriented model for modeling fate and transport of pesticides in the environment and their effects on population dynamics of non-target organisms. Computers and Electronics in Agriculture, 166: 105022. https://doi.org/10.1016/j.compag.2019.105022

Fern, E.B., Watzke, H., Barclay, D.V., Roulin, A. \& Drewnowski, A. 2015. The nutrient balance concept: a new quality metric for composite meals and diets. PLoS One, 10, no. 7: e0130491.

Fernández-Lobato, L., López-Sánchez, Y., Blejman, G., Jurado, F., Moyano-Fuentes, J. \& Vera, D. 2021. Life cycle assessment of the Spanish virgin olive oil production: a case study for Andalusian region. Journal of Cleaner Production, 290.

Food SCP RT, 2013. ENVIFOOD Protocol, Environmental Assessment of Food and Drink Protocol. European Food Sustainable Consumption and Production Round Table (SCP RT). Working Group 1. Brussels, Belgium.

Forster, P., Storelvmo, T., Armour, K., Collins, W., Dufresne, J.L., Frame, D., Lunt, D.J. et al. 2021. The Earth's Energy Budget, Climate Feedbacks, and Climate Sensitivity. In: V.P. MassonDelmotte, V., A. Zhai, S.L. Pirani, C. Connors, S. Péan, N. Berger, Y. Caud, et al., eds. Climate Change 2021: The Physical Science Basis. Contribution of Working Group I to the Sixth Assessment Report of the Intergovernmental Panel on Climate Change. Cambridge University Press. In Press.

Friedlingstein, P., 0'Sullivan, M., Jones, M.W., Andrew, R.M., Hauck, J., Olsen, A., Peters, G.P. et al. 2020. Global Carbon Budget 2020. Earth System Science Data, 12(4): 3269-3340.

Frischknecht, R. \& Jolliet, 0. 2019. Global Guidance for Life Cycle Impact Assessment Indicators: Volume 2. UNEP/SETAC Life Cycle Initiative. United Nations Environment Programme/Society for Environmental Toxicology and Chemistry Life Cycle Initiative. Paris, France.

Frischknecht, R., Steiner, R. \& Jungbluth, N. 2008. Ökobilanzen: Methode der ökologischen Knappheit - Ökofaktoren 2006: Methode für die Wirkungsabschätzung in Ökobilanzen. Zürich, Öbu.

Frischknecht, R., \& Stucki, M. 2010. Scope-dependent modelling of electricity supply in life cycle assessments. International Journal of Life Cycle Assessment, 15(8): 806-816.

Fulgoni, V.L., Keast, D.R. \& Drewnowski, A., 2009. Development and Validation of the Nutrient-Rich Foods Index: A Tool to Measure Nutritional Quality of Foods. The Journal of Nutrition, 139: 1549-1554.

Fulgoni, V.L., Wallace, T.C., Stylianou, K.S. \& Jolliet, 0. 2018. Calculating Intake of Dietary Risk Components Used in the Global Burden of Disease Studies from the What We Eat in America / National Health and Nutrition Examination Surveys. Nutrients, 10: 1441, https://doi.org/10.3390/nu10101441.

García-Herrero, L., De Menna, F. \& Vittuari, M. 2019. Food waste at school. The environmental and cost impact of a canteen meal. Waste Management, 100: 249-258.

Gava, 0., Bartolini, F., Venturi, F., Brunori, G., Zinnai, A., \& Pardossi, A. 2019. A reflection of the use of the Life Cycle Assessment tool for agri-food sustainability. Sustainability, 11(1): 71. 
Gentil, C., Fantke, P., Mottes, C. \& Basset-Mens, C. 2020. Challenges and ways forward in pesticide emission and toxicity characterization modeling for tropical conditions. The International Journal of Life Cycle Assessment, 25: 1290-1307. doi.org/10.1007/s11367-019-01685-9

Gentil-Sergent, C., Basset-Mens, C., Gaab, J., Mottes, C., Melero, C. \& Fantke, P. 2021. Quantifying pesticide emission fractions for tropical conditions. Chemosphere, 275: 130014. https://doi.org/10.1016/j.chemosphere.2021.130014

Gianfredi, V., Salvatori, T., Nucci, D., Villarini, M. \& Moretti, M. 2018. Can chocolate consumption reduce cardio-cerebrovascular risk? A systematic review and meta-analysis. Nutrition, 46: 103-114.

GLAD. 2018. Global LCA Data Access Network. United Nations Environmental Programme. Life Cycle Initiative. www.globallcadataaccess.org/

GLAM. 2020. Global LCIA Guidance Phase 3. Creation of a Global Life Cycle Impact Assessment Method. Scoping document. UN Life Cycle Initiative, pp. 166. www.lifecycleinitiative.org/wp-content/uploads/2021/02/GLAM3-Scoping-document.pdf

Goedkoop, M., Heijungs, R., Huijbregts, M., De Schryver, A., Struijs, J. \& van Zelm, R. 2008. Main Report, Part 1: Characterization, 1st ed. Ministerie van Volkshuisvesting, Ruimtelijke Ordening en Milieubeheer (VROM). The Hague. www.leidenuniv.nl/cml/ssp/publications/recipe_characterisation.pdf

González-García, S., Esteve-Llorens, X., Moreira, M.T. \& Feijoo, G. 2018. Carbon footprint and nutritional quality of different human dietary choices. Science of The Total Environment, 644: 77-94.

Goossens, Y., Berrens, P., Charleer, L., Coremans, P., Houbrechts, M., Vervaet, C., De Tavernier, J. \& Geeraerd, A. 2017a. Qualitative assessment of eco-labels on fresh produce in Flanders (Belgium) highlights a potential intention-performance gap for the supply chain. Journal of Cleaner Production, 140: 986-995.

Goossens, Y., Annaert, B., De Tavernier, J., Mathijs, E., Keulemans, W. \& Geeraerd, A. 2017b. Life cycle assessment (LCA) for apple orchard production systems including low and high productive years in conventional, integrated and organic farms. Agricultural Systems, 153, 81-93.

Green, A., Nemecek, T., Chaudhary, A. \& Mathys, A. 2020. Assessing nutritional, health, and environmental sustainability dimensions of agri-food production. Global Food Security, 26: 100406.

Green, A., Nemecek, T., Smetana, S. \& Mathys, A. 2021. Reconciling regionally-explicit nutritional needs with environmental protection by means of nutritional life cycle assessment. Journal of Cleaner Production: 127696.

Grigoriadis, V., Nugent, A. \& Brereton, P. 2021. Working Towards a Combined Measure for Describing Environmental Impact and Nutritive Value of Foods: A Review. Trends in Food Science \& Technology, 112: 298-311. doi:https://doi.org/10.1016/j.tifs.2021.03.047.

Groen, E. A. \& Heijungs, R. 2017. Ignoring correlation in uncertainty and sensitivity analysis in life cycle assessment: what is the risk? Environmental Impact Assessment Review, 62: 98-109.

Groen E.A., Van Zanten, H.H.E., Heijungs, R., Bokkers, E.A.M. \& De Boer, I.J.M. 2016. Sensitivity analysis of greenhouse gas emissions from a pork production chain. Journal of Cleaner Production, 129: 202-211.

Gronlund, C., Humbert, S., Shaked, S., O'Neil, M. \& Jolliet, 0. 2015. Characterizing the burden of disease of particulate matter for life cycle assessment. Air Quality, Atmosphere \& Health, 8 (1): 29-46 http://dx.doi.org/10.1007/s11869-014-0283-6

Grouzet, P., Leonard, J., Nixon, S.W., Rees, Y., Parr, W., Laffon, L., Bogestrand, J. et al. 2000. Nutrients in European Ecosystems (No. 4), Environmental Assessment Report. European Environment Agency. Copenhagen, Denmark.

Guerry, A.D., Polasky, S., Lubchenco, J., Chaplin-Kramer, R., Daily, G.C., Griffin, R., Ruckelshaus, M. 
et al. 2015. Natural capital and ecosystem services informing decisions: From promise to practice. Proceedings of the National Academy of Sciences of the United States of America, 112: 7348-7355.

Guinée, J.B., Heijungs, R., van Oers, L.F.C.M., Sleeswijk, A.W., van de Meent, D., Vermeire, T. \& Rikken, M. 1997. USES: Uniform System for the Evaluation of Substances. The International Journal of Life Cycle Assessment, 1: 133-138. https://doi.org/10.1007/BF02978940

Guo, J., Astrup, A., Lovegrove, J.A., Gijsbers, L., Givens, D.I. \& Soedamah-Muthu, S. S. 2017. Milk and dairy consumption and risk of cardiovascular diseases and all-cause mortality: doseresponse meta-analysis of prospective cohort studies. European Journal of Epidemiology, 32(4): 269-287.

Guo, A., Bryngelsson, S., Strid, A., Bianchi, M., Winkvist, A. \& Hallström, E. 2021. Choice of health metrics for combined health and environmental assessment of foods and diets: a systematic review of methods. Submitted.

Guyatt, G., Oxman, A.D., Akl, E.A., Kunz, R., Vist, G., Brozek, J., Norris, S. et al. 2011. GRADE guidelines: 1. Introduction-GRADE evidence profiles and summary of findings tables. Journal of Clinical Epidemiology, 64(4): 383-94.

Haber, G.B., Heaton, K.W., Murphy, D. \& Burroughs, L.F. 1977. Depletion and disruption of dietary fibre: effects on satiety, plasma-glucose, and serum-insulin. The Lancet, 310(8040): 679-682.

Haines-Young, R. \& Potschin, M. 2010. The links between biodiversity, ecosystem services and human well-being. Ecosystem Ecology: A New Synthesis, 1: 110-139.

Haines-Young, R. \& Potschin, M. 2018. Common International Classification of Ecosystem Services (CICES) V5.1 and Guidance on the Application of the Revised Structure. Fabis Consulting Ltd. The Paddocks, Chestnut Lane, Barton in Fabis, Nottingham, NG11 OAE, UK, available from: www.cices.com

Hallstrom, E., Bajzelj, B., Håkansson, N., Sjons, J., Åkesson, A., Wolk, A. \& Sonesson, U. 2021. Dietary climate impact: Contribution of foods and dietary patterns by gender and age in a Swedish population. Journal of Cleaner Production, 306: 127189

Hallström, E., Bergman, K., Mifflin, K., Parker, R., Tyedmers, P., Troell, M. \& Ziegler, F. 2019. Combined climate and nutritional performance of seafoods. Journal of Cleaner Production, 230: 402-411.

Hallström, E., Davis, J., Woodhouse, A. \& Sonesson, U. 2018. Using dietary quality scores to assess sustainability of food products and human diets: A systematic review. Ecological Indicators, 93: 219-230. doi.org/10.1016/J.ECOLIND.2018.04.071.

Hanafiah, M.M., Xenopoulos, M.A., Pfister, S., Leuven, R.S.E. W. \& Huijbregts, M.A. J. 2011 Characterization factors for water consumption and greenhouse gas emissions based on freshwater fish species extinction. Environmental Science \& Technology, 45(12): 5272-5278. doi.org/10.1021/es1039634

Hauschild, M.Z., Huijbregts, M.A.J., Jolliet, O., Macleod, M., Margni, M., van de Meent, D., Rosenbaum, R.K. \& McKone, T.E. 2008. Building a model based on scientific consensus for life cycle impact assessment of chemicals: The search for harmony and parsimony. Environmental Science \& Technology, 42: 7032-7037. https://doi.org/10.1021/es703145t

Hauschild, M.Z. \& Potting, J. 2005. Spatial differentiation in LCA impact assessment - The EDIP2003 methodology (No. Environmental News No. 2005). Technical University of Denmark - Institute for Product Development.

Health Council of the Netherlands. 2015. Dutch dietary guidelines 2015. The Hague.

Heard, B.R., Bandekar, M., Vassa, B. \& Miller, S.A. 2019. Comparison of life cycle environmental impacts from meal kits and grocery store meals. Resources Conservation and Recycling, 147: 189-200.

Heller, M.C. \& Keoleian, G.A., 2003. Assessing the sustainability of the US food system: a life cycle 
perspective. Agricultural Systems 76: 1007-1041.

Heller, M.C., Keoleian, G.A. \& Willett, W.C. 2013. Toward a life cycle-based, diet-level framework for food environmental impact and nutritional quality assessment: a critical review. Environmental Science and Technology, 47(22): 12632-12647. doi.org/10.1021/es4025113

Helmes, R.J.K., Huijbregts, M.A.J., Henderson, A.D. \& Jolliet, 0. 2012. Spatially explicit fate factors of phosphorous emissions to freshwater at the global scale. The International Journal of Life Cycle Assessment, 17: 646-654. doi.org/10.1007/s11367-012-0382-2

Helo, P. \& Ala-Harja, H. 2018. Green logistics in food distribution-a case study. International Journal of Logistics Research and Applications, 21: 464-479.

Henderson, A.D. 2015. Eutrophication. In: M.Z. Hauschild, M.A.J. Huijbregts, eds. Life Cycle Impact Assessment, LCA Compendium - The Complete World of Life Cycle Assessment. Springer Netherlands, pp. 177-197.

Henderson, A.D., Asselin-Balençon, A.C., Heller, M., Lessard, L., Vionnet, S. \& Jolliet, 0. 2017. Spatial Variability and Uncertainty of Water Use Impacts from U.S. Feed and Milk Production. Environmental Science \& Technology, 51(4): 2382-2391.

Henriksson, P., Cucurachi, S., Guinée, J.B., Heijungs, R., Troell, M. \& Ziegler, F. 2021. A rapid review of meta-analyses and systematic reviews of environmental footprints of food commodities and diets. Global Food Security, 28: 100508.

Herforth, A., Bai, Y., Venkat, A., Mahrt, K., Ebel, A. \& Masters, W.A. 2020. Cost and affordability of healthy diets across and within countries. Background paper for The State of Food Security and Nutrition in the World 2020. FAO Agricultural Development Economics Technical Study No. 9. Rome, FAO. doi.org/10.4060/cb2431en

Herforth, A., M. Arimond, C. Álvarez-Sánchez, J. Coates, Christianson, K. \& Muehlhoff, E. 2019. A Global Review of Food-Based Dietary Guidelines. Advances in Nutrition, 10(4): 590-605.

Hessle, A., Kumm, K. I., Bertilsson, J., Stenberg, B. \& Sonesson, U. 2017. Combining environmentally and economically sustainable dairy and beef production in Sweden. Agricultural Systems, 156: 105-114.

Hoekstra, A.Y., Chapagain, A.K., Aldaya, M.M. \& Mekonnen, M.M. 2009. Water footprint manual. Enschede, The Netherlands, Water Footprint Network. http://ayhoekstra.nl/pubs/hoekstra-et-al-2009-waterfootprintmanual.pdf

Horstman, A.M., Ganzevles, R.A., Kudla, U., Kardinaal, A.F., van den Borne, J.J. \& Huppertz, T. 2021. Postprandial blood amino acid concentrations in older adults after consumption of dairy products: The role of the dairy matrix. International Dairy Journal, 113: 104890

Huijbregts, M.A.J., Steinmann, Z.J.N., Elshout, P.M.F., Stam, G., Verones, F., Vieira, M., Zijp, M., Hollander, A. \& van Zelm, R. 2017. ReCiPe2016: a harmonised life cycle impact assessment method at midpoint and endpoint level. The International Journal of Life Cycle Assessment, 22: 138-147. doi.org/10.1007/s11367-016-1246-y

Humbert, S., Marshall, J.D., Shaked, S., Spadaro, J.V., Nishioka, Y., Preiss, P., McKone, T.E., Horvath, A. \& Jolliet, 0. 2011. Intake fraction for particulate matter: Recommendations for life cycle impact assessment. Environmental Science \& Technology, 45 : 4808-4817. doi.org/10.1021/es103563z

Houssard, C., Maxime, D., Benoit, S., Pouliot, Y. \& Margni, M. 2020. Comparative Life Cycle Assessment of Five Greek Yogurt Production Systems: A Perspective beyond the Plant Boundaries. Sustainability, 12: 9141

Huijbregts, M. 1998. Application of uncertainty and variability in LCA. The International Journal of Life Cycle Assessment, 3(5): 273. 
Huijbregts, M.A.J., Steinmann, Z.J.N., Elshout, P.M.F., Stam, G., Verones, F., Vieira, M., Zijp, M., Hollander, A. \& van Zelm, R. 2017. ReCiPe 2016: A harmonised life cycle impact assessment method at midpoint and endpoint level. The International Journal of Life Cycle Assessment, 22: 138-147. doi.org/10.1007/s11367-016-1246-y

Hurrell, R. 2002. How to ensure adequate iron absorption from iron-fortified food. Nutrition Reviews, 60: S7-S15.

Hurrell, R.F., Reddy, M. \& Cook, J.D. 1999. Inhibition of non-haem iron absorption in man by polyphenolic-containing beverages. British Journal of Nutrition, 81: 289-95.

Hurrell, R.F., Reddy, M.B., Burri, J. \& Cook, J.D. 2002. Phytate degradation determines the effect of industrial processing and home cooking on iron absorption from cereal-based foods. British Journal of Nutrition, 88(2): 117-123.

ILCD. 2010. International Reference Life Cycle Data System (ILCD) Handbook - General guide for Life Cycle Assessment - Detailed guidance. First edition (March 2010). European Commission - Joint Research Centre - Institute for Environment and Sustainability. Luxembourg, EUR 24708 EN.

Ingram, D.L., Hall, C.R. \& Knight, J. 2018. Carbon footprint and ecosystem services during the life cycle of woody landscape plants. International Society for Horticultural Science (ISHS), Leuven, Belgium, pp. 139-144.

IPCC. 2014. Climate Change 2014: Synthesis Report. Contribution of Working Groups I, II and III to the Fifth Assessment Report of the Intergovernmental Panel on Climate Change. [Core Writing Team, R.K. Pachauri and L.A. Meyer (eds.)]. Geneva, IPCC.

IPCC. 2019a. Intergovernomental Panel on Climate Change. Refinement to the 2006 IPCC Guidelines for National Greenhouse Gas Inventories. E. Calvo Buendia, K. Tanabe, A. Kranjc, J. Baasansuren, M. Fukuda, S. Ngarize, A. Osako, Y. Pyrozhenko, P. Shermanau \& S. Federici eds. Geneva, IPCC.

IPCC. 2019b. Climate Change and Land: an IPCC special report on climate change, desertification, land degradation, sustainable land management, food security, and greenhouse gas fluxes in terrestrial ecosystems. P.R. Shukla, J.S., E. Calvo Buendia, V. Masson-Delmotte, H.-O. Pörtner, D.C. Roberts, P. Zhai, R. Slade, S. Connors, R. van Diemen, M. Ferrat, E. Haughey, S. Luz, S. Neogi, M. Pathak, J. Petzold, J. Portugal Pereira, P. Vyas, E. Huntley, K. Kissick, M. Belkacemi, J. Malley, eds. Geneva, IPCC.

ISO. 2006a. ISO 14040:2006: Environmental management - Life cycle assessment - Principles and framework. Geneva, ISO.

IS0. 2006b. 14044:2006 Environmental management - Life cycle assessment - Requirements and guidelines. Geneva: ISO.

ISO. 2016. 16140-1:2016(en): Microbiology of the food chain - Method validation - Part 1: Vocabulary. Geneva, ISO.

ISO. 2017. ISO 14044:2006/AMD 1:2017. Environmental management - Life cycle assessment Requirements and guidelines - Amendment 1. https://www.iso.org/standard/72357.html

IUCN. 2015. Habitat Classification Scheme, version 3.1. In: IUCN Red List. Cambridge. Cited 25 June 2018. wuw.iucnredlist.org/technical-documents/classification-schemes/habitats-classification-scheme-ver3

Jenkins, D.J., Thorne, M.J., Camelon, K., Jenkins, A., Rao, A.V., Taylor, R.H., Thompson, L.U., Kalmusky, J., Reichert, R. \& Francis, T. 1983. Effect of processing on digestibility and the blood glucose response: a study of lentils. The American Journal of Clinical Nutrition, 36(6): 1093-1101.

Jeswani, H.K., Hellweg, S. \& Azapagic, A. 2018. Accounting for land use, biodiversity and ecosystem services in life cycle assessment: Impacts of breakfast cereals. Science of the Total Environment, 645: 51-59. 
Jolliet, 0., Antón, A., Boulay, A.-M., Cherubini, F., Fantke, P., Levasseur, A., McKone, T. E., Michelsen, 0., Milà i Canals, L., Motoshita, M., Pfister, S., Verones, F., Vigon, B. \& Frischknecht, R. 2018. Global guidance on environmental life cycle impact assessment indicators: impacts of climate change, fine particulate matter formation, water consumption and land use. The International Journal of Life Cycle Assessment, 23(11): 2189-2207. https://doi.org/10.1007/s11367-018-1443-y

Jørgensen, B.B. \& Richardson, K. 1996. Eutrophication in Coastal Marine Ecosystems. Coastal Estuarine Studies, 52: 1-273. doi.org/10.1029/CE052

Jungbluth, N., Büsser, S., Frischknecht, R., Flury, K. \& Stucki, M. 2012. Feasibility of environmental product information based on life cycle thinking and recommendations for Switzerland. Journal of Cleaner Production, 28: 187-197.

Kashyap, S., Shivakumar, N., Varkey, A., Preston, T., Devi, S. \& Kurpad, A. V. 2019. Co-ingestion of black tea reduces the indispensable amino acid digestibility of hens' egg in Indian adults. The Journal of Nutrition, 149(8): 1363-1368.

Kätelhön, A., Bardow, A. \& Suh, S. 2016. Stochastic technology choice model for consequential life cycle assessment. Environmental Science \& Technology, 50(23): 12575-12583.

Knutti, R., Rogelj, J., Sedláček, J. \& Fischer, E.M. 2017. A Scientific Critique of the Two-Degree Climate Change Target. Nature Geoscience, 9(1): 13-18.

Koellner, T., De Baan, L., Beck, T., Brandão, M., Civit, B., Margni, M., I Canals, L.M., Saad, R., De Souza, D.M. \& Müller-Wenk, R. 2013. UNEP-SETAC guideline on global land use impact assessment on biodiversity and ecosystem services in LCA. International Journal of Life Cycle Assessment, 18: 1188-1202.

Koellner, T. \& Geyer, R. 2013. Global land use impact assessment on biodiversity and ecosystem services in LCA. International Journal of Life Cycle Assessment, 18: 1185-1187.

Konstantas, A., Stamford, L. \& Azapagic, A. 2020. A framework for evaluating life cycle eco-efficiency and an application in the confectionary and frozen-desserts sectors. Sustainable Production and Consumption, 21: 192-203.

Kounina, A., Margni, M., Bayart, J.-B., Boulay, A.-M., Berger, M., Bulle, C., Frischknecht, R. et al. 2013. Review of methods addressing freshwater use in life cycle inventory and impact assessment. The International Journal of Life Cycle Assessment, 18(3): 707-721. doi.org/10.1007/s11367-012-0519-3

Kovacs, B., Miller, L., Heller, M.C. \& Rose, D. 2021. The carbon footprint of dietary guidelines around the world: a seven country modeling study. Nutrition Journal, 20: 15.

Kuipers, K.J., May, R. \& Verones, F. 2021. Considering habitat conversion and fragmentation in characterisation factors for land-use impacts on vertebrate species richness. Science of The Total Environment, 801: 149737.

Kuipers, K.J.J., Hellweg, S. \& Verones, F. 2019. Potential Consequences of Regional Species Loss for Global Species Richness: A Quantitative Approach for Estimating Global Extinction Probabilities. Environmental Science \& Technololy, 53(9): 4728-4738 doi.org/10.1021/acs.est.8b06173

Larrea-Gallegos, G., Vázquez-Rowe, I., Wiener, H. \& Kahhat, R., 2019. Applying the technology choice model in consequential life cycle assessment: a case study in the Peruvian agricultural sector. Journal of Industrial Ecology, 23(3): 601-614.

Larrea-Gallegos, G. \& Vázquez-Rowe, I., 2020. Optimization of the environmental performance of food diets in Peru combining linear programming and life cycle methods. Science of the Total Environment, 699: 134231. 
Larrey-Lassalle, P., Loiseau, E., Roux, P., Lopez-Ferber, M. \& Rosenbaum, R.K. 2018. Developing characterisation factors for land fragmentation impacts on biodiversity in LCA: key learnings from a sugarcane case study. The International Journal of Life Cycle Assessment 23(11): 2126-2136.

Lathuillière, M.J., Bulle, C. \& Johnson, M.S. 2019. Complementarity in mid-point impacts for water use in life cycle assessment applied to cropland and cattle production in Southern Amazonia. Journal of Cleaner Production, 219: 497-507. doi.org/10.1016/j.jclepro.2019.02.021

Lauder, A.R., Enting, I.G., Carter, J.O., Clisby, N., Cowie, A.L., Henry, B.K. \& Raupach, M.R. 2013. Offsetting Methane Emissions - An Alternative to Emission Equivalence Metrics. International Journal of Greenhouse Gas Control, 12: 419-429.

Leão, S., Roux, P., Núñez, M., Loiseau, E., Junqua, G., Sferratore, A., Penru, Y. \& Rosenbaum, R.K. 2018. A worldwide-regionalised water supply mix (WSmix) for life cycle inventory of water use. Journal of Cleaner Production, 172 : 302-313. doi.org/10.1016/j.jclepro.2017.10.135

Leão, S., Roux, P., Loiseau, E., Junqua, G., Sferratore, A., Penru, Y. \& Rosenbaum, R.K. 2019 Prospective Water Supply Mix for Life Cycle Assessment and Resource Policy SupportAssessment of Forecasting Scenarios Accounting for Future Changes in Water Demand and Availability. Environmental Science \& Technology, 53(3): 1374-1384. https://doi.org/10.1021/acs.est.8b04071

Lee, S., Choi, Y., Jeong, H.S., Lee, J. \& Sung, J. 2018. Effect of different cooking methods on the content of vitamins and true retention in selected vegetables. Food Science and Biotechnology, 27(2): 333-342.

Lenzen, M., Moran, D., Kanemoto, K., Foran, B., Lobefaro, L. \& Geschke, A. 2012. International trade drives biodiversity threats in developing nations. Nature. 486: 109-112.

Lewis, J. 2019. Codex nutrient reference values. Rome. FAO and WHO.

Life Cycle Initiative. 2021. Global LCIA Guidance (GLAM) Phase 3 - Creation of a Global Life Cycle Impact Assessment Method. UNEP. www.lifecycleinitiative.org/activities/key-programmeareas/life-cycle-knowledge-consensus-and-platform/global-guidance-for-life-cycleimpact-assessment-indicators-and-methods-glam/

Liu, X. \& Bakshi, B.R. 2019. Ecosystem Services in Life Cycle Assessment while Encouraging TechnoEcological Synergies. Journal of Industrial Ecology, 23: 347-360.

Liu, X., Bakshi, B.R., Rugani, B., de Souza, D.M., Bare, J., Johnston, J.M., Laurent, A. \& Verones, F. 2020. Quantification and valuation of ecosystem services in life cycle assessment: Application of the cascade framework to rice farming systems. Science of the Total Environment, 747: 141278.

Lucas, E., Guo, M. \& Guillén-Gosálbez, G. 2021. Optimising diets to reach absolute planetary environmental sustainability through consumers. Sustainable Production and Consumption, 28: 877-892. doi.org/10.1016/j.spc.2021.07.003

Lynch, J. 2019. Availability of Disaggregated Greenhouse Gas Emissions from Beef Cattle Production: A Systematic Review. Environmental Impact Assessment Review, 76: 69-78.

Lynch, J., Cain, M., Pierrehumbert, R. \& Allen, M. 2020. Demonstrating GWP*: a means of reporting warming-equivalent emissions that captures the contrasting impacts of short- and longlived climate pollutants. Environmental Research Letters, 15(4): 044023.

Mackay, D. 1979. Finding fugacity feasible. Environmental Science \& Technology, 13 : 1218-1223.

Maia de Souza, D., Flynn, D.F.B., DeClerck, F., Rosenbaum, R.K., de Melo Lisboa, H. \& Koellner, T. 2013. Land use impacts on biodiversity in LCA: proposal of characterization factors based on functional diversity. The International Journal of Life Cycle Assessment, 18(6): 1231-1242.

Maia de Souza, D., Lopes, G.R., Hansson, J. \& Hansen, K. 2018. Ecosystem services in life cycle assessment: A synthesis of knowledge and recommendations for biofuels. Ecosystem Services, 30: 200-210. 
Mair, L., Bennun, L.A., Brooks, T.M., Butchart, S.H., Bolam, F.C., Burgess, N.D., Ekstrom, J.M. et al. 2021. A metric for spatially explicit contributions to science-based species targets. Nature Ecology \& Evolution, 5(6): 836-844.

Manaia, C.M. 2017. Assessing the Risk of Antibiotic Resistance Transmission from the Environment to Humans: Non-Direct Proportionality between Abundance and Risk. Trends in Microbiology, 25 (3): 173-181. doi.org/10.1016/j.tim.2016.11.014

Martínez-Blanco, J., Antón, A., Rieradevall, J., Castellari, M. \& Muñoz, P. 2011. Comparing nutritional value and yield as functional units in the environmental assessment of horticultural production with organic or mineral fertilization. The International Journal of Life Cycle Assessment, 16: 12-26.

Masset, G., Vieux, F. \& Darmon, N. 2015 Which functional unit to identify sustainable foods? Public Health Nutrition, 18(13): 2488-2497. doi:10.101.1017/S1368980015000579

Matthews, Damon, H., Zickfeld, K., Knutti, R. \& Allen, M.R. 2018. Focus on Cumulative Emissions, Global Carbon Budgets and the Implications for Climate Mitigation Targets. Environmental Research Letters, 13(1): 010201.

Matuštík, J., Hnátková, T. \& Kočí, V. 2020. Life cycle assessment of biochar-to-soil systems: A review. Journal of Cleaner Production, 259: 120998.

Mbow, C., Xu, Y., Rosenzweig, C., Barioni, L.G., Benton, T.G., Herrero, M., Krishnapillai, M., Liwenga, E., Pradhan, P., Rivera-Ferre, M.G., Sapkota, T. Tubiello, F.N. et al. 2019. Food Security. Report. IPCC. https://www.ipcc.ch/site/assets/uploads/sites/4/2021/02/08_Chapter-5_3.pdf.

McAuliffe, G.A., Takahashi, T. \& Lee, M.R.F. 2018. Framework for life cycle assessment of livestock production systems to account for the nutritional quality of final products. Food and Energy Security, 7: e00143.

McAuliffe, G.A., Takahashi, T. \& Lee, M.R.F. 2020. Applications of nutritional functional units in commodity-level life cycle assessment (LCA) of agri-food systems. The International Journal of Life Cycle Assessment, 25: 208-221.

McKone, T.E. 1993. CalTOX, A Multimedia Total Exposure Model for Hazardous-Waste Sites (No. UCRLCR-111456, Parts I-IV). Lawrence Livermore National Laboratory, Livermore, California.

MEA. 2005a. Ecosystems and Human Well-being, Millenium Ecosystem Assessment. Island Press, Washington, DC, USA.

MEA. 2005b. Environmental Degradation and Human Well-Being: Report of the Millennium Ecosystem Assessment, Blackwell Publishing Ltd. 31: 389-398.

Mertens, E., Van't Veer, P., Hiddink, G.J., Steijns, J.M. \& Kuijsten, A. 2017. Operationalising the health aspects of sustainable diets: a review. Public Health Nutrition, 20: 739-757.

Milà i Canals, L., Chenoweth, J., Chapagain, A., Orr, S., Antón, A. \& Clift, R. 2009. Assessing freshwater use impacts in LCA: Part I-inventory modelling and characterisation factors for the main impact pathways. The International Journal of Life Cycle Assessment, 14(1): 28-42. https://doi.org/10.1007/s11367-008-0030-z

Milà i Canals, L., Sim, S., García-Suárez, T., Neuer, G., Herstein, K., Kerr, C., Rigarlsford, G. \& King, H. 2011. Estimating the greenhouse gas footprint of Knorr. The International Journal of Life Cycle Assessment, 16: 50-58.

Moberg, E., Walker Andersson, M., Säll, S. Hansson, P-A. \& Röös, E. 2019. Determining the climate impact of food for use in a climate tax-design of a consistent and transparent model. The International Journal of Life Cycle Assessment, 24: 1715-1728.

Mogensen, L., Heusale, H., Sinkko, T., Poutanen, K., Sozer, N., Hermansen, J. E. \& Knudsen, M. T. 2020. Potential to reduce GHG emissions and land use by substituting animal-based proteins by foods containing oat protein concentrate. Journal of Cleaner Production, 274: 122914. 
Montemayor, E., Bonmatí, A., Pereira, E., \& Antón, A. 2021. Advancing the life cycle inventory of organic farming products: critical aspects and improvements. The International Journal Life Cycle Assessment (to be submitted).

Motoshita, M., Ono, Y., Pfister, S., Boulay, A.-M., Berger, M., Nansai, K., Tahara, K., Itsubo, N. \& Inaba, A. 2018. Consistent characterisation factors at midpoint and endpoint relevant to agricultural water scarcity arising from freshwater consumption. The International Journal of Life Cycle Assessment, 23(12): 2276-2287. doi.org/10.1007/s11367-014-0811-5

Motoshita, M., Ono, Y., Pfister, S., Boulay, A.M., Berger, M., Nansai, K., Tahara, K., Itsubo, N.

\& Inaba, A. 2014. Consistent characterisation factors at midpoint and endpoint relevant to agricultural water scarcity arising from freshwater consumption. The International Journal of Life Cycle Assessment, 23 : 2276-2287.

Moughan, P.J. 2021. Population Protein Intakes and Food Sustainability Indices: The Metrics Matter. Global Food Security, 29: 100548.

Müller-Wenk, R. \& Brandäo, M. 2010. Climatic impact of land use in LCA-carbon transfers between vegetation/soil and air. The International Journal of Life Cycle Assessment, 15: 172-182.

Mundi. 2021. Commodity Prices. In: Index Mundi. Cited August 2021. www.indexmundi.com/commodities

NAS. 1969. Eutrophication: causes, consequences, correctives; proceedings of a symposium. U.S. National Academy of Sciences, Washington, DC, USA.

Nemecek, T., Bengoa, X., Lansche, J., Mouron, P., Riedener, E., Rossi V. \& Humbert, S. 2015. Methodological Guidelines for the Life Cycle Inventory of Agricultural Products. Version 3.0, July 2015. World Food LCA Database (WFLDB). Quantis and Agroscope, Lausanne and Zurich, Switzerland.

Nemecek T., Bengoa X., Lansche J., Roesch A., Faist-Emmenegger M., Rossi V. \& Humbert S. 2019. Methodological guidelines for the Life Cycle Inventory of agricultural products. Version 3.5, December. World Food LCA Database (WFLDB). Lausanne and Zurich, Quantis and Agroscope.

Nemecek, T. \& Erzinger, S., 2005. Modelling Representative Life Cycle Inventories for Swiss Arable Crops. International Journal Life Cycle Assessment, 10(1), 1-9.

Nemecek, T., Jungbluth, N., Mila i Canals, L.M. \& Schenck, R. 2016. Environmental impacts of food consumption and nutrition: where are we and what is next? The International Journal of Life Cycle Assessment, 21: 607-620.

Newbold, T., Hudson, L.N.; Hill, S.L., Contu, S., Lysenko, I., Senior, R.A., Börger, L. et al. 2015. Global effects of land use on local terrestrial biodiversity. Nature, 520 (7545): 45-50.

Nijdam, D., Rood, T. \& Westhoek, H. 2012. The price of protein: Review of land use and carbon footprints from life cycle assessments of animal food products and their substitutes. Food Policy, 37: 760-70.

Notarnicola, B. 2011. 7th International conference on life cycle assessment in the agri-food sector (LCA Food 2010), 22-24 September 2010, Bari (Italy). The International Journal of Life Cycle Assessment, 16(2): 102-105.

Notarnicola, B., Sala, S., Anton, A., McLaren, S.J., Saouter, E. \& Sonesson, U. 2017. The role of life cycle assessment in supporting sustainable agri-food systems: a review of the challenges. Journal of Cleaner Production, 140: 399-409.

Notarnicola, B., Tassielli, G., Renzulli, P. A. \& Monforti, F. 2017. Energy flows and greenhouses gases of EU (European Union) national breads using an LCA (Life Cycle Assessment) approach. Journal of Cleaner Production, 140: 455-469.

Núñez, M., Pfister, S., Roux, P. \& Anton, A. 2013. Estimating water consumption of potential natural vegetation on global dry lands: Building an LCA framework for green water flows. Environmental Science \& Technology, 47(21) : 12258-12265. doi.org/10.1021/es403159t 
Núñez, M., Rosenbaum, R.K., Karimpour, S., Boulay, A.-M., Lathuillière, M.J., Margni, M., Scherer, L., Verones, F. \& Pfister, S. 2018. A Multimedia Hydrological Fate Modeling Framework to Assess Water Consumption Impacts in Life Cycle Assessment. Environmental Science \& Technology, 52(8): 4658-4667. doi.org/10.1021/acs.est.7b05207

Nyberg, 0., Rico, A., Guinée, J.B. \& Henriksson, P.J.G. 2021. Characterizing antibiotics in LCA-a review of current practices and proposed novel approaches for including resistance. The International Journal of Life Cycle Assessment, 26: 1816-1831. doi.org/10.1007/s11367-021-01908-y

Oberschelp, C., Pfister, S., Raptis, C.E. \& Hellweg, S. 2019. Global emission hotspots of coal power generation. Nature Sustainability, 2: 113-121. doi.org/10.1038/s41893-019-0221-6

0’Connor, L. E., Kim, J.E. \& Campbell, W. W. 2017. Total red meat intake of $\geqslant 0.5$ servings/d does not negatively influence cardiovascular disease risk factors: a systemically searched metaanalysis of randomized controlled trials. The American Journal of Clinical Nutrition, 105(1), 57-69.

OECD (Organisation for Economic Co-operation and Development). 2010. Sustainable management of water resources in agriculture. Paris, OECD.

OLCA-Pest. 2020. Operationalising Life Cycle Assessment of Pesticides (2017-2020). Olca-pest web.

Omolayo, Y., Feingold, B.J., Neff, R.A. \& Romeiko, X.X. 2021. Life cycle assessment of food loss and waste in the food supply chain. Resources, Conservation and Recycling, 164, 105119.

O'Neill, J. 2014. The Review on Antimicrobial Resistance. Antimicrobial Resistance: Tackling a Crisis for the Health and Wealth of Nations.

Oonincx, D.G.A.B. \& de Boer, I.J.M. 2012. Environmental impact of the production of mealworms as a protein source for humans - a life cycle assessment. PLoS One, 7: e51145.

Osendarp, S.J.M., Brown, K.H., Neufeld, L.M., Udomkesmalee, E. \& Moore, S.E. 2020. The double burden of malnutrition-further perspective. The Lancet, 396(10254): 813.

Othoniel, B., Rugani, B., Heijungs, R., Benetto, E. \& Withagen, C. 2017. Assessment of Life Cycle Impacts on Ecosystem Services: Promise, Problems, and Prospects. Environmental Science \& Technology, 50: 1077-1092.

Othoniel, B., Rugani, B., Heijungs, R., Beyer, M., Machwitz, M. \& Post, P. 2019. An improved life cycle impact assessment principle for assessing the impact of land use on ecosystem services. Science of The Total Environment, 693: 133374.

Paerl, H.W. \& Barnard, M.A. 2020. Mitigating the global expansion of harmful cyanobacterial blooms: Moving targets in a human- and climatically-altered world. Harmful Algae, 96: 101845. doi.org/10.1016/j.hal.2020.101845

Palazzo, J., Geyer, R. \& Suh, S. 2020. A review of methods for characterizing the environmental consequences of actions in life cycle assessment. Journal of Industrial Ecology, 24(4): 815-829.

Parker, R.W., Blanchard, J.L., Gardner, C., Green, B.S., Hartmann, K., Tyedmers, P.H. \& Watson, R.A. 2018. Fuel use and greenhouse gas emissions of world fisheries. Nature Climate Change, 8(4): 333-337.

Payen, S., Civit, B., Golden, H., Niblick, B., Uwizeye, A., Winter, L. \& Henderson, A.D. 2019. Acidification and Eutrophication. In: R. Frischknecht, O. Jolliet, eds. Global Guidance for Life Cycle Impact Assessment Indicators: Volume 2. United Nations Environment Program/Society for Environmental Toxicology and Chemistry Life Cycle Initiative, Paris, France, pp. 60-79.

Payen, S., Núñez, M., Bjørn, A., Laurent, A., Bare, J., Civit, B., Golden, H., Niblick, B. \& Henderson, A.D. (forthcoming). Eutrophication and acidification midpoint CFs in the GLAM consensus model: the importance of aggregation scheme. The International Journal of Life Cycle Assessment.

Pelletier, N., Ardente, F., Brandão, M., De Camillis, C. \& Pennington, D. 2015. Rationales for and limitations of preferred solutions for multi-functionality problems in LCA: is increased consistency possible? The International Journal of Life Cycle Assessment, 20(1): 74-86. 
Pelletier, N. \& Tyedmers, P. 2011. An Ecological Economic Critique of the Use of Market Information in Life Cycle Assessment Research. Journal of Industrial Ecology, 15(3): 342-354.

Pennings, B., Groen, B.B., van Dijk, J.W., de Lange, A., Kiskini, A., Kuklinski, M., Senden, J.MG. \& Van Loon, L.J. 2013. Minced beef is more rapidly digested and absorbed than beef steak, ù resulting in greater postprandial protein retention in older men. The American journal of clinical nutrition, 98(1): 121-128.

Pereira, H. M., Ziv, G. \& Miranda, M. 2014. Countryside Species-Area Relationship as a Valid Alternative to the Matrix-Calibrated Species-Area Model. Conservation Biology, 28 (3): 874-877.

Persson, U.M., Johansson, D.J.A., Cederberg, C., Hedenus, F. \& Bryngelsson, D., 2015. Climate metrics and the carbon footprint of livestock products: where's the beef? Environmental Research Letters, 10: 034005

Pfister, S. \& Bayer, P. 2014. Monthly water stress: spatially and temporally explicit consumptive water footprint of global crop production. Journal of Cleaner Production, 73: 52-62. doi.org/10.1016/j.jclepro.2013.11.031

Pfister, S., Bayer, P., Koehler, A. \& Hellweg, S. 2011. Environmental impacts of water use in global crop production: hotspots and trade-offs with land use. Environmental Science \& Technology, 45(13): 5761-5768. doi.org/10.1021/es1041755

Pfister, S., Boulay, A.-M., Berger, M., Hadjikakou, M., Motoshita, M., Hess, T. \& Ridoutt, B. 2017. Understanding the LCA and ISO water footprint: A response to Hoekstra (2016) A critique on the water-scarcity weighted water footprint in LCA. Ecological Indicators, 72: 352-359. doi.org/10.1016/j.ecolind.2016.07.051

Pfister, S., Koehler, A. \& Hellweg, S. 2009. Assessing the environmental impacts of freshwater consumption in LCA. Environmental Science \& Technology, 43(11): 4098-4104. doi.org/10.1021/es802423e

Pfister, S., Scherer, L. \& Buxmann, K. 2020. Water scarcity footprint of hydropower based on a seasonal approach - Global assessment with sensitivities of model assumptions tested on specific cases. The Science of the TotalEnvironment, 724:138188.doi.org/10.1016/j.scitotenv.2020.138188

Pfister, S., Vionnet, S., Levova, T. \& Humbert, S. 2017. Ecoinvent 3: assessing water use in LCA and facilitating water footprinting. The International Journal of Life Cycle Assessment, 21(9): 1349-1360. doi.org/10.1007/s11367-015-0937-0

Plevin, R.J., Delucchi, M.A. \& Creutzig, F. 2014. Using attributional life cycle assessment to estimate climate-change mitigation benefits misleads policy makers. Journal of Industrial Ecology, 18(1): 73-83.

Poore, J. \& T. Nemecek. 2018. Reducing food's environmental impacts through producers and consumers. Science, 360: 987-92.

Potter, H. K. \& Roos, E. 2021. Multi-criteria evaluation of plant-based foods -use of environmental footprint and LCA data for consumer guidance. Journal of Cleaner Production, 280: 124721.

Pradinaud, C., Northey, S., Amor, B., Bare, J., Benini, L., Berger, M., Boulay, A.-M. et al. 2019. Defining freshwater as a natural resource: A framework linking water use to the area of protection natural resources. The International Journal of Life Cycle Assessment, 24(5): 960-974. doi.org/10.1007/s11367-018-1543-8

Querini, F. \& Benetto, E. 2014. Agent-based modelling for assessing hybrid and electric cars deployment policies in Luxembourg and Lorraine. Transportation Research Part A: Policy and Practice 70: 149-161.

Quinteiro, P., Dias, A.C., Silva, M., Ridoutt, B.G., \& Arroja,L. 2015. A contribution to the environmental impact assessment of green water flows. Journal of Cleaner Production, 93: 318-329. doi.org/10.1016/j.jclepro.2015.01.022 
Quinteiro, P., Rafael, S., Villanueva-Rey, P., Ridoutt, B., Lopes, M., Arroja L. \& Dias, A.C. 2018. A characterisation model to address the environmental impact of green water flows for water scarcity footprints. The Science of the Total Environment, 626: 1210-1218. https://doi.org/10.1016/j.scitotenv.2018.01.201

Redfield, A.C. 1958. The biological control of chemical factors in the environment. Journal of American Science. 46: 205-221

Rege, S., Arenz, M., Marvuglia, A., Vázquez-Rowe, I., Benetto, E., Igos, E. \& Koster, D., 2015. Quantification of Agricultural Land Use Changes in Consequential Life Cycle Assessment Using Mathematical Programming Models Following a Partial Equilibrium Approach. Journal of Environmental Informatics, 26(2).

Renouf, M. A., Pagan, R. J. \& Wegener, M. K. 2011. Life cycle assessment of Australian sugarcane products with a focus on cane processing. The International Journal of Life Cycle Assessment, 16(2): 125-137.

Ritchie, H., Reay, D.S. \& Higgins, P., 2018. The impact of global dietary guidelines on climate change. Global Environmental Change. 49: 46-55.

RIVM, 2019. NEVO online database. In: The National Institute for Public Health and the Environment, Ministry of Health, Welfare and Sport, Netherlands. www.rivm.nl/en/dutch-food-compositiondatabase/access-nevo-data/nevo-online

RIVM, 2021. Database milieubelasting voedingsmiddelen. In: The National Institute for Public Health and the Environment, Ministry of Health, Welfare and Sport, Netherlands. www.rivm.nl/documenten/database-milieubelasting-voedingsmiddelen.

Roop, D.J., Shrestha, D.S., Saul, D.A. \& Newman, S.M. 2014. Cradle-to-Gate Life Cycle Assessment of Regionally Produced Beef in the Northwestern U.S. Transactions of the ASABE, 57: 927-935.

Rosenbaum, R.K., Anton, A., Bengoa, X., Bjørn, A., Brain, R., Bulle, C., Cosme, N. et al. 2015. The Glasgow consensus on the delineation between pesticide emission inventory and impact assessment for LCA. The International Journal of Life Cycle Assessment, 20: 765-777. doi.org/10.1007/s11367-015-0871-1

Rosenbaum, R.K., Bachmann, T.M., Gold, L.S., Huijbregts, M.A.J., Jolliet, O., Juraske, R., Koehler, A. et al. 2008. USEtox - The UNEP-SETAC toxicity model: Recommended characterisation factors for human toxicity and freshwater ecotoxicity in life cycle impact assessment. The International Journal of Life Cycle Assessment, 13: 532-547. https://doi.org/10.1007/s11367-008-0038-4

Rosenbaum, R.K., Georgiadis, S. \& Fantke, P. 2018. Uncertainty Management and Sensitivity Analysis. Life Cycle Assessment: Theory and Practice. M. Z. Hauschild, R. K. Rosenbaum and S. I. Olsen. Cham, Springer International Publishing, 271-321.

Rosegrant, M.W., Cai, X. \& Cline, S.A. 2002. Global Water Outlook to 2025: Averting an Impending Crisis. International Food Policy Research Institute,572-2016-39087).

Roy, P., Nei, D., Orikasa, T., Xu, Q., Okadome, H., Nakamura, N. \& Shiina, T. 2009. A review of life cycle assessment (LCA) on some food products. Journal of Food Engineering, 90(1): 1-10.

Rugani, B., Maia de Souza, D., Weidema, B.P., Bare, J., Bakshi, B., Grann, B., Johnston, J.M., Pavan, A.L.R., Liu, X., Laurent, A. \& Verones, F. 2019. Towards integrating the ecosystem services cascade framework within the Life Cycle Assessment (LCA) cause-effect methodology. Science of The Total Environment, 690: 1284-1298.

Ryberg, M.W., Rosenbaum, R.K., Mosqueron, L. \& Fantke, P., 2018. Addressing bystander exposure to agricultural pesticides in life cycle impact assessment. Chemosphere, 197: 541-549. doi.org/10.1016/j.chemosphere.2018.01.088 
Saad, R., Koellner, T. \& Margni, M. 2013. Land use impacts on freshwater regulation, erosion regulation, and water purification: A spatial approach for a global scale level. International Journal of Life Cycle Assessment, 18: 1253-1264.

Saarinen, M., Fogelholm, M., Tahvonen, R. \& Kurppa, S. 2017. Taking nutrition into account within the life cycle assessment of food products. Journal of Cleaner Production, 149: 828-844. doi.org/10.1016/j.jclepro.2017.02.062

Sabo, R.D., Clark, C.M., Gibbs, D.A., Metson, G.S., Todd, M.J., LeDuc, S.D., Greiner, D., Fry, M.M., Polinsky, R., Yang, Q., Tian, H. \& Compton, J.E. 2021. Phosphorus Inventory for the Conterminous United States (2002-2012). Journal of Geophysical Research: Biogeosciences, 126: e2020JG005684. doi.org/10.1029/2020JG005684

Sacchi, R. 2018. A trade-based method for modelling supply markets in consequential LCA exemplified with Portland cement and bananas. The International Journal of Life Cycle Assessment, 23(10): 1966-1980.

Saget, S., Costa, M., Barilli, E., Wilton de Vasconcelos, M., Santos, C. S., Styles, D. \& Williams, M. 2020. Substituting wheat with chickpea flour in pasta production delivers more nutrition at a lower environmental cost. Sustainable Production and Consumption, 24:26-38.

Sala, S., Anton, A., McLaren, S.J., Notarnicola, B., Saouter, E. \& Sonesson, U. 2017. In quest of reducing the environmental impacts of food production and consumption. Journal of Cleaner Production, 140: 387-398.

Salazar T.M., Cai, H., Bailey, R. \& Huang, J.Y. 2019. Defining nutritionally and environmentally healthy dietary choices of omega-3 fatty acids. Journal of Cleaner Production, 228: 1025-1033.

Salou, T., Le Mouël, C. \& van der Werf, H.M. 2017. Environmental impacts of dairy system intensification: the functional unit matters! Journal of Cleaner Production, 140: 445-454. doi.org/10.1016/J. JCLEPRO.2017.05.019

Saylor, C. 2004. The circle of health: a health definition model. Journal of Holistic Nursing : Official Journal of the American Holistic Nurses' Association, 22(2): 97-115. doi.org/10.1177/0898010104264775

Saxe, H., Jensen, J. D., Bølling Laugesen, S. M. \& Bredie, W. L. P. 2019. Environmental impact of meal service catering for dependent senior citizens in Danish municipalities. The International Journal of Life Cycle Assessment, 24: 654-666.

Scarborough, P., Arambepola, C., Kaur, A., Bhatnagar, P. \& Rayner, M. 2010. Should nutrient profile models be "category specific" or "across-the-board"? A comparison of the two systems using diets of British adults. European Journal of Clinical Nutrition, 64, no. 6: 553-560.

Schau, E.M. \& Fet, A.M. 2008. LCA studies of food products as background for environmental product declarations. The International Journal of Life Cycle Assessment, 13: 255-264.

Schaubroeck, T., Alvarenga, R.A.F., Verheyen, K., Muys B. \& Dewulf, J. 2013. Quantifying the Environmental Impact of an Integrated Human/Industrial-Natural System Using Life Cycle Assessment; A Case Study on a Forest and Wood Processing Chain. Environmental Science \& Technology, 47: 13578-13587.

Schaubroeck, T., Ceuppens, S., Luong, A.D., Benetto, E., De Meester, S., Lachat, C. \& Uyttendaele, M. 2018. A pragmatic framework to score and inform about the environmental sustainability and nutritional profile of canteen meals, a case study on a university canteen. Journal of Cleaner Production, 187: 672-686.

Schaubroeck, T., Schaubroeck, S., Heijungs, R., Zamagni, A., Brandao, M. \& Benetto, E. 2021. Atrributional \& Consequential Life Cycle Assessment: Definitions, Conceptual Characteristics and Modelling Restrictions. Sustainability, 13: 7386.

Scherer, L., van Baren, S.A. \& van Bodegom, P.M. 2020. Characterizing Land Use Impacts on Functional Plant Diversity for Life Cycle Assessments. Environmental Science \& Technology, 54(11): 6486-6495. 
Scherer, L., Pfister, S. 2015. Modelling spatially explicit impacts from phosphorus emissions in agriculture. The International Journal of Life Cycle Assessment, 20: 785-795. doi.org/10.1007/s11367-015-0880-0

Scherer, L. \& Pfister, S. 2017. Dealing with uncertainty in water scarcity footprints. Environmental Research Letters, 11(5): 54008. doi.org/10.1088/1748-9326/11/5/054008

Schindler, D.W. 1977. Evolution of phosphorus limitation in lakes. Science, 195: 260-262.

Schindler, D.W. 2007. Recent advances in the understanding and management of eutrophication. Limnol. Oceanography, 51: 356-363

Schmidhuber, J., Sur, P., Fay, K., Huntley, B., Salama, J., Lee, A., Cornaby, L., Horino, M., Murray, C. \& Afshin, A. 2018. The Global Nutrient Database: availability of macronutrients and micronutrients in 195 countries from 1980 to 2013. The Lancet Planetary Health, 2, no. 8: e353-e368.

Scrucca, F., Baldassarri, C., Baldinelli, G., Bonamente, E., Rinaldi, S., Rotili, A. \& Barbanera, M. 2020. Uncertainty in LCA: An estimation of practitioner-related effects. Journal of Cleaner Production, 268: 122304

Searchinger, T., Heimlich, R., Houghton, R.A., Dong, F., Elobeid, A., Fabiosa, J. \& Yu, T.H., 2008. Use of US croplands for biofuels increases greenhouse gases through emissions from land-use change. Science, 319(5867): 1238-1240.

Searchinger, T.D., Wirsenius, S., Beringer, T. \& Dumas, P. 2018. Assessing the Efficiency of Changes in Land Use for Mitigating Climate Change. Nature, 564: 249-253.

Seitzinger, S.P., Mayorga, E., Bouwman, A.F., Kroeze, C., Beusen, A.H.W., Billen, G., Van Drecht, G., Dumont, E., Fekete, B.M., Garnier, J. \& Harrison, J.A. 2010. Global river nutrient export: A scenario analysis of past and future trends. Global Biogeochemical Cycles, 24. https://doi.org/10.1029/2009GB003587

Sims, R., Flammini, A., Puri, M. \& Bracco, S. 2015. Opportunities for agri-food chains to become energysmart. Rome, FAO, and Washington, USAID.

Smetana, S., Mathys, A., Knoch, A. \& Heinz, V. 2015. Meat Alternatives: Life Cycle Assessment of most Known Meat Substitutes. The International Journal of Life Cycle Assessment, 20 (9): 1254-1267. doi:10.1007/s11367-015-0931-6

Sonderegger T, Berger M, Alvarenga R, Bach V, Cimprich A, Dewulf J, Frischknecht R. et al. 2020. Mineral resources in life cycle impact assessment-part I: a critical review of existing methods. International Journal of Life Cycle Assessment, 25: 784-797 doi.org/10.1007/s11367-020-01736-6

Sonesson, U., Davis, J., Flysjo, A., Gustaysson, J. \& Witthoft, C. 2017. Protein quality as functional unit - A methodological framework for. inclusion in life cycle assessment of food. Journal of Cleaner Production, 140: 470-478.

Sonesson, U., Davis. J., Hallström, E. \& Woodhouse, A. 2019. Dietary-dependent nutrient quality indixes as a complementary functional unit in LCA: a feasible option? Journal of Cleaner Production, 211 (2019): 620-627.

Springmann, M., Wiebe, K., Mason-D'Croz, D., Sulser, T.B., Rayner, M. \& Scarborough, P. 2018. Health and nutritional aspects of sustainable diet strategies and their association with environmental impacts: a global modelling analysis with country-level detail. The Lancet Planetary Health, 2(10): e451-e461.

Steffen, W., Richardson, K., Rockström, J., Cornell, S.E., Fetzer, I., Bennett, E.M., Biggs, R. et al. 2015. Planetary boundaries: Guiding human development on a changing planet. Science, 347 : 1259855-1259855. doi.org/10.1126/science.1259855

Sterner, R.W. 2008. On the Phosphorus Limitation Paradigm for Lakes. International Review of Hydrobiology, 93: 433-445. doi.org/10.1002/iroh.200811068 
Stover, P.J., Garza, C., Durga, J. \& Field, M.S. 2020. Emerging Concepts in Nutrient Needs. Journal of Nutrition, 150(Suppl 1): 2593S-601S.

Strid, A., Hallström, E., Sonesson, U., Sjons, J., Winkvist, A. \& Bianchi, M. 2021. Sustainability indicators for foods benefiting climate and health. Sustainability, 13: 3621. https://doi.org/10.3390/su13073621.

Stylianou, K.S. 2018. Nutritional and Environmental Impacts of Foods on Human Health, Environmental Health Sciences. University of Michigan, Ann Arbor, Michigan, USA: 247. https://deepblue.lib.umich.edu/handle/2027.42/147641

Stylianou, K.S., Fulgoni, V.L. \& Jolliet, 0. 2021. Small targeted dietary changes can yield substantial gains for human health and the environment. Nature Food, 2: 616-627. www.nature.com/articles/s43016-021-00343-4

Stylianou, K.S., Heller, M.C., Fulgoni, V.L., Ernstoff, A.S., Keoleian, G.A. \& Jolliet, 0. 2016. A life cycle assessment framework combining nutritional and environmental health impacts of diet: a case study on milk. International Journal of Life Cycle Assessment, 21(5): 734-746.

Suh, S. \& Yang, Y., 2014. On the uncanny capabilities of consequential LCA. The International Journal of Life Cycle Assessment, 19: 1179-1184.

Sundin, N., Rosell, M., Eriksson, M., Jensen, C. \& Bianchi, M. 2021. The climate impact of excess food intake-An avoidable environmental burden. Resources, Conservation and Recycling, 174: 105777.

Sykes, A.J., Macleod, M., Eory, V., Rees, R.M., Payen, F., Myrgiotis, V., Williams, M. et al. 2020. Characterising the Biophysical, Economic and Social Impacts of Soil Carbon Sequestration as a Greenhouse Gas Removal Technology. Global Change Biology, 26(3): 1085-1108.

Takacs, B. \& Borrion, A. 2020. The use of life cycle-based approaches in the food service sector to improve sustainability: A systematic review. Sustainability, 12: 3504.

Talsma, E.F., Moretti, D., Ly, S.C., Dekkers, R., van den Heuvel, E.G., Fitri, A., Boelsma, E., Stomph, T.J., Zeder, C. \& Melse-Boonstra, A. 2017. Zinc absorption from milk is affected by dilution but not by thermal processing, and milk enhances absorption of zinc from high-phytate rice in young Dutch women. The Journal of Nutrition, 147(6): 1086-1093.

Tang, L., Hayashi, K., Kohyama, K. \& Leon, A. 2018. Reconciling Life Cycle Environmental Impacts with Ecosystem Services: A Management Perspective on Agricultural Land Use. Sustainability, 10.

Tapsell, L.C., Neale, E.P., Satija, A. \& Hu, F.B. 2016. Foods, Nutrients, and Dietary Patterns: Interconnections and Implications for Dietary Guidelines. Advanced Nutrition, 7(3): 445-54.

Teixeira, R.F.M. 2014. Critical Appraisal of Life Cycle Impact Assessment Databases for Agri-food Materials. Journal of Industrial Ecology, 19 (1): 38-50.

Teixeira, R.F.M., Souza, D.M.D., Curran, M.P., Antón, A., Michelsen, O. \& Canals, L.M.I. 2017. Towards consensus on land use impacts on biodiversity in LCA: UNEP/SETAC Life Cycle Initiative preliminary recommendations based on expert contributions. Journal of Cleaner Production, 112: 4283-4287.

Tendall, D.M., Hellweg, S., Pfister, S., Huijbregts, M.A. \& Gaillard, G. 2014. Impacts of River Water Consumption on Aquatic Biodiversity in Life Cycle Assessment - A Proposed Method, and a Case Study for Europe. Environmental Science \& Technology, 48(6): 3236-3244. doi.org/10.1021/es4048686

Tessum, C.W., Hill, J.D. \& Marshall, J.D. 2017. InMAP: A model for air pollution interventions. PLOS One, 12: e0176131. doi.org/10.1371/journal.pone.0176131

Teysseire, R., Manangama, G., Baldi, I., Carles, C., Brochard, P., Bedos, C. \& Delva, F. 2020. Assessment of residential exposures to agricultural pesticides: A scoping review. PLOS ONE, 15: e0232258. doi.org/10.1371/journal.pone.0232258 
Thomas, C., Grémy-Gros, C., Perrin, A., Symoneaux, R. \& Maître, I. 2020. Implementing LCA early in food innovation processes: Study on spirulina-based food products. Journal of Cleaner Production, 268: 121793.

Thomassen, M.A., Dalgaard, R., Heijungs, R. \& de Boer, I.J.M. 2008. Attributional and consequential LCA of milk production. International Journal of Life Cycle Assessment, 13(4): 339-349.

Thrane, M. \& Flysjö, A. 2010. 13 - Ecodesign of food products. In: U. Sonesson, J. Berlin, F. Ziegler, eds. Environmental Assessment and Management in the Food Industry. Woodhead Publishing Series in Food Science, Technology and Nutrition, Woodhead Publishing. ISBN 9781845695521.

Tilman, D. 1999. Global environmental impacts of agricultural expansion: The need for sustainable and efficient practices. Proceedings of the National Academy of Sciences of the United States of America, 96: 5995-6000.

Tol, R.S.J., Berntsen, T.K., O'Neill, B.C., Fuglestvedt, J.S. \& Shine, K.P. 2012. A Unifying Framework for Metrics for Aggregating the Climate Effect of Different Emissions. Environmental Research Letters, 7: 044006.

Tonini, D., Hamelin, L., Wenzel, H. \& Astrup, T. 2012. Bioenergy production from perennial energy crops: a consequential LCA of 12 bioenergy scenarios including land use changes. Environmental Science \& Technology, 46(24): 13521-13530.

Tonini, D., Albizzati, P.F. \& Astrup, T.F. 2018. Environmental impacts of food waste: Learnings and challenges from a case study on UK. Waste Management, 76: 744-766.

Torbatinejad, N.M., Rutherfurd, S.M. \& Moughan, P.J. 2005. Total and reactive lysine contents in selected cereal-based food products. Journal of Agricultural and Food Chemistry, 53(11): 4454-4458.

Torres, A.V., Tiwari, C. \& Atkinson, S.F. 2021. Progress in ecosystem services research: A guide for scholars and practitioners. Ecosystem Services, 49.

Tubiello, F.N., Rosenzweig, C., Conchedda, G., Karl, G.K., Gütschow, J., Xueyao, P., Obli-Laryea, G., et al. 2021. Greenhouse Gas Emissions from Food Systems: Building the Evidence Base. Environmental Research Letters, 16: 065007.

Udo de Haes, H.A., Finnveden, G., Goedkoop, M., Hauschild, M.Z., Hertwich, E.G., Hofstetter, P., Jolliet, O., Klöpffer, W., Krewitt, W., Lindeijer, E., Müller-Wenk, R., Lindeijer, Erwin, Olsen, S.I., Pennington, D.W., Potting, J., Steen, B. (Eds.). 2002. Life cycle impact assessment: Striving towards best practice. SETAC Press, Pensacola, USA.

UNEP (United Nations Environment Programme). 2017. Global Guidance for Life Cycle Impact Assessment Indicators; UNEP (United Nations Environment Programme): Paris, 2017; Vol.1, Chapter 6 (http://www.lifecycleinitiative.org/training-resources/global-guidance-lcia-indicators-v-1/).

UNEP. 2020. Guidelines for Social Life Cycle Assessment of Products and Organizations 2020.

In: C. Benoît Norris, M. Traverso, S. Neugebauer, E. Ekener, T. Schaubroeck, S. Russo Garrido, M. Berger, S. Valdivia, A. Lehmann, M. Finkbeiner \& G. Arcese (eds.). https://wedocs.unep.org/handle/20.500.11822/34554

UNEP. 2021. Life cycle thinking - e-learning courses. In: Life Cycle Initiative. Paris. Cited 15 September 2021. https://www.lifecycleinitiative.org/resources-2/e-learning-modules

United Nations. 2015. Transforming our world: the 2030 agenda for sustainable development. United Nations.

United Nations. 2021. SDG Knowledge. In: The 17 Goals. Accessed 30 September 2021. https://sdgs.un.org/goals

USCDC. 2021. Antibiotic/Antimicrobial Resistance. In: CDC. Cited 20 June 2021. www.cdc.gov/drugresistance

Valdivia, S., Backes, J.G., Traverso, M., Sonnemann, G., Cucurachi, S., Guinée, J.B., Schaubroeck, T. et al. 2021. Principles for the application of life cycle sustainability assessment. International Journal of Life Cycle Assessment 26(9): 1900-1905. 
Van Der Werf, H.M.G. \& Salou, T. 2015. Economic value as a functional unit for environmental labelling of food and other consumer products. Journal of Cleaner Production, 94: 394-397.

van Lieshout, G.A., Lambers, T.T., Bragt, M.C. \& Hettinga, K.A. 2020. How processing may affect milk protein digestion and overall physiological outcomes: A systematic review. Critical Reviews in Food Science and Nutrition, 60(14): 2422-2445.

Van Selm, B., Frehner, A., de Boer. I.J.M., Van Hal, O., Hijbeek, R., Van Ittersum, M.K., Talsma, E.F., Lesschen, J.P., Hendriks, C.M.J., Herrero, M. \& Van Zanten, H.H.E. 2021. The compatibility of animal-source food and circularity in healthy European diets. Under open review, DOI: 10.21203/rs.3.rs-147410/v1 Nature Food.

Van Zanten, H.H., Bikker, P., Meerburg, B.G. \& de Boer, I.J.M. 2018. Attributional versus consequential life cycle assessment and feed optimization: alternative protein sources in pig diets. The International Journal of Life Cycle Assessment, 23(1): 1-11.

van Zelm, R., van der Velde, M., Balkovic, J., Čengić, M., Elshout, P.M.F., Koellner, T., Núñez, M., Obersteiner, M., Schmid, E. \& Huijbregts, M.A.J. 2018. Spatially explicit life cycle impact assessment for soil erosion from global crop production. Ecosystem Services, 30: 220-227.

VanderWilde, C.P. \& Newell, J.P. 2021. Ecosystem services and life cycle assessment: A bibliometric review. Resources, Conservation and Recycling, 169: 105461.

Vázquez-Rowe, I., Ziegler-Rodriguez, K., Margallo, M., Kahhat, R. \& Aldaco, R. 2021. Climate action and food security: Strategies to reduce GHG emissions from food loss and waste in emerging economies. Resources, Conservation and Recycling, 170: 105562.

Vázquez-Rowe, I., Laso, J., Margallo, M., Garcia-Herrero, I., Hoehn, D., Amo-Setien, F., Bala, A., Abajas, R., Sarabia, C., Dura, M.J., Fullana-i-Palmer, P. \& Aldaco, R. 2020. Food loss and waste metrics: a proposed nutritional cost footprint linking linear programming and life cycle assessment. The International Journal of Life Cycle Assessment, 25(7): 1197-1209.

Verones, F., Bare, J., Bulle, C., Frischknecht, R., Hauschild, M., Hellweg, S., Henderson, A. et al. 2017. LCIA framework and cross-cutting issues guidance within the UNEP-SETAC Life Cycle Initiative. Journal of Cleaner Production, 161. 957-967.

Verones, F., Hellweg, S., Antón, A., Azevedo, L.B., Chaudhary, A., Cosme, N., Cucurachi, S. et al. 2020. LC-IMPACT: A regionalized life cycle damage assessment method. Journal of Industrial Ecology, 24: 1201-1219. https://doi.org/10.1111/jiec.13018

Verones, F., Huijbregts, M.A., Chaudhary, A., de Baan, L., Koellner, T. \& Hellweg, S. 2015. Harmonizing the assessment of biodiversity effects from land and water use within LCA. Environmental Science \& Technology, 49(6): 3584-3592.

Vidergar, P., Perc, M. \& Lukman, R.K. 2021. A survey of the life cycle assessment of food supply chains. Journal of Cleaner Production, 286: 125506.

Vitousek, P.M., Mooney, H.A., Lubchenco, J. \& Melillo, J.M. 1997. Human Domination of Earth's Ecosystems. Science, 277: 494-499. doi.org/10.1126/science.277.5325.494

von Liebig, J. 1855. Principles of agricultural chemistry with special reference to the late researches made in England. In: Pomeroy, L.R., ed. Cycles of Essential Elements. Benchmark Papers in Ecology. Dowden, Hutchinson, and Ross, UK, pp. 11-28.

Weber, K.A. 1907. Aufbau und vegetation der Moore Norddeutschlands. Beibl. Bot. Jahrb., 90: 19-34.

Weidema, B. 1998. Application typologies for life cycle assessment. The International Journal of Life Cycle Assessment, 3: 237-240.

Weidema, B. P. 2003. Market information in life cycle assessment. 2.-0 LCA consultants, Environmental Project No. 863, Miljøstyrelsen, Danish Environmental Protection Agency.

Weidema, B.P., Bauer, C., Hischier, R., Mutel, C., Nemecek, T., Reinhard, J., Vadenbo, C.0. \& Wernet, G. 2013. Overview and ethodology. Data quality guideline for the ecoinvent database version 3. Ecoinvent Report 1(v3). St. Gallen: The ecoinvent Centre. 
Weidema, B.P., Pizzol, M., Schmidt, J. \& Thoma, G. 2018. Attributional or consequential life cycle assessment: a matter of social responsibility. Journal of Cleaner Production, 174: 305-314.

Weidema, B.P. \& Stylianou, K.S. 2020. Nutrition in the life cycle assessment of foods-function or impact? The International Journal of Life Cycle Assessment, 25: 1210-1216.

Weidema, B., Wenzel, H., Petersen, C. \& Hansen, K. 2004. The product, functional unit and reference flows in LCA. Environ News, 70: 1-46.

Werner, L.B., Flysjö, A. \& Tholstrup, T. 2014. Greenhouse gas emissions of realistic dietary choices in Denmark: the carbon footprint and nutritional value of dairy products. Food \& Nutrition Research, 58: 20687.

Wernet, G., Bauer, C., Steubing, B., Reinhard, J., Moreno-Ruiz, E. \& Weidema, B. 2016. The ecoinvent database version 3 (part I): overview and methodology. The International Journal of Life Cycle Assessment, 21: 1218-1230.

WHO (World Health Organization). 2012. Promoting a healthy diet for the WHO Eastern Mediterranean Region: user-friendly guide. Cairo, WHO. Regional Office for the Eastern Mediterranean.

WHO. 2014. Antimicrobial Resistance Global Report on Surveillance.

WHO. 2015. Global Action Plan on Antimicrobial Resistance.

WHO. 2017. WHO guidelines on use of medically important antimicrobials in food-producing animals.

WHO. 2021. Fact Sheet/Obesity and overweight. In: WHO. Cited 22 September 2021. www.who.int/news-room/fact-sheets/detail/obesity-and-overweight

Williamson, G. 2017. The role of polyphenols in modern nutrition. Nutrition Bulletin, 42(3): 226-235.

Willett, W., Rockström, J., Loken, B., Springmann, M., Lang, T., Vermeulen, S., Garnett, T. et al. 2019. Food in the Anthropocene: the EAT-Lancet Commission on healthy diets from sustainable food systems. The Lancet, 393(10170): 447-492.

Wimolrattanasil, T., Thepanondh, S., Sattler, M.L. \& Laowagul, W. 2018. Quantitative evaluation of cleaner production and environmental policy toward the co-benefit of greenhouse gas and odor reduction: case study of Tapioca starch industry. Clean Technologies and Environmental Policy, 20: 2333-2343.

Wohner, B., Gabriel, V.H., Krenn, B., Krauter, V. \& Tacker, M. 2020. Environmental and economic assessment of food-packaging systems with a focus on food waste. Case study on tomato ketchup. Science of the Total Environment, 738: 139846.

Wolever, T.M. 1990. The glycemic index. World Review of Nutrition and Dietetics, 62: 120-185.

Woods, J.S., Damiani, M., Fantke, P., Henderson, A.D., Johnston, J.M., Bare, J., Sala, S. et al. 2018. Ecosystem quality in LCIA: status quo, harmonization and suggestions for the way forward. The International Journal of Life Cycle Assessment, 23(10): 1995-2006.

Xiong, W., Sun, Y., Zhang, T., Ding, X., Li, W., Wang, M. \& Zeng, Z. 2015. Antibiotics, Antibiotic Resistance Genes, and Bacterial Community Composition in Fresh Water Aquaculture Environment in China. Microbial Ecology, 70: 425-432. https://doi.org/10.1007/s00248-015-0583-x

Xu, Z., Fu, Z., Zhai, Z., Yang, X., Meng, F., Feng, X., Zhong, J., Dai, Y., Xu, W., Cheng, J.-H. \& Zhang, Z. 2020. Comparative evaluation of carbon footprints between rice and potato food considering the characteristic of Chinese diet. Journal of Cleaner Production, 257: 120463.

Xu, Z., Xu, W., Peng, Z., Yang, Q. \& Zhang, Z. 2018. Effects of different functional units on carbon footprint values of different carbohydrate-rich foods in China. Journal of Cleaner Production, 198: 907-916.

Xue, X., Hawkins, T.R., Ingwersen, W.W. \& Smith, R.L. 2015. Demonstrating an approach for including pesticide use in life-cycle assessment: Estimating human and ecosystem toxicity of pesticide use in Midwest corn farming. The International Journal of Life Cycle Assessment, 20:

1117-1127. doi.org/10.1007/s11367-015-0902-y 
Xue, L., Liu, G., Parfitt, J., Liu, X., Van Herpen, E., Stenmarck, Å., O’Connor, C., Östergren, K. \& Cheng, S. 2017. Missing Food, Missing Data? A Critical Review of Global Food Losses and Food Waste Data. Environmental Science \& Technology, 51(12): 6618-6633.

Yan, M. \& Holden, N.M. 2018. Life cycle assessment of multi-product dairy processing using Irish butter and milk powders as an example. Journal of Cleaner Production, 198: 215-230.

Yang, Y. 2016. Two sides of the same coin: Consequential life cycle assessment based on the attributional framework. Journal of Cleaner Production, 127: 274-281.

Yao, L., Liu, T., Chen, X., Mahdi, M. \& Ni, J. 2018. An integrated method of life-cycle assessment and system dynamics for waste mobile phone management and recycling in China. Journal of $C$ leaner Production, 187: 852-862.

Zamagni, A., Guinée, J., Heijungs, R., Masoni, P. \& Raggi, A. 2012. Lights and shadows in consequential LCA. International Journal of Life Cycle Assessment, 17(7): 904-918.

Zampori, L. \& Pant, R., 2019. Suggestions for updating the Product Environmental Footprint (PEF) method. (https://eplca.jrc.ec.europa.eu/permalink/PEF_method.pdf).

Zhang, Y. I., Singh, S. \& Bakshi, B. R. 2010. Accounting for ecosystem services in life cycle assessment part I: A critical review. Environmental Science and Technology, 44: 2232-2242.

Zhao, C., Liu, Y., Lai, S., Cao, H., Guan, Y., San Cheang, W., Liu, B., Zhao, K., Miao, S., Riviere, C, Capanoglu, E. \& Xiao, J. 2019. Effects of domestic cooking process on the chemical and biological properties of dietary phytochemicals. Trends in Food Science \& Technology, 85: 55-66.

Zhu, Y.G., Johnson, T.A., Su, J-Q., Qiao, M., Guo, J-X., Stedtfeld, R.D., Hashsham, S.A. \& Tiedje, J.M. 2013. Diverse and abundant antibiotic resistance genes in Chinese swine farms. Proceedings of the National Academy of Sciences of the United States of America, 110(9): 3435-3440.

Ziegler, F., Groen, E.A., Hornborg, S., Bokkers, E.A.M., Karlsen, K M. \& Boer, I.J.M.D. 2018. Assessing broad life cycle impacts of daily onboard decision-making, annual strategic planning, and fisheries management in a northeast Atlantic trawl fishery. The International Journal of Life Cycle Assessment, 23: 1357-1367.

Ziegler, F., Nilsson, K., Levermann, N., Dorph, M., Lyberth, B., Jessen, A.A. \& Desportes, G. 2021. Local Seal or Imported Meat? Sustainability Evaluation of Food Choices in Greenland, Based on Life Cycle Assessment. Foods, 10: 1194.

Zimmermann, A., Baumgartner, D., Nemecek, T. \& Gaillard, G. 2011. Are public payments for organic farming cost-effective? Combining a decision-support model with LCA. The International Journal of Life Cycle Assessment, 16: 548-560. 


\section{Glossary}

\section{Acceptable daily intake (ADI)}

An estimate of the amount of a substance in food or drinking water that can be consumed daily over a lifetime without presenting an appreciable risk to health. ADI is usually expressed as milligrams of the substance per kilogram of body weight and applies to chemical substances such as food additives, pesticide residues and veterinary drugs.

\section{Adequate intake (Al)}

A dietary recommendation used when there isn't enough data to calculate an average requirement. An $\mathrm{Al}$ is the average nutrient level consumed daily by a typical healthy population, and it is assumed to be adequate for the population's needs.

\section{Anti-nutritional compounds/anti-nutritional factors/antinutrients}

Compounds in foods that interfere with the absorption of nutrients. Examples include:

- phytic acid

- oxalic acid

- glucosinolates

- protease inhibitors

- lipase inhibitors

- amylase inhibitors

- tannins

- lectins

- saponins

\section{Bioavailability}

The proportion of a nutrient that is digested, absorbed and metabolized via normal pathways.

\section{Bioaccessibility}

The proportion of a nutrient that is released from its matrix in the gastrointestinal tract and available for absorption.

\section{Capping}

Cutting off nutrient scores at 100 percent of daily recommended intake values.

\section{Conditionally-essential nutrient}

A nutrient that is ordinarily produced by the body in sufficient amounts to meet physiological requirements but might need to be taken via food under certain conditions, such as when biosynthesis is inadequate for the body to produce vitamin $\mathrm{D}$.

\section{Disability adjusted life years (DALYs)}

One DALY represents the loss of the equivalent of one year of full health. DALYs for a disease or health condition are the sum of the years of life lost due to premature mortality and the years lived with a disability due to prevalent cases of the disease or health condition in a population.

\section{Estimated average requirement (EAR)}

The estimated level of a nutrient in the diet that is necessary to meet the daily needs of half the people in a typical healthy population. 


\section{Essential nutrient}

A nutrient required by the human body that cannot be synthesized by the human body. Examples include:

- amino acids (Phe, Val, Thr, Leu, Ile, Lys, His, Met, Trp);

- fatty acids (<-linolenic acid, linoleic acid);

- vitamins (A, B1, B2, B3, B5, B6, B7, B9, B12, C, D, E, K - note that vitamin D is considered conditionally essential);

- minerals (K, Cl, Na, Ca, Mg, P, Fe, Zn, Mn, Cu, I, Cr, Mo, Se, Co); and

- choline.

\section{Food}

A substance that people eat or drink to support growth and development, and to maintain life.

\section{Food item}

A substance that contributes in whole or in part, or following further preparation (typically in a home or restaurant), as a source of nourishment when consumed by humans. Food items may sometimes be used as ingredients in other food items. For example, a beef steak may be considered a food item if it is served alone, or it may be considered an ingredient if it is diced and used as one ingredient in a stew. Substances that require subsequent industrial processing prior to consumption (such as pasteurization, sterilization, homogenization, extrusion) are not considered food items in this report. For example, sugar beet undergoes further industrial processing to produce sugar prior to human consumption; therefore, sugar beet is not considered a food item in this report, though sugar is a food item.

\section{Food product}

A substance that can be used or prepared for use as food.

\section{Food product components}

Any component present in a food product (nutrient and non-nutrient).

\section{Macronutrient}

A calorie-containing component of food (i.e. fat, protein, carbohydrate) needed in significant quantities (typically >1 g per day) for normal growth, development and maintenance of health.

\section{Micronutrient}

A nutrient required by the body in small amounts (typically $<1 \mathrm{~g}$ per day) for normal growth, development and maintenance of health (vitamins and minerals).

\section{Nutrient}

A substance in food that can be used by the human body, after it has been absorbed, to support normal growth, development and maintenance of health.

\section{Nutrition}

The process where an organism uses food to support its normal growth, development and maintenance of health via ingestion, absorption, assimilation, biosynthesis, catabolism and excretion.

\section{Nutritional life cycle assessment (nLCA)}

A life cycle assessment (LCA) study that includes information on the nutrient quantity, and preferably nutritional quality, in the functional unit and/or human health impact category. 


\section{Non-essential nutrient}

A nutrient that is required by the human body and which can be synthesized by the human body. Examples include:

- amino acids (Ala, Arg, Asn, Asp, Cys, Gln, Glu, Gly, Pro, Ser, Tyr);

- all digestible carbohydrates; and

- all fatty acids except for $\alpha$-linolenic acid, linoleic acid.

\section{Non-nutrient component}

Any component present in a food product that is not classified as a nutrient (fibre, phytochemicals). The fact that such compounds are not classified as nutrients does not mean that they do not affect human health. Typically, no estimated average requirement or recommended dietary allowance is established for these compounds, although an adequate intake may be established.

\section{Recommended daily allowance (RDA)/recommended daily intake (RDI)}

The level of a nutrient in the diet that meets the daily needs of almost all ( 97 to 98 percent) of healthy people in a population. 


\section{Appendix 1 - Project Group Members}

\section{Assumpció Antón Vallejo (Institute of Agrifood Research and Technology, Spain)}

In 1982 Assumpció Antón Vallejo became officer of the Agricultural Department of Generalitat of Catalunya (DACC), and in 1985 became a researcher at the Institute of Agrifood Research and Technology (IRTA). She has been teaching LCA and supervising Bachelor's, Master's and Doctoral thesis students in the field of LCA applied to the agricultural sector for fifteen years, first as Associate Professor in the Chemical Engineering Department at the University Rovira Virgili (Spain) and currently as Associate Professor of the Agrifood Engineering and Biotechnology Department at the Universitat Politécnica de Catalunya (Spain). She has been involved in different international initiatives (UNEP-LCI, LEAP-FAO, PAS2020, ECOINVENT, EC-TAB-AWG). Her area of expertise is the development and application of LCA methodology in agriculture. She focuses her research on the improvement of agricultural inventories and the development of life cycle impact assessment methods related to agricultural processes, i.e. carbon footprint, land use, water consumption, eutrophication and toxicity due to pesticides use.

\section{Andrew Berardy (Loma Linda University, United States of America)}

Andrew Berardy's work focuses on the benefits and limitations of applying life cycle assessments to the study of sustainable food systems. He is currently a postdoctoral fellow at Loma Linda University in California. He held two previous postdoctoral positions at Arizona State University in the School of Sustainable Engineering and the Built Environment, and then the College of Health Solutions. His research spans disparate disciplines through a common connection to food.

\section{Marta Bianchi (Research Institutes of Sweden, Sweden)}

Marta Bianchi is a researcher in sustainable nutrition in the Unit of Sustainable Consumption and Production at the Research Institutes of Sweden (RISE). In this role, she has been involved in both research and contract projects focusing on the integration of nutrition and health into environmental sustainability. Her work includes the application of nutrient density indices to both foods and diets. She has a background in molecular biology and a PhD in human nutrition from Parma University, Italy. Before joining RISE, she worked for more than ten years in the food industry as a nutrition manager, where she gained international experience in food products formulation for better health, bridging between product development, academic research and legislative frameworks to substantiate health benefits from foods. She has also collaborated with the Barilla Center for Food and Nutrition Foundation.

\section{Abhishek Chaudhary (Indian Institute of Technology Kanpur, India)}

Abhishek Chaudhary is an Assistant Professor of sustainability data analytics at the Indian Institute of Technology Kanpur (IITK). His area of research includes sustainable agriculture and diets, biodiversity conservation, life cycle assessment and environmental foot printing. Prior to joining IITK, he held a senior scientist position at ETH Zurich, Switzerland. Currently, he is a member of the IUCN SSC Phylogenetic Diversity Task Force (PDTF) and of the ES\&T Early Career Editorial Advisory Board. He is one of the 26 global scientists on the One Health High Level Expert Panel (OHHLEP) jointly led by WHO, OIE, FAO and UNEP. He has contributed to the EAT-Lancet Commission report on healthy diets, and the UNEP-SETAC Life Cycle Initiative on biodiversity assessment. He has also worked at the United States Environmental Protection Agency in Cincinnati and also served as a member of the technical advisory group to the LEAP initiative of UN FAO. 


\section{Canxi Chen (Institute of Food, Nutrition and Health, ETH Zurich)}

Canxi Chen is currently a doctoral candidate at the Institute of Food, Nutrition and Health at the Swiss Federal Institute of Technology (ETH Zurich, Switzerland) and is funded by the Swiss National Science Foundation (NRP 73 "Sustainable Economy"). In her doctoral research, she focuses on qualifying the impact of food systems on human nutrition and environmental sustainability at the national and global levels. She obtained an M.S. in Food Science from ETH Zürich in 2018 and a B.E in Food Science and Technology from Zhejiang University, China in 2016.

\section{Margot Cooreman-Algoed (Ghent University, Belgium)}

Margot Cooreman-Algoed has been working as a doctoral researcher and academic assistant at the Sustainable System Engineering (STEN) research group. Her PhD covers the environmental sustainability of food production and consumption. She focuses on food LCA practices and their gaps, such as the integration of the nutritional value of food and the behaviour of consumers regarding food waste. She has taught in the field of sustainable development in production and consumption systems next to process engineering. She has also been a researcher working on assessing the environmental profile of the cultivation and processing of seaweed from the Belgian part of the North Sea.

\section{Camillo De Camillis, (FAO LEAP)}

Camillo De Camillis is the manager of the Livestock Environmental Assessment and Performance (FAO LEAP) partnership. With a background in environmental economics, Camillo has a $\mathrm{PhD}$ in science and lso specialized through a Post-Doc in resource use efficiency, environmental assessment and life cycle thinking in food systems. He has co-authored more than 90 publications, including technical specifications on the environmental footprint. Building consensus through technical and political dialogue has been at the core of his duties as facilitator of multi-stakeholder partnerships for the last 11 years. A qualified Associate Professor, Camillo has given classes in Food Total Quality Management at the University of International Studies of Rome UNINT for the last six years.

\section{Hongmin Dong (Chinese Academy of Agricultural Sciences, China)}

Hongmin Dong's research focuses on the livestock environment, manure management, and greenhouse gas emissions and mitigation. She is the lead researcher in the Livestock Environment Engineering Program at the Chinese Academy of Agricultural Sciences (CAAS). She had been the principal investigator on a national project on livestock, environment and manure management, as well as on a national project on low carbon livestock production. She has twice won second prize at the National Scientific and Technological Progress Award, as well as winning the National Outstanding Women Award, and the National Outstanding Scientific and Technological Workers Award. She has been responsible for compiling national GHG emission inventories for the livestock sector and was lead author of Chapter 11 on livestock and manure management of the 2006 IPCC guideline for national GHG inventories. She has also been the lead reviewer of the national GHG inventory developed under the UNFCCC, and a lead author of IPCC AR5.

\section{Tim Grant (Lifecycles, Australia)}

Tim Grant is a specialist in LCA with more than twenty years of experience in developing, teaching and applying LCA. Tim is a co-chair of the Ecosystem Services and Natural Resource Task Force in Global Guidance on Environmental Life Cycle Impact Indicators (GLAM), which is part of the Life Cycle Initiative, hosted by UNEP. Tim works across many different sectors in LCA including packaging, agriculture, energy, fuels, water products, buildings and waste management. In addition, he has worked on the development of LCA databases for Australia and internationally. He is an author of the book "Life Cycle Assessment - Principles, Practice and Prospects" published by CSIRO in 2009. 


\section{Ashley Green (ETH Zurich and Agroscope, Switzerland)}

Ashley Green is a PhD student at ETH Zurich and Agroscope. Her work focuses on methodological facets of integrating nutritional dimensions into environmental analyses of agrifood production systems. Previously, she held a consultancy position at FAO and was an analyst at the World Resources Institute.

\section{Elinor Hallström (Research Institute of Sweden, Sweden)}

Elinor Hallström is senior researcher at the Research Institute of Sweden (RISE) where she is the coordinator of the expertise field of Sustainable Nutrition. Elinor has an interdisciplinary background with a Master's Degree in Nutrition and a PhD in Environmental System Studies. Her research focuses on the combined analysis of nutrition, health and environmental effects of food consumption and production.

Andrew Henderson (Eastern Research Group and University of Texas School of Public Health, the United States of Americal

Andrew Henderson aims to combine rigorous modelling and spatially explicit datasets to improve environmental models of complex systems. He is currently a Senior Sustainability Engineer at the Eastern Research Group and an Adjunct Professor of Environmental Sciences in the University of Texas School of Public Health (UT-SPH). He is an active contributor to the UNEP Life Cycle Initiative, having co-chaired the Acidification/Eutrophication Task Force for Phase II of the Global Life Cycle Impact Assessment Method (GLAM) effort. He previously worked for the United States Environmental Protection Agency to build LCIA models and LCA capacity, and prior to that as a faculty member at the UT-SPH, always with the goal of improving models and their relevance to decision-making.

\section{Hong-Minh Hoang (National Research Institute for Agriculture, Food and Environment, France)}

Hong-Minh Hoang has worked on the heat transfer, thermal energy storage and environmental assessment of refrigeration systems for more than ten years. She is currently the leader of the Energy and Environmental Impact of Refrigeration Systems team of the Refrigerating Process Research Unit (FRISE) at the French National Research Institute for Agriculture, Food and Environment (INRAE). Her work aims to develop efficient and environmentally friendly refrigeration systems for food supply chains, by lowering the impact of these systems on climate change and global warming while maintain food quality and safety, through the reduction of greenhouse gas emissions and energy consumption. She has been developing LCA methodology for analysing food supply chains in various recent projects since 2015 .

\section{Nicholas Holden (University College Dublin, Ireland)}

Nicholas Holden is Professor of Biosystems Engineering in the School of Biosystems and Food Engineering, University College Dublin, and is Deputy Director of BiOrbic Bioeconomy, SFI Research Centre. His research addresses the impact and sustainability of agriculture and food systems at the interface of bioeconomy, food production, and soil science, using system modelling, life cycle assessment and other quantitative methods.

\section{Thom Huppertz (Wageningen University \& Research, the Netherlands)}

Thom Huppertz has been active in academic, industrial and contract research in the areas of food science and technology and nutrition, with a primary focus on dairy products, for more than 20 years. He currently combines the roles of Professor of Dairy Science and Technology at Wageningen University, Principal Scientist at FrieslandCampina and Distinguished Visiting Professor at Victoria University (Australia),and has previously worked at NIZO food research (the Netherlands), University of Queensland (Australia) and University of Cork (Ireland). In addition, he currently serves in several Standing Committees and Action Teams for the International Dairy Federation and is the Editor-in-Chief for the International Dairy Journal. His current research focusses on nutritional and processing aspects in food systems. 


\section{Olivier Jolliet (University of Michigan, United States)}

Olivier Jolliet is Full Professor of Environmental Health Sciences at the School of Public Health, University of Michigan. Olivier has developed, with colleagues, the LCA method for agriculture and food production since the early 1990s. He has compared the nutritional and environmental impacts of food systems, determining minutes of healthy life gained and lost for 5800 individual foods, and this high impact research was reported by more than 1000 news media. Olivier co-initiated the Life Cycle Initiative, hosted at UNEP, and is currently coordinating the effort of more than 150 scientists worldwide towards developing impact assessment approaches. His work aims to al compare the life cycle risks and benefits of foods, consumer products and emerging technologies; and b) model and screen population exposure and effect on health. Olivier has authored or co-authored more than 220 peer-reviewed publications or book chapters.

\section{Adrian Leip (European Commission)}

Since August 2021, Adrian Leip has worked at the European Commission's Directorate General Research \& Innovation as Head of Sector - Bioeconomy in the Food Systems and Bioeconomy Unit. Before joining DG RTD, he worked for almost twenty years at the European Commission-Joint Research Centre in Ispra, Italy, last in the Directorate Sustainable Resources, Food Security Unit. Among his tasks was to lead a project on Modelling Mitigation of Food Systems and to co-chair the Expert Panel on Nitrogen and Food under the Task Force on Reactive Nitrogen (UN-ECE LRTAP Convention). He is currently Lead Author of the IPCC 6th Assessment Report on a "food system" section. Adrian has a PhD in geo-ecology from the University of Bayreuth, Germany.

\section{John Lynch (University of Oxford, the United Kingdom of Great Britain and Northern Ireland)}

John Lynch is an environmental scientist interested in the impacts of agricultural production. His current research focuses on the contribution of agricultural greenhouse gas emissions, and particularly those associated with livestock, to global warming. In previous positions at the Irish Agriculture and Food Development Authority (Teagasc) and the University of Nottingham, he contributed to work on agricultural sustainability assessments. He also has a broad background in agronomy, ecology and evolutionary biology, and is interested in integrated approaches to address environmental concerns.

\section{Graham McAuliffe (Rothamsted Research, the United Kingdom of Great Britain and Northern Ireland)} Graham McAuliffe has a PhD in Veterinary Science, specializing in LCA. His career-focus to date has largely centred on methodological improvements to LCA, including novel quantification of uncertainties and the consideration of nutritional composition/quality within the burgeoning field of nutritional LCA (nLCA). Graham's wider academic interests cover most aspects of agrifood sustainability, including but not limited to, cradle-to-plate "hotspot" identification of various pollutants and their environmental impacts (such as methane's effect on global warming), development of novel and/or site-specific emission factors, devising new approaches to integrate spatial heterogeneity into the LCA framework, for instance using Geographical Information Systems to assess impacts to nature from differing farming systems at the catchment scale, exploring trade-offs between different sustainability metrics and appropriate interpretations of comparative systems analysis, and merging sustainability metrics (as in nLCA) to elucidate better understandings of risks and benefits associated with different food products.

\section{Sarah McLaren (Massey University, New Zealand)}

Sarah McLaren has worked collaboratively with businesses and government to integrate life cycle thinking into management practices, product design and policymaking for more than twenty-five years in both the United Kingdom of Great Britain and Northern Ireland and New Zealand. She is currently Director of the New Zealand Life Cycle Management Centre (NZLCM Centre), and Professor 
in Life Cycle Management at Massey University. She has also worked at the Office of the Parliamentary Commissioner for the Environment (New Zealand), Landcare Research (New Zealand), and the University of Surrey (the United Kingdom of Great Britain and Northern Ireland). She has served as the New Zealand representative on the ISO Water Footprint Working Group and EIANZ Qualifications Accreditation Board, and on the Office of the Prime Minister's Chief Science Advisor's Rethinking Plastics Panel, MfE Planetary Boundaries New Zealand Advisory Board, and New Zealand Food Awards Judging Panel. Her research focuses on the development and application of LCAs and related approaches such as planetary boundaries, industrial ecology and the circular economy.

\section{Marguerite Renouf (Queensland University of Technology, Australia)}

Marguerite Renouf is a Senior Research Fellow (Circular Bioeconomy) at the Queensland University of Technology's Centre for Agriculture and the Bioeconomy in Brisbane, Australia. She conducts research that quantifies the environmental performance of agrifood and bio-production systems using LCA, to support the strategic development of sustainable and circular production pathways. She also contributes to furthering the application of LCA in Australia through her longstanding involvement with the Australian Life Cycle Assessment Society. This has included contributing data to Australia's life cycle inventory database (AusLCI) and practitioner guidelines for impact assessment. Her achievements have included an LCA of Australian sugarcane, which has informed government policy on cane-derived bio-fuels and bio-materials, and developing customized LCA tools for agricultural crops being used to promote sustainable growing practices.

\section{Brad Ridoutt (The Commonwealth Scientific and Industrial Research Organisation, Australia)}

Brad Ridoutt is a Principal Research Scientist with Australia's national science agency - The Commonwealth Scientific and Industrial Research Organisation (CSIRO). His expertise is in the life cycle sustainability assessment in the agriculture and food sectors, which is used to address strategic challenges in relation to climate change, water scarcity, sustainable food systems and sustainable diets. $\mathrm{He}$ is engaged in a range of international processes relating to the standardization of sustainability assessment and environmental labelling. His research is in creating an evidence base concerning the environmental impacts of dietary habits in Australia.

\section{Benedetto Rugani (Luxembourg Institute of Science and Technology, Luxembourg)}

Benedetto Rugani has been working on environmental sustainability and the LCA of products and services, with special attention to the agrifood sector, for the last fifteen years. He is responsible for research activities in European research and innovation projects related to the study of sustainability in the urban environment, ecosystem services and enhancement of natural capital. He is a PhD and MSc student supervisor and is first author or co-author of approximately 100 scientific publications in interdisciplinary journals of relevance in the field of environment, with particular reference to ecological modelling and human-nature interaction.

\section{Merja Saarinen (Natural Resources Institute Finland, Finland)}

Merja Saarinen (PhD, Agroecology; M.Sc, Environmental Protection) is a senior researcher and has worked on food LCA for about 15 years. Her research focuses on the development and application of LCAs, particularly to integrate the nutritional aspect into LCA at the product and diet levels, related product-level consumer communication, and to improve chain-specific accuracy in the LCA of food and agricultural products. She has collaborated with food companies and the Government of Finland to promote the sustainability of the agriculture and food sector, diets and food products. She has participated in the Technical Advisory Board of the European Union's Product Environmental Footprint 
(PEF) initiative and related Nordic collaboration.

\section{Sophie Saget (Trinity College Dublin, Ireland)}

Sophie Saget recently completed her PhD on the environmental and nutritional assessment of legumebased production pathways at Trinity College Dublin. She worked with food manufacturers to compare the environmental impact of innovative legume-based processed foods with their traditional alternative, integrating nutrient density in the assessment. She is currently investigating through a consequential LCA the potential environmental effects of increased legume production and consumption at a European scale, considering diet change and substitution of animal protein and South American soy imported to Europe, to align better with the recommended sustainable EAT Lancet diet.

\section{Laura Scherer (Leiden University, the Netherlands)}

Laura Scherer is an Assistant Professor at the Institute of Environmental Sciences (CML) at Leiden University. Her research focuses on food, water, biodiversity and animal welfare with an industrial ecology perspective, developing and applying methods like LCA and multi-regional input-output analysis. She is serving as a member of the Life Cycle Initiative hosted by UNEP and the scientific committee of the International Conference on Life Cycle Assessment of Food. Laura received her PhD in 2016 from ETH Zurich.

\section{Hanna Tuomisto (University of Helsinki, Finland)}

Hanna Tuomisto is an Associate Professor in Sustainable Food Systems at the University of Helsinki where she leads the Future Sustainable Food Systems research group. She has 15 years of experience in the development and use of the LCA method especially in the context of agriculture and food systems. She is currently involved in various projects exploring ways to improve the sustainability of food systems through developing sustainable agricultural systems, using novel food production technologies and changing diets. She holds an MSc degree in Agroecology from the University of Helsinki and a doctoral degree from the University of Oxford. She gained postdoctoral research experience at the European Commission's Joint Research Centre (JRC) where she was involved in the development of carbon footprint and environmental footprint methods, and at London School of Hygiene \& Tropical Medicine (LSHTM) where her work focused on the links between environmental change, nutrition and health.

\section{Peter Tyedmers (Dalhousie University, Canada)}

Peter Tyedmers's research explores questions related to understanding the scale of human dependence on ecosystem services and productivity, the environmental implications of technological substitutions and the biophysical sustainability of food production systems. His ongoing research interests include understanding the energy performance of capture fisheries globally and identifying opportunities to reduce the resource dependence and improve the environmental performance of food systems using LCA. He is a Professor in the School for Resource and Environmental Studies at Dalhousie University in Halifax, Nova Scotia and currently serves as the Director of the Interdisciplinary PhD program at Dalhousie.

\section{Jolieke van der Pols (Queensland University of Technology, Australia)}

Jolieke van der Pols is a nutritional epidemiologist based at the Queensland University of Technology in Brisbane, Australia. She obtained an MSc in Human Nutrition from Wageningen University in the Netherlands, and a PhD from the University of Cambridge, in the United Kingdom of Great Britain and Northern Ireland. Over the past 20 years, most of her research has focused on assessing how nutritional factors (nutrients, foods, dietary patterns) play a role in chronic disease risk, in particular cancer and cardiovascular diseases. Her research has focused on nutrition and health in high-income 
as well as in low-and-middle income countries.

\section{Hannah van Zanten (Wageningen University, the Netherlands)}

Hannah van Zanten is an Associate Professor at the Farming Systems Ecology group at Wageningen University and the project leader of the Circular Food Systems team. It is her ambition to unravel how circular food systems can contribute to producing healthy foods for a growing population within the carrying capacity of the Earth. Hannah graduated cum laude from Wageningen University in 2009 with a Master's degree in Animal Sciences. Her PhD project focused on the environmental benefits of using human-inedible-sources as livestock feed. Since graduating, again cum laude, for her PhD, she continued to work in this research area at the university. With her team, she is now developing a circular food systems (CiFoS) model where stakeholders can co-design and evaluate innovative yet attainable food systems that secure human and planetary health.

\section{lan Vázquez-Rowe (Pontificia Universidad Católica del Peru, Peru)}

lan Vázquez-Rowe is a Full Professor in the Department of Engineering at the Pontificia Universidad Católica del Peru (PUCP). He graduated in Biology in 2006 at the University of Texas at Arlington. He then continued his graduate studies in Environmental Engineering at the University of Santiago de Compostela - USC (2006-2008). In October 2008, he initiated his research career at USC, where he obtained his PhD in Chemical Engineering in July 2012. After a short period (2012-2013) at CRTE Public Henri Tudor (now LIST, in Luxembourg), he started working at PUCP in 2014. He is now the director of the Peruvian LCA \& Industrial Ecology Network (PELCAN) research group at that institution. His research interests have focused mainly on LCA methods and inventories linked to the agricultural and fishery sectors, as well as wastewater and waste management in developing nations. More recently, issues linked to deforestation, mainly due to road expansion in tropical rainforests, and marine litter and its development in LCIA, have been new topics of interest. He has developed research in Spain and Peru on the environmental impacts of diets. 


\section{Office of Communications - January 2022}

Integration of environment and nutrition in life cycle assessment of food items: opportunities and challenges.

\section{Corrigendum}

Updated on 10/01/2022

The following corrections were made to the PDF after it went to print.

\begin{tabular}{|c|c|c|c|}
\hline Page & Location & Text in printed PDF & Text in corrected PDF \\
\hline 3 & Authors & $\begin{array}{l}\text { Sarah McLaren, Andrew Berardy, } \\
\text { Andrew Henderson, Nicholas Holden, } \\
\text { Thom Huppertz, Olivier Jolliet, } \\
\text { Marguerite Renouf, Benedetto Rugani, } \\
\text { Merja Saarinen, Jolieke van der Pols, } \\
\text { Ian Vázquez-Rowe, Assumpció Antón } \\
\text { Vallejo, Marta Bianchi, Abhishek } \\
\text { Chaudhary, Canxi Chen, Margot } \\
\text { Cooreman-Algoed, Hongmin Dong, } \\
\text { Tim Grant, Ashley Green, Elinor } \\
\text { Hallström, Hong Minh Hoang, Adrian } \\
\text { Leip, John Lynch, Graham McAuliffe, } \\
\text { Brad Ridoutt, Sophie Saget, Laura } \\
\text { Scherer, Hanna Tuomisto, Peter } \\
\text { Tyedmers, Hannah van Zanten }\end{array}$ & $\begin{array}{l}\text { Sarah McLaren, Andrew Berardy, Andrew } \\
\text { Henderson, Nicholas Holden, Thom } \\
\text { Huppertz, Olivier Jolliet, Camillo De } \\
\text { Camillis, Marguerite Renouf, Benedetto } \\
\text { Rugani, Merja Saarinen, Jolieke van der } \\
\text { Pols, Ian Vázquez-Rowe, Assumpció } \\
\text { Antón Vallejo, Marta Bianchi, Abhishek } \\
\text { Chaudhary, Canxi Chen, Margot } \\
\text { Cooreman-Algoed, Hongmin Dong, Tim } \\
\text { Grant, Ashley Green, Elinor Hallström, } \\
\text { Hong Minh Hoang, Adrian Leip, John } \\
\text { Lynch, Graham McAuliffe, Brad Ridoutt, } \\
\text { Sophie Saget, Laura Scherer, Hanna } \\
\text { Tuomisto, Peter Tyedmers, Hannah van } \\
\text { Zanten }\end{array}$ \\
\hline 4 & $\begin{array}{c}\text { Required } \\
\text { Citation }\end{array}$ & $\begin{array}{l}\text { McLaren, S., Berardy, A., Henderson, } \\
\text { A., Holden, N., Huppertz, T., Jolliet, O., } \\
\text { Renouf, M., Rugani, B., Saarinen, M., } \\
\text { van der Pols, J., Vázquez-Rowe, I., } \\
\text { Antón Vallejo, A., Bianchi, M., } \\
\text { Chaudhary, A., Chen, C., } \\
\text { CooremanAlgoed, M., Dong, H., Grant, } \\
\text { T., Green, A., Hallström, E., Hoang, H., } \\
\text { Leip, A., Lynch, J., McAuliffe, G., } \\
\text { Ridoutt, B., Saget, S., Scherer, L., } \\
\text { Tuomisto, H., Tyedmers, P. \& van } \\
\text { Zanten, H. 2021. Integration of } \\
\text { environment and nutrition in life cycle } \\
\text { assessment of food items: } \\
\text { opportunities and challenges. Rome, } \\
\text { FAO }\end{array}$ & $\begin{array}{l}\text { McLaren, S., Berardy, A., Henderson, A., } \\
\text { Holden, N., Huppertz, T., Jolliet, O., De } \\
\text { Camillis, C., Renouf, M., Rugani, B., } \\
\text { Saarinen, M., van der Pols, J., Vázquez- } \\
\text { Rowe, I., Antón Vallejo, A., Bianchi, M., } \\
\text { Chaudhary, A., Chen, C., } \\
\text { CooremanAlgoed, M., Dong, H., Grant, T., } \\
\text { Green, A., Hallström, E., Hoang, H., Leip, } \\
\text { A., Lynch, J., McAuliffe, G., Ridoutt, B., } \\
\text { Saget, S., Scherer, L., Tuomisto, H., } \\
\text { Tyedmers, P. \& van Zanten, H. 2021. } \\
\text { Integration of environment and nutrition } \\
\text { in life cycle assessment of food items: } \\
\text { opportunities and challenges. Rome, } \\
\text { FAO. }\end{array}$ \\
\hline
\end{tabular}

\section{Contact: publishing-submissions@fao.org}





\section{Integration of environment and nutrition in life cycle assessment of food items: opportunities and challenges}

